UNIVERSIDADE DE SÃO PAULO

FACULDADE DE ECONOMIA, ADMINISTRAÇÃO E CONTABILIDADE DEPARTAMENTO DE ADMINISTRAÇÃO

PROGRAMA DE MESTRADO PROFISSIONAL EM EMPREENDEDORISMO

TIAGO LEMOS DE OLIVEIRA

RELACIONAMENTOS ENTRE UMA GRANDE EMPRESA E STARTUPS: BARREIRAS INTERNAS E PROPOSIÇÃO DE AÇÕES A PARTIR DE UMA PESQUISA-AÇÃO 
Prof. Dr. Vahan Agopyan

Reitor da Universidade de São Paulo

Prof. Dr. Fábio Frezatti

Diretor da Faculdade de Economia, Administração e Contabilidade

Prof. Dr. Moacir de Miranda Oliveira Júnior

Chefe do Departamento de Administração

Prof. Dr. Marcelo Caldeira Pedroso

Coordenador do Programa de Mestrado Profissional em Empreendedorismo 
TIAGO LEMOS DE OLIVEIRA

\section{RELACIONAMENTOS ENTRE UMA GRANDE EMPRESA E STARTUPS: BARREIRAS INTERNAS E PROPOSIÇÃO DE AÇÕES A PARTIR DE UMA PESQUISA-AÇÃO}

Dissertação apresentada ao Programa de Mestrado Profissional em Empreendedorismo do Departamento de Administração da Faculdade de Economia, Administração e Contabilidade da Universidade de São Paulo, como requisito parcial para a obtenção do título de Mestre em Ciências.

Área de Concentração: Empreendedorismo e Inovação

Orientadora: Profa. Dra. Jane A. Marques

\section{Versão Corrigida}

(versão original disponível na Faculdade de Economia, Administração e Contabilidade)

\section{SÃO PAULO}


Catalogaçăo na Publicaçăo (CIP)

Ficha Catalográfica com dados inseridos pelo autor

Oliveira, Tiago Lemos de.

RELACIONAMENTOS ENTRE UMA GRANDE EMPRESA E STARTUPS: BARREIRAS INTERNAS E PROPOSIÇĀO DE AÇOES A PARTIR DE UMA PESQUISA-AÇĀO / Tiago Lemos de Oliveira. - Săo Paulo. 2019. $303 \mathrm{p}$.

Dissertação (Mestrado) - Universidade de Săo Paulo, 2019.

Orientador: Jane A. Marques.

1. Parcerias Assimétricas. 2. Startups. 3. Grandes Empresas. 4. Inovaçăo Aberta. 5. Corporate Venturing. I. Universidade de Săo Paulo. Faculdade de Economia, Administração e Contabilidade. II. Título. 
A Deus, à minha esposa e à minha filha. 



\section{AGRADECIMENTOS}

Agradeço primeiramente a Deus, pela oportunidade de poder estudar em tão nobre instituição e por ter me permitido concluir essa etapa tão marcante da minha vida.

Agradeço à minha esposa, Monique, que abdicou do seu tempo para que eu pudesse concluir esse trabalho e à minha filha, Lívia, que, mesmo sem ainda saber, foi refrigério e um dos motivadores para finalizar essa missão.

Agradeço à minha orientadora, Profa. Dra. Jane A. Marques, por ter acreditado neste projeto, por ter me aceito como seu orientando, e por doar seu tempo precioso e sua experiência a fim de concluir este trabalho.

Agradeço às pessoas queridas do Mestrado Profissional em Empreendedorismo - FEA, pelo apoio, convivência e trocas de experiências: à Fabiana, aos meus queridos colegas e, em especial, aos docentes. 


\section{RESUMO}

A competição no mercado financeiro brasileiro vem crescendo com a entrada de novos players. As fintechs, exemplos dessa expansão, cresceram mais de $1.000 \%$ entre 2015 e 2019. Procurando manterem-se competitivas, as instituições financeiras encontraram no relacionamento com startups, alternativa para obter novas capacidades. Essa relação assimétrica apresenta oportunidades, mas também traz desafios internos às instituições financeiras. Nesse contexto, buscou-se compreender uma intervenção ocorrida na empresa XYZ, que visou a melhorar seu relacionamento com startups. Em paralelo a essa intenção corporativa, do ponto de vista acadêmico, questionou-se: 'Quais ações internas são as mais adequadas para melhorar o relacionamento da empresa XYZ com as startups?' Alinhado a essa indagação, o objetivo da presente dissertação foi compreender as formas de 'viabilizar o melhor relacionamento entre uma grande empresa e startups'. Trata-se de uma pesquisa exploratória, de abordagem qualitativa, que usa a PesquisaAção como método, sendo o pesquisador um dos membros do grupo de intervenção. Os dados da pesquisa foram coletados por meio de oito entrevistas com membros da intervenção, realizadas com base em um roteiro estruturado, e pelas observações do pesquisador, anotadas em um diário de bordo. Ambos foram analisados com auxílio de software. Na análise, puderam ser identificados: dezesseis conjuntos de barreiras, nove habilitadores e quinze novas ações/melhorias. Dentre as principais barreiras constatadas, destacam-se: aversão a riscos, limitação de tempo dos interventores, falta de engajamento dos pares e lideranças, indefinição dos objetivos, comunicação pouco frequente com patrocinador e visão/conhecimento parcial dos processos internos. Dentre os principais habilitadores encontrados, destacam-se: a atuação decisória do patrocinador, ações de aculturamento, comunicação e ferramental e o amadurecimento do grupo interventor. Ademais, as informações obtidas por meio da investigação, confrontadas com abordagens de Corporate Venturing, Inovação/Inovação Aberta e Corporate-Startup Engagement permitiram gerar vinte e uma recomendações à empresa XYZ. Os relatos, as barreiras e as proposições desta pesquisa proveem a base inicial para grandes empresas e startups que buscam construir parcerias. Desta forma, espera-se que a presente pesquisa venha a contribuir para o estudo das relações entre grandes empresas e startups, tema ainda pouco explorado, trazendo nova perspectiva organizacional interna.

Palavras-chave: parcerias assimétricas; startups; inovação aberta; corporate venturing. 


\begin{abstract}
Competition in the Brazilian financial market has been growing with the entry of some new players. Fintechs, examples of this expansion, grew more than $1000 \%$ between 2015 and 2019. Seeking to remain competitive, financial institutions have found in their relationship with startups an alternative to gain new capabilities. This asymmetrical relationship presents opportunities, but also brings internal challenges to financial institutions. In this context, we sought to understand an intervention that occurred in the company XYZ, which aimed to improve its relationship with startups. In parallel with this corporate intention, from the academic point of view, the following question was asked: 'What internal actions are the most appropriate to improve XYZ's relationship with startups?' In line with this question, the purpose of this dissertation was to understand the ways of 'enabling the best relationship between a large company and startups'. This is an exploratory research, with a qualitative approach, that uses Action Research as a method, and the researcher is one of the members of the intervention group. Survey data were collected through eight interviews with intervention members, based on a structured script, and the researcher's observations, recorded in a logbook. Both were analyzed using software. In the analysis, sixteen sets of barriers, nine enablers and fifteen new actions/ improvements could be identified. Among the main barriers found, the following stand out: risk aversion, time constraints of the interveners, lack of engagement of peers and leaders, undefined objectives, infrequent communication with sponsor and partial insight/ knowledge of internal processes. Among the main enablers found, the following stand out: the sponsor's decisive action, acculturation, communication and tooling actions and the maturing of the intervention group. Moreover, the information obtained by means of the investigation, confronted with approaches of Corporate Venturing, Innovation / Open Innovation and Corporate-Startup Engagement allowed generating twenty-one recommendations to the company XYZ. The reports, barriers and propositions of this research provide the initial basis for large companies and startups seeking to build partnerships. Thus, it is expected that the present research will contribute to the study of the relationships between large companies and startups, a theme that is still little explored, bringing a new internal organizational perspective.
\end{abstract}

Keywords: asymmetrical partnerships; startups; open innovation; corporate venturing. 


\section{LISTA DE ABREVIATURAS E SIGLAS}

\begin{tabular}{|c|c|}
\hline API & Application Programming Interface \\
\hline $\mathrm{CEO}$ & Chief Executive Officer \\
\hline CEP & Comitê de Ética em Pesquisa \\
\hline CRM & Customer Relationship Management \\
\hline CSE & Corporate-Startup Engagement \\
\hline $\mathrm{CV}$ & Corporate Venturing \\
\hline CVC & Corporate Venturing Capital (Capital de Risco Corporativo) \\
\hline CVE & Corporate Venture Externo \\
\hline CVI & Corporate Venture Interno \\
\hline CVM & Comissão de Valores Mobiliários \\
\hline Febraban & Federação Brasileira de Bancos \\
\hline IA & Inovação Aberta \\
\hline MVP & Minimum Viable Product (Mínimos Produtos Viáveis) \\
\hline OCDE & Organização para a Cooperação e Desenvolvimento Econômico \\
\hline OKR & Objectives and Key-Results \\
\hline $\mathrm{P} \& \mathrm{D}$ & Pesquisa e Desenvolvimento \\
\hline $\mathrm{PoC}$ & Proof of Concept (Prova de Conceito) \\
\hline$p d f$ & portable document format \\
\hline Sebrae & Serviço Brasileiro de Apoio às Micro e Pequenas Empresas \\
\hline SLA & Service Level Agreement \\
\hline TI & Tecnologia da Informação \\
\hline TRM & Technology Roadmap \\
\hline WEF & World Economic Forum (Fórum Econômico Mundial) \\
\hline
\end{tabular}




\section{LISTA DE TABELAS}

Tabela 1 - Quantidade e Área dos Integrantes dos Grupos Responsáveis pela Intervenção 107

Tabela 2 - Codificações dos Temas Versus Aspectos Pesquisados ........................................ 125 


\section{LISTA DE QUADROS}

Quadro 1 - Resumo das Atividades da 'Pesquisa-Ação Central' 30

Quadro 2 - Comparativo Entre a Estrutura do Presente Trabalho e a Proposição de Coghlan e Brannick (2005) ................................................................................. 35

Quadro 3 - Comparação das Referências sobre Corporate-Startup Engagement - CSE ....... 58

Quadro 4 - Abordagens de Corporate-Startup Engagement (CSE) Versus as de Corporate Venturing (CV) e as de Inovação Aberta............................................. 64

Quadro 5 - Barreiras no Estabelecimento de Parcerias entre Startups e Grandes Empresas . 89

Quadro 6 - Melhores Práticas e Recomendações no Estabelecimento de Parcerias entre Startups e Grandes Empresas.............................................................................. 91

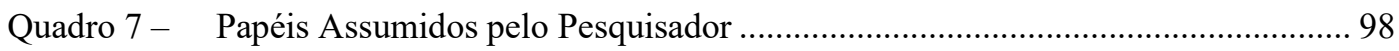

Quadro 8 - Estruturas da Pesquisa-Ação …………............................................................... 100

Quadro 9 - Responsabilidades dos integrantes dos grupos envolvidos na intervenção,

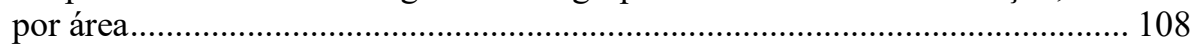

Quadro 10 - Situação geral das iniciativas mapeadas pelo Comitê.......................................... 119

Quadro 11 - Resultado das Categorizações e Sintetização para Elaboração de Roteiro de

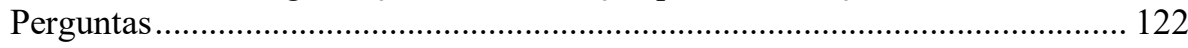

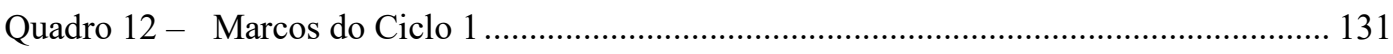

Quadro 13 - Questionário base para criação da Cartilha .......................................................... 139

Quadro 14 - Situação geral das iniciativas mapeadas pelo grupo no período da intervenção 145

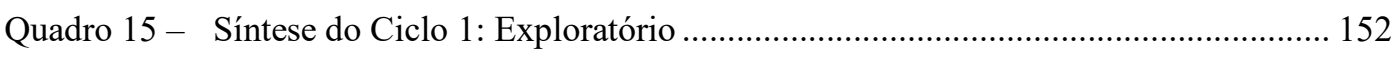

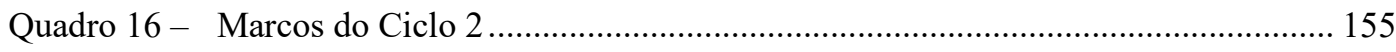

Quadro 17 - Melhores práticas de organizações que atuam com startups, coletadas durante os seminários do Ciclo 2 ................................................................... 157

Quadro 18 - Melhores práticas coletadas a partir das entrevistas com benchmarks ............... 160

Quadro 19 - Síntese do Ciclo 2 - Capacitação Interna, Aculturamento e Ferramental........... 182

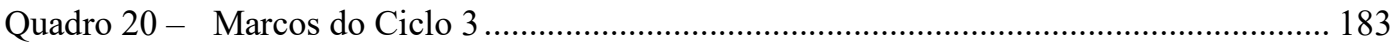

Quadro 21 - Síntese do Ciclo 3: Expansão de Aculturamento e Experimentação do Ferramental 


\section{LISTA DE FIGURAS}

Figura 1 - Visão Simplificada dos Impedimentos Levantados no Ciclo 1 ................................ 28

Figura 2 - Matriz de Amarração da Dissertação........................................................................... 33

Figura 3 - Correlação entre a Dinâmica da 'Pesquisa-Ação Central' e da 'Pesquisa-Ação Dissertação' e os capítulos do trabalho........................................... 36

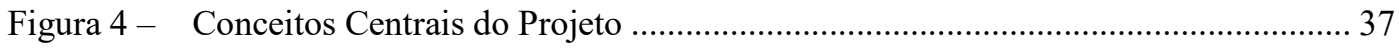

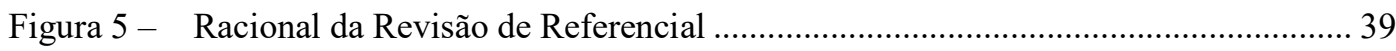

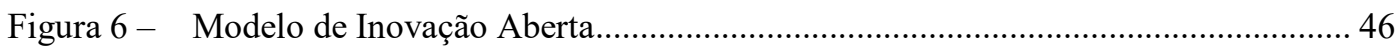

Figura 7 - Potenciais Objetivos para uma Organização Atuar com Startups, com Base em Mocker, Bielli e Haley (2015) ............................................................... 55

Figura 8 - Potenciais Objetivos para uma Organização Atuar com Startups, com Base em Bonzom e Netessine (2016) .................................................................. 56

Figura 9 - Intersecções entre o Conceito de Corporate-Startup Engagement, o de Corporate Venturing e o de Inovação Aberta...................................................... 63

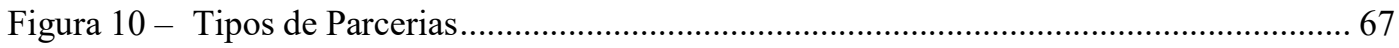

Figura 11 - Síntese dos Assuntos e Referenciais Utilizados como Fundamentos para

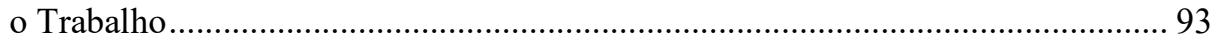

Figura 12 - Etapas do Ciclo Principal da Pesquisa-Ação ........................................................ 101

Figura 13 - Espirais dos Ciclos de Pesquisa-Ação ..................................................................... 102

Figura 14 - "Evolução" das Teorias Envolvidas na Presente Dissertação................................ 103

Figura 15 - Relacionamento entre 'Pesquisa-Ação Central' e 'Pesquisa-Ação Dissertação'.. 105

Figura 16 - Dinâmica entre os Componentes da Presente Dissertação .................................... 105

Figura 17 - Meta-Ciclo de Investigação Associado aos Ciclos de Ações ................................. 115

Figura 18 - Procedimentos para Elaboração do Roteiro de Entrevista ..................................... 121

Figura 19 - Modelo de Análise e Discussão dos Resultados ....................................................... 126

Figura 20 - Principais Dificuldades Encontradas pelas Startups em Fazer Negócios com Grandes Empresas ……………………………….......................................... 133

Figura 21 - Apresentação das Ações Inicialmente propostas pela Equipe da Força-Tarefa.... 135

Figura 22 - Detalhe da Cartilha de Processos de Contratação de Startups............................... 140 
Figura 23 - Detalhes da Apresentação do Modelo de Processo para Avaliação de Startups .. 143

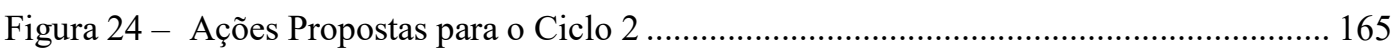

Figura 25 - Modelo de Relacionamento Considerando Startups como Provedoras de Solução para Problemas de Negócios ................................................................ 168

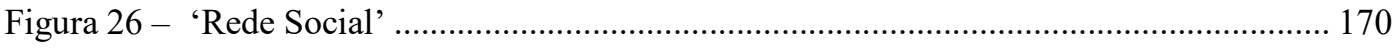

Figura 27 - Detalhe do Questionário de Avaliação - Pilar da Empresa ..................................... 173

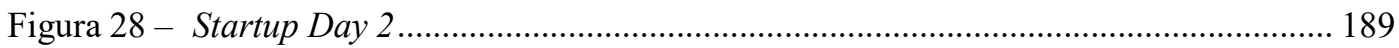

Figura 29 - Framework de Aspectos Internos, Barreiras e Proposições para a Empresa XYZ .............................................................................................. 281 


\section{SUMÁRIO}

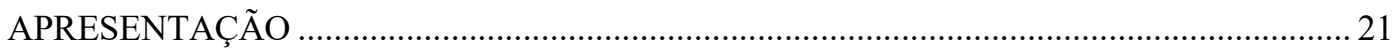

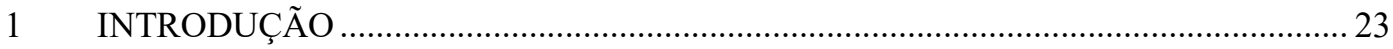

$1.1 \quad$ Contexto Externo da Empresa Estudada ............................................................... 23

1.2 Contexto Interno da Empresa Estudada: situação-problema................................ 25

1.3 Objetivos 'Pesquisa-Ação Central' versus Objetivos 'Pesquisa-Ação

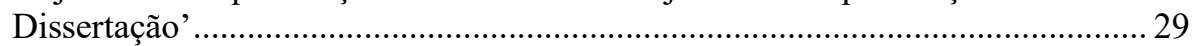

1.4 Objetivos 'Pesquisa-Ação Dissertação' ................................................................... 30

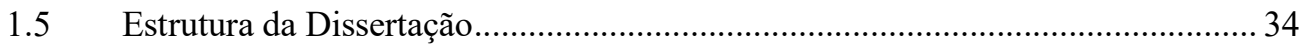

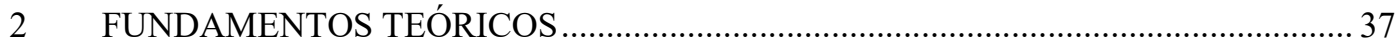

2.1 Estruturação dos Fundamentos ...................................................................... 37

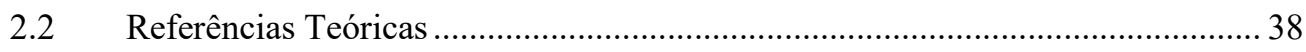

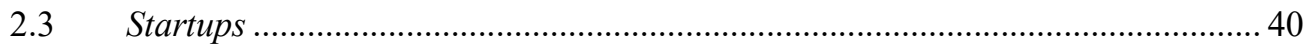

2.3.1 Relacionamento entre startups e o setor financeiro ............................................ 41

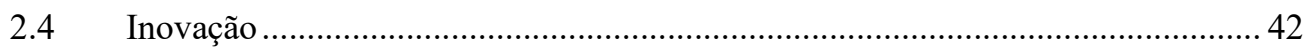

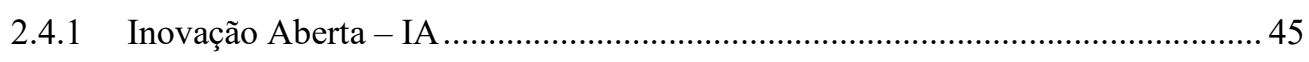

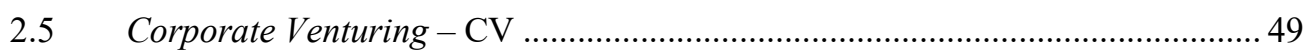

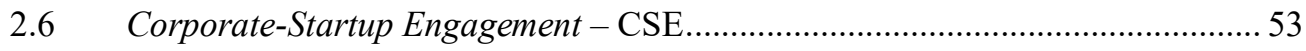

2.7 Intersecções e Diferenças entre os Conceitos de Corporate-Startup Engagement (CSE), Corporate Venturing (CV) e Inovação Aberta (IA) ............. 61

2.7.1 Intersecções e diferenças entre o conceito de Inovação Aberta (IA) versus o de Corporate Venturing (CV) ................................................................ 61

2.7.2 Intersecções e diferenças entre o conceito de Corporate-Startup Engagement versus o de Corporate Venturing e o de Inovação Aberta ............... 63

2.8 Considerações sobre os Escopos Teórico e Prático da Pesquisa............................. 65

2.8.1 Parcerias: startups como provedoras de solução para grandes empresas ............ 66

2.8.2 Aspectos internos associados ao relacionamento de grandes empresas............... 69

2.8.3 Aspectos internos da organização associados à inovação e à inovação aberta .... 70

2.8.4 Aspectos internos da organização associados ao Corporate Venturing................ 76

2.8.5 Aspectos internos da organização associados ao Corporate-Startup

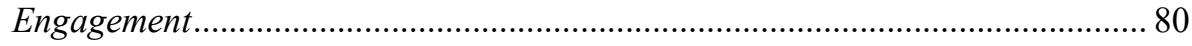

2.8.6 Consolidação dos principais aspectos em relação a barreiras e melhores

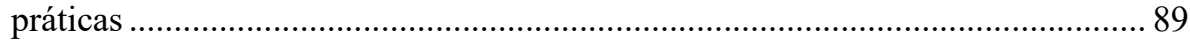

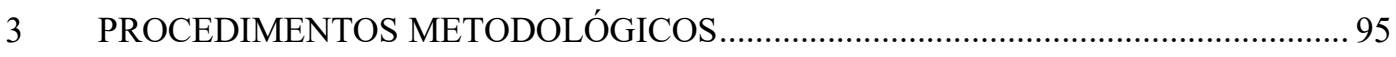

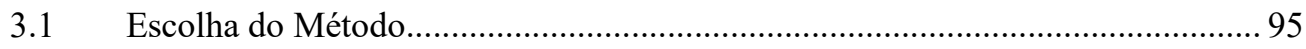

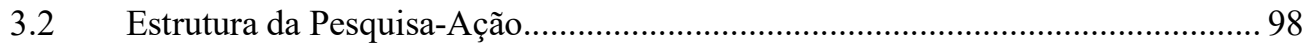


3.3 Uso da Fundamentação Teórica na Pesquisa-Ação.............................................. 102

3.4 Dinâmicas da Pesquisa-Ação: 'Central' e 'Dissertação' ........................................ 104

3.5 Etapas e Fases dos Ciclos da 'Pesquisa-Ação Central' ....................................... 106

3.5.1 Etapa 1 - Contexto / Propósito........................................................................ 108

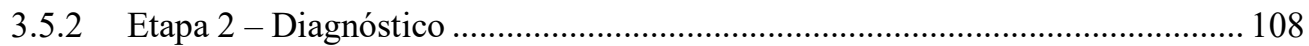

3.5.3 Etapa 3 - Planejamento das Ações.................................................................... 112

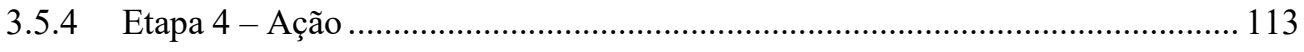

3.5.5 Etapa 5 - Avaliação ................................................................................ 113

3.6 Meta-Ciclo - 'Pesquisa-Ação Dissertação' ....................................................... 114

3.7 Coleta de Dados para a 'Pesquisa-Ação Dissertação' ........................................... 116

3.8 Elaboração do Roteiro de Entrevistas .............................................................. 120

3.9 Análise de Dados para a 'Pesquisa-Ação Dissertação' .......................................... 123

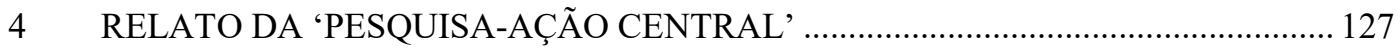

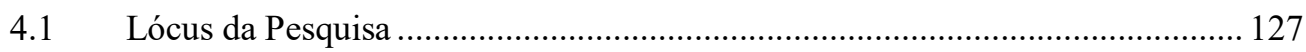

4.2 Proposta de 'Pesquisa-Ação' ............................................................................... 129

4.2.1 Ciclo 1 - Preparação e Definição de Propósito..................................................... 130

4.2.2 Ciclo 2 - Capacitação Interna, Aculturamento e Ferramental ........................... 154

4.2.3 Ciclo 3 - Expansão de Aculturamento e Experimentação do Ferramental ......... 183

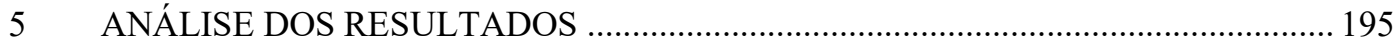

5.1 Barreiras para Aproximação da Empresa XYZ com Startups ……………….... 195

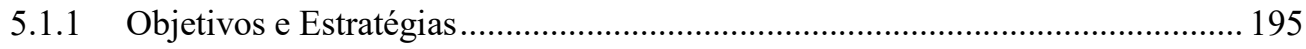

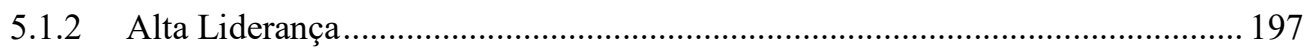

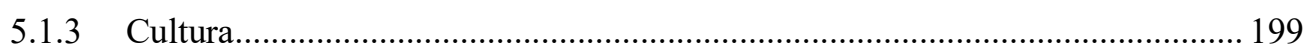

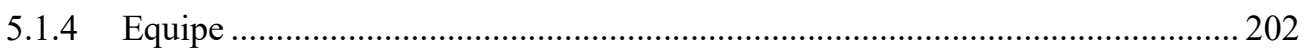

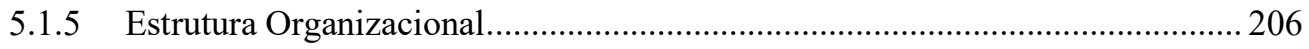

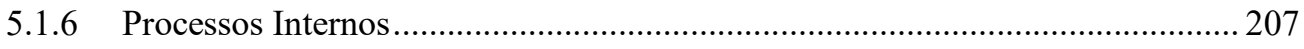

5.2 Elementos Habilitadores de Aproximação da Empresa XYZ com as

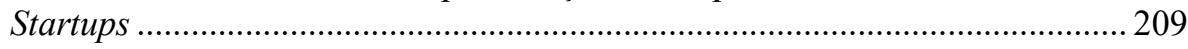

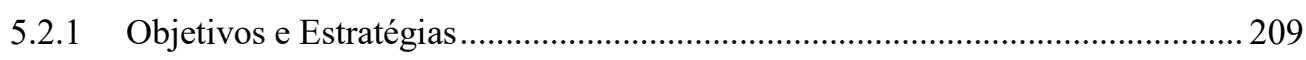

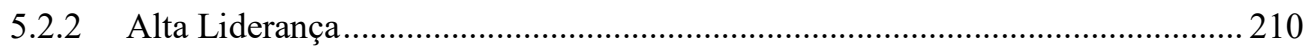

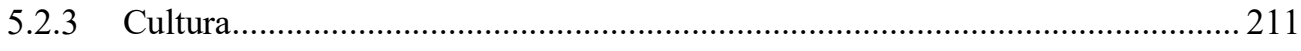

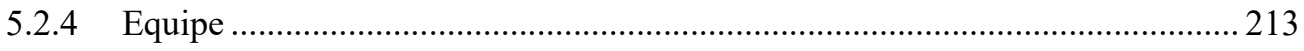

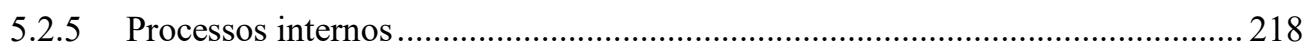

5.3 Sugestões de Ações e Melhorias para os Próximos Ciclos .................................. 220

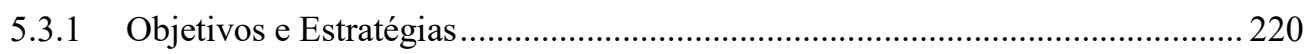

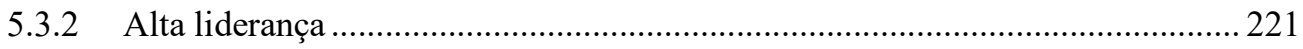




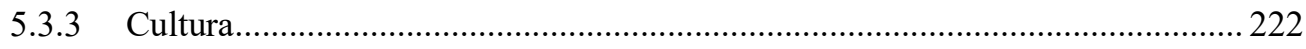

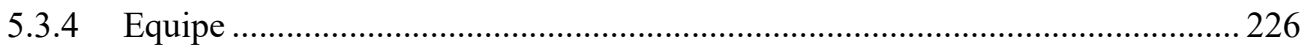

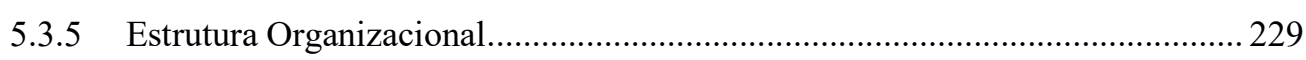

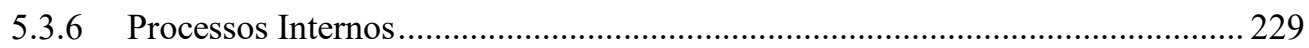

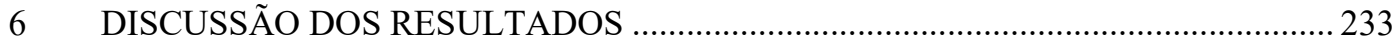

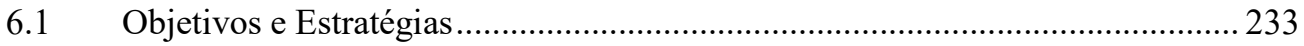

6.1.1 Barreiras: indefinição do escopo e da estratégia quanto a startups para

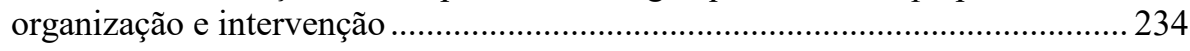

6.1.2 Elementos habilitadores - definição do objetivo e da estratégia da

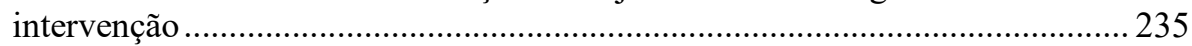

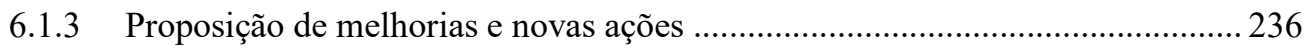

6.1.4 Resumo do aspecto 'Objetivos e Estratégias' .................................................... 238

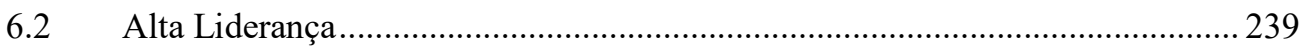

6.2.1 Barreiras: falta de apoio da alta liderança, conflito de prioridades dos times de apoio e comunicação esporádica com os executivos....................................... 239

6.2.2 Elementos habilitadores - Patrocínio de um Alto Executivo ............................... 241

6.2.3 Proposição de melhorias e novas ações .............................................................. 242

6.2.4 Resumo do aspecto alta liderança .................................................................... 246

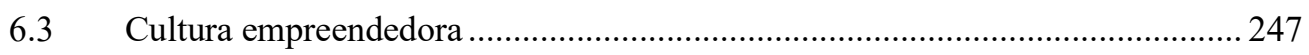

6.3.1 Barreiras: ausência de cultura empreendedora................................................ 247

6.3.2 Falta de conhecimento sobre empreendedorismo/startups ................................ 248

6.3.3 Elementos habilitadores - eventos de aculturamento e 'rede social' .................. 249

6.3.4 Proposição de melhorias e novas ações ............................................................... 252

6.3.5 Resumo do aspecto cultura empreendedora/orientação empreendedora............. 254

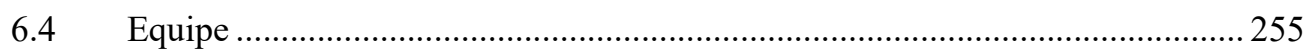

6.4.1 Barreiras: falta de capacitação/conhecimento e falta de tempo .......................... 256

6.4.2 Elementos habilitadores - aprendizado, motivação e autonomia........................ 258

6.4.3 Proposição de melhorias e novas ações .................................................................. 261

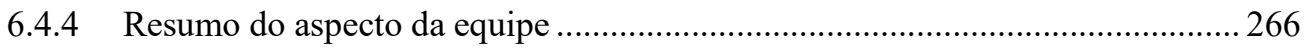

6.5 ESTRUTURA ORGANIZACIONAL E PROCESSOS INTERNOS................. 266

6.5.1 Barreiras: estrutura organizacional rígida e processos complexos e longos ...... 268

6.5.2 Elementos habilitadores - cartilha e ferramenta para avaliação de startups...... 270

6.5.3 Proposição de melhorias e novas ações ............................................................. 271

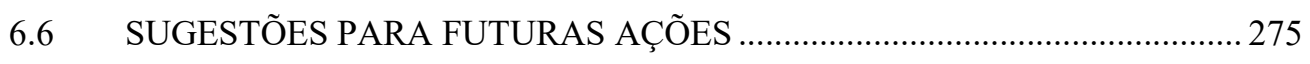

7 CONSIDERAÇÕES FINAIS, RECOMENDAÇÕES E LIMITAÇÕES DO

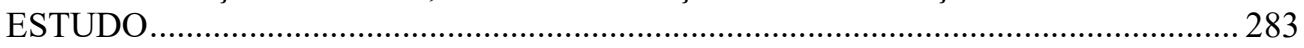

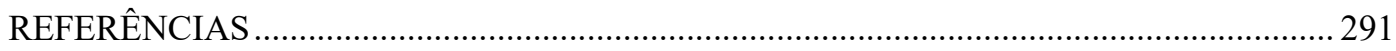


APÊNDICES.

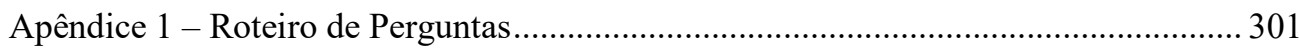

Apêndice 2 - Modelo do Termo de Consentimento Livre e Esclarecido ........................ 304

Apêndice 3 - Amostra do Diário de Bordo..................................................................... 306 


\section{APRESENTAÇÃO}

Há 14 anos venho atuando profissionalmente na área de Tecnologia da Informação, em corporações nos setores de software (Totvs), indústria (KaVo), consultoria (Stefanini) e, por fim, no financeiro, onde nos últimos 11 anos venho consolidando minha carreira no gerenciamento de projetos transformadores.

Ademais, fora do ambiente corporativo, empreendi no ramo de software (Rocketmind) e de educação (Day2), o que me permitiu experienciar uma série de desafios, incluindo o de me relacionar com grandes empresas.

Atualmente, como Arquiteto Enterprise em uma organização financeira de grande porte, administro consultorias de transformação digital focadas em canais e Customer Relationship Management (CRM), muitas delas envolvendo interfaces com startups. Isso me fez perceber os desafios dessas empresas emergentes em atuar como provedoras de solução para corporações. Tal situação despertou em mim o interesse em pesquisar academicamente linhas relacionadas ao Corporate Venturing e ao Corporate-Startup Engagement, temas em ascensão no ambiente profissional e com oportunidades no meio acadêmico (100 Open Startups, 2017).

Em contato com um dos executivos da organização onde atuo, coloquei-me à disposição para contribuir com a busca por soluções para esse contexto e a partir daí surgiu a oportunidade para compor um grupo multidisciplinar e para conduzir colegiadamente ciclos internos de ações, visando a aproximar a organização de novas startups.

Esses ciclos internos práticos foram conduzidos à luz da metodologia científica de Pesquisa-Ação. Neles, além de pesquisador, pude atuar como membro fixo e como consultor/organizador em boa parte dos ciclos. 


\section{INTRODUÇÃO}

\subsection{CONTEXTO EXTERNO DA EMPRESA ESTUDADA}

O mercado financeiro brasileiro vem sofrendo transformações devido a duas linhas de influência: a primeira, diz respeito ao ambiente econômico interno, fruto de instabilidade política; e a segunda, ao movimento de novos entrantes que traz inovações em modelos de negócios.

No que tange à primeira linha de influência de transformações, ambiente econômico interno, o relatório de pesquisa realizado pelo Banco Mundial Econômico indica que o Brasil tem um dos piores pilares de inovação. Num ranking de 138 (cento e trinta e oito) países, o país ocupa a $100^{\mathrm{a}}$ (centésima) posição. Esse tópico é reconhecido como umas das 16 (dezesseis) principais barreiras para se fazer negócios no país (Schwab \& Sala-IMartin, 2016).

A segunda linha de influência de transformações refere-se às forças internas e externas do setor bancário que vêm redefinindo o mercado com uma velocidade sem precedentes. Esse ambiente é instaurado devido à fragmentação do mercado com a chegada de novos entrantes - como as fintechs (termo originado de uma contração de financial technology) (Puschmann, 2017) e empresas não bancárias oferecendo serviços financeiros - e com a adequação das empresas já estabelecidas para conseguir enfrentá-las (Deloitte, 2015).

A elevação do número de fintechs demonstra claramente a mudança que vem ocorrendo no mercado financeiro. Em 2015, eram 54 (cinquenta e quatro) empresas mapeadas. Em

junho de 2019, passaram a ser 604 (seiscentos e quatro), o que representa um crescimento de $1.118 \%$ nesse curto intervalo de tempo (Fintechlab, 2019). Cerca de 50 (cinquenta) dessas fintechs são denominadas 'bancos digitais', oferecendo serviços similares aos bancos tradicionais (Anprotec \& Sebrae, 2018). Os investimentos nas fintechs vêm acompanhando essa taxa de crescimento. Em 2018, foi investido R \$ 1,8 bilhão nessas empresas, valor sete vezes superior ao de 2016 - R\$ 203 milhões (Fintechlab, 2019). 
Esses exemplos demonstram a dimensão do cenário desafiador a ser enfrentado pelas instituições financeiras tradicionais no Brasil.

Órgãos governamentais, como a Comissão de Valores Mobiliários (CVM), corroboram com essa visão, ao reconhecerem o impacto potencial de transformação dos novos entrantes no mercado financeiro nacional. Na perspectiva da CVM (2016), as novas tecnologias financeiras têm capacidade de transformação para construir novos produtos, serviços, processos e mercados.

Como uma via para enfrentar esse novo cenário, instituições financeiras têm buscado engajamento com startups - denominação dada a novas empresas tecnológicas que possuem capacidades inovadoras e escaláveis (Sebrae, 2015). Entre os propósitos dessas grandes empresas para o engajamento está a renovação das capacidades competitivas e a proteção do posicionamento no mercado financeiro (Bonzom \& Netessine, 2016; Kelly, Ferenzy, \& McGrath, 2017).

Segundo a Febraban (2018), os bancos tradicionais brasileiros vêm seguindo a tendência de mercado, construindo relacionamentos com startups por meio do provisionamento de recursos, contratação de serviços dessas empresas e desenvolvimento de novos produtos e modelos de negócios.

Alguns desses casos são amplamente divulgados na mídia (Meio\&Mensagem, 2018). O Banco Santander, por exemplo, oferece às startups o programa de aceleração Radar, com mentoria, acesso a profissionais e oportunidades de negócios para aquelas que trouxerem soluções voltadas aos desafios propostos pela instituição (Santander, 2019). A empresa estatal Banco do Brasil permite que startups possam desenvolver softwares utilizando sua plataforma web por meio de interfaces tecnológicas (BBStartups, 2019). Outro exemplo de iniciativa é o Cubo Coworking, espaço de coworking subsidiado pelo Banco Itaú, que permite às startups acesso facilitado a atores interessados no ecossistema empreendedor, como mentores, investidores e universidades (Cubo, 2019). Outra instituição financeira aberta às startups é o Banco Bradesco, que busca criar parcerias para desenvolver modelos de negócios, produtos e serviços a partir de seu Programa de Inovação Aberta Inovabra - e de seu espaço de coworking e coinovação - Habitat (Inovabra, 2019). 
Esses fatos demonstram que as startups têm recebido atenção notável das instituições financeiras brasileiras que buscam por transformação digital e inovação (Meio\&Mensagem, 2018).

Em paralelo a esses acontecimentos há também no cenário nacional um crescimento elevado de startups. Em 2015, o número de startups brasileiras era de 4.151; em 2019, chegou a 13.018, representando um crescimento de 313\% neste período (Abstartups, 2019).

Esses dois fenômenos - crescimento do volume de startups e interesse das instituições financeiras por essas empresas - trazem consigo desafios e oportunidades de relacionamento para ambos os lados.

\subsection{CONTEXTO INTERNO DA EMPRESA ESTUDADA: SITUAÇÃO- PROBLEMA}

A empresa $X Y Z^{1}$ - organização analisada neste estudo - é um exemplo de instituição financeira que vem protagonizando ações sistemáticas e pontuais voltadas ao engajamento com startups. Por consequência, vem obtendo sucesso e vem aprendendo com os desafios dessas relações.

Entre 2014 e 2017, essa empresa tomou decisões estratégicas pontuais relacionadas a Corporate Venturing, como a incorporação de uma startup tecnológica de meios de pagamento e a aquisição minoritária de uma startup de investimentos.

No entanto, um movimento sistemático feito pela organização para se aproximar de startups foi o estabelecimento de um espaço compartilhado para essas empresas, cujo foco principal foi o de observar a dinâmica do ecossistema de startups.

\footnotetext{
${ }^{1}$ Por questões éticas, optou-se por não identificar a empresa analisada, o que não inviabiliza os resultados.
} 
Apesar dessas diversas atividades, a maior parte do volume de interações da empresa XYZ com startups vem de parcerias, como a contratação de serviços e produtos e codesenvolvimento. O volume de parcerias com startups é maior do que o de outras formas de relacionamento pelo grande volume de áreas de negócios existentes e de suas dezenas de diretorias, interessadas em utilizar startups para resolver problemas ou habilitar oportunidades.

Nesse sentido, a organização vem dando sinais aos colaboradores sobre sua intenção de se aproximar das startups. No entanto, essa mudança de paradigma tem sido um grande desafio para a empresa, principalmente pela complexidade dos aspectos internos construídos ao longo de décadas de existência.

Contrariamente a essa realidade, alguns importantes trabalhos acadêmicos nos domínios de Corporate Venturing, Inovação e, mais recentemente, Corporate-Startup Engagement abordam os desafios de relacionamentos entre grandes empresas e atores externos (Mortara, Napp, Slacik, \& Minshall, 2009; Minshall, Mortara, Napp, \& Probert, 2010; Weilen \& Chesbrough, 2015; Rundquist \& Österling, 2018). No entanto, os materiais encontrados na literatura costumam ser abrangentes quanto aos desafios internos de adaptação de grandes empresas e às proposições associadas ao fato de ter startups como provedoras de solução.

A escassez de detalhes sobre desafios internos associados à inovação, bem como ações para superá-los, tornam-se ainda mais evidentes quando se busca por conteúdos relacionados com o setor financeiro (Das, Verburg, Verbraeck, \& Bonebakker, 2018).

Aspectos internos culturais, estratégicos, processuais e estruturais dificultavam a aproximação entre startups e a empresa XYZ, o que impedia que ela obtivesse novas capacidades e maior velocidade por meio de soluções externas.

No passado, na empresa XYZ, por exemplo, houve casos de parcerias que demoraram mais de um semestre para serem efetivadas, o que reduziu as janelas de oportunidades associadas ao uso da inovação. 
Sabe-se que, analisando sob a ótica das startups, o tempo é fator decisivo. A celeridade para efetivar uma parceria pode significar a expansão dos negócios pelo aumento de fluxo de caixa ou até mesmo o encerramento da empresa por falta de recursos, caso o processo seja moroso demais (Minshall, Mortara, Napp, \& Probert, 2010).

No contexto da empresa XYZ, havia, portanto, dificuldades na execução de iniciativas envolvendo startups, pois a organização não havia adaptado a tempo seus mecanismos internos para que pudesse interagir com essas empresas emergentes ou para que absorvesse suas tecnologias. A dificuldade em obter novas competências é um desafio para a maioria das grandes empresas, o que Tushman e O'Reilly (1996, p. 18) denominam 'inércia organizacional' ou 'colesterol organizacional'.

$\mathrm{Na}$ empresa XYZ, um exemplo de inércia era a rigidez processual. Sem processos compatíveis a essas novas empresas, a startup era avaliada da mesma forma que um fornecedor estabelecido. Para se tornarem provedoras de soluções tecnológicas, as startups eram submetidas à avaliação de, ao menos, sete áreas distintas, dentre estas, a de tecnologia. Tais processos, em geral, limitavam as chances de aprovação, causavam a desistência das áreas de negócios envolvidas ou resultavam na busca por aprovações via altos executivos.

Segundo conversas isoladas com membros das equipes envolvidas, os desafios internos estavam associados a questões culturais, organizacionais e tecnológicas, mas não se sabia quais ações internas poderiam ser implantadas para que a empresa XYZ pudesse melhorar a forma de se relacionar com startups, nem quais impeditivos poderiam ser encontrados nessa jornada.

Diretamente afetado por esse contexto, o presente pesquisador entendeu que havia oportunidade para propor a adoção de uma pesquisa científica que permitisse uma intervenção direcionada ao provisionamento de solução desse problema.

Após alinhamento com seu diretor, este pesquisador passou a fazer parte de um grupo multidisciplinar, cujo objetivo inicial foi realizar ações de melhoria no relacionamento da empresa XYZ com startups. 
Inicialmente, workshops foram realizados para identificar os impedimentos internos distribuídos em: problemas de engajamento cultural; transparência processual; governança/processos; metodologia/avaliação técnica; e avaliação de riscos. A Figura 1 apresenta uma visão simplificada desses impedimentos. Este foi o marco inicial da intervenção, mas sofreu mudanças ao longo do tempo. As ações priorizadas no Ciclo 1 tiveram foco nos processos, incluindo sua comunicação, e no acompanhamento de projetos envolvendo startups.

\section{Figura 1 - Visão simplificada dos impedimentos levantados no Ciclo 1}

\begin{tabular}{|c|c|c|c|}
\hline & $\begin{array}{c}\text { Problemas de } \\
\text { Engajamento Cultural }\end{array}$ & $\begin{array}{l}\text { Problemas de } \\
\text { Avaliação de Riscos }\end{array}$ & $\begin{array}{c}\text { Problemas de Metodologia } \\
\text { e Avaliação Técnica }\end{array}$ \\
\hline $\begin{array}{l}\text { Visão } \\
\text { simplificada } \\
\text { dos }\end{array}$ & $\begin{array}{l}\text { falta de: conhecimento } \\
\text { sobre startups; visão de } \\
\text { parceria com startups; } \\
\text { propósito das áreas } \\
\text { envolvidas; confiança }\end{array}$ & $\begin{array}{l}\text { excesso de provas de } \\
\text { conceito; falta de } \\
\text { políticas adequadas } \\
\text { para avaliar riscos }\end{array}$ & $\begin{array}{l}\text { avaliação de soluções } \\
\text { técnicas não adaptadas } \\
\text { para startups; equipes } \\
\text { sem preparo adequado } \\
\text { para avaliar startups }\end{array}$ \\
\hline $\begin{array}{l}\text { impedimentos } \\
\text { levantados } \\
\text { nos } \\
\text { workshops }\end{array}$ & $\begin{array}{l}\text { falta de visão e } \\
\text { conhecimento dos } \\
\text { processos internos }\end{array}$ & \multicolumn{2}{|c|}{$\begin{array}{l}\text { processos envolvendo startups burocráticos e sem } \\
\text { integração; ausência de pontos focais das áreas; } \\
\text { falta de autonomia do times; ausência de } \\
\text { orçamento para pilotos e testes }\end{array}$} \\
\hline & $\begin{array}{l}\text { Problemas de } \\
\text { Transparência }\end{array}$ & \multicolumn{2}{|c|}{ Problemas de Governança/Processos } \\
\hline
\end{tabular}

Fonte: Elaborada pelo autor com base nas discussões internas.

Posteriormente, para efeito de escopo da intervenção, esse grupo de trabalho detalhou o 'relacionamento com startups' almejado como 'parcerias para provisionamento de soluções aos problemas de negócios'.

Em paralelo ao desafio prático profissional, este pesquisador identificou que o tema 'relacionamento de grandes empresas com startups' está em ascensão no meio acadêmico (Usman \& Vanhaverbeke, 2017). Notou, inclusive, a oportunidade de poder contribuir com a Academia, com conhecimentos a partir de práticas profissionais que permitam margens para exploração. Sendo assim, a presente dissertação visa a contribuir com a solução de problemas e/ou situações análogas às da empresa XYZ. 


\subsection{OBJETIVOS 'PESQUISA-AÇÃO CENTRAL' VERSUS OBJETIVOS 'PESQUISA-AÇÃO DISSERTAÇÃO'}

Em uma Pesquisa-Ação, segundo Perry e Zuber-Skerritt (1992), há duas pesquisas acontecendo paralelamente: (1) a 'Pesquisa-Ação Central', focada na intervenção em si, dentro da organização, onde ocorrem os ciclos de ações; e (2) a 'Pesquisa-Ação Tese', tratada no presente trabalho como 'Pesquisa-Ação Dissertação', buscando compreender o que ocorre em um determinado processo de intervenção.

A 'Pesquisa-Ação Central' buscou executar ações que aproximassem a empresa XYZ de startups considerando-as 'parceiras no provisionamento de soluções aos problemas de negócios'.

Sob o ponto de vista das dinâmicas adotadas, o grupo foi direcionado estrategicamente pelo diretor-patrocinador, mas teve autonomia para tomar decisões táticas e operacionais na intervenção, sempre de forma colegiada.

Conforme mencionado anteriormente, na Apresentação, além de pesquisador, o autor desta dissertação também é membro participante do grupo, conduzindo ações e também transitando entre o papel de consultor, trazendo informações científicas e práticas; e de líder de time, apoiando na organização de cada atividade do grupo.

Para melhor compreensão do leitor, o relato de toda a intervenção realizada apresenta-se nesta dissertação, apesar de este não ter sido o objetivo da mesma.

A 'Pesquisa-Ação Central', ou intervenção propriamente dita, foi realizada em três ciclos, conforme demonstra o Quadro 1. 
Quadro 1 - Resumo das atividades da 'Pesquisa-Ação Central'

\begin{tabular}{|c|c|c|c|c|}
\hline & $\begin{array}{c}\text { Papel do } \\
\text { Pesquisador }\end{array}$ & Período & Principais atividades do Ciclo & Entregas Realizadas \\
\hline $\begin{array}{c}\text { Ciclo } 1- \\
\text { Exploratório }\end{array}$ & $\begin{array}{l}\text { Membro e } \\
\text { Consultor }\end{array}$ & $\mid \begin{array}{c}29 / 12 / 2016 \\
a \\
31 / 03 / 2017\end{array}$ & $\begin{array}{l}\text { - Identificação do propósito e do } \\
\text { objetivo da intervenção } \\
\text { (workshops). } \\
\text { - Identificação de quais seriam os } \\
\text { principais problemas ao se } \\
\text { relacionar com startups } \\
\text { (workshops). } \\
\text { - Planejamento e ações focados } \\
\text { em processos a e } \\
\text { acompanhamento de startups. }\end{array}$ & $\begin{array}{l}\text { - Cartilha com processo de } \\
\text { contratação de startups. } \\
\text { - Comitê quinzenal para } \\
\text { acompanhamento de } \\
\text { projetos envolvendo } \\
\text { startups. } \\
\text { - Modelo evolutivo para } \\
\text { avaliação de startups. }\end{array}$ \\
\hline $\begin{array}{l}\text { Ciclo 2- } \\
\text { Capacitação } \\
\text { Interna, } \\
\text { Aculturamento } \\
\text { e Definição do } \\
\text { Ferramental }\end{array}$ & $\begin{array}{l}\text { Membro e } \\
\text { Consultor }\end{array}$ & $\left|\begin{array}{c}03 / 04 / 2017 \\
a \\
08 / 09 / 2017\end{array}\right|$ & $\begin{array}{l}\text { - Revisão do plano inicial da } \\
\text { intervenção. } \\
\text { - Capacitação do Grupo do } \\
\text { (entrevistas, artigos e relatórios } \\
\text { profissionais). } \\
\text { - Planejamento e ações focadas } \\
\text { em aculturamento e critérios de } \\
\text { avaliação de startups. }\end{array}$ & $\begin{array}{l}\text { - } \text { Rede Social. } \\
\text { - Critérios de Avaliação } \\
\text { para Soluções de } \\
\text { startups. } \\
\text { - Startup Day - Evento de } \\
\text { Aculturamento. }\end{array}$ \\
\hline $\begin{array}{c}\text { Ciclo } 3 \text { - } \\
\text { Expansão do } \\
\text { Aculturamento } \\
\text { e } \\
\text { Experimentação } \\
\text { do Ferramental }\end{array}$ & $\begin{array}{l}\text { Membro e } \\
\text { Líder do } \\
\text { Time } \\
\text { (Team } \\
\text { Leader) }\end{array}$ & $\left|\begin{array}{c}12 / 09 / 2017 \\
a \\
11 / 12 / 2017\end{array}\right|$ & $\begin{array}{l}\text { - } \text { Repriorização das ações. } \\
\text { em acultinuidade de ações focadas } \\
\text { avaliação de startups. }\end{array}$ & $\begin{array}{l}\text { - Piloto e Divulgação dos } \\
\text { Critérios de Avaliação } \\
\text { para Soluções de } \\
\text { Startups. } \\
\text { - Startup Day 2- Evento } \\
\text { de Aculturamento. }\end{array}$ \\
\hline
\end{tabular}

Fonte: Elaborado pelo autor.

O Ciclo 1 da 'Pesquisa-Ação Central', denominado exploratório, promoveu workshops para diagnósticos dos problemas a serem tratados e definição de ações iniciais, enquanto os Ciclos 2 e 3 da 'Pesquisa-Ação Central' passaram por uma revisão completa quanto ao escopo e tiveram foco no aculturamento e na definição do ferramental para avaliação de startups, sendo necessária uma capacitação prévia dos colaboradores envolvidos na intervenção.

\subsection{OBJETIVOS 'PESQUISA-AÇÃO DISSERTAÇÃO'}

Diante do objetivo prático oriundo da 'Pesquisa-Ação Central' - melhorar o relacionamento entre a empresa XYZ e startups - surgem questionamentos importantes sobre os aspectos internos para que esse objetivo seja alcançado: 
- Segundo Tushman e O'Reilly (1996) e Morris e Kuratko (2002), a própria organização, na busca por novas competências, produz impedimentos para sí. Nesse sentido, para o contexto da pesquisa surge a pergunta: Como os aspectos internos podem impactar as ações do grupo da intervenção?

- Embora houvesse na 'Pesquisa-Ação Central' um conjunto de barreiras e proposições de ações iniciais, sabe-se que da experiência prática de um grupo interventor podem ser extraídos aprendizados importantes para aprimorar a própria prática (Schön, 1983; Kolb, 1984), diante disso surge a indagação sob a intervenção: Quais as lições aprendidas o grupo obterá ao executar as ações no contexto da empresa XYZ? E como podem ser aplicadas nas interações subsequentes?

- Mesmo havendo proposições na teoria e na prática sobre o relacionamento de grandes empresas com startups, a seleção dessas proposições varia de acordo com os aspectos internos, maturidade e objetivos estratégicos de cada organização (Bonzom \& Netessine, 2016; Bannerjee, Bielli, \& Hale, 2016; Minshall, Mortara, Napp, \& Probert, 2010). Desta forma, emerge do escopo da intervenção o seguinte questionamento: Quais seriam as ações mais adequadas para continuidade da intervenção após o final dos ciclos pesquisados?

Diante dessas indagações, a 'Pesquisa-Ação Dissertação' busca examinar o seguinte problema prático: 'Como as ações internas podem melhorar o relacionamento da empresa XYZ com startups?'

Dado o problema exposto, este estudo está estruturado de forma a atender ao seguinte objetivo geral: 'Viabilizar o melhor relacionamento entre uma grande empresa e startups'. 
Como objetivos específicos delimitou-se:

(1) Identificar barreiras internas que impeçam a realização das ações de aproximação com startups;

(2) Compreender boas práticas e oportunidades de melhoria identificadas a partir da experiência do grupo de intervenção;

(3) Analisar a aderência de boas práticas e recomendações extraídas da teoria e da prática à luz da intervenção na organização;

(4) Propor um conjunto de ações voltadas aos aspectos internos que possam aproximar a empresa XYZ das startups.

Desta forma, buscou-se conectar o problema de pesquisa, o objetivo principal e os objetivos específicos com os capítulos, para melhor compreensão e evolução do trabalho, assim como sua coerência, a fim de responder ao problema apresentado. A representação dessa conexão é disposta na Figura 2 a seguir. 
Figura 2 - Matriz de Amarração da Dissertação

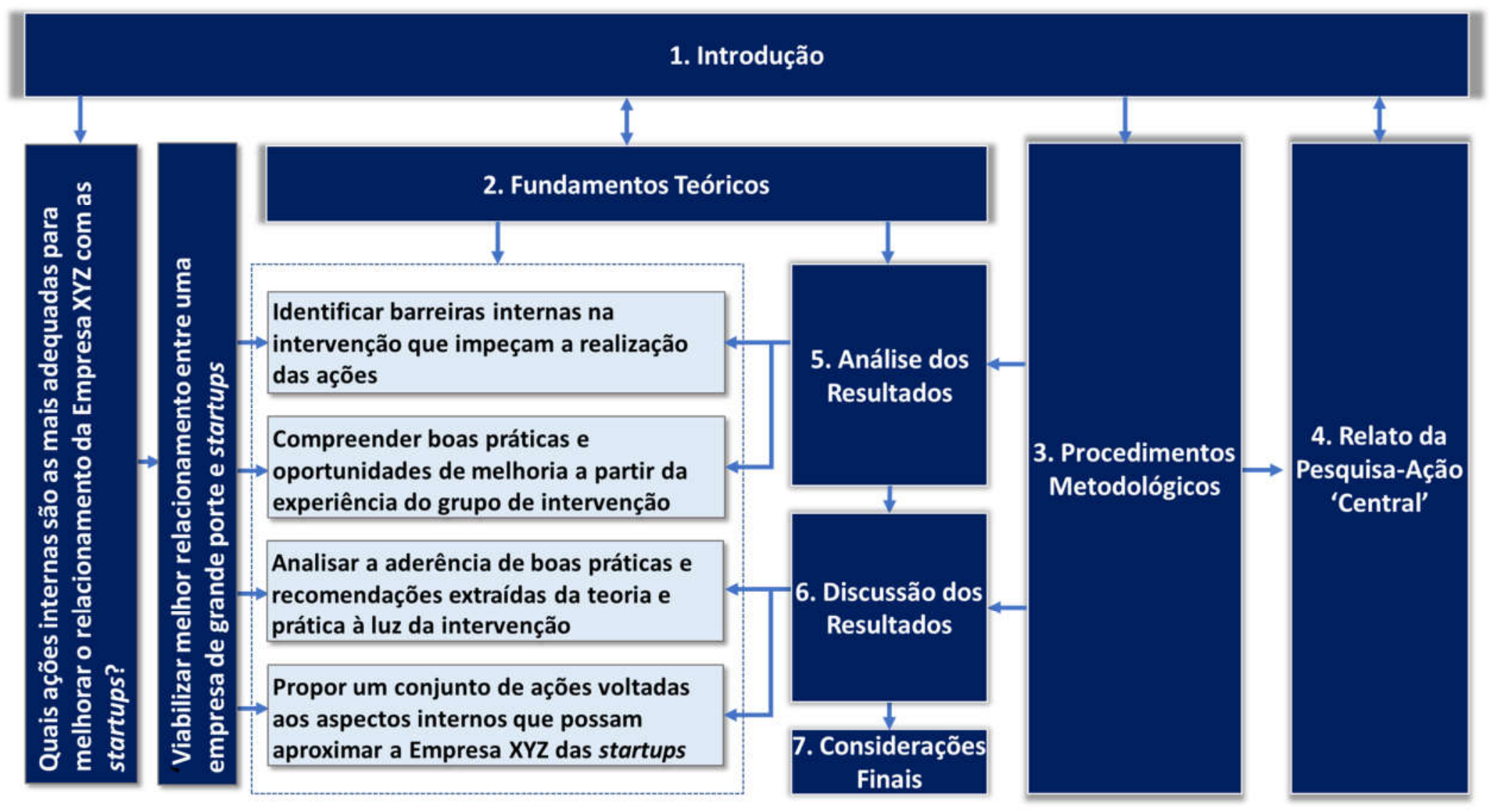

Fonte: Elaborada pelo autor, com base em Mazzon (2018). 


\subsection{ESTRUTURA DA DISSERTAÇÃO}

Para atender aos objetivos propostos pela 'Pesquisa-Ação Dissertação' e visando a apresentar os resultados da intervenção - 'Pesquisa-Ação Central' -, o presente trabalho utilizou como base a estrutura de dissertação proposta por Coghlan e Brannick (2005), que se diferencia da pesquisa acadêmica tradicional, por apresentar os aspectos práticos e reflexões do pesquisador-interventor. Devido ao fato de essa estrutura não ser rígida, desde que se apresentem os assuntos recomendados (Coghlan \& Brannick, 2005), foi possível adaptá-la, conforme o Quadro 2, para que fique aderente às apresentações convencionais de trabalhos acadêmicos:

- Introdução: contexto, razão da pesquisa científica e relevância social-acadêmica da pesquisa. Refere-se ao 'contexto', 'propósito e racional da pesquisa' e à estrutura dos autores.

- Fundamentos Teóricos e Práticos: aprofundamento sobre o tema e sobre os conceitos centrais da pesquisa. $\mathrm{O}$ assunto é diluído na estrutura dos autores e não possui seção específica.

- Procedimentos Metodológicos: apresentação da escolha do(s) método(s) e da(s) técnica(s) propostos como dinâmicas da 'Pesquisa-Ação Central' e da 'PesquisaAção Dissertação', além da estruturação da dissertação. Refere-se à 'metodologia e métodos de investigação’ dos autores.

- Relato da 'Pesquisa-Ação Central': relato da intervenção detalhando ciclos e entregas. É considerado pelos autores como o centro da dissertação, pois dá base para entendimento dos acontecimentos antes que as análises sejam apresentadas. Conforme recomendação dos autores, durante os relatos, as percepções do pesquisador serão dispostas em caixas de texto e as autorreflexões apresentadas ao final dos ciclos. Esse capítulo se refere às sessões de 'história e resultados' e 'autorreflexão e aprendizagem do pesquisador da ação relato da intervenção' de Coghlan e Brannick (2005).

- Análises: estruturação e análise dos dados coletados de entrevistas e observações, contemplando com os referenciais teóricos, a fim de atender aos objetivos da pesquisa. Refere-se ao subitem 'reflexão sobre a história à luz da experiência e da teoria' dos autores. 
- Discussão dos Resultados: discussão dos resultados à luz dos objetivos de pesquisa. Segundo recomendação dos autores, busca-se compreender a teoria e alinhá-la com a prática. Refere-se ao subitem 'reflexão sobre a história à luz da experiência e da teoria' dos autores.

- Recomendações e Conclusões: apresentação das recomendações de ações, contribuições científicas e práticas, limitações do estudo e sugestões para pesquisas futuras. Refere-se ao subitem 'extrapolação para um contexto mais amplo e articulação do conhecimento utilizável' de Coghlan e Brannick (2005).

Quadro 2 - Comparativo entre a estrutura do presente trabalho e a proposição de Coghlan e Brannick (2005)

\begin{tabular}{|c|c|c|}
\hline Capítulos & $\begin{array}{l}\text { Estrutura do } \\
\text { Trabalho }\end{array}$ & Estrutura (Coghlan \& Brannick, 2005) \\
\hline 1 & Introdução & $\begin{array}{l}\text { - Propósito e Racional da pesquisa } \\
\text { - Contexto }\end{array}$ \\
\hline 2 & $\begin{array}{l}\text { Fundamentos Teóricos } \\
\text { e Práticos }\end{array}$ & (Não especificado na estrutura) \\
\hline 3 & $\begin{array}{l}\text { Procedimentos } \\
\text { Metodológicos }\end{array}$ & - Metodologia e métodos de investigação \\
\hline 4 & $\begin{array}{l}\text { Relato da 'Pesquisa- } \\
\text { Ação Central' }\end{array}$ & $\begin{array}{l}\text { - História e Resultados } \\
\text { - Autorreflexão e Aprendizagem do pesquisador da ação }\end{array}$ \\
\hline 5 & $\begin{array}{l}\text { Análises dos } \\
\text { Resultados }\end{array}$ & \multirow{2}{*}{ - Reflexão sobre a história à luz da experiência e da teoria } \\
\hline 6 & $\begin{array}{l}\text { Discussão dos } \\
\text { Resultados }\end{array}$ & \\
\hline 7 & $\begin{array}{l}\text { Considerações Finais e } \\
\text { Recomendações }\end{array}$ & $\begin{array}{l}\text { - Extrapolação para um contexto mais amplo e articulação } \\
\text { do conhecimento utilizável }\end{array}$ \\
\hline
\end{tabular}

Fonte: Elaborado pelo autor.

A 'Pesquisa-Ação Central' e a 'Pesquisa-Ação Dissertação' acontecem em paralelo na maior parte do tempo, sendo assim uma alimenta a outra constantemente. Por exemplo, as reflexões da investigação podem mudar as ações e as ações da intervenção, por sua vez, podem gerar novas observações para a investigação (Perry \& Zuber-Skerritt, 1992; Coghlan \& Brannick, 2005). Dessa forma, cabe mencionar que os capítulos deste trabalho têm correlação com essa dinâmica, conforme demonstra a Figura 3. 
Figura 3 - Correlação entre a Dinâmica da 'Pesquisa-Ação Central' e da 'Pesquisa-Ação Dissertação’ e os capítulos do trabalho
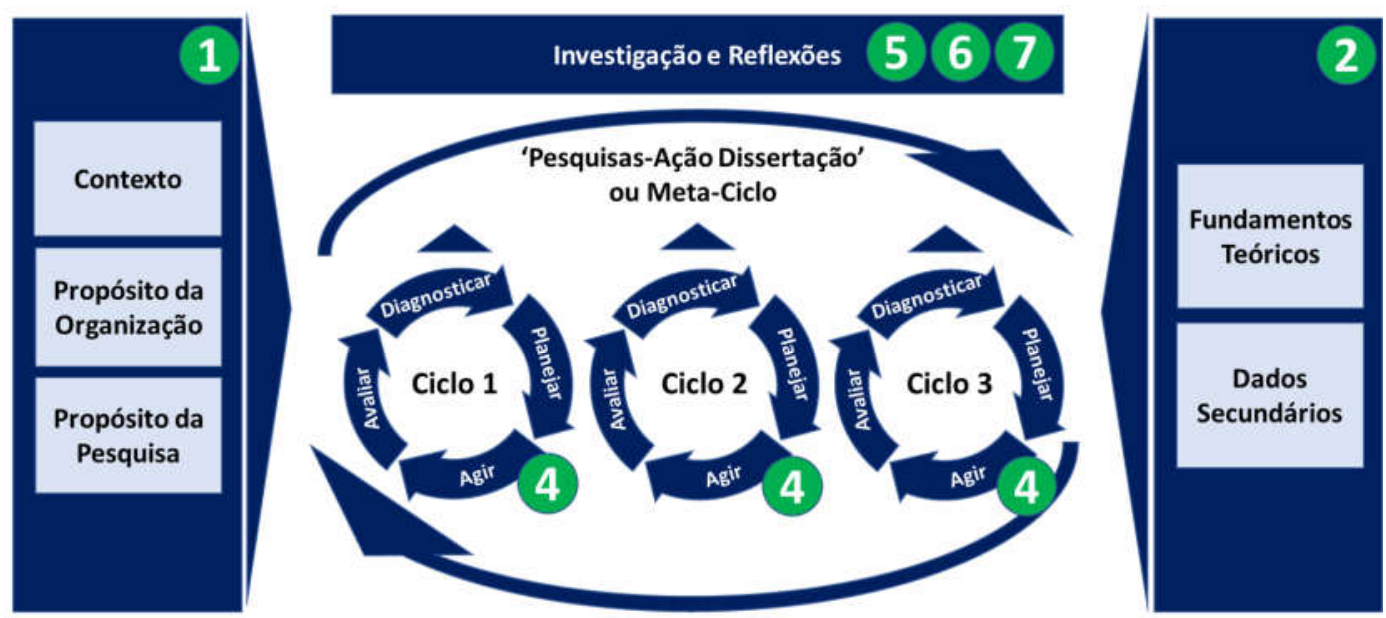

3 Procedimentos Metodológicos

Fonte: Elaborada pelo autor, com base em Coghlan e Brannick (2005). 


\section{FUNDAMENTOS TEÓRICOS}

\subsection{ESTRUTURAÇÃO DOS FUNDAMENTOS}

Face aos problemas e aos objetivos supramencionados, procurou-se trabalhar na seleção dos conceitos em duas vias: a primeira, dá-se pelo funil de temas que permeiam a situação-problema. Inicialmente, trabalhou-se apenas com o conceito de Corporate Venturing e seu tema maior, Corporate Entrepreneurship. No entanto, com o amadurecimento da intervenção, deparou-se com um conceito sobreposto, e ainda recente, o de Corporate-Startup Engagement (Kohler, 2016; Bonzom \& Netessine, 2016). Posteriormente, foram sendo agregados conceitos complementares, tais como Inovação e Inovação Aberta, os quais desencadearam e sustentaram as demais abordagens.

A segunda via dá-se pela identificação de referenciais que pudessem apoiar os Objetivos Específicos: Startups como Parceiras, Aspectos Internos da Organização Relacionados às Startups, Principais Barreiras Internas, Recomendações e Boas Práticas. Tal representação apresenta-se na Figura 4, juntamente com o racional das 2 (duas) perspectivas.

Figura 4 - Conceitos centrais do projeto

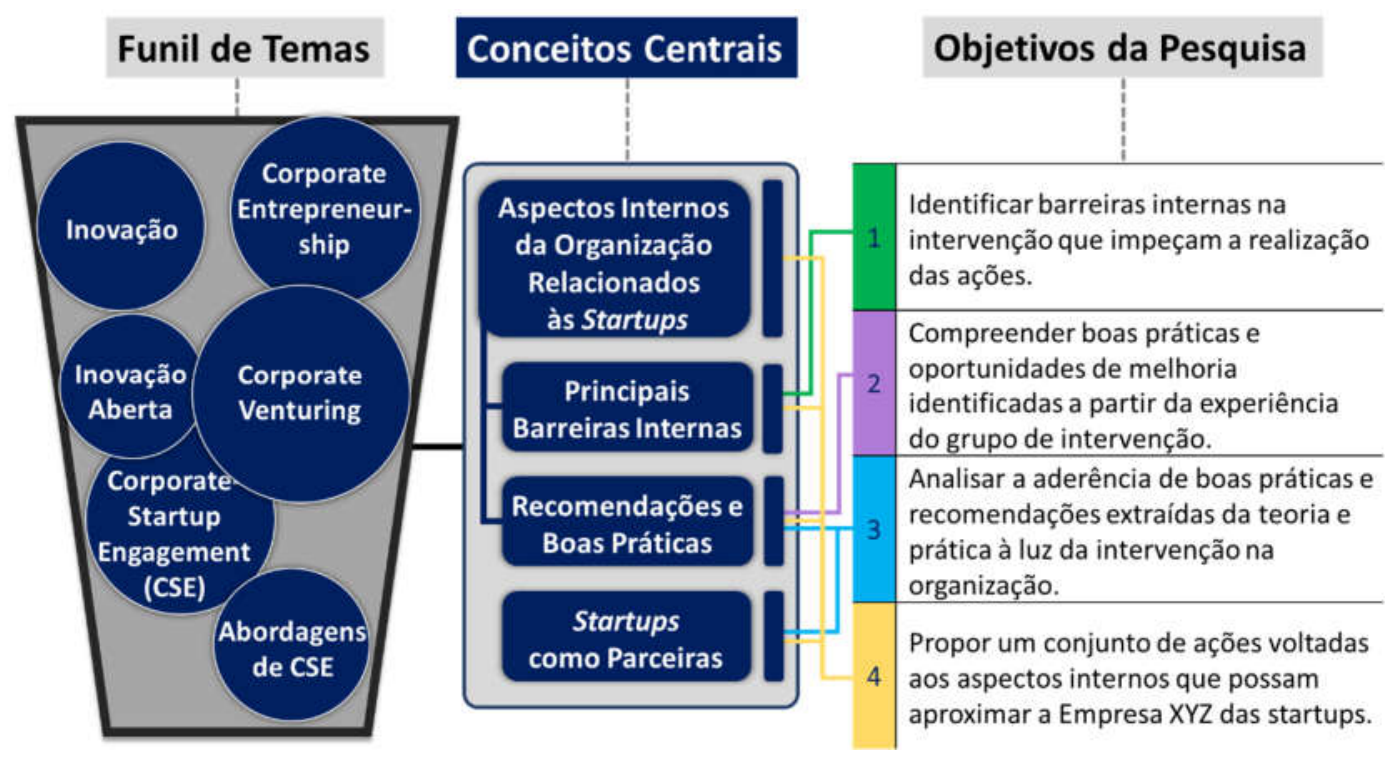

Fonte: Elaborada pelo autor. 


\subsection{REFERÊNCIAS TEÓRICAS}

Com o propósito de embasar as ações realizadas na parte empírica deste estudo e de garantir a qualidade do trabalho, elementos teóricos e práticos serviram de apoio para a elaboração do roteiro de entrevista, para a coleta e análise dos dados, para a discussão e para as recomendações. Para tanto, efetuou-se a revisão da literatura, o que, segundo Creswell (2007), permite ao pesquisador delimitar o escopo de sua pesquisa; transmitir a relevância dos temas abordados; dialogar de forma abrangente sobre os temas; preencher as lacunas científicas; e entender o histórico dos estudos relacionados com os temas.

Dada a origem prática desta pesquisa, a compreensão dos fatos e a coleta de dados foram iniciadas paralelamente ao processo teórico, sendo necessário refinar a literatura na medida em que a intervenção evoluía.

Uma vez estabelecidos os objetivos da pesquisa, iniciou-se, de forma ainda não tão bem estruturada, a exploração de referências na base de dados Google Scholar, para então se chegar aos domínios de pesquisa. Identificou-se, primeiramente, o domínio Corporate Venturing, passando por Corporate-Startup Engagement, tema central, e finalmente se complementou com os domínios Inovação e Inovação Aberta. À medida que a exploração avançava, outros assuntos derivados desses domínios, associados aos objetivos da pesquisa, também foram sendo identificados, tais como: barreiras internas associadas, fatores críticos de sucesso e abordagens.

Posteriormente, baseando-se nas proposições de Creswell (2007), foram efetuadas as seguintes etapas a fim de estruturar os referenciais do projeto, conforme demonstra a Figura 5:

1. Seleção das plataformas bases de pesquisa, a saber: Web of Science, Scopus, JSTOR e Google Scholar.

2. Pesquisa nas plataformas mencionadas no que tange às palavras-chave associadas ao tema e seus objetivos, feita em fevereiro de 2019. As buscas foram 
ordenadas por 'relevância', de acordo com os algoritmos de cada uma das plataformas.

3. Leitura dos títulos e resumos dos primeiros cinquenta resultados de cada busca retornada, selecionando os artigos julgados pertinentes.

4. Eliminação das referências duplicadas encontradas nessas bases.

5. Constatação de que havia apenas trinta e sete estudos associados à CorporateStartup Engagement. Por esse motivo, a busca passou a ser por relatórios profissionais e por outras publicações referenciadas nos estudos préselecionados.

6. Leitura das referências identificadas de forma abrangente - leitura em diagonal -, a fim de compreender e sintetizar os conteúdos, adequando-os aos objetivos desta dissertação.

7. Desenvolvimento do arcabouço teórico e prático da pesquisa, o que resultou em um total de 133 referências.

Figura 5 - Racional da Revisão de Referencial

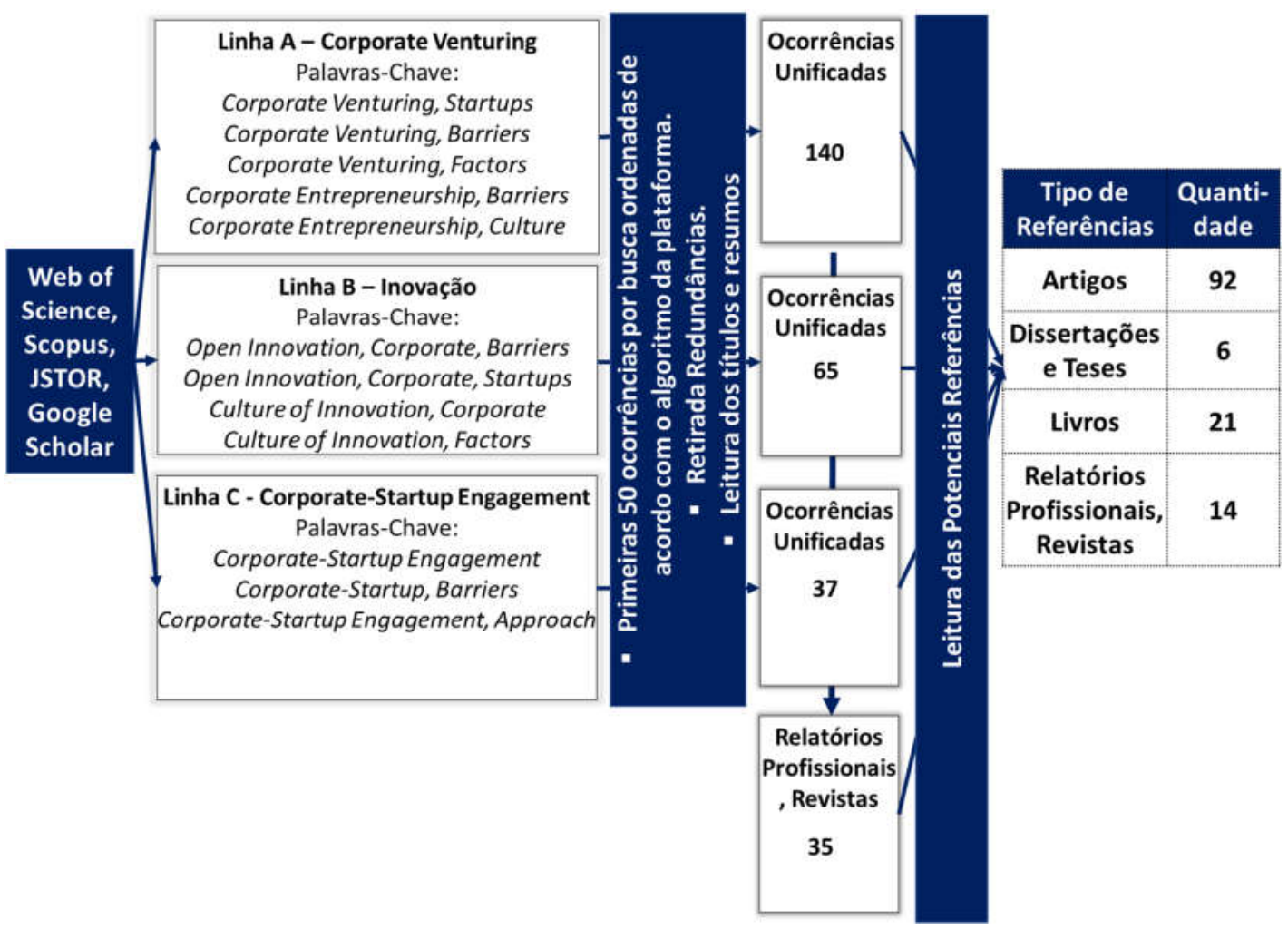

Fonte: Elaborada pelo autor. 
O arcabouço teórico e prático é constituído por 92 artigos científicos, 21 livros ou capítulos de livros, 6 dissertações e teses e 14 relatórios profissionais e demais publicações selecionadas.

No que tange aos relatórios profissionais e às revistas, eles foram fundamentais para a compreensão de questões associadas à presente pesquisa, que teve origem em um ambiente profissional dinâmico. Soma-se a isso, a escassez de referências quanto ao conceito Corporate-Startup Engagement, ainda recente na Academia (Thieme, 2017). No entanto, visando a manter a qualidade e a confiabilidade deste estudo acadêmico, para esse grupo de elementos foram incluídas referências oriundas apenas de especialistas, consultorias e organizações que atuam no relacionamento entre grandes empresas e startups. Algumas dessas referências já tinham sido anteriormente mencionadas em outros estudos científicos.

\subsection{STARTUPS}

Há diferentes interpretações sobre o que é de fato uma startup. Blank (2010), por exemplo, descreve startup como uma organização temporária que cria produtos de tecnologia inovadora e não tem histórico operacional anterior. De acordo com Ries (2012, p. 7), startup é "uma instituição humana projetada para criar produtos e serviços sob condições de extrema incerteza". Essas definições distinguem startups de organizações estabelecidas que, em geral, têm mais recursos e já vem atuando em um mercado maduro.

A definição de startup, segundo o Sebrae (2015), restringe-se a empresas de base tecnológica e mescla fragmentos tanto da definição de Blank (2010), no sentido de escalabilidade, quanto da de Ries (2012), no que tange à estrutura mínima. Na visão do Sebrae (2015), startup é uma empresa em fase inicial que concentra os seguintes elementos: proposta inovadora, modelo de negócios escalável, base tecnológica, baixo custo para iniciar as atividades e uma ideia com potencial para se transformar em negócio. 
Embora não exista uma definição unificada para o que sejam startups, no presente estudo será considerada a definição elaborada pelo Sebrae (2015), pois atende ao cenário nacional, ao vir de um agente do ecossistema empreendedor brasileiro, e abrange as principais características enfatizadas por Blank (2010) e por Ries (2012).

Avaliando as startups, Blank e Dorf (2014) as classificam em seis tipos: scalable startups (startup escalável), buyable startups (startup 'comprável'), large-company startup (startup de grandes empresas), social startups (startups sociais) e lifestyle startups (startups de estilo de vida). Para a proposta desta dissertação destacam-se as scalable startups e as buyable startups.

As scalable startups alcançam receitas elevadas, na faixa de milhões de reais. Assim, esse tipo de startup exige um enorme investimento de capital para alimentar seu motor de pesquisa e sua expansão. Scalable startups, em geral, são as de bases tecnológicas (Blank \& Dorf, 2014). As buyable startups são as autofinanciadas. Estas empresas têm baixo risco de capital e são projetadas para serem posteriormente adquiridas por empresas maiores (Blank \& Dorf, 2014).

\subsubsection{Relacionamento entre startups e o setor financeiro}

As startups são reconhecidas por oferecerem produtos/serviços que entregam inovação tecnológica. A aproximação de startups com grandes empresas, como as do segmento financeiro, são oportunidades para viabilizar receitas, financiamentos, visibilidade, rede de relacionamentos, volume de clientes, além de recursos e expertises (WEF, 2018; Minshall, Mortara, Valli, \& Probert, 2010).

Em contrapartida, as instituições financeiras veem as startups como um meio para atender à transformação digital, face à velocidade de mudanças no setor financeiro, antes conservador e fechado, e agora com ameaças de fragmentação. Dentre os benefícios dessas grandes empresas, advindos do engajamento com startups, pode-se citar: a obtenção de inovações disruptivas; a obtenção de fornecedores inovadores; e o fomento da cultura inovadora e empreendedora na organização (WEF, 2018). 
As instituições financeiras, assim como outras empresas de grande porte, têm criado iniciativas voltadas ao relacionamento com startups com diversos graus de envolvimento e propósito, como: eventos (hackathons, challenges); fornecimento de recursos (coworking); suporte a negócios (aceleradoras, incubadoras); parcerias (codesenvolvimento, adoção de startups como fornecedoras), investimentos e aquisições (Mocker, Bielli, \& Haley, 2015; Bonzom \& Netessine, 2016; Kelly, Ferenzy, \& McGrath, 2017).

Apesar de buscarem se aproximar de startups, as instituições financeiras encontram dificuldades internas para avaliar e implementar os produtos/serviços oferecidos por essas empresas emergentes e muitas vezes perdem oportunidades de transformação digital de curto e médio prazo (Schueffel \& Vadana, 2015).

\subsection{INOVAÇÃO}

O termo inovação é derivado do latim innovatio e significa novidade ou aquilo que é novo. De acordo com Tidd e Bessant (2015), a inovação é o resultado de tornar algo novo, reconstruir ou introduzir determinada novidade. Schumpeter (1982) afirma que a inovação pode adquirir múltiplos formatos, não sendo mandatório que se idealize algo novo; pode até mesmo introduzir alguma ideia pré-existente a uma forma inédita de como realizá-la ou a uma nova conjuntura.

O Manual de Oslo (OCDE, 2005), documento que objetiva trazer orientação e padronização de conceitos e metodologias associados à pesquisa e ao desenvolvimento (P\&D), apresenta uma relevante definição de inovação:

Uma inovação é a implementação de um produto (bem ou serviço) novo ou significativamente melhorado, ou um processo, ou um novo método de marketing, ou um novo método organizacional nas práticas de negócios, na organização do local de trabalho ou nas relações externas. (OCDE, 2005, p. 55).

Quanto às formas e tipos de inovação, a literatura apresenta grande variedade, incluindo algumas sobreposições. Orientando-se pela implementação, a OCDE (2005) classifica as inovações em quatro categorias: 
- Inovação de processo: corresponde à implantação de processos novos ou com substanciais melhorias voltados para a produção, logística e serviços. Essas inovações podem ser técnicas, de hardware ou de software e buscam reduzir custos, com eficiência e qualidade;

- Inovação de produto: remete ao lançamento no mercado de bens e serviços novos ou existentes, que tenham consideráveis melhorias/evoluções. Essas inovações podem ser técnicas, funcionais, de componentes e materiais, de software e de interface;

- Inovação de marketing: diz respeito à implementação de novos métodos de marketing ou melhorias significativas nos métodos já existentes. Essas inovações podem ser referentes à estética (produto/embalagem), ao posicionamento e ao modo de precificar, de distribuir e de divulgar. A inovação de marketing é orientada em função das necessidades dos clientes e se concentra no aumento das vendas;

- Inovação organizacional: trata-se da implementação de métodos inéditos na organização, voltados à "prática do negócio, organização do trabalho e/ou relações externas" (OCDE, 2005, p. 61). Essas inovações são orientadas pela redução de custos, melhorias na satisfação dos colaboradores e acesso/compartilhamento de conhecimento. É comum nesse tipo de inovação, a definição de uso de novas rotinas organizacionais, novas metodologias e/ou uso de sistemas de informação. De acordo com a OCDE (2005), a inovação organizacional permite a introdução de elementos da cultura inovadora como a autonomia para tomada de decisão e o encorajamento para compartilhar ideias.

Outra forma de abordar a tipologia das inovações é diferenciá-las entre radicais e incrementais. Segundo Dewar e Dutton (1986), as radicais são as que apresentam mudanças fundamentais a partir de nova tecnologia ou de novas práticas. Gatignon, Tushman, Smith e Anderson (2002) ressaltam que as inovações radicais, em geral, trazem maiores benefícios para a organização, como ganho de novas competências ou destruição de competências obsoletas. Em contrapartida, essas inovações causam maior grau de incerteza por ingressarem em novos mercados, canibalizarem produtos existentes e até 
mesmo por causarem reestruturações internas nas organizações (Laukkanen, Sainio, \& Jauhiainen, 2008).

As inovações incrementais, por sua vez, são as orientadas à continuidade. Segundo Dewar e Dutton (1986), elas resultam em pequenas melhorias ou ajustes simplificados, usando tecnologias quase sempre já disponíveis na organização. Em geral, grandes empresas têm pré-disposição para investir nesse tipo de inovação, pois apresenta menor risco associado (Laukkanen, Sainio, \& Jauhiainen, 2008).

Alguns autores sintetizam a diferença entre esses dois tipos de inovação. Segundo Schumpeter (1982), inovações 'radicais' são as que causam rupturas mais claras, enquanto as inovações 'incrementais' são as que dão prosseguimento a um processo de mudança iniciado anteriormente. De acordo com Dewar e Dutton (1986), as inovações radicais e as incrementais diferenciam-se pelo grau de aporte tecnológico e de conhecimento aplicado.

Tushman e O'Reilly (1996) salientam o conflito em explorar essas duas formas de inovação. No entanto, esclarecem que é necessário que as organizações adotem ambas as formas para que tenham sucessos no decorrer das transformações inevitáveis dos mercados. As empresas que utilizam ambas as formas de inovação são chamadas 'organizações ambidestras' (Tushman \& O'Reilly, 1996). Segundo Das, Verburg, Verbraeck e Bonebakker (2018), as instituições financeiras enfrentam dificuldades em se adaptar a esse cenário, pois durante décadas sobreviveram nos mercados com o uso de melhorias incrementais, em contraste com a pouca geração de inovações radicais, como novas competências internas. Das, Verburg, Verbraeck e Bonebakker (2018) alertam para a importância de as instituições financeiras tornarem-se cada vez mais ágeis na adoção de inovações radicais, a fim de enfrentarem os novos entrantes do mercado financeiro. 


\subsubsection{Inovação Aberta - IA}

O fato de as empresas fazerem uso dos recursos e canais internos para gerar inovações, deu origem ao modelo clássico de 'Inovação Fechada'. No entanto, frente às dificuldades de se manterem restritas a eles, surgiu a discussão sobre 'Inovação Aberta'.

O termo 'Inovação Aberta' foi cunhado por Henry Chesbrough (2003), que propôs novo paradigma sobre o mesmo, descrevendo as razões das mudanças do processo tradicional para o processo de inovação, explicando princípios básicos, contrastando paradigmas e provendo alguns exemplos de como as empresas poderiam aproveitar o potencial da Inovação Aberta.

Os subsídios de Chesbrough (2003) trouxeram grande impacto no campo da gestão da inovação, tornando-se muito popular entre acadêmicos e profissionais.

A Inovação Aberta é um paradigma que assume que as empresas podem e devem usar ideias externas assim como ideias internas, e caminhos internos e externos para alcançar o mercado, enquanto elas desenvolvem suas tecnologias. A Inovação Aberta combina ideias internas e externas em arquiteturas e sistemas cujos requerimentos são definidos por um modelo de negócio. (Chesbrough, 2003, p. 8).

De acordo com Chesbrough (2003), inovar no ambiente atual exige que as empresas sejam 'abertas'. Isso também pode ajudar a transformar um negócio em uma plataforma para que outros possam construir, reduzir o custo da inovação, compartilhar riscos/benefícios e acelerar o tempo necessário para entregar inovações ao mercado. 
Figura 6 - Modelo de Inovação Aberta

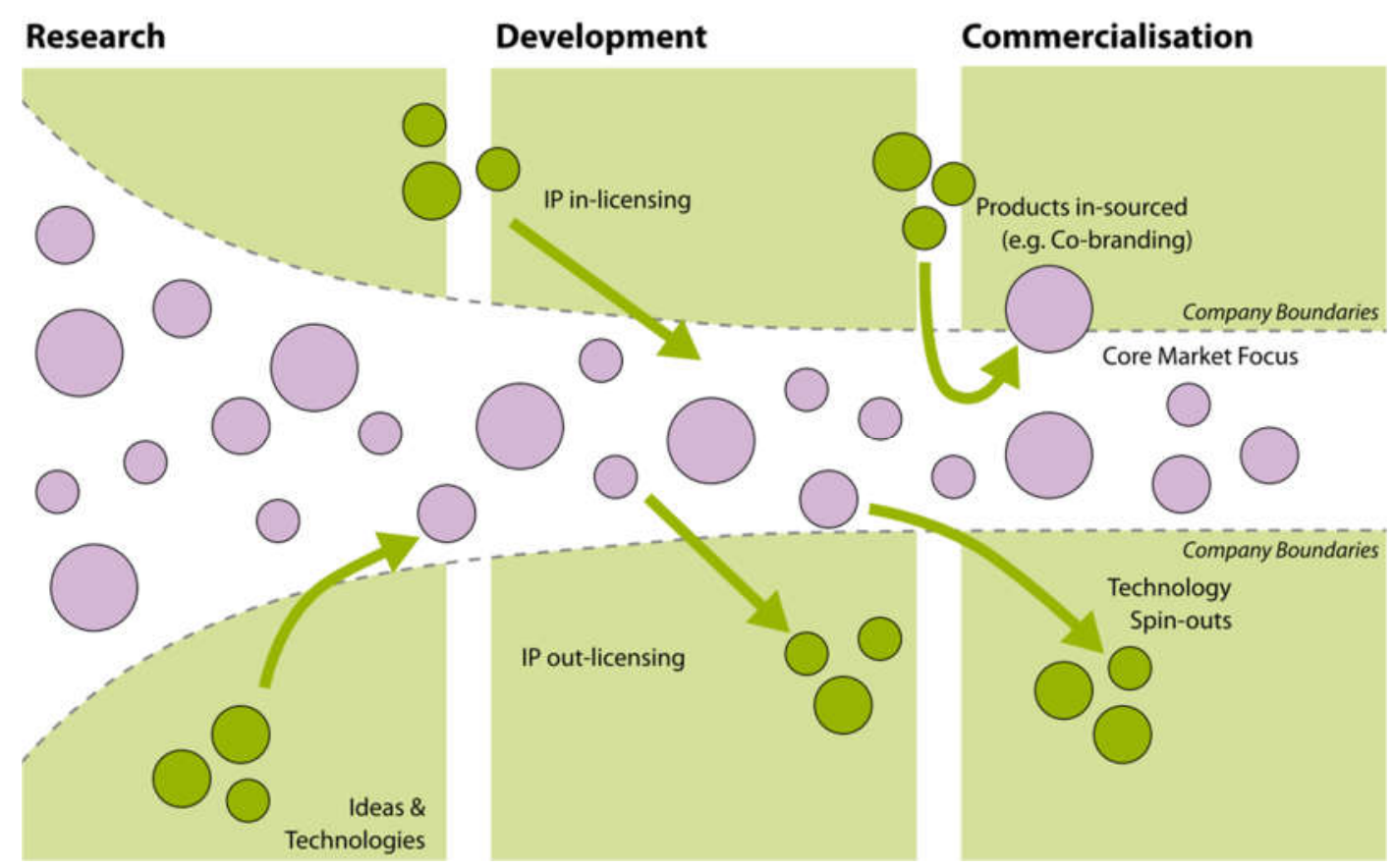

Fonte: Mortara, Napp, Slacik e Minshall (2009, p. 16)².

A Figura 6 ilustra um modelo de Inovação Aberta funcionando em formato de funil com vários orifícios, ou seja, um processo que combina ideias internas e externas, tornando mais flexíveis e 'porosos' os limites entre a organização e o ambiente externo, derrubando barreiras para o desenvolvimento de novos produtos e para a melhoria de processos por meio do fluxo dos conhecimentos. Mortara, Napp, Slacik e Minshall (2009) complementam o modelo de Inovação Aberta especificando os estágios nos quais as entradas de conhecimento podem gerar inovação: Pesquisa, Desenvolvimento e Comercialização.

Esses conhecimentos fluem em dois tipos de movimentos: 'de fora para dentro' - outside in e 'de dentro para fora' - inside out. No movimento 'de fora para dentro' - outside in, as ideias e tecnologias externas são trazidas para o processo de inovação da empresa. Este movimento é mais comumente conhecido como Inovação Aberta. O outro movimento, menos conhecido, é o 'de dentro para fora' - inside out, no qual ideias e tecnologias não utilizadas e subutilizadas na organização estão autorizadas a serem incorporadas em

\footnotetext{
2 Apesar de Mortara, Napp, Slacik e Minshall (2009) representarem o funil de Inovação Aberta de forma detalhada, Chesbrough (2003, p. 37) foi quem o apresentou pela primeira vez.
} 
processos de inovação de outras empresas (Chesbrough, 2011). Gassmann e Enkel (2004) acrescentam uma outra variação aos processos de Chesbrough (2011), denominada 'processo de acoplamento', conforme explicado a seguir:

- Processo de fora para dentro - outside in: enriquecimento da base de conhecimento da empresa por meio da integração com fornecedores e com clientes;

- Processo de dentro para fora - inside out: ganho de lucros, levando ideias para o mercado, vendendo propriedade intelectual e multiplicando a tecnologia na transferência para o ambiente exterior;

- Processo de acoplamento: associação dos processos de fora para dentro e dos de dentro para fora, trabalhando em alianças com parceiros complementares.

A proposta de realizar parcerias por meio da Inovação Aberta é, na maioria dos casos, bem aceita. Todavia, o compartilhamento de informações é uma preocupação, pois significa que a empresa precisa abrir suas fronteiras sólidas para permitir que conhecimento e informações valiosas passem para o exterior, a fim de criar oportunidades para os processos de inovação de cooperação com parceiros, clientes e/ou fornecedores (Gassmann \& Enkel, 2004).

Van de Vandre, Jong, Vanhaverbeke e Rochemont (2009) definem alguns formatos de atuação prática, segundo suas tipologias tecnológicas, que podem ser combinadas para maximizar as capacidades tecnológicas e outras competências de uma empresa:

- Aproveitamento da tecnologia - technology exploitation: capacidades tecnológicas existentes aproveitadas fora dos limites da empresa;

- Exploração de tecnologia - technology exploration: fontes externas de inovação utilizadas para melhorar os desenvolvimentos tecnológicos atuais.

Baseando-se nas definições apresentadas por Gassmann e Enkel (2004) e por Van de Vandre, Jong, Vanhaverbeke e Rochemont (2009), pode-se delimitar os conceitos e exemplos a seguir. Primeiramente, cabe esclarecer que a situação-problema desta dissertação está focada no processo 'de fora para dentro', seguindo as definições de Gassmann e Enkel (2004), pois o propósito é buscar conhecimento de fornecedores, 
startups de base tecnológica, para agregar valor aos negócios. Nessa perspectiva, é possível classificar a atuação prática deste estudo como 'exploração de tecnologia' (technology exploration), seguindo a abordagem de Van de Vandre, Jong, Vanhaverbeke e Rochemont (2009).

Os modos de Inovação Aberta estão, portanto, relacionados com a transferência de conhecimento entre a empresa e as partes externas. A seleção desses modos dependerá da estratégia da empresa, da maturidade do setor e dos desafios internos de implementação como: cultura, procedimentos internos, habilidades necessárias e aspectos motivacionais (Mortara, Napp, Slacik, \& Minshall, 2009; Chesbrough, 2003).

Os modos de Inovação Aberta podem ser vistos sob várias perspectivas, nomenclaturas e agrupamentos (Chesbrough \& Brunswicker, 2013; Ahn, Minshall, \& Mortara, 2015). No entanto, a pesquisa realizada por Chesbrough e Brunswicker (2013) com 125 (cento e vinte e cinco) grandes empresas apresenta, de forma representativa, dezessete modos de realizar Inovação Aberta, mencionados também por outros autores, tais como: Van de Vandre, Jong, Vanhaverbeke e Rochemont (2009); Mortara, Napp, Slacik e Minshall (2009); Gassmann e Enkel (2004); e Enkel, Gassmann e Chesbrough (2009). Chesbrough e Brunswicker (2013) distinguem os modos de Inovação Aberta em função de dois principais tipos de movimentos conhecidos, a saber:

- De fora para dentro: cocriação de clientes e consumidores, redes informais, pesquisas universitárias, consórcios de Pesquisa e Desenvolvimento (P\&D), contratação de P\&D, competições de startups, licenciamento, inovação de fornecedores, crowdsourcing, serviços de intermediários e parcerias;

- De dentro para fora: joint-ventures, venda de produtos prontos para o mercado, participação na padronização pública, incubação de empresas e empreendimentos, out-licensing e spin-off.

Apesar da representatividade, não se deve considerar os modos apresentados como definitivos, pois a Inovação Aberta atua em rede, o que permite que novos modos sejam desenvolvidos a partir das interações entre os atores (Enkel, Gassmann, \& Chesbrough, 2009). 


\subsection{CORPORATE VENTURING - CV}

Apesar de na prática já existir desde a década de 1960, o termo Corporate Venturing foi introduzido em trabalho acadêmico por Von Hippel (1977, p. 163), que o definiu como "uma atividade que busca gerar novos negócios para a corporação em que reside, por meio do estabelecimento de empreendimentos externos ou internos".

O conceito de Corporate Venturing possui dubiedades, pois não é universalizado, tendo surgido várias evoluções no decorrer dos últimos 40 anos (Kanbach \& Stubner, 2016; Gutmann, 2019; Hill \& Birkinshaw, 2008). O crescente aumento de interesse nos últimos 20 anos também vem contribuindo para uma definição mais adequada do termo. Por outro lado, Narayanan, Yang e Zahra (2009) e Reimsbach e Hauschild (2012) acrescentam que a alta demanda por compreensão do tema e sua variedade de significados acabam dificultando pesquisas, exigindo criações e atualizações de sua tipologia.

Burgelman (1983, p. 1.349) sugere que o conceito de Corporate Venturing tenha foco apenas interno, apresentando-o como um "processo pelo qual as empresas se engajam na diversificação por meio do desenvolvimento interno".

Também se associa o Corporate Venturing à criação de novos negócios por meio da inovação. Zahra (1991, p. 262) o define como "atividades formais ou informais destinadas a criar negócios em empresas estabelecidas por meio de inovações de produtos, processos e desenvolvimentos de mercado".

Em trabalho dedicado à consolidação dos significados associados ao Corporate Venturing, Narayanan, Yang e Zahra (2009, p. 59) o conceituam como um "conjunto de sistemas organizacionais, processos e práticas que focam na criação de negócios em mercados existentes ou novos - usando meios internos e externos".

Embora alguns autores relacionem Corporate Venturing à “criação de um negócio", a teoria também apresenta outros meios, como investimentos e criação de parcerias com empresas emergentes externas - startups (Phan, Wright, Ucbasaran, \& Tan, 2009; 
Narayanan, Yang, \& Zahra, 2009; Schildt, Maula, \& Keil, 2005; e Miles \& Covin, 2002). Neste escopo, Birkinshaw, Van Basten Batenburg e Murray (2002, p. 10) definem Corporate Venturing como "processo de investimento em startups por corporações". Zaremba, Bode e Wagner (2017); e Moschner, Fink, Kurpjuweit, Wagner e Herstatt (2019) reforçam a parceria como meio de Corporate Venturing ao apresentarem a aproximação de corporações com startups, em uma relação preferencial de clientefornecedor.

O Corporate Venturing também já havia sido anteriormente abordado como um conceito mais abrangente, o de empreendedorismo corporativo. Narayanan, Yang e Zahra (2009, p. 59) afirmam que empreendedorismo corporativo são "meios pelos quais as empresas podem criar negócios e gerar novos fluxos de renda e valor para os acionistas". O empreendedorismo corporativo também pode ser definido como "a soma dos esforços de inovação, renovação e novos empreendimentos de uma empresa” (Zahra, 1995, p. 227). Sharma e Chrisman (1999, p. 18) definem empreendedorismo corporativo como "o processo pelo qual um indivíduo ou um grupo de indivíduos que, em associação com uma organização existente, criam um negócio, ou instigam a renovação e inovação dentro dessa organização".

Sharma e Chrisman (1999) separam o empreendedorismo corporativo em dois subelementos: a renovação estratégica e o empreendimento corporativo, sendo este também conhecido como Corporate Venturing. A renovação estratégica, também mencionada na literatura como empreendedorismo estratégico, compõe uma gama de conceitos relacionados à renovação tanto da estrutura quanto da estratégia da organização, incluindo reconstrução dos modelos de negócios (Covin \& Miles, 1999; Covin \& Miles, 2007). O empreendedorismo estratégico consiste em buscar oportunidades dentro da organização, enquanto a mesma mantém a sustentação do negócio. O empreendimento corporativo (Corporate Venturing) explica a origem de novos negócios dentro da organização estabelecida (Sharma \& Chrisman, 1999; Guth \& Ginsberg, 1990).

Sharma e Chrisman (1999) também destacam um elemento agregador entre renovação estratégica e empreendimento corporativo, a inovação. O Corporate Venturing pode fazer uso da inovação como base para desenvolvimento de novos produtos, serviços e 
processos ou acessar novos mercados; e também se associa à renovação estratégica, pois ocasiona mudanças na organização, por exemplo, a cultura empreendedora (Narayanan, Yang, \& Zahra, 2009).

Quanto aos propósitos, o Corporate Venturing abre algumas possibilidades de compreensão. De acordo com Block e MacMillan (1993), ele pode visar ao aumento de vendas, lucros, valor agregado, produtividade e qualidade. Miles e Covin (2002) reafirmam esses propósitos e acrescentam a obtenção de aprendizado organizacional que se adquire com esse processo. Battistini, Hacklin e Baschera (2013) sugerem que o Corporate Venturing também possa aprimorar as competências internas. Todos esses propósitos para Corporate Venturing, segundo Battistini, Hacklin e Baschera (2013), são em geral categorizados por dois grupos de propósitos, financeiro e estratégico, a saber:

- Financeiro: associado a empresas que buscam aumentar as receitas e os lucros no menor prazo possível (Morris, Kuratko, \& Covin, 2010). Um exemplo clássico é o uso de Corporate Venturing Capital - CVC para investimento em empresas jovens, como as startups (Chesbrough, 2002). O objetivo dessa abordagem pode ser a geração de dinheiro com ativos subutilizados da organização ou a concentração na negociação de papéis comprados de outras empresas (Hill \& Birkinshaw, 2008).

- Estratégico: associado à intenção de aumentar o potencial de crescimento da organização (Chesbrough \& Tucci, 2004). Engloba o desenvolvimento da capacidade de inovação e de aceleração da empresa, por meio do fomento à cultura empreendedora e do acesso a conhecimentos externos (Campbell, Birkinshaw, Morrison, \& Batenburg, 2003; Battistini, Hacklin, \& Baschera, 2013). Os objetivos estratégicos também podem estar associados ao aprendizado organizacional e à obtenção de novas competências e tecnologias (Williams \& Lee, 2009; Tidd \& Taurins, 1999). Entre as abordagens para atingir esses propósitos estão o desenvolvimento de processos de inovação e a realização de parcerias (Battistini, Hacklin, \& Baschera, 2013).

Outra característica de consenso entre os principais teóricos é que as atividades de Corporate Venturing podem ocorrer tanto interna quanto externamente à organização 
(Sharma \& Chrisman, 1999; Morris, Kuratko, \& Covin, 2010; Von Hippel, 1977), conforme detalhado a seguir:

- Corporate Venturing Interno - CVI: são atividades que criam entidades dentro dos domínios da própria organização (Kuratko, 2007; Sharma \& Chrisman, 1999). Segundo Henry Chesbrough (2002), o CVI envolve o financiamento de empreendimentos que permanecem legalmente ligados à organização. Para Block e MacMillan (1993), uma das principais diferenças dos CVIs em relação a outras atividades internas é o risco associado a esses empreendimentos. Exemplos de CVIs são incubadoras internas, fundos de investimentos para desenvolvimento de ideias de colaboradores, processo de inovação para desenvolvimento de produtos e programas de suporte aos intraempreendedores (Miles \& Covin, 2002; Saalasti, 2016; Gutmann, 2019; Neumann et al., 2019). Ademais, o lócus interno também envolve utilizar recursos subutilizados para geração de receita, como o licenciamento de patentes e a monetização de dados (Miles \& Covin, 2002; Hill \& Birkinshaw, 2008; Gutmann, 2019).

- Corporate Venture Externo - CVE: na visão de Sharma e Chrisman (1999), são eventos que ocorrem fora do domínio da empresa e podem ter autonomia total ou parcial na condução. O uso de CVE também permite inovar e crescer de forma mais rápida, se comparado com determinadas abordagens internas (Schildt, Maula, \& Keil, 2005). Miles e Covin (2002) e Reimsbach e Hauschild (2012) reforçam que os CVEs geralmente estão associados à busca por inovações, tecnologias e competências que a empresa não possui e/ou não pode desenvolver internamente. Nesse modelo, a unidade CV normalmente procura investir ou desenvolver parcerias com pequenas empresas e empreendedores, por exemplo, startups (Hill \& Birkinshaw, 2014). As formas mais tradicionais de CVE são spin-off, capital de risco corporativo - CVC, licenciamento, aquisições, parcerias e joint-venture (Sharma \& Chrisman, 1999; Phan, Wright, Ucbasaran, \& Tan, 2009; Narayanan, Yang, \& Zahra, 2009; Reimsbach \& Hauschild, 2012; Gutmann, 2019).

A partir da década de 2000, segundo Gutmann (2019, p. 122), há "uma crescente heterogeneidade" acerca de CV. Entre essas novas abordagens estão as iniciativas 
voltadas ao relacionamento com startups, como: eventos culturais, aceleradoras, incubadoras, coworkings e parcerias sem capital - fornecedor preferencial e codesenvolvimento (Saalasti, 2016; Zaremba, Bode, \& Wagner, 2017; Gobble, 2018; Neumann et al., 2019; Moschner et al., 2019). Segundo Gobble (2018, p. 60), o movimento de CV direcionado a startups oferece um "conjunto diferente de benefícios em relação aos modos mais tradicionais de Corporate Venturing como investimentos de risco e alianças”. Entre os benefícios dessas novas perspectivas estão o posicionamento da marca, a renovação cultural e a busca por resolução de problemas de negócios de forma mais fluída (Dauderstädt, 2013; Gobble, 2018).

Pode-se verificar sobreposições com abordagens também associadas à Inovação Aberta como parcerias, joint-ventures, incubação de empresas, out-licensing, spin-offs, cocriação de clientes e consumidores, competições de startups e inovação de fornecedores.

Apesar de o Corporate Venturing possuir diversas definições e tipologias, de acordo com o enfoque de diferentes autores, como mencionado anteriormente, no presente trabalho, esse termo está sendo utilizado para explicar as atividades e processos de uma organização, voltados a desenvolver empreendimentos dentro e fora dos seus limites de atuação, por meio da inovação. O propósito é gerar lucro, competências, conhecimento e aumentar a qualidade e/ou a produtividade da organização.

\subsection{CORPORATE-STARTUP ENGAGEMENT - CSE}

Até o início dos anos 2000, as corporações, em geral, utilizavam as abordagens clássicas de investimento para se relacionar com startups, como CVC, licenciamentos, aquisições e joint ventures (Phan, Wright, Ucbasaran, \& Tan, 2009). No entanto, muitas das grandes empresas que iniciaram aproximações de Corporate Venturing com startups, abandonaram-nas com o passar do tempo por diversas razões, tais como diferenças culturais, investimentos e custos envolvidos na viabilização dessas iniciativas de risco (Weiblen \& Chesbrough, 2015). 
Em paralelo, nos anos 2000, o crescimento exponencial de startups e a pressão dos mercados exigiram que grandes empresas fossem mais velozes, flexíveis e que buscassem novas formas de inovação. Inicia-se, então, uma crescente tendência em colaborar com startups, com o objetivo de transformá-las em motores para inovação corporativa, provedoras de solução para problemas de negócios, imagem institucional, renovação cultural, além de acesso a novos mercados (Weilen \& Chesbrough, 2015; Bonzom \& Netessine, 2016; Kohler, 2016).

Esses novos objetivos também viabilizaram novos meios de relacionamentos com startups. Grandes empresas passaram a atuar de forma colaborativa, com compartilhamento de recursos e de contratos preferenciais, além das abordagens tradicionais, como investimentos diretos ou aquisições dessas novas empresas (Bonzom \& Netessine, 2016; Kohler, 2016; Bannerjee, Bielli, \& Haley, 2016). Essas novas abordagens, menos invasivas, reduzem custos, trazem menores riscos e mais agilidade, quando comparadas com os CV Externos tradicionais (Weilen \& Chesbrough, 2015).

Apesar de já terem sido publicados alguns artigos científicos sobre o tema, o conceito de Corporate-Startup Engagement - CSE ainda é pouco explorado na academia, o que reforça sua atualidade, mas exige maior senso crítico para avaliação das referências. A exemplo de outros estudos sobre o tema CSE, como os de Kohler (2016), Thieme (2017), Rundquist e Österling (2018), recorreu-se a publicações profissionais de empresas renomadas e a agências de pesquisas para complementar as referências deste trabalho. Cabe esclarecer que, na presente dissertação, o termo Corporate-Startup EngagementCSE está sendo utilizado no sentido de conjunto de ações de uma corporação para desenvolver relacionamentos colaborativos com startups, com o intuito de buscar renovação da imagem, inovação, mudança cultural, solução para problemas de negócios e acessos a novos mercados.

Weiblen e Chesbrough (2015) recomendam que um dos primeiros passos para uma organização atuar com startups deve ser definir previamente o objetivo desejado para, posteriormente, estabelecer a melhor forma de relacionamento. Kohler (2016) sugere cinco objetivos possíveis, a saber: preencher lacunas de inovação; resolver desafios de negócios; expandir para novos mercados; rejuvenescer a cultura corporativa; e atrair e 
reter talentos. Mocker, Bielli e Haley (2015) e Bonzom e Netessine (2016) aprimoram a recomendação de Weiblen e Chesbrough (2015) e propõem matrizes associando os objetivos em conjuntos e abordagens mais recomendadas, com base em casos práticos, conforme apresentado nas Figuras 7 e 8. A seguir, são apresentados, de forma sintetizada, os potenciais objetivos e abordagens associados ao CSE.

Figura 7 - Potenciais objetivos para uma organização atuar com startups, com base em Mocker, Bielli e Haley (2015)

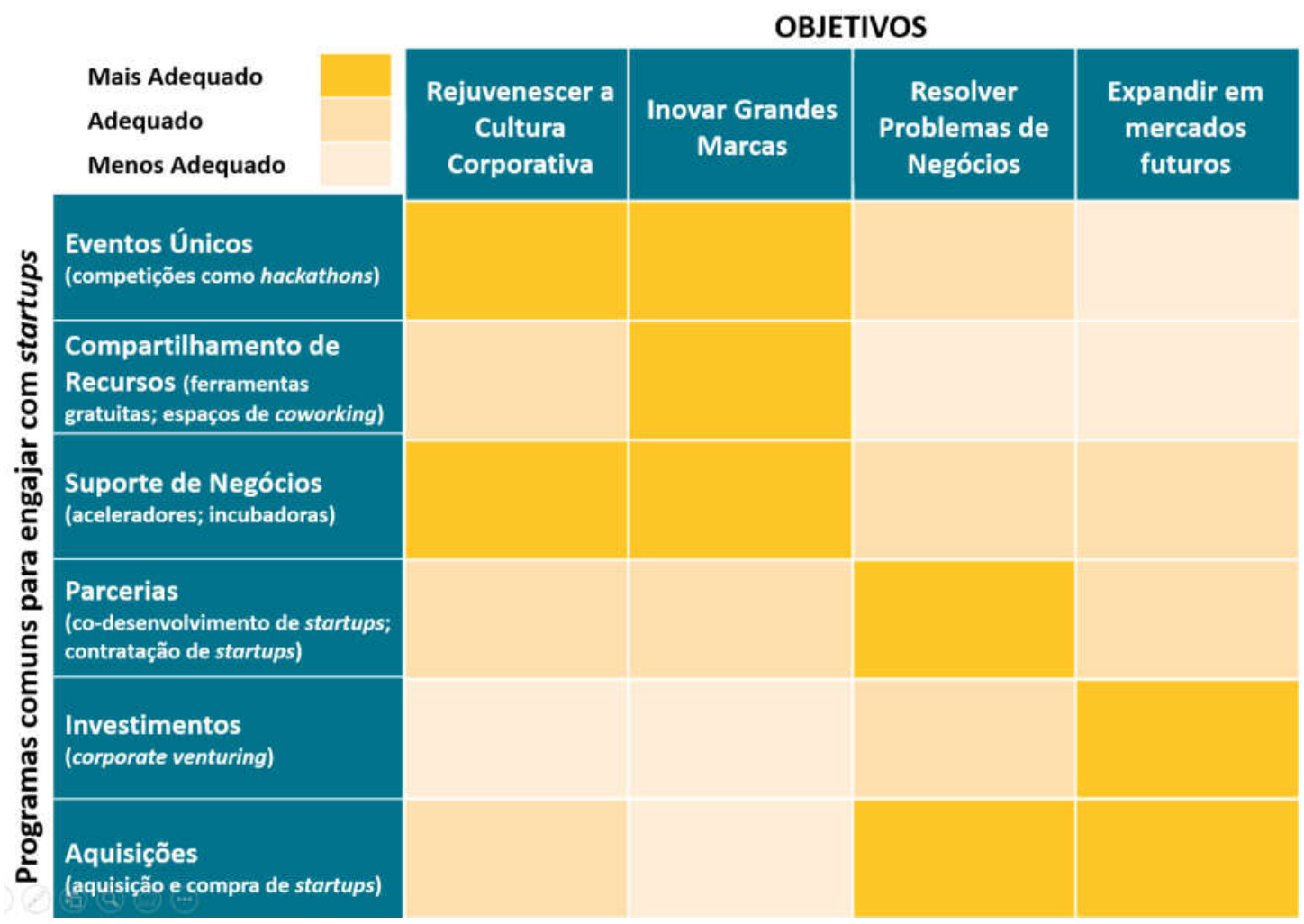

Fonte: Adaptado de Mocker, Bielli e Haley (2015, p. 12). 
Figura 8 - Potenciais objetivos para uma organização atuar com startups, com base em

Bonzom e Netessine (2016)

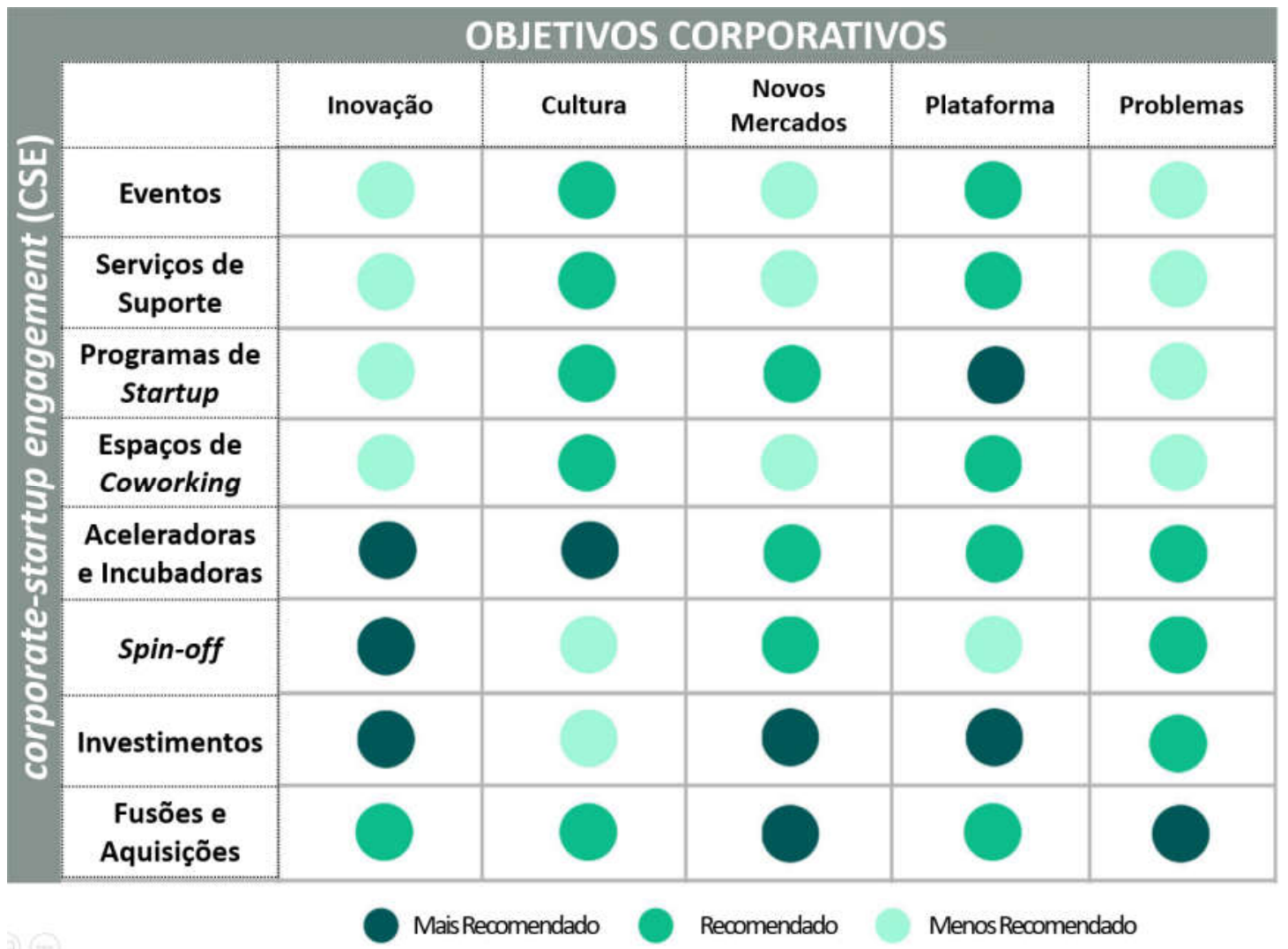

Fonte: Adaptado de Bonzom e Netessine (2016, p. 7).

Ao comparar os objetivos de Mocker, Bielli e Haley (2015) (Figura 7) com os de Bonzom e Netessine (2016) (Figura 8) e com os de Kohler (2016), é possível identificar cinco grupos de objetivos relacionados ao engajamento com startups:

- Inovação: envolve utilizar a atuação com startups para fins de P\&D, desenvolvimento de produtos, serviços e novos modelos de negócios (Kohler, 2016; Bonzom \& Netessine, 2016). Acrescenta-se também nesse grupo o objetivo de atrair startups para o fortalecimento de plataformas tecnológicas (Bonzom \& Netessine, 2016);

- Resolução de Problemas de Negócios: está relacionada com a apresentação de soluções de produtos e serviços inovadores para os negócios existentes, de forma 
mais ágil, econômica e escalável, quando comparados com o desenvolvimento interno (Kohler, 2016; Mocker, Bielli, \& Haley, 2015);

- Expansão para novos mercados: a atuação com startups pode permitir a uma grande empresa competir de forma rápida em setores emergentes ou expandir suas operações ao utilizar tecnologias inovadoras (Kohler, 2016; Mocker, Bielli, \& Haley, 2015);

- Rejuvenescimento da cultura corporativa: ações de aproximação com startups podem ser utilizadas para sinalizar aos colaboradores a intenção da organização de fomentar a cultura empreendedora e de inovar (Mocker, Bielli, \& Haley, 2015; Kohler, 2016). Mocker, Bielli e Haley (2015) e Kohler (2016) também entendem que a atuação com startups influencia os colaboradores a serem agentes de mudança na organização, pois lhes permite ficar mais expostos às dinâmicas de trabalho ágeis e a métodos lean ${ }^{3}$, além de lhes propiciar conhecimentos sobre tecnologias externas;

- Posicionamento da marca: a atuação com startups pode contribuir com o posicionamento da marca como inovadora, frente aos desafios de transformação digital (Mocker, Bielli, \& Haley, 2015). Esse posicionamento visa a envolver a construção ou manutenção da imagem da organização junto aos clientes, investidores, parceiros, mas também a atrair futuros colaboradores com perfil empreendedor (Bonzom \& Netessine, 2016; Mocker, Bielli, \& Haley, 2015; Kohler, 2016).

Ao comparar as abordagens associadas ao CSE, é possível perceber que há interpretações e nomenclaturas distintas, conforme sintetizado no Quadro 3 (Weiblen \& Chesbrough, 2015; Bonzom \& Netessine, 2016; Mocker, Bielli, \& Haley, 2015; Kohler, 2016). No entanto, é possível organizá-las em sete grupos: eventos, 'aceleradoras e incubadoras', suporte e compartilhamento de recursos, parcerias, investimentos, 'fusões e aquisições' e spin-offs.

\footnotetext{
${ }^{3} \mathrm{O}$ método lean corresponde à melhoria contínua, tanto na gestão quanto nos processos da empresa, com ênfase na prevenção de desperdícios (tempo, mão de obra e insumos) e na produção de produtos e/ou serviços, de forma a gerar valor mais elevado aos clientes com menos recursos (Womack, Jones, \& Roos, 2007).
} 
Quadro 3 - Comparação das Referências sobre Corporate-Startup Engagement - CSE

\begin{tabular}{|c|c|c|c|c|}
\hline Kohler (2016) & $\begin{array}{c}\text { Bonzom \& } \\
\text { Netessine (2016) }\end{array}$ & $\begin{array}{c}\text { Mocker, } \\
\text { Bielli, \& Haley } \\
\text { (2015) }\end{array}$ & $\begin{array}{c}\text { Weiblen \& } \\
\text { Chesbrough (2015) }\end{array}$ & Visão Geral \\
\hline $\begin{array}{l}\text { Hackathons } \\
\text { corporativos }\end{array}$ & Eventos & Eventos pontuais & & Eventos \\
\hline $\begin{array}{l}\text { Incubadoras de } \\
\text { negócios }\end{array}$ & Aceleradoras e & $\begin{array}{l}\text { Suporte aos } \\
\text { negócios }\end{array}$ & \multirow{4}{*}{$\begin{array}{c}\text { Programa de } \\
\text { startups - de fora } \\
\text { para dentro }\end{array}$} & Aceleradoras \\
\hline \multirow{5}{*}{$\begin{array}{l}\text { Aceleradoras } \\
\text { corporativas }\end{array}$} & incubadoras & $\begin{array}{l}\text { (Aceleradoras e } \\
\text { incubadoras) }\end{array}$ & & e Incubadoras \\
\hline & Coworking & \multirow{3}{*}{$\begin{array}{c}\text { Compartilhamento } \\
\text { de recursos - } \\
\text { coworking e } \\
\text { ferramentas }\end{array}$} & & \multirow{3}{*}{$\begin{array}{c}\text { Suporte e } \\
\text { Compar- } \\
\text { tilhamento } \\
\text { de Recursos }\end{array}$} \\
\hline & $\begin{array}{l}\text { Serviços de } \\
\text { suporte }\end{array}$ & & & \\
\hline & $\begin{array}{l}\text { Programas de } \\
\text { startups }\end{array}$ & & $\begin{array}{c}\text { Programas de } \\
\text { startups - } \\
\text { plataformas } \\
\end{array}$ & \\
\hline & & Parcerias & & Parcerias \\
\hline $\begin{array}{l}\text { Corporate } \\
\text { Venturing }\end{array}$ & Investimentos & Investimentos & \multirow{2}{*}{$\begin{array}{l}\text { Corporate } \\
\text { Venturing }\end{array}$} & Investimentos \\
\hline $\begin{array}{l}\text { Fusões e } \\
\text { aquisições }\end{array}$ & $\begin{array}{l}\text { Fusões e } \\
\text { Aquisições }\end{array}$ & Aquisições & & $\begin{array}{c}\text { Fusões e } \\
\text { Aquisições }\end{array}$ \\
\hline $\begin{array}{l}\text { Incubação } \\
\text { corporativa }\end{array}$ & Spin-offs & & $\begin{array}{l}\text { Incubação } \\
\text { corporativa }\end{array}$ & Spin-Offs \\
\hline
\end{tabular}

Fonte: Elaborado pelo autor.

A partir da síntese apresentada no Quadro 3, pode-se descrever as potencialidades de CSE como:

- Eventos culturais: modalidade que visa a realizar eventos isolados com a participação de startups. Esse modo de engajamento é tido como um ponto de partida para a atuação com startups devido ao baixo custo e à característica pontual (Mocker, Bielli, \& Haley, 2015; Bonzom \& Netessine, 2016). Os formatos para execução dos eventos, em geral, são conferências e competições entre startups, conhecidas como challenges e hackathons. Os eventos buscam o aculturamento da organização, expondo seus colaboradores à mentalidade empreendedora das startups e às suas tecnologias emergentes (Mocker, Bielli, \& Haley, 2015). Os eventos costumam trazer resultados menos tangíveis quando comparados com as demais modalidades, pois seu produto é o aculturamento e não a inovação em si (Mocker, Bielli, \& Haley, 2015; Bonzom \& Netessine, 2016); 
- Aceleradoras e incubadoras: têm o objetivo de apoiar o crescimento de startups até que se estruturem e estejam prontas para escalarem e receberem investimentos (Bonzom \& Netessine, 2016). Segundo Mocker, Bielli e Haley (2015), as empresas podem utilizar esses modelos como instrumento de mudança cultural ao envolverem colaboradores como mentores de startups abarcadas com esses programas. As incubadoras são modelos tradicionais de fomento às startups, que lhes provisionam infraestrutura, como espaço físico e acesso à rede de relacionamentos e serviços especializados, como marketing e assessoria jurídica. Mais recentes, as aceleradoras oferecem apoio intensivo para a estruturação de startups, em geral, recebendo equidade em contrapartida. Esse apoio consiste na evolução de seus modelos de negócios, por meio de iterações com mentores e outros atores envolvidos no ecossistema empreendedor. Os programas de aceleração ocorrem em um período de tempo determinado e curto, em geral, entre 3 e 6 meses (Mocker, Bielli, \& Haley, 2015; Bonzom \& Netessine, 2016; Kohler, 2016);

- Suporte e compartilhamento de recursos: modalidade que visa a oferecer serviços e recursos para apoiar startups, incluindo apoio técnico e de negócios, acesso à rede de fornecedores e clientes e disponibilização de espaço físico, de softwares e de equipamentos (Bonzom \& Netessine, 2016; Mocker, Bielli, \& Haley, 2015). Exemplos recentes dessa modalidade são empresas de plataforma, como AWS, Google e Microsoft, as quais oferecem recursos computacionais para que as startups possam construir soluções tecnológicas a partir dessas infraestruturas. Outra forma de compartilhamento crescente são os espaços de coworking, espaços físicos onde as startups podem atuar próximas umas das outras, além de terem relacionamento estreitado com investidores, universidades e outras grandes empresas (Bonzom \& Netessine, 2016; Mocker, Bielli, \& Haley, 2015);

- Investimentos: na perspectiva do CSE, o investimento direto em startups em troca de participação é considerado sinônimo de Corporate Venturing (Mocker, Bielli, \& Haley, 2015, Weiblen \& Chesbrough, 2015; Kohler, 2016). Apesar de orientadas primordialmente ao retorno financeiro, o investimento direto em startups também pode trazer benefício estratégico, como acesso às novas 
tecnologias (Mocker, Bielli, \& Haley, 2015; Bonzom \& Netessine, 2016). Entre as formas reconhecidas como investimentos para CSE estão o Corporate Venturing Capital - CVC, o private equity e os fundos especializados de Venturing Capital (Mocker, Bielli, \& Haley, 2015; Bonzom \& Netessine, 2016). Além dessas possíveis formas de investimentos a essa modalidade, Bonzom e Netessine (2016) também associam a concessão de crédito, como empréstimos e microcréditos;

- Parcerias - Codesenvolvimento e contrato de fornecimento: Mocker, Bielli e Haley (2015) e Kohler (2016) sugerem como parcerias de domínio de CSE as que abordam as startups como fornecedoras para execução de projetos, pilotos ou desenvolvimento de produtos, conjuntamente com a empresa estabelecida. A contratação de soluções provenientes de startups pode trazer benefícios, como acesso a tecnologias emergentes, resolução de problemas de negócios de forma mais eficiente ou capacitação para novos modelos de negócios (Mocker, Bielli, \& Haley, 2015). No codesenvolvimento, por sua vez, a grande empresa torna-se parceira de startups para gerar inovações. O codesenvolvimento envolve desde a elaboração de pilotos e provas de conceitos até a validação para prosseguir, ou não, com os projetos (Mocker, Bielli, \& Haley, 2015). Segundo Zaremba, Bode e Wagner (2017), diferentemente de um processo convencional de aquisição, atuar com startups exige uma nova visão do relacionamento compradorfornecedor. Essa nova tratativa pode requerer um processo contratual mais dinâmico ou dedicado e o estabelecimento de startups como fornecedoras preferenciais (Mocker, Bielli, \& Haley, 2015; Reuer, Olk, \& Ariño, 2011);

- Aquisições e fusões: refere-se à compra de startups por completo ou da maior parte de seu capital social. A startup pode ser integrada à organização ou permanecer de forma independente (Schildt, Maula, \& Keil, 2005). De acordo com Mocker, Bielli e Haley (2015) e Kohler (2016), a aquisição de startups é uma forma rápida e impactante para se obter tecnologias ou recursos que resolvam problemas de negócios ou que permitam acesso a novos mercados. Mocker, Bielli e Haley (2015) e Bonzom e Netessine (2016) afirmam que, além de ter acesso aos produtos, a aquisição de startups permite também formar equipes capacitadas em tecnologias emergentes; 
- Spin-off: trata-se de startup gerada a partir de capital, ideias, modelos de negócios e tecnologias de uma empresa estabelecida. Essa empresa pode nascer dentro da organização, mas posteriormente será separada dela (Bonzom \& Netessine, 2016). As spin-offs diferenciam-se da corporação que as criou por possuírem um maior risco associado e uma estratégia distinta. (Narayanan, Yang, \& Zahra, 2009; Parhankangas \& Arenius, 2003). Em alguns casos, essas novas empresas podem ser constituídas por colaboradores das empresas-mães e/ou por empreendedores externos (Bonzom \& Netessine, 2016).

\subsection{INTERSECÇÕES E DIFERENÇAS ENTRE OS CONCEITOS DE CORPORATE-STARTUP ENGAGEMENT (CSE), CORPORATE VENTURING (CV) E INOVAÇÃO ABERTA (IA)}

As intersecções entre os conceitos de Corporate Venturing (CV), Inovação Aberta (IA) e Corporate-Startup Engagement (CSE) ainda carecem de estudos mais aprofundados, conforme indicado anteriormente. Alguns autores correlacionam tais temas, porém, de forma ainda superficial (Gobble, 2018; Vanhaverbeke, Van de Vrande, \& Chesbrough, 2008; Thieme, 2017; Lichtenthaler, 2008). A fim de justificar a utilização de tais termos como base para compreensão dos fenômenos pesquisados, é relevante esclarecer as intersecções entre esses três domínios.

\subsubsection{Intersecções e diferenças entre o Conceito de Inovação Aberta (IA) versus o de Corporate Venturing (CV)}

O conceito de Corporate Venturing (CV) antecede ao de Inovação Aberta (IA) e tem foco na criação, no investimento e no desenvolvimento de novos negócios, enquanto a inovação é considerada apenas um dos meios para alcançar tais objetivos (Von Hippel, 1977; Sharma \& Chrisman, 1999).

O conceito de Inovação Aberta (IA), por sua vez, tem como propósito principal a geração de inovações - produtos, serviços e marketing - através da troca de conhecimentos entre 
os meios interno e externo. O desenvolvimento de um novo negócio é o resultado indireto deste processo (Chesbrough, 2003).

Em relação às interfaces externas, a IA permite explicitamente a troca de conhecimento por redes de parceiros, fornecedores, clientes, órgãos governamentais e universidades. Em contrapartida, apesar de o conceito de CV considerar gestão de portfólios de empreendimentos, a relação com as entidades externas acontece de forma individualizada e menos sistematizada (Huizingh, 2011; Clark, Evald, \& Munksgaard, 2012).

Quanto ao lócus de atuação, ambas as práticas possuem elementos externos e internos. No CV os ambientes internos e externos são bem delimitados e possuem abordagens segregadas (Sharma \& Chrisman, 1999). Na IA, no entanto, os limites internos e externos são difusos, pois o valor gerado da inovação está justamente na troca de conhecimento entre estes dois meios (Clarke, Evald, \& Munksgaard, 2012).

Quando avaliada a intersecção de enfoques entre os dois temas, uma interpretação comum é considerar o CV como ferramenta ou meio de habilitar a IA (Neumann et al., 2019; Mortara, Slacik, Napp, \& Minshall, 2010; van de Vrande, Vanhaverbeke \& Duysters, 2011). Outra interpretação é que as abordagens de IA e as de CV estão sobrepostas quanto ao assunto startups, como eventos, incubadoras e aceleradoras (Gobble, 2018; Chesbrough \& Brunswicker, 2013; Thieme, 2017).

Em relação às diferenças, o termo $\mathrm{CV}$ possui algumas abordagens fomentadas apenas internamente, como a criação de empresas dentro da organização e o suporte ao intraempreendedorismo (Dauderstädt, 2013; Lichtenthaler, 2008), enquanto a IA possui abordagens externas que exploram uma rede maior de atores, por exemplo, iniciativas de P\&D com universidades e crownsourcing com clientes e fornecedores (Chesbrough \& Brunswicker, 2013). 


\subsubsection{Interseç̧ões e diferenças entre o Conceito de Corporate-Startup Engagement versus o de Corporate Venturing e o de Inovação Aberta}

Kohler (2016), Thieme (2017) e Weiblen e Chesbrough (2015) consideram em suas pesquisas que o CV é um tipo específico de engajamento com startups, ou seja, um subgrupo de CSE, por focar no relacionamento por meio do capital e com propósito predominantemente financeiro. O CSE diferencia-se do CV por focar no uso do ambiente externo, enquanto o $\mathrm{CV}$ pode ter desenvolvimentos interno e externo (Battistini, Hacklin, \& Baschera, 2013; Hill \& Birkinshaw, 2008).

Quando comparado com a IA, o CSE pode ser considerado um subconjunto, pois a IA possui outros atores externos para geração de inovação, além das startups (Thieme, 2017). O CSE também se diferencia da IA quanto ao escopo reduzido no fluxo de conhecimento, por focalizar nas startups, na ênfase de fora para dentro da organização. A IA, por sua vez, além de abordagens de fora para dentro, também pode atender as de dentro para fora (Gassmann \& Enkel, 2004, Van de Vandre, Jong, Vanhaverbeke, \& Rochemont, 2009).

Com base nessas perspectivas, entende-se que o domínio de CV e o de IA tem intersecção com o de CSE, quando os elementos envolvem startups, mas os transcendem por também direcionar suas abordagens ao contexto interno e por interagir com atores além das startups, conforme representado na Figura 9.

Figura 9 - Interseç̧ões entre o Conceito de Corporate-Startup Engagement, o de Corporate

Venturing e o de Inovação Aberta

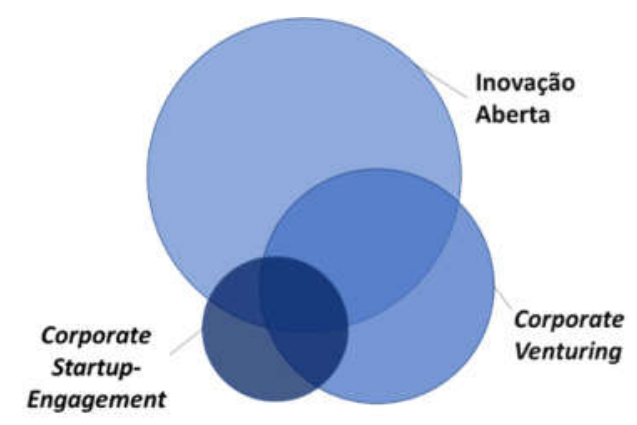

Fonte: Elaborada pelo autor. 
As intersecções entre os três domínios são reforçadas quando comparadas com as suas abordagens, conforme o Quadro 4 a seguir.

\section{Quadro 4 - Abordagens de Corporate-Startup Engagement (CSE)}

versus as de Corporate Venturing (CV) e as de Inovação Aberta

\begin{tabular}{|c|c|c|}
\hline \multirow{2}{*}{$\begin{array}{c}\text { Corporate-Startup } \\
\text { Engagement }\end{array}$} & \multicolumn{2}{|c|}{ Autores } \\
\hline & Corporate Venturing & Inovação Aberta \\
\hline Eventos & $\begin{array}{c}\text { Dauderstädt, 2013; Gobble, 2018; } \\
\text { Gutmann, 2019; Prats, Amigó, Ametller, \& } \\
\text { Batlle, 2017; Kanbach \& Stubner, 2016 }\end{array}$ & $\begin{array}{l}\text { Prats, Siota, Canonici, \& Contijoch, } \\
\text { 2018; Chesbrough \& Brunswicker, } 2013\end{array}$ \\
\hline $\begin{array}{l}\text { Aceleradoras e } \\
\text { Incubadoras }\end{array}$ & $\begin{array}{l}\text { Dauderstädt, 2013; Gobble, 2018; } \\
\text { Gutmann, 2019; Prats, Amigó, Ametller, \& } \\
\text { Batlle, 2017; Kanbach \& Stubner, } 2016\end{array}$ & $\begin{array}{l}\text { Prats, Siota, Canonici, \& Contijoch, } \\
\text { 2018; Spender, Corvello, Grimaldi, \& } \\
\text { Rippa, 2017; Mortara, Napp, Slacik, \& } \\
\text { Minshall, 2009; Chesbrough \& } \\
\text { Brunswicker, } 2013\end{array}$ \\
\hline $\begin{array}{c}\text { Suporte e } \\
\text { Compartilhamento } \\
\text { de Recursos }\end{array}$ & $\begin{array}{l}\text { Prats, Amigó, Ametller, \& Batlle, 2017; } \\
\text { Battistini, Hacklin, \& Baschera, } 2013\end{array}$ & $\begin{array}{l}\text { Prats, Siota, Canonici, \& Contijoch, } \\
\text { 2018; West \& Bogers, } 2014\end{array}$ \\
\hline $\begin{array}{l}\text { Parcerias - } \\
\text { Contrato de } \\
\text { fornecimento, } \\
\text { codesenvolvimento }\end{array}$ & $\begin{array}{l}\text { Dauderstädt, 2013; Zaremba, Bode, \& } \\
\text { Wagner, 2017; Moschner et al., 2019; } \\
\text { Prats, Amigó, Ametller, \& Batlle, 2017; } \\
\text { Minshall, Mortara, Napp, \& Probert, 2010; } \\
\text { Gutmann, 2019; Kanbach \& Stubner, } \\
\text { 2016; Gobble, 2018; Markham, Gentry, } \\
\text { Hume, Ramachandran, \& Kingon, } 2005\end{array}$ & $\begin{array}{l}\text { Prats, Siota, Canonici, \& Contijoch, } \\
\text { 2018; Tietz \& Kugler, 2018; Mortara, } \\
\text { Napp, Slacik, \& Minshall, 2009; } \\
\text { Chesbrough \& Brunswicker 2013; } \\
\text { Groote \& Backmann, 2019; } \\
\text { Chesbrough, } 2003\end{array}$ \\
\hline Investimentos & $\begin{array}{c}\text { Campbell, Birkinshaw, Morrison, \& } \\
\text { Batenburg, 2003; Chesbrough, 2002; Hill } \\
\text { \& Birkinshaw, 2008; Miles \& Covin, } \\
\text { 2002; Sharma \& Chrisman, 1999; Schildt, } \\
\text { Maula, \& Keil, 2005; Narayanan, Yang, \& } \\
\text { Zahra, 2009; Prats, Amigó, Ametller, \& } \\
\text { Batlle, } 2017\end{array}$ & $\begin{array}{l}\text { Prats, Siota, Canonici, \& Contijoch, } \\
\text { 2018; Spender, Corvello, Grimaldi, \& } \\
\text { Rippa, 2017; Van de Vandre, Jong, } \\
\text { Vanhaverbeke, \& Rochemont, 2009; } \\
\text { Usman \& Vanhaverbeke, } 2017\end{array}$ \\
\hline Fusões e Aquisições & $\begin{array}{l}\text { Miles \& Covin, 2002; Sharma \& } \\
\text { Chrisman, 1999; Schildt, \& Keil, 2005; } \\
\text { Narayanan, Yang, \& Zahra, 2009; Prats } \\
\text { Amigó, Ametller, \& Batlle, } 2017\end{array}$ & $\begin{array}{c}\text { Prats, Siota, Canonici, \& Contijoch, } \\
\text { 2018; Lichtenthaler, 2008; West \& } \\
\text { Bogers, 2014; Usman \& Vanhaverbeke, } \\
2017\end{array}$ \\
\hline Spin-offs & $\begin{array}{l}\text { Dauderstädt, 2013; Miles \& Covin, 2002; } \\
\text { Campbell, Birkinshaw, Morrison, \& } \\
\text { Batenburg,2003; Narayanan, Yang, \& } \\
\text { Zahra, 2009; Sharma \& Chrisman, 1999; } \\
\text { Phan, Wright, Ucbasaran, \& Tan, } 2009\end{array}$ & $\begin{array}{c}\text { Prats, Siota, Canonici, \& Contijoch, } \\
\text { 2018; Chesbrough, 2003; Chesbrough \& } \\
\text { Brunswicker } 2013\end{array}$ \\
\hline
\end{tabular}

Fonte: Elaborada pelo autor.

Abordagens de CSE, como eventos, aceleradoras, incubadoras, compartilhamento de recursos e parcerias sem equidade, são encontradas em publicações mais recentes acerca de CV (Dauderstädt, 2013; Gobble, 2018; Gutmann, 2019; Prats, Amigó, Ametller, \& Batlle, 2017; Kanbach \& Stubner, 2016; Zaremba, Bode \& Wagner, 2017; Moschner et al., 2019). Abordagens como spin-offs, investimentos diretos, fusões e aquisições, no 
entanto, podem ser encontradas em publicações mais distribuídas ao longo do tempo (Dauderstädt, 2013; Campbell, Birkinshaw, Morrison, \& Batenburg, 2003; Chesbrough, 2002; Hill \& Birkinshaw, 2008; Miles \& Covin, 2002; Sharma \& Chrisman, 1999; Schildt, Maula, \& Keil, 2005; Narayanan, Yang, \& Zahra, 2009; Prats, Amigó, Ametller, \& Batlle, 2017; Phan, Wright, Ucbasaran, \& Tan, 2009).

As abordagens adotadas por CSE também podem ser identificadas em publicações de IA, a começar pela primeira publicação sobre o conceito (Chesbrough, 2003). Ao longo dos anos, também foram publicadas várias referências às mesmas (Prats, Siota, Canonici, \& Contijoch, 2018; Chesbrough \& Brunswicker, 2013; Spender, Corvello, Grimaldi, \& Rippa, 2017; Mortara \& Minshall, 2011; West \& Bogers, 2014; Tietz \& Kugler, 2018; Groote \& Backmann, 2019; Van de Vandre, Jong, Vanhaverbeke, \& Rochemont, 2009; Usman \& Vanhaverbeke, 2017; Lichtenthaler, 2008).

Dentre as diversas abordagens apresentadas, destacam-se as parcerias e eventos, pois estão associadas à realidade da Pesquisa-Ação desenvolvida neste estudo. Os grupos envolvidos na intervenção executaram eventos de aculturamento e a abordagem de parceria teve papel ainda mais relevante, pois norteou a priorização das ações a partir do Ciclo 2, o que será abordado no Capítulo 4.

\subsection{CONSIDERAÇÕES SOBRE OS ESCOPOS TEÓRICO E PRÁTICO DA PESQUISA}

Com base na intersecção dos domínios representados na Figura 9, os conceitos de Corporate Venturing, Corporate-Startup Engagement e Inovação Aberta são utilizados como fundamento para analisar elementos internos associados à aproximação da empresa XYZ com startups, bem como habilitadores, barreiras, melhores práticas e recomendações envolvidas.

Apesar disso, devido à intervenção estar associada estritamente com o relacionamento entre uma grande empresa e startups, entende-se que o Corporate-Startup Engagement seja o domínio central mais adequado para se tratar do problema da pesquisa em questão. 


\subsubsection{Parcerias: startups como provedoras de solução para grandes empresas}

Parceria entre empresas, segundo Mayer e Teece (2008), remete a alianças de cooperação, colaboração, codesenvolvimento ou criação de valor que gerem algum benefício para as organizações envolvidas. Minshall, Mortara, Napp e Probert (2010) compreendem a parceria como uma forma de as empresas poderem acessar ativos complementares, por exemplo, canais de distribuição, recursos financeiros e clientes.

Bannerjee, Bielli e Haley (2016) sugerem que podem ser definidas diferentes estruturas de parcerias baseadas nas estratégias de cada organização em particular. Essas parcerias podem ser de curto ou de longo prazo, ou mesmo podem mudar com o passar do tempo, dependendo do ciclo dos produtos ou dos serviços envolvidos (Minshall, Mortara, Napp, \& Probert, 2010; Prats, Amigó, Ametller, \& Batlle, 2017).

Outros autores ampliam as possibilidades de parcerias, de acordo com o grau de integração e comprometimento de cada uma das partes. Pekar e Margulis (2003) e Reurer, Olk e Ariño (2011), por exemplo, apresentam modelos de parcerias (Figura 10) usados em literaturas que abordam o Corporate Venturing e o relacionamento entre grandes empresas e startups (Minshall, Mortara, Napp, \& Probert, 2010; Prats, Amigó, Ametller, \& Batlle, 2017). Pekar e Margulis (2003) sugerem sete variações de parcerias, começando por serviços contratuais, enquanto Reuer, Olk e Ariño (2011) apresentam onze, iniciando por fornecedores preferenciais.

Os serviços contratuais, para Pekar e Margulis (2003), e os fornecedores preferenciais, para Reuer, Olk e Ariño (2011), podem ser equivalentes, reconhecendo-se a relação 'cliente-fornecedor' como o tipo de parceria com menor nível de integração e de comprometimento. 
Figura 10 - Tipos de Parcerias

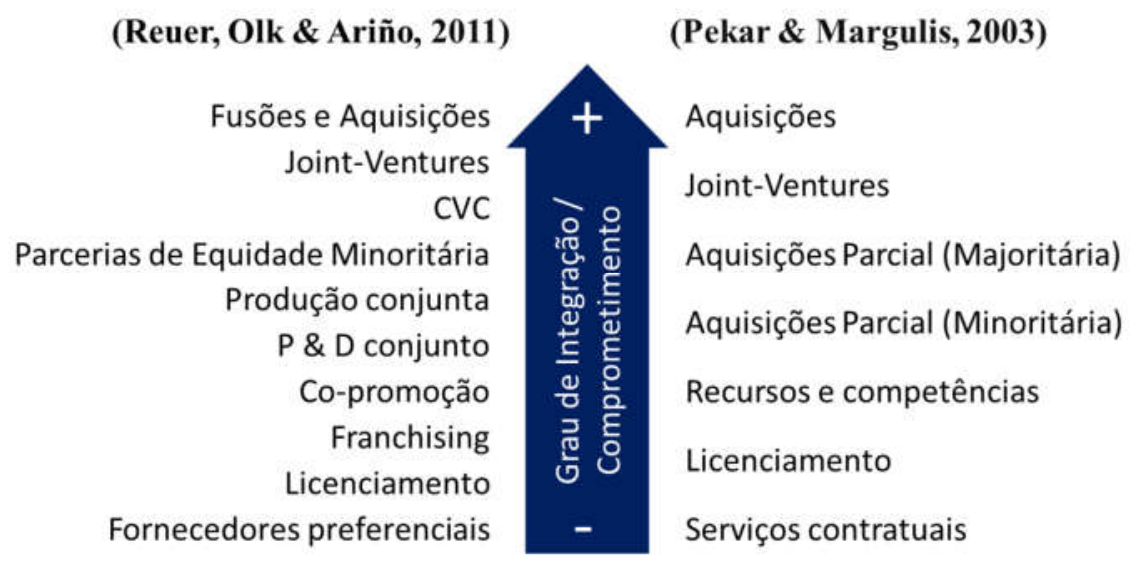

Fonte: Baseado em Reuer, Olk e Ariño (2011) e Pekar e Margulis (2003).

No que se refere às parcerias entre grandes empresas e startups, como é o caso desta dissertação, Minshall, Mortara, Napp e Probert (2010) reconhecem desafios de ambas as partes devido às disparidades de recursos e às capacidades envolvidas, denominadas por eles 'parcerias assimétricas'. Ou seja, uma parceria é considerada assimétrica quando envolve cooperação entre duas empresas com diferenças marcantes, em termos de recursos e de posição de mercado (Barabel, Meier, \& Soparnot, 2014). Essas parcerias podem apresentar desafios econômicos e de engajamento tecnológico em busca de inovações (Barabel, Meier, \& Soparnot, 2014; Minshall, Mortara, Napp, \& Probert, 2010).

Minshall, Mortara, Napp e Probert (2010) e Zaremba, Bode e Wagner (2017) alegam que, em um cenário no qual as empresas abrem-se para soluções externas visando a aprimorarem suas capacidades, as startups podem ser relevantes fontes de inovação, principalmente quando a grande empresa não consegue desenvolver tecnologias internamente, seja por falta de capacidade, seja por falta de tempo hábil. Há também um potencial benefício para as startups que, limitadas comercialmente e em ganho de escala, podem se beneficiar por trabalhar com grandes empresas capazes de prover uma quantidade maior de recursos e canais, como fornecedores, clientes e parceiros (Minshall, Mortara, Napp, \& Probert, 2010). 
Apesar da aparente oportunidade, muitos desafios precisam ser superados para que haja benefício mútuo a partir de tais 'parcerias assimétricas' (Minshall, Mortara, Napp, \& Probert, 2010). Em geral, grandes empresas percebem problemas associados à inexperiência e à falta de prontidão das startups, enquanto, por outro lado, as startups identificam problemas associados à cultura, à lentidão nas decisões e a eventuais riscos de uma relação abusiva por parte da corporação (Barabel, Meier, \& Soparnot, 2014; Mortara, Napp, Slacik, \& Minshall, 2009; Minshall, Mortara, Napp, \& Probert, 2010).

De acordo com Prats, Amigó, Ametller e Batlle (2017), as parcerias podem se iniciar com o desenvolvimento de um projeto piloto e, posteriormente, migrarem para outros formatos como o codesenvolvimento de produtos e a contratação da startup como fornecedora para a solução de problemas de negócios. Apesar de o processo inicial para qualificação ser, em geral, árduo para as startups, sua contratação como fornecedoras traz menores riscos e comprometimento para ambas as partes envolvidas, quando comparadas com outras formas de parcerias (Bannerjee, Bielli, \& Haley, 2016). Mocker, Bielli e Haley (2015) complementam esse ponto de vista, explicando que parcerias como o codesenvolvimento e a contratação de startups passam a ser atraentes para ambas as empresas, especialmente, devido ao acesso a recursos financeiros para as startups e à aplicação mais rápida de serviços por parte da grande empresa.

Parcerias do tipo 'cliente-fornecedor' exigem pouca maturidade, quando confrontadas com as demais abordagens. No entanto, são necessárias mudanças, sobretudo na grande empresa, para que o relacionamento tenha maiores chances de sucesso (Minshall, Mortara, Napp, \& Probert, 2010). Zambera, Bode e Wagner (2017) sugerem que as grandes empresas compreendam a dinâmica das startups para desenvolverem capacidades para gerenciar essas relações. Mocker, Bielli e Haley (2015) e Prats, Amigó, Ametller e Batlle (2017) afirmam que a construção de parcerias de codesenvolvimento e a contratação de fornecedores levam ambas as partes a enfrentarem certos desafios, sobretudo por parte da grande empresa e principalmente no que tange à adaptação do seu contexto interno, o que exige apoio das lideranças, definição clara de objetivos, mudança de cultura, alteração de processos e redefinição de papéis e responsabilidades. 


\subsubsection{Aspectos Internos Associados ao Relacionamento de Grandes Empresas}

Antes da criação do conceito de Corporate-Startup Engagement (CSE), pesquisadores dos domínios de Corporate Venturing e de Inovação já reconheciam a relevância dos aspectos internos das organizações no fomento às iniciativas empreendedoras e inovativas que considerassem entidades externas (Kuratko, Hornsby, \& Covin, 2014; Martins \& Terblanche, 2003; Dombrowski, Kim, Desouza, Braganza, Papagari, Baloh, \& Jha, 2007). Pode-se resumir os aspectos internos associados ao Corporate Venturing e à Inovação na cultura interna, na estratégia, na atuação das lideranças, no acesso a recursos, nas estruturas organizacionais, nas equipes e nos incentivos (Kuratko, Hornsby, \& Covin, 2014; Martins \& Terblanche; 2003, Dombrowski et al., 2007).

Com o aumento do número de engajamentos entre grandes empresas e startups, parte dos aspectos internos identificados como de Corporate Venturing e de Inovação passaram a ser utilizados também por CSE, porém com foco mais pragmático, utilizando abordagens e melhores práticas direcionadas para um relacionamento colaborativo entre ambas as partes (Thieme, 2017). Ainda assim, novos aspectos também surgem a partir da construção desses novos relacionamentos como atividades internas, por exemplo, revisão de processos de compras e avaliação das soluções das startups (Thieme, 2017; Minshall, Mortara, Napp, \& Probert, 2010; Kohler, 2016).

Partindo dos conceitos de Corporate-Startup Engagement, Corporate Venturing e Inovação, incluindo Inovação Aberta, serão apresentados, a seguir, alguns autores que identificam elementos - habilitadores, barreiras, melhores práticas e recomendações associados aos aspectos internos da organização. Na sequência, esses elementos serão organizados e sintetizados para melhor compreensão da relação entre grandes empresas e startups. 


\subsubsection{Aspectos Internos da Organização Associados à Inovação e à Inovação} Aberta

Dombrowski et al. (2007) pesquisam as características necessárias para gerar uma cultura de inovação organizacional, utilizando as teorias de Inovação e as de Inovação Aberta. Como resultado, os autores sintetizam os elementos para uma cultura inovativa em oito grupos, a saber:

- Missão inovativa e declaração de visão: diz respeito aos objetivos únicos para a organização ou minimamente alinhados entre as áreas de negócios;

- Comunicação democrática e lateral: estimula a participação dos colaboradores na identificação de oportunidades e no desenvolvimento de inovações dentro da organização. Uma das formas de viabilizar a democratização desses dados é através de sistemas de informação. Dombrowski et al. (2007) usam como exemplo a empresa Whirlpool, que desenvolveu uma intranet para que seus colaboradores pudessem compartilhar conhecimentos sobre inovações. Casos semelhantes também são encontrados na pesquisa de Angehrn, Luccini e Maxwell (2009) sobre o uso de redes sociais para gerar inovação;

- Lugares seguros: remete preferencialmente à segregação (ao menos temporária) entre os espaços de desenvolvimento das inovações e o espaço cotidiano da empresa. Envolve também o provisionamento de recursos para a realização de atividades nesses ambientes. Outra forma de estabelecer um 'lugar seguro' é dedicar tempo suficiente para que os colaboradores possam inovar. Entre as boas práticas, Dombrowski et al. (2007) apresentam casos, como o da $3 \mathrm{M}$, que disponibiliza tempo para que seus funcionários possam executar ações e projetos de inovação;

- Flexibilidade: refere-se à abertura da organização para proposição de melhorias internas e buscas por oportunidades externas;

- Colaboração: envolve a capacidade dos colaboradores para trabalharem em grupo e para se comunicarem em busca da resolução de problemas. Dombrowski et al. (2007) sugerem o trabalho de equipes multidisciplinares para fomentar a colaboração e a comunicação entre departamentos; 
- Alargamento das fronteiras: remete à capacidade para colaborar, além das fronteiras departamentais, com o desenvolvimento de iniciativas empreendedoras;

- Incentivos: permite que todo colaborador tenha responsabilidade proporcional para com as entregas relacionadas à inovação dentro da organização;

- Liderança: iniciativas de inovação requerem um 'Líder' com suporte da alta direção para gerenciá-las diante dos desafios internos. Dombrowski et al. (2007, p. 199) também apresentam o papel do "patrocinador de ideias", um executivo com perfil para aconselhar e ajudar os colaboradores a viabilizarem ações inovadoras.

Dombrowski et al. (2007) também apresentam barreiras associadas à cultura de inovação, dentre as quais destacam três: a primeira, é a falta de engajamento por parte dos líderes, devido à perda de poder com as mudanças acarretadas pela inovação; a segunda, diz respeito à eliminação das ideias inovadoras ao serem submetidas a aprovações por parte das camadas superiores; e a última, remete à falta de incentivos para que colaboradores transpassem suas zonas departamentais ao se depararem com iniciativas de inovação promissoras.

Complementarmente a Dombrowski et al. (2007), Freeman e Engel (2007) afirmam que os incentivos desalinhados ou subdimensionados causam problemas de lentidão nos processos de inovação. Em contrapartida, Freeman e Engel (2007) sugerem que os incentivos estejam alinhados entre todos os impactados, para que sejam coerentes com os riscos associados às ações inovadoras.

Ao analisarem a implementação de ações voltadas a inovações externas em 13 (treze) grandes empresas, Mortara, Napp, Slacik e Minshall (2009) identificam as principais boas práticas e habilitadores a serem aplicados internamente pelas corporações, classificando-os em quatro dimensões:

- Cultural: envolve a mudança nas práticas e nos comportamentos em prol da inovação. Entre os principais elementos está o suporte da alta gerência, o que significa apoiar o contexto e gerar engajamento dos demais colaboradores. 
Mortara, Napp, Slacik e Minshall (2009) recomendam que os times envolvidos nas ações efetuem alinhamentos constantes com os executivos, para garantirem suporte, recursos e comprometimento, além de evitarem conflitos de poder e eventuais mudanças sinalizadoras de cortes orçamentários ou de despriorização das atividades;

- Procedimentos: envolve o provisionamento da estrutura para que a atuação com soluções externas possa acontecer. Entre os habilitadores estão o estabelecimento de uma equipe dedicada em tempo integral e multidisciplinar para realizar as adequações, além do provisionamento orçamentário;

- Habilidades: na visão dos autores, a capacitação dos colaboradores para atuarem com iniciativas envolvendo inovações externas é essencial para o sucesso das ações;

- Motivação: remete ao desenvolvimento de um sistema de incentivos para que os colaboradores se sintam encorajados a adotar práticas abertas, o que reflete no reforço da cultura de inovação e de empreendedorismo.

Na pesquisa de Mortara, Napp, Slacik e Minshall (2009) também são abordadas as dificuldades para implementação de inovações externas nas grandes empresas. Os autores alegam que parte delas se origina quando as ações são executadas de forma inadequada ou deixam de ser executadas. Mortara, Napp, Slacik e Minshall (2009) apresentam as principais barreiras, utilizando, então, as mesmas quatro dimensões citadas anteriormente para agrupá-las:

- Cultural: comportamento dos altos executivos contrários às inovações externas; acompanhamento à distância das ações pelos patrocinadores; resistência dos colaboradores em usar soluções externas; medo da perda de poder devido a restruturações internas;

- Procedimentos: processos rígidos tornando as decisões internas lentas; estrutura hierárquica rígida dificultando a integração entre as pessoas que atuam com inovação; e falta de autonomia dos grupos envolvidos; 
- Habilidades: carência de pessoas capacitadas e com conhecimento sobre inovação e intraempreendedorismo, impactando na morosidade e no retrabalho das atividades;

- Motivação: falta de incentivos quanto à busca por solução e mecanismos velados de punição quando experimentos falham.

Martins e Terblanche (2003) desenvolveram um modelo com determinantes culturais que influenciam a criatividade e a inovação nas organizações. Além de sintetizar esses determinantes, eles também identificam quais ações impactam positiva ou negativamente a organização:

- Estratégia: os objetivos da organização podem promover ou inibir a inovação. A determinante estratégia envolve o desenvolvimento de visão e da missão associado à inovação. Esses elementos devem vislumbrar a longo prazo e devem ser de conhecimento dos colaboradores;

- Estrutura: a maneira como a estrutura organizacional é criada pode favorecer ou inibir a inovação: estruturas planas, equipes colaborativas e autônomas promovem inovação; e estruturas padronizadas e hierárquicas inibem-na;

- Mecanismos de Suporte: a inovação deve ser suportada por cinco elementos: disponibilidade de tempo, disponibilidade de recursos, incentivos/recompensas, tecnologia da informação e pessoas capacitadas. Esses mecanismos permitem que um comportamento empreendedor e inovativo torne-se cada vez mais dominante. Em relação à disponibilidade de tempo, Martins e Terblanche (2003) apresentam casos de empresas que permitem que seus colaboradores dediquem $15 \%$ de sua carga horária em projetos inovadores. Eles também defendem que os sistemas de informação sejam utilizados como potencializadores de compartilhamento e de troca de conhecimentos sobre inovação;

- Comportamento que encoraja a inovação: é preciso definir valores e normas que desenvolvam uma perspectiva positiva em relação às mudanças, estimulando o risco, a tolerância ao erro, a experimentação e o aprendizado contínuo; 
- Comunicação: permitir a comunicação de forma transparente e aberta entre as camadas horizontais e verticais das organizações para que as ações tenham fluidez.

Ahmed (1998) também identifica fatores relevantes para estabelecer um clima de inovação na organização, dentre eles a comunicação clara dos executivos sobre qual é a mudança cultural desejada e a tolerância ao risco que a organização deseja seguir, além do suporte emocional para os times que implementarão as ações.

Apesar desses fatores, Ahmed (1998) ressalta ainda uma série de outros itens relevantes, dentre eles a motivação e a autonomia das equipes. Ele, assim como outros autores, distingue os fatores motivacionais entre intrínsecos (associados ao desafio pessoal) e os extrínsecos (referentes às recompensas financeiras) (Ahmed 1998; Amabile, 1998; Martins \& Terblanche, 2003).

Embora as motivações intrínsecas sejam mais sustentáveis às iniciativas envolvendo inovação do que as extrínsecas, ambas são relevantes para o engajamento dos colaboradores (Osterloh \& Frey, 2000; Ahmed, 1998; Martins \& Terblanche, 2003). Essa visão é corroborada por Makri, Lane e Gomez-Mejia (2006), que concluem que os benefícios financeiros oferecidos aos altos líderes trazem resultados positivos para as iniciativas inovadoras.

Outro aspecto importante abordado no domínio da inovação é a autonomia das equipes envolvidas nas ações inovadoras. De acordo com Ahmed (1998), há dois tipos de autonomia: a parcial, centrada no nível tático; e a integral, focada no nível estratégico.

Das, Verburg, Verbraeck e Bonebakker (2018) exploram os obstáculos internos que influenciam projetos inovadores dentro de grandes empresas de serviços financeiros. Como conclusão, identificaram seis principais barreiras, a saber:

- Falta de exploração de novas ideias: ideias de inovação sem força para serem implementadas por falta de apoio do executivo; 
- Inércia causada por arquitetura de sistemas: departamentos de tecnologia burocráticos e complexos, que buscam mitigar riscos e manter o poder;

- Estrutura organizacional não-suportada / rígida: faz com que cada área de negócio atue com ações de inovação distintas;

- Gestão de risco excessivamente zelosa: restrições de órgãos reguladores e processos internos, como prevenção contra fraudes e compras, limitando a execução de iniciativas de cunho inovador;

- Síndrome do 'não inventado aqui': preferência dos colaboradores pelo uso de tecnologias previamente criadas ou utilizadas em seus departamentos;

- Nenhuma P\&D interna: áreas de negócios que não trocam conhecimento sobre iniciativas voltadas à inovação.

Outras pesquisas e relatórios associados ao domínio da inovação complementam os estudos dos autores supracitados. Rehder e Levi (2011), por exemplo, convergem com a visão de Das, Verburg, Verbraeck e Bonebakker (2018) sobre a inovação no setor financeiro, ao afirmarem que as empresas desse setor não priorizam iniciativas de inovação, pois são orientadas para recompensas de curto prazo e com menores riscos.

Outros autores voltados à inovação também estabelecem como barreira a aversão ao risco. Ahmed (1998), ao tratar do clima para inovação, ressalta que essa característica inibe a ocorrência de ações inovadoras, em geral, pelo medo da incerteza, o que consequentemente leva à inércia organizacional. Além da aversão ao risco, autores associados à inovação e à transformação organizacional (Rumelt, 1995; Fasnacht, 2009) ressaltam que a falta de capacitação e de entendimento dos colaboradores pode impedir a ocorrência de mudanças organizacionais voltadas à inovação.

Weiss e Hoegl (2016) enfatizam a boa prática de ter um time estável e de tamanho adequado para a implementação das ações. Eles defendem que uma equipe reduzida permite aumentar a motivação, a responsabilidade, a autonomia e a eficiência em ações voltadas às inovações, em contraste com as numerosas que, em geral, são ineficientes e sofrem com o problema da falta de definição de papéis e de responsabilidades. Weiss e Hoegl (2016) ponderam sua própria visão e levantam problemas associados a um time 
menor, dentre eles o subdimensionamento, que comprometeria as entregas por incapacidade do mesmo.

Por fim, em complementação à questão de formação dos times, Howell e Boies (2004) e Howell e Higgins (1990) defendem a atuação dos 'líderes' em iniciativas de inovação tecnológica, ajudando a promover ideias, apresentando o valor estratégico e financeiro das inovações, eliminando resistências, construindo o apoio com os executivos por meios formais e informais e gerindo interesses da alta direção da empresa.

\subsubsection{Aspectos Internos da Organização Associados ao Corporate Venturing}

Quando se adentra no domínio do Corporate Venturing, podem ser encontrados outros elementos associados aos aspectos internos que propiciam direta e/ou indiretamente um melhor relacionamento com empresas externas, como as startups.

Os pesquisadores Kuratko, Hornsby e Covin (2014) sintetizam os elementos internos necessários para se criar um ambiente organizacional favorável à inovação e ao empreendedorismo corporativo, domínio sob o qual está o Corporate Venturing. Eles agrupam esses elementos em cinco dimensões, a saber:

- Suporte da alta gerência: é necessário apoio dos executivos para que a organização alcance resultados a partir da inovação. Esse apoio é materializado pelo estabelecimento de objetivos e metas, pela promoção do comportamento empreendedor, pela defesa das ideias voltadas à inovação e pelo provisionamento de recursos. Segundo esses pesquisadores, o papel de suporte não depende somente da alta gerência, mas também de todos os líderes dentro da organização;

- Autonomia do trabalho: os colaboradores precisam ser encorajados a enxergar oportunidades empreendedoras. Desenvolver essa dimensão requer que a organização estimule a tolerância à falha e à experimentação de inovações, além de dar autonomia às equipes, delegando atividades; 
- Recompensas e reforços: é essencial estabelecer incentivos que permitam inovar. Os sistemas de recompensas adequados reforçam o comportamento empreendedor dos colaboradores. Juntamente com a disponibilidade de recursos, o sistema de incentivo é considerado pelos pesquisadores como um dos principais determinantes do comportamento empreendedor;

- Disponibilidade de tempo: necessidade de disponibilizar tempo adequado para que os colaboradores, em grupo ou individualmente, possam atuar em iniciativas inovadoras;

- Limites organizacionais: remetem à geração de novas oportunidades e melhoria da comunicação pela fluidez da troca de informações entre os departamentos da organização e também entre a organização e o meio externo.

Com ponto de vista mais pragmático, Prats, Amigó, Ametller e Batlle (2017) desenvolvem uma estrutura voltada às grandes empresas para alavancar iniciativas de Corporate Venturing com startups. Eles sugerem oito fatores críticos para que essas iniciativas obtenham sucesso com startups, a saber:

- Compromisso absoluto e apoio da alta administração;

- Intenção estratégica de inovação corporativa clara e com objetivos definidos;

- Indicadores-chave de desempenho para medir o sucesso;

- Autonomia dos times na forma de colaboração com startups;

- Alto nível de interação com o restante das unidades de negócios;

- Bom nível de recursos financeiros;

- Acompanhamento com startups; e

- Avaliação contínua.

Prats, Amigó, Ametller e Batlle (2017) também recomendam que as empresas evitem determinadas ações que possam levar à ineficiência e ao desperdício de recursos, como executar iniciativas com startups sem uma estratégia definitiva de Corporate Venturing. Eles sugerem, inclusive, melhores práticas de acordo com a abordagem de Corporate 
Venturing utilizada. Numa eventual abordagem de parceria, como na relação clientefornecedor preferencial, destacam-se as duas práticas mais eficazes:

- Piloto: identificar casos relevantes de negócios para criar pilotos com startups, sendo que os mesmos devem ter critérios e orçamentos previamente estabelecidos, além de um prazo pré-determinado para conclusão;

- 'Líder' e Equipe: ter uma equipe dedicada em tempo integral e talentosa, além de um 'Líder' com poder de decisão, é pré-requisito para atuar em ações de parcerias com startups.

Em meio aos inúmeros casos de falhas ao tentar executar iniciativas de Corporate Venturing, Shah, Zegveld e Roodhart (2008) pesquisam quais são as melhores práticas desse domínio adotadas pelas empresas IBM, Nokia e Shell. A pesquisa identifica que um dos elementos para o sucesso de Corporate Venturing é a criação de um ambiente interno 'certo' que, segundo os autores, envolve cinco fatores críticos, a saber:

- Recursos assegurados: segundo os autores, é essencial que haja um comprometimento a longo prazo com iniciativas de Corporate Venturing. Esse comprometimento deve ser refletido principalmente por recursos financeiros;

- Capital humano: é preciso envolver as pessoas corretas e capacitá-las para atuarem em iniciativas de Corporate Venturing. Dentre elas estão os membros de equipe e o 'Líder';

- Executivos sêniores envolvidos: é imperativo o envolvimento dos altos executivos nas iniciativas para que haja sucesso efetivo. Segundo os autores, os executivos sêniores podem auxiliar na criação de uma cultura de inovação, garantir recursos, definir objetivos e defender as iniciativas de ameaças como cortes ou perda de priorização;

- Mecanismo de governança: a evolução de iniciativas de Corporate Venturing deve ter objetivos claros e critérios de sucesso a curto e longo prazos. Para manter o compromisso, deve haver um acompanhamento periódico por parte dos altos executivos; 
- Processo de transferência de projetos: refere-se ao estabelecimento de processos que garantam que as iniciativas de Corporate Venturing consigam se desenvolver desde a fase de incubação até o uso efetivo.

Kuratko e Goldsby (2004), assim como Morris e Kuratko (2002), direcionam suas pesquisas aos obstáculos internos que impedem a organização de habilitar o empreendedorismo corporativo (Morris \& Kuratko, 2002) e seu reflexo nos aspectos éticos das lideranças (Kuratko \& Goldsby, 2004). Segundo eles, as grandes empresas criam estruturas rígidas e sem incentivos, o que limita a flexibilidade e o desejo de correrem riscos, frustrando líderes e demais colaboradores. A partir dessas duas pesquisas, é possível sintetizar seis grupos de obstáculos que inibem as mudanças internas na empresa. São eles:

- Sistemas: de recompensa e de mensuração com incentivos a curto prazo reforçam comportamentos como busca por segurança e por conservadorismo;

- Estruturas: a estrutura organizacional rígida e as várias camadas hierárquicas reduzem a capacidade de a organização buscar oportunidades externas e de provisionar recursos para novas iniciativas;

- Políticas e procedimentos: os organizacionais produzem burocracia, consumindo tempo e desestimulando a realização de iniciativas empreendedoras;

- Direção Estratégica: ausência de objetivos e de estratégias claras associadas à inovação e ao empreendedorismo na organização e falta de metas associadas a esses objetivos;

- Pessoas: consideradas os principais obstáculos, segundo os autores. A barreira está associada à intolerância e à resistência natural das pessoas a mudanças. Segundo os autores, a resistência é motivada pela necessidade de manter poder e status, causando a proteção de recursos e de informações;

- Cultura: falta de definição de valores organizacionais voltados ao empreendedorismo corporativo, bem como à priorização de ações de reforço e de recompensa a esse tipo de prática. 
Outros autores que atuam em pesquisas no campo de Corporate Venturing identificam barreiras e boas práticas complementares às de Kuratko, Hornsby e Covin (2014), Prats, Amigó, Ametller e Batlle (2017), Shah, Zegveld e Roodhart (2008), Kuratko e Goldsby (2004) e Morris e Kuratko (2002). Battistini, Hacklin e Baschera (2013), por exemplo, ao pesquisarem como 48 (quarenta e oito) corporações organizaram-se para atuar com Corporate Venturing, identificaram alguns desafios associados às lideranças, dentre os quais destacam: a falta de comprometimento e de engajamento a longo prazo; a falta de patrocínio; e a falta de proximidade entre os responsáveis pelas ações empreendedoras e os altos executivos.

Simon, Houghton e Gurney (1999), por sua vez, sugerem que organizações de grande porte estabeleçam determinados papéis e responsabilidades para garantir o equilíbrio entre autonomia e controle das iniciativas de Corporate Venturing. Dentre esses papéis destacam o de 'padrinho', cujas atribuições seriam ajudar a reduzir as resistências das áreas internas e proteger a autonomia do time responsável pelas ações.

\subsubsection{Aspectos Internos da Organização associados ao Corporate-Startup Engagement}

Em sua pesquisa sobre o uso estratégico de Corporate-Startup Engagement (CSE), Thieme (2017) estrutura os aspectos internos de acordo com os níveis de gestão das organizações, considerando os aspectos estratégico, organizacional e operacional. Além de explicá-los, a autora faz recomendações às empresas quanto ao engajamento com startups, a saber:

- Estratégico: está associado ao nível executivo. É importante ter objetivos claros quanto às startups para engajá-las; para definir um propósito pelo qual a empresa busca se relacionar com startups; para mensurar os objetivos; e para alocar recursos adequados às ações. Thieme $(2017$, p. 79) também afirma que as empresas podem adotar inicialmente uma estratégia aberta ou "estratégia deliberativa" com startups, como forma de aprender e experimentar diferentes possibilidades. Outra sugestão é considerar parceiros para atuarem nas iniciativas, caso a empresa tenha pouca experiência com startups; 
- Organizacional: este nível aborda elementos transversais entre as unidades da organização. Dentre os pontos recomendados estão: garantir suporte dos altos executivos; alinhar previamente as iniciativas com executivos de outras unidades, a fim de mitigar riscos; e utilizar um 'Líder' como articulador entre as áreas de negócios e as iniciativas;

- Operacional: camada de elementos associada às melhores práticas de engajamento. Entre as sugestões de atuação estão: testar as soluções com startups por meio de iterações rápidas como experimentos e pilotos; e padronizar os procedimentos para seleção de startups parceiras.

Thieme (2017) também identifica barreiras internas associadas à colaboração de grandes empresas com startups. Ao observar detalhadamente essas barreiras, a autora as classifica em oito grupos. São eles:

- Filtros de informação e percepção distorcida: preconceito contra novas perspectivas; descrédito em relação a novas ameaças; descrença sobre oportunidades futuras; e visão de retorno financeiro a curto prazo;

- Foco na inovação incremental: priorização de atividades para explorar tecnologias existentes na organização;

- Rotinas organizacionais e estruturas burocráticas: rigidez organizacional causada pela busca por eficiência e por padronização dos procedimentos internos;

- Dependência de recursos: falta de recursos para colaboração com startups, por comprometimento com as operações existentes;

- Medo de canibalização: medo do impacto sobre os produtos e serviços atuais por problemas operacionais e riscos de custos/investimentos irrecuperáveis;

- Poder e políticas: conflitos de interesses e de poder entre as unidades, considerando os recursos financeiros e os humanos impactados pelas mudanças organizacionais;

- Falta de cultura empreendedora: falta de incentivos que compensem o risco de inovar; e manutenção e estabilidade do poder e do modo de trabalho; 
- Lacuna de capacitação: falta de capacitação das pessoas envolvidas para executarem ações inovadoras.

A maioria dessas barreiras, na opinião da autora, está associada aos conflitos entre exploração de competências existentes (exploration) e exploração de novas competências (exploitation). A busca por novas competências faz com que os mecanismos existentes na organização resistam para manterem inalterados os recursos e as estruturas de poder, incrementando apenas as competências existentes e causando comportamento de aversão e atrofiamento de iniciativas voltadas a novas capacidades (Hill \& Rothaermel, 2003; Rumelt, 1995; Tushman \& O'Reilly, 1996). Em sua pesquisa sobre organizações ambidestras, Tushman e O'Reilly (1996, p. 18) denominam essas dificuldades "inércia estrutural" e "inércia cultural".

Antes mesmo da concepção de Corporate-Startup Engagement, Minshall, Mortara, Napp e Probert (2010) realizaram estudos de parcerias de tecnologia entre grandes empresas e startups, considerando uma amostra de 37 (trinta e sete) startups e 20 (vinte) grandes empresas associadas ao Polo Técnico de Cambridge. Nessa pesquisa, eles adotaram quatro dimensões a serem desenvolvidas pelas grandes empresas quando do relacionamento com startups: estratégica/modelo de negócios, tecnológica, organizacional e inicialização da parceria. Com base nessas dimensões, eles fizeram algumas recomendações às grandes empresas ao estabelecerem parcerias com startups:

- Estratégica e Modelo de Negócios: envolve o desenvolvimento de estratégia de inovação corporativa que considere as próximas tecnologias necessárias à organização. Os autores recomendam, inclusive, a adaptação dos processos internos para utilização e aquisição de tecnologias das startups;

- Tecnológica: engloba a comunicação clara às startups sobre as intenções da empresa, compartilhando, inclusive, o roadmap de suas necessidades. Além disso, os autores indicam o estabelecimento de mecanismos para avaliação de startups, considerando a prontidão tecnológica e comercial. Essa avaliação, na perspectiva dos autores, é importante para verificar a aderência da solução com a estratégia de inovação da empresa; 
- Organizacional: consiste no mapeamento, clarificação e simplificação dos processos internos, de modo que sejam compreendidos pelos colaboradores e, principalmente, pelas startups. Ademais, os autores recomendam o estabelecimento de um time dedicado em tempo integral e de um 'Líder' para defender as startups de questões burocráticas e para melhorar os alinhamentos internos entre as áreas da organização. Minshall, Mortara, Napp e Probert (2010) apresentam também parceiros intermediários, como forma de estruturar os relacionamentos com startups;

- Inicialização da Parceria: consiste na operacionalização da parceria com startups, o que inclui o gerenciamento dos principais envolvidos na avaliação das startups e de suas tecnologias, englobando compras, jurídico e comercial. Como forma de iniciar as parcerias de maneira empática e colaborativa, Minshall, Mortara, Napp e Probert (2010) apresentam casos nos quais profissionais de grandes empresas imergem dentro das startups, conhecendo o seu dia a dia e retornando com proposições de melhorias para a organização. Os autores também ressaltam a importância de se estabelecer projetos de menor porte, como pilotos e experimentos. Essa perspectiva é compartilhada, inclusive, por Bonzom e Netessine (2016, p. 7), que recomendam às empresas "começarem pequeno".

Minshall, Mortara, Napp e Probert (2010) também apontam em seus estudos os principais obstáculos na geração das parcerias entre grandes empresas e startups de base tecnológica. Sob a ótica das startups, as principais barreiras identificadas na relação com grandes empresas são a falta de definição de responsáveis, os processos inadequados, a não atribuição de relevância às startups, a morosidade na tomada de decisão e a distinta cultura organizacional. Os autores sintetizam esses obstáculos em cinco agrupamentos:

- Ponto de contato: as motivações dos colaboradores variam de acordo com a área;

- Transferência de responsabilidade: há falta de protagonismo na resolução de problemas nas zonas cinzentas de responsabilidade. São frequentes frases como: 'Não é comigo; isso é com compras; é com jurídico'; 
- Relevância das parcerias: baixo senso de velocidade e de urgência em relação às startups;

- Burocracia: tomada de decisão interna complexa devido às camadas de gestão e aos conflitos de interesse;

- Cultura Organizacional: resistências a novas tecnologias e falta de conhecimento sobre o funcionamento das startups.

Em sua pesquisa sobre transposição dos obstáculos para criar colaboração entre corporações e startups, Bannerjee, Bielli e Haley (2016) apresentam quatro agrupamentos de aspectos internos. São eles: estratégico, estrutural, cultural e processual. Baseado em casos práticos e em referências teóricas, eles propõem, para cada um deles, as melhores práticas a serem adotadas pelas empresas, a saber:

- Estratégico: engloba a identificação das necessidades organizacionais, o engajamento e a conquista do compromisso dos altos executivos para realizar ações voltadas à aproximação com startups. Uma das formas sugerida por Bannerjee, Bielli e Haley (2016) para obter apoio e patrocínio dos executivos é a realização de projetos pilotos ou de experimentos que provem benefícios tangíveis. Os pilotos e os experimentos, segundo os autores, também permitem estudar melhores estratégias para futuras ações de engajamento. Ademais, eles sugerem a realização de reuniões periódicas, envolvendo os grupos que atuam diretamente com as startups e os executivos, a fim de alinhar expectativas e de mitigar riscos. Semelhantemente, o relatório do Fórum Econômico Mundial (WEF, 2018) destaca a importância de abranger todas as unidades de negócios antes de executar ações voltadas às startups, a fim de evitar conflitos, quando as ações ganharem destaque;

- Estrutural: inclui aspectos associados à estrutura organizacional, à tomada de decisão e ao estabelecimento de papéis e de responsabilidades. Os autores afirmam que a horizontalização e a delegação de poder aos colaboradores facilitam a viabilidade das iniciativas associadas à inovação e às startups. Tendo em vista a complexidade e a burocracia das grandes organizações, eles entendem que a definição do 'Líder' com penetração política e de equipes dedicadas em tempo integral com autonomia, assim como o acesso a recursos financeiros são 
medidas que podem mitigar a rigidez organizacional. Bannerjee, Bielli e Haley (2016) também sugerem que grandes empresas considerem contratar organizações externas especializadas. Essa medida garantiria imparcialidade diante de interesses das áreas e mitigaria os riscos advindos da falta de experiência da organização em lidar com startups;

- Cultural: inclui os elementos da cultura empreendedora na organização. De acordo com Bannerjee, Bielli e Haley (2016, p. 30), uma empresa tem cultura empreendedora se "novas ideias e criatividade são esperadas, o risco é encorajado, o fracasso é tolerado, o aprendizado é promovido, inovações de produto, de processos e administrativas são defendidas, e mudança contínua é vista como transportadora de oportunidades". Como recomendações, Bannerjee, Bielli e Haley (2016) sugerem que os executivos sinalizem de forma pública a intenção de a empresa se aproximar de startups; de que os colaboradores tenham tempo disponível para realizar ações criativas e de integração com startups; de selecionar um 'Líder' com habilidade para disseminar as iniciativas entre as unidades de negócios; e de definir incentivos coerentes com a exposição ao risco de atuar com startups. Esses autores também recomendam o uso de eventos (desafios, hackathons e competições), como forma inicial de engajar os colaboradores e de se aproximar das startups. Outra boa prática de aculturamento apresentada pelos autores é a realização de programas de imersão cultural, como a atuação de colaboradores em startups ou a criação de equipes internas nos moldes de startup;

- Processual: estabelece como são constituídos e adaptados os processos internos para considerarem a atuação das startups com a organização. Os autores sugerem uma série de recomendações associadas aos processos, entre elas: a flexibilização de processos críticos, por exemplo, de tecnologia, jurídico e de compras para que sejam mais rápidos; a elaboração de uma comunicação simplificada dos processos para colaboradores e startups, denominada, por Bannerjee, Bielli e Haley (2016, p. 21) "esconder a fiação"; e a criação de processos específicos para startups, chamados "fast-track" (Bannerjee et al., 2016 p. 19). Para esses autores, tais atividades dependem também do engajamento dos altos executivos. 
Além disso, Bannerjee, Bielli e Haley (2016) identificam barreiras internas relacionadas à colaboração com startups, dentre elas: a incompatibilidade de velocidade para tomar decisões, as diferenças culturais, os problemas de comunicação, e processos e pessoas responsáveis poucos claros. As barreiras identificadas por esses autores foram categorizadas em quatro agrupamentos:

- Estratégico: falta de apoio da alta-administração; estratégias e metas corporativas internas desalinhadas; equívoco sobre o conceito de startups; e comunicação disfuncional;

- Estrutural: hierarquia organizacional rígida e horizontalizada; e modelo de decisão não claramente definido;

- Cultural: manutenção da cultura corporativa atual, individualismo; aversão a tecnologias externas; ausência de cultura empreendedora; aversão a riscos e a falhas;

- Processual: processos internos rígidos; morosidade na tomada de decisão; fluxo de informações não transparentes; e mudança de pessoas responsáveis pelo relacionamento com startups.

Schättgen e Mur (2016), ao tratarem da preparação interna da organização para atuar com startups, identificam cinco fatores críticos para que a colaboração possa ser bemsucedida. São eles:

- Compromisso da alta direção: envolve assegurar o suporte da alta gerência, o que inclui a tolerância ao risco e o comprometimento com objetivos a longo prazo. Essa atuação da alta direção é importante, pois mantém o assunto em voga e oferece resistência para o enfrentamento dos desafios internos;

- Responsabilidades claramente atribuídas: os autores consideram essencial que todas as áreas e pessoas envolvidas dentro da organização tenham clareza de suas responsabilidades com relação ao engajamento com startups. Segundo Schättgen e Mur (2016), as organizações devem iniciar as interações com startups com objetivos compartilhados, podendo individualizar esses objetivos, caso atinjam maturidade; 
- Recursos suficientes e adequados: trata-se de disponibilizar pessoas e de definir o orçamento para realizar as atividades. Os autores alegam que não basta ter pessoas habilitadas e capacitadas para executar as ações, elas precisam ter tempo suficiente para se concentrarem nas atividades que exijam mudança organizacional. Em relação ao orçamento, deve-se provisionar recursos antes do início das atividades e dar acesso aos mesmos para facilitar tomadas de decisões mais ágeis;

- Agilidade na configuração e no processo: significa manter um processo de comunicação eficiente e fluído com startups. Os autores sugerem que as equipes de intervenções com startups sejam pequenas, para que consigam manter agilidade na realização das ações. Na pesquisa, são relatados casos nos quais grupos internos de 15 (quinze) pessoas reuniam-se com apenas uma startup, causando dificuldades em atribuir responsabilidades e em acompanhar as ações;

- Forte envolvimento dos responsáveis pelos negócios: a participação dos líderes de negócios ao qual as startups impactarão é fundamental para o sucesso das ações, segundo os autores. Para aumentar o envolvimento desses líderes, sugere-se estabelecer metas compartilhadas desde o início das ações.

Além das pesquisas de Thieme (2017), das de Minshall, Mortara, Napp e Probert (2010), Bannerjee, Bielli e Haley (2016) e das de Schättgen e Mur (2016), também é possível identificar habilitadores, melhorias e barreiras distribuídos em estudos complementares sobre Corporate-Startup Engagement. Um deles é o de De la Tour, Soussan, Harlé, Chevalier e Duportet (2017), o qual propõe uma estrutura para colaboração de grandes empresas com startups de base tecnológica. Para compor essa estrutura e tornar o ambiente interno favorável às startups, os autores sugerem algumas ações. São elas:

- Governança: estabelecer formalmente comitês com executivos-chave para supervisionar as ações de relacionamentos com startups, alinhar expectativas e permitir tomadas de decisões rápidas;

- Programas de imersão: permitir que colaboradores trabalhem temporariamente dentro das startups, promovendo mudanças em prol de uma cultura empreendedora e da inovação interna na grande empresa; 
- Garantir processos mais leves e rápidos: adaptar processos críticos ou criar processos paralelos - fast-tracks - para promover interações mais ágeis com startup;

- Equipe dedicada: estabelecer equipe dedicada em tempo integral para que o restante da organização permaneça focado nas unidades de negócios.

Mocker, Bielli e Haley (2015) também fazem outras recomendações para que grandes empresas possam colaborar com startups, dentre elas: negociar a disponibilidade de tempo do time antes do início das ações, sob o risco de, posteriormente, não conseguir dar andamento adequado a elas; e propor que os executivos sejam padrinhos de startups. O apadrinhamento lhes traria indiretamente uma percepção das dificuldades impostas pelas suas próprias organizações.

Linna (2017) aborda os desafios da empresa Nokia ao adotar startups como fontes externas de inovação e relata algumas recomendações importantes extraídas da prática. São elas: o apadrinhamento de executivos como forma de garantir engajamento e mitigar conflitos de interesse e o uso de processos e critérios para avaliar soluções provenientes de startups como forma de atenuar parcialidades e decisões emotivas. Linna (2017) ainda considera como aprendizado que os conflitos de interesses possam fazer com que as ações voltadas às startups fracassem. Ele evidencia uma tentativa falha para criar um processo de fast-track.

Em relatórios profissionais, também é possível encontrar indicações relacionadas à colaboração de grandes empresas com startups. Um relatório de destaque é o desenvolvido pela Mind the Bridge e Nesta (2017), em pesquisa para a Startup Europe Partnership, plataforma criada pela Comissão da União Europeia para aumentar o número de startups. $\mathrm{O}$ estudo apresenta práticas adotadas por grandes empresas no relacionamento com startups, dentre elas: o uso de eventos para aculturar e engajar colaboradores de forma inicial; e a revisão de processos internos como forma de trazer eficiência na contratação de startups, com a simplificação dos processos existentes e a criação de fast-tracks. 
Por fim, a consultoria KPMG (2015) também apresenta elementos de impacto na construção de relacionamentos colaborativos com startups. Destacam-se aspectos associados às pessoas, como a recomendação de equipes dedicadas em tempo integral à realização de ações voltadas às startups e o risco de essas equipes perderem legitimidade perante a organização e aos executivos, à medida que as dificuldades na condução de iniciativas forem aparecendo.

\subsubsection{Consolidação dos Principais Aspectos em Relação a Barreiras e Melhores Práticas}

Considerando-se as similaridades, sobreposições e complementariedades relacionadas aos aspectos internos apresentados neste capítulo, que agrega referenciais teóricos e práticos, propõe-se uma classificação de seis aspectos internos, a saber: cultura, alta liderança, objetivo e estratégia, equipe, estrutura organizacional e processos internos.

Como forma de associar e de padronizar nomenclaturas dos vários elementos derivados desses aspectos, apresentam-se duas classificações condizentes com os objetivos desta pesquisa: barreiras e melhores práticas e recomendações. Essas classificações e seus elementos são apresentados nos Quadros 5 e 6, respectivamente.

Quadro 5 - Barreiras no Estabelecimento de Parcerias entre Startups e Grandes Empresas

\begin{tabular}{|c|c|c|}
\hline & Barreiras & Autores \\
\hline \multirow{6}{*}{ Cultura } & Falta de conhecimento sobre startups e empreendedorismo. & \multirow{6}{*}{$\begin{array}{l}\text { Ahmed,1998; Freeman \& } \\
\text { Engel, 2007; Mortara, } \\
\text { Napp, Slacik, \& Minshall, } \\
\text { 2009; Minshall, Mortara, } \\
\text { Napp, \& Probert, 2010; } \\
\text { Bannerjee, Bielli, \& } \\
\text { Haley, 2016; Linna, 2017; } \\
\text { Thieme, 2017; Prats, } \\
\text { Siota, Canonici, \& } \\
\text { Contijoch, 2018; Das, } \\
\text { Verburg, Verbraeck, \& } \\
\text { Bonebakker, 2018. }\end{array}$} \\
\hline & Falta de incentivos que compensem o risco de inovar. & \\
\hline & $\begin{array}{l}\text { Síndrome do 'não foi inventado aqui' - falta de incentivos ou } \\
\text { de conhecimentos para considerar tecnologias externas. }\end{array}$ & \\
\hline & Punição à falha / aversão ao risco e à falha. & \\
\hline & Medo da perda de poder (recursos humanos e financeiros). & \\
\hline & Receio de perder estabilidade. & \\
\hline
\end{tabular}




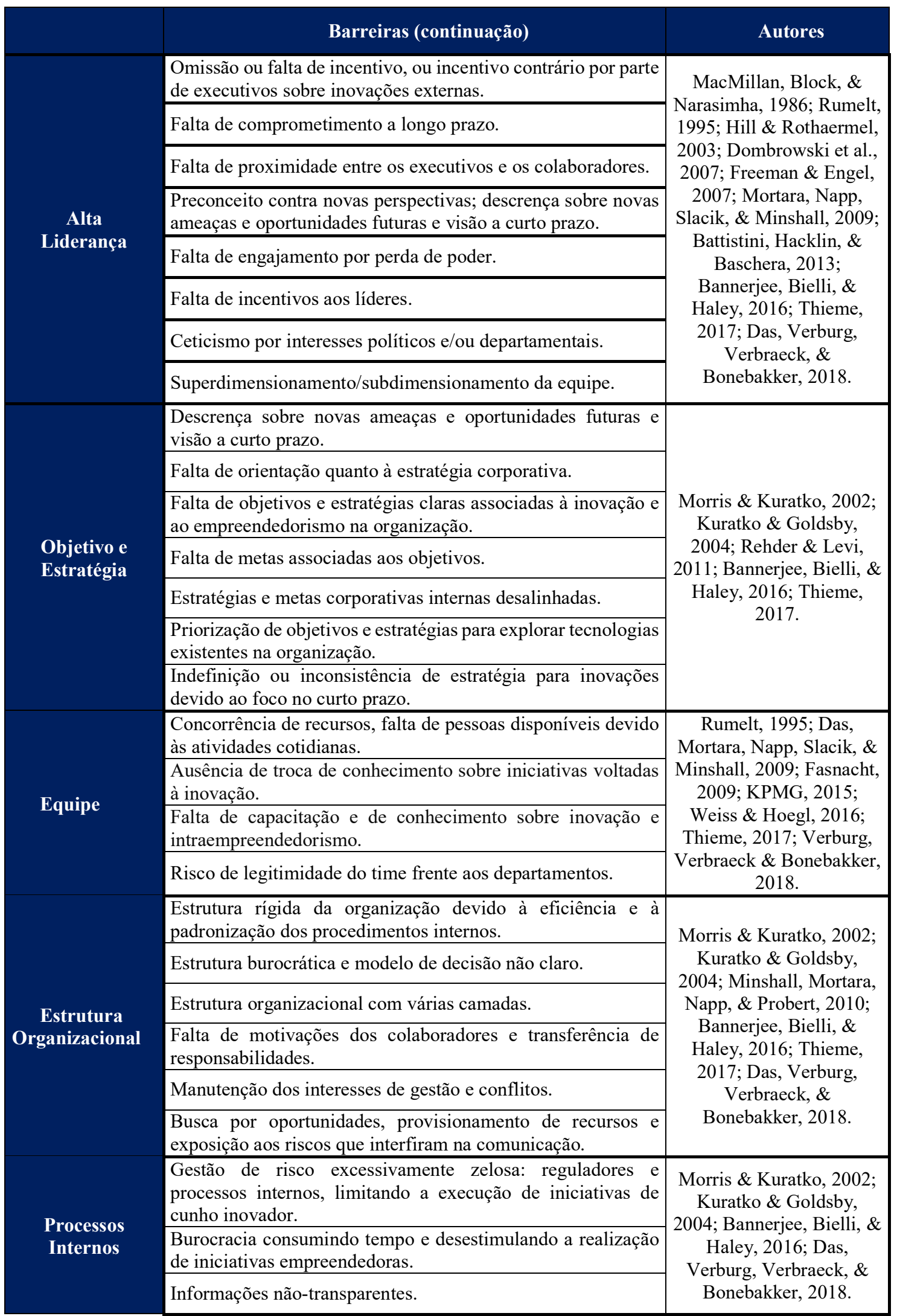

Fonte: Elaborado pelo autor. 


\section{Quadro 6 - Melhores Práticas e Recomendações no Estabelecimento de Parcerias}

entre Startups e Grandes Empresas

\begin{tabular}{|c|c|c|}
\hline & Melhores Práticas e Recomendações & Autores \\
\hline \multirow{5}{*}{ Cultura } & Eventos de aculturamento. & \multirow{5}{*}{$\begin{array}{l}\text { Ahmed, 1998; Martins \& Terblanche, 2003; } \\
\text { Howell \& Boies, 2004; Dombrowski et al. } \\
\text { 2007; Minshall, Mortara, Napp, \& Probert, } \\
\text { 2010; Mortara, Slacik, Napp, \& Minshall, } \\
\text { 2010; Mortara \& Minshall, 2011; Kuratko, } \\
\text { Hornsby, \& Covin, 2014; Accenture, 2015; } \\
\text { KPMG, 2015; Mocker, Bielli, \& Haley, } \\
\text { 2015; Bannerjee, Bielli, \& Haley, 2016; } \\
\text { Bonzom \& Netessine, 2016; Kohler, 2016; } \\
\text { Prats, Amigó, Ametller, \& Batlle, 2017; } \\
\text { Mind the Bridge \& Nesta, 2017; Rundquist } \\
\text { \& Österling, 2018 }\end{array}$} \\
\hline & Criação de programas de imersões culturais. & \\
\hline & $\begin{array}{l}\text { Utilização de 'Líder' como promotor do } \\
\text { aculturamento entre áreas. }\end{array}$ & \\
\hline & $\begin{array}{l}\text { Uso de rede de compartilhamento de } \\
\text { informações internas. }\end{array}$ & \\
\hline & $\begin{array}{l}\text { Estabelecimento de incentivos intrínsecos e } \\
\text { extrínsecos. }\end{array}$ & \\
\hline \multirow{6}{*}{ Alta Liderança } & $\begin{array}{l}\begin{array}{l}\text { Apresentação de pilotos para apresentar } \\
\text { proposta de valor. }\end{array} \\
\end{array}$ & \multirow{6}{*}{\begin{tabular}{|c|} 
Ahmed, 1998; Simon, Houghton, \& \\
Gurney, 1999; Howell \& Boies, 2004; \\
Makri, Lane, \& Gomez-Mejia, 2006; \\
Dombrowski et al., 2007; Shah, Zegveld, \& \\
Roodhart, 2008; Minshall, Mortara, Napp, \\
\& Probert, 2010; Mortara \& Minshall, \\
2011; Battistini, Hacklin, \& Baschera, \\
2013; Schättgen \& Mür, 2013; Mocker, \\
Bielli, \& Haley, 2015; Bannerjee, Bielli, \& \\
Haley, 2016; Bonzom \& Netessine, 2016; \\
Kohler, 2016; De la Tour et al., 2017; \\
Linna, 2017; Prats, Amigó, Ametller, \& \\
Batlle, 2017
\end{tabular}} \\
\hline & $\begin{array}{l}\text { Definição de um diretor-patrocinador das } \\
\text { iniciativas. }\end{array}$ & \\
\hline & Recompensa monetária aos altos executivos. & \\
\hline & $\begin{array}{l}\text { Eventos de proximidade com executivos - } \\
\text { reuniões periódicas e governança. }\end{array}$ & \\
\hline & Estabelecimento de 'padrinhos' para iniciativas. & \\
\hline & $\begin{array}{l}\text { Utilização de 'Líder' para promover proposta de } \\
\text { valor das ações juntos aos altos executivos. }\end{array}$ & \\
\hline \multirow{4}{*}{$\begin{array}{l}\text { Objetivo e } \\
\text { Estratégia }\end{array}$} & $\begin{array}{l}\text { Definição das estratégias de iniciativas de } \\
\text { experimentação, para entendimento sobre como } \\
\text { colaborar com startups. }\end{array}$ & \multirow{4}{*}{$\begin{array}{l}\text { Shah, Zegveld, \& Roodhart, 2008; } \\
\text { Minshall, Mortara, Napp, \& Probert, 2010; } \\
\text { Mortara \& Minshall, 2011; Battistini, } \\
\text { Hacklin, \& Baschera, 2013; Mocker, Bielli, } \\
\text { \& Haley, 2015; Bannerjee, Bielli, \& Haley, } \\
\text { 2016; Kohler, 2016; Prats, Amigó, } \\
\text { Ametller, \& Batlle, 2017; De la Tour et al., } \\
\text { 2017; Thieme, 2017; WEF, } 2018\end{array}$} \\
\hline & $\begin{array}{l}\text { Definição da intenção estratégica com startups } \\
\text { no início do programa de colaboração. }\end{array}$ & \\
\hline & $\begin{array}{l}\text { Realização de reuniões de aproximação das } \\
\text { áreas de negócios para alinhar necessidades. }\end{array}$ & \\
\hline & $\begin{array}{l}\text { Alinhamento periódico dos objetivos com altos } \\
\text { executivos por meio de reuniões periódicas ou } \\
\text { de governança. }\end{array}$ & \\
\hline \multirow{5}{*}{ Equipe } & $\begin{array}{l}\text { Estabelecimento de equipe dedicada em tempo } \\
\text { integral desde o início das atividades. }\end{array}$ & \multirow{5}{*}{$\begin{array}{l}\text { Ahmed, 1998; Martins \& Terblanche, 2003; } \\
\text { Howell \& Boies, 2004; Dombrowski et al., } \\
\text { 2007; Freeman \& Engel, 2007; Minshall, } \\
\text { Mortara, Napp, \& Probert, 2010; Mortara \& } \\
\text { Minshall, 2011; Kuratko, Hornsby, \& } \\
\text { Covin, 2014; Mocker, Bielli, \& Haley, } \\
\text { 2015; Bannerjee, Bielli, \& Haley, 2016; } \\
\text { Kohler, 2016; Schättgen \& Mur, 2016; } \\
\text { Weiss \& Hoegl, 2016; Prats, Amigó, } \\
\text { Ametller, \& Batlle, } 2017\end{array}$} \\
\hline & $\begin{array}{l}\text { Definição de um 'Líder' com poder de decisão e } \\
\text { apoio dos altos executivos. }\end{array}$ & \\
\hline & $\begin{array}{l}\text { Disponibilização aos membros da equipe de } \\
\text { incentivos monetários e não monetários (por } \\
\text { exemplo: disponibilidade de tempo para } \\
\text { trabalhar com inovações) proporcionais ao } \\
\text { desafio. }\end{array}$ & \\
\hline & $\begin{array}{l}\text { Caso não seja possível dedicação, garantia de } \\
\text { disponibilidade de tempo fixo e proporcional à } \\
\text { equipe. }\end{array}$ & \\
\hline & $\begin{array}{l}\text { Manutenção da equipe enxuta, para melhoria da } \\
\text { comunicação e eficiência. }\end{array}$ & \\
\hline
\end{tabular}




\begin{tabular}{|c|c|c|}
\hline & $\begin{array}{l}\text { Melhores Práticas e Recomendações } \\
\text { (continuação) }\end{array}$ & Autores \\
\hline $\begin{array}{c}\text { Estrutura } \\
\text { Organizacional }\end{array}$ & 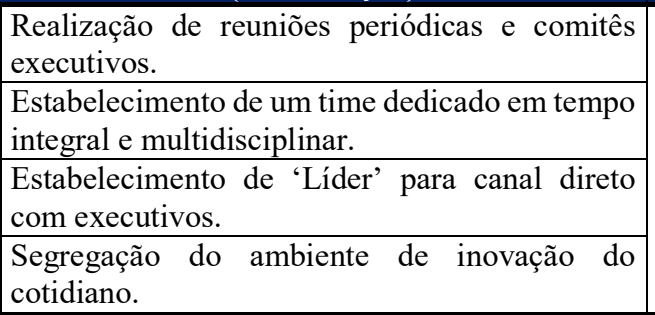 & $\begin{array}{c}\text { Mortara \& Minshall, 2011; } \\
\text { Bannerjee, Bielli, \& Haley, 2016; } \\
\text { Dombrowski et al., 2007; Thieme, } 2017\end{array}$ \\
\hline $\begin{array}{l}\text { Processos } \\
\text { Internos }\end{array}$ & \begin{tabular}{|l|}
$\begin{array}{l}\text { Realização de pilotos a curto prazo para provar } \\
\text { valor. }\end{array}$ \\
$\begin{array}{l}\text { Criação de processos específicos para startups - } \\
\text { fast-track. }\end{array}$ \\
Simplificação de processos atuais. \\
$\begin{array}{l}\text { Estabelecimento de processos e ferramentas } \\
\text { para avaliação de soluções de startups. }\end{array}$ \\
\end{tabular} & $\begin{array}{l}\text { Minshall, Mortara, Napp, \& Probert, 2010; } \\
\text { Mocker, Bielli, \& Haley, 2015; Bannerjee, } \\
\text { Bielli, \& Haley, 2016; Prats, Amigó, } \\
\text { Ametler, \& Batlle, 2017; De la Tour et al., } \\
\text { 2017; Mind the Bridge \& Nesta, } 2017\end{array}$ \\
\hline
\end{tabular}

Fonte: Elaborado pelo autor.

Os grupos referentes aos aspectos internos, incluindo a sintetização de suas barreiras, melhores práticas e recomendações, servirão de base estrutural para a análise, para a discussão dos resultados da pesquisa, bem como para o suporte para as recomendações à organização.

O presente capítulo buscou, de forma lógica, encadear os assuntos que apoiam a PesquisaAção, partindo dos domínios-base - Corporate Venturing, Corporate Entrepreneurship, Inovação, Inovação Aberta e Corporate-Startup Engagement - até chegar nos aspectos internos organizacionais e suas barreiras, habilitadores e melhores práticas. Esse encadeamento e suas referências estão dispostos na Figura 11, que sintetiza e finaliza o capítulo.

No capítulo a seguir, serão apresentados os procedimentos metodológicos utilizados na 'Pesquisa-Ação Central' e na 'Pesquisa-Ação Dissertação'. 
Figura 11 - Síntese dos assuntos e referenciais utilizados como fundamentos para o trabalho

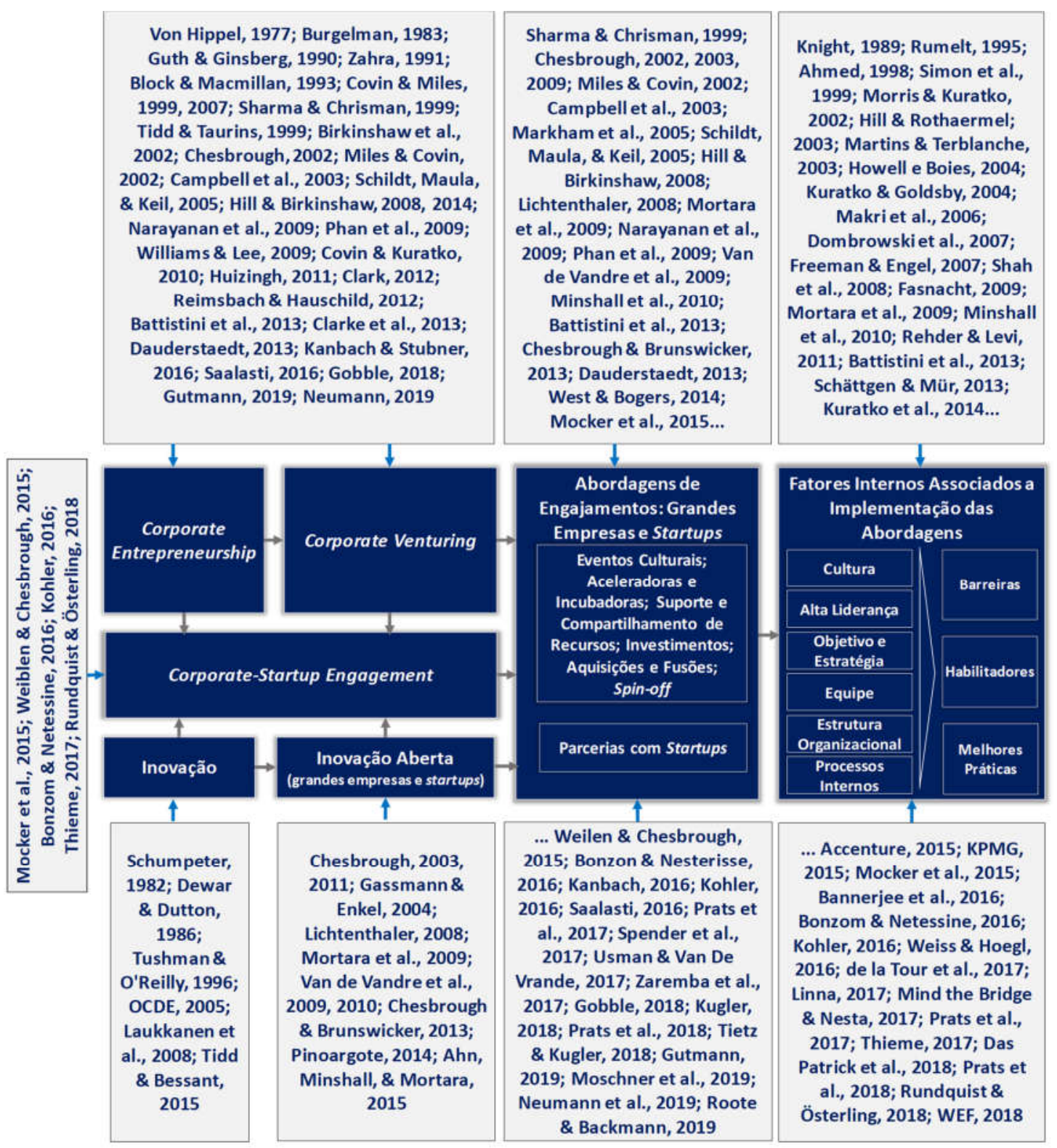

Fonte: Elaborado pelo autor. 


\section{PROCEDIMENTOS METODOLÓGICOS}

Neste capítulo, são apresentados os procedimentos metodológicos adotados na 'PesquisaAção Central' e na 'Pesquisa-Ação Dissertação'. Entende-se que esses procedimentos têm como objetivo garantir o rigor científico da pesquisa a fim de que seja possível replicá-la em futuras oportunidades.

Quanto aos objetivos, trata-se de uma pesquisa exploratória, pois visa a analisar temas ainda recentes, ao menos no Brasil, que envolvem a relação de uma grande empresa com startups.

A abordagem adotada é qualitativa, seguindo as propriedades das Ciências Sociais e Sociais Aplicadas, uma vez que possibilita compreender as razões e as motivações do problema que está sendo investigado (Bryman, 1989).

Segundo Gil (1991), as pesquisas, quando comparadas em função de seus procedimentos técnicos, podem ser classificadas em: bibliográfica, documental, experimental, levantamento de dados, estudo de campo, estudo de caso e Pesquisa-Ação. Devido à necessidade de identificar os problemas em um contexto real, com o objetivo de propor e discutir possíveis soluções, considerou-se cabível, para o presente estudo, a utilização da Pesquisa-Ação. Desta forma, o procedimento metodológico foi estruturado na escolha da abordagem, na estrutura da Pesquisa-Ação, no método para elaboração do roteiro de perguntas e nos aspectos éticos.

\subsection{ESCOLHA DO MÉTODO}

Um conjunto de características importantes difere a Pesquisa-Ação das pesquisas tradicionais. Lewin (1946), um dos precursores dessa metodologia, destaca dentre elas, a reeducação possível, a partir da mudança de pensamento dos indivíduos e dos grupos envolvidos. Essa mudança reflete em regras e valores do ambiente a serem modificados. 
Neste estudo, o foco da investigação é a empresa XYZ, que pretende executar ações que a aproximem de startups, visando à consolidação de 'parcerias no provisionamento de soluções aos problemas de negócios', conforme evidenciado no Capítulo 1 desta dissertação.

Segundo Coughlan e Coghlan (2002), uma particularidade da Pesquisa-Ação é a importância do grupo de intervenção como agente de mudanças. Coghlan e Brannick (2005) acrescentam que a reeducação depende efetivamente da participação e do engajamento das pessoas pertencentes à organização, tanto no que tange aos diagnósticos quanto às decisões tomadas pelos membros envolvidos com a mudança em questão.

Segundo Thiollent (2005), a Pesquisa-Ação é um tipo de pesquisa com base empírica, idealizada e concretizada em estreita associação com uma ação ou com a resolução de um problema coletivo, na qual pesquisadores e partícipes, que representam a situação ou o problema, agem de forma cooperativa ou participativa. Baldissera (2001) define a PesquisaAção como a aplicação de técnicas e ações para obter a ciência da realidade ou parte dela, com o objetivo de transformá-la pela ação de um grupo de pessoas.

Tripp (2005), por sua vez, entende a Pesquisa-Ação como um tipo de investigação-ação contínua, que usa técnicas largamente conhecidas para melhorar a prática. Segundo ele, a Pesquisa-Ação é um aprimoramento da prática fundamentada por meio de experiências ininterruptas e organizadas. "É toda tentativa continuada, sistemática e empiricamente fundamentada de aprimorar a prática” (Tripp, 2005, p. 443).

A Pesquisa-Ação visa, portanto, a mudanças na organização e no desenvolvimento dos membros participantes, além de agregar valor ao conhecimento científico (Coghlan \& Brannick, 2005). Nesse sentido, Coghlan e Brannick (2005) e Coughlan e Coghlan (2002) reforçam que a Pesquisa-Ação é focada na 'pesquisa em ação' e deve ser realizada em colaboração, em paralelo à ação e em ciclos de interação, tendo em vista a resolução de problemas e a geração de novos conhecimentos. Esses autores defendem que a PesquisaAção, como abordagem científica, estuda a resolução de problemas sociais ou 
organizacionais relevantes, juntamente com aqueles que vivenciam tais problemas, ou seja, de forma participativa.

Nesse sentido, é preciso também discorrer sobre a ética na Pesquisa-Ação, pois implica em construir uma pesquisa participativa com indivíduos designados pela organização ou mesmo com voluntários. Supõe-se, então, que todos tenham consciência de que há uma pesquisa sendo realizada, o que Coghlan e Brannick (2005, p. 48) nomeiam investigação “consciente”.

De acordo com Coghlan e Brannick (2005), é menos comum que a apresentação da PesquisaAção seja conduzida por membros da organização. Dependendo da função que o pesquisador exerça na organização, pode haver conflitos na condução das atividades, considerando-se que o mesmo pode ser, inclusive, o gestor funcional do grupo da intervenção. Nessas situações, o pesquisador assume o papel de participante ativo, além de membro regular ou pesquisador explícito.

O conflito, no caso do presente estudo, foi amenizado, pois o pesquisador não tinha influência hierárquica sobre os grupos de colaboradores participantes, por exercer função de Arquiteto de Negócios na organização XYZ e por atuar em projetos estratégicos de base tecnológica. Essencialmente, ele atua como consultor interno, o que Coghlan e Brannick (2005) afirmam ser o papel mais recomendável para a condução de uma Pesquisa-Ação.

Cabe destacar, no entanto, que o pesquisador assumiu papéis específicos durante a intervenção, que se alteravam na medida em que os ciclos iam sendo desenvolvidos. Durante os Ciclos 1 e 2, o pesquisador atuou como consultor. A partir do Ciclo 3, passou a atuar como 'Líder do time' (Team Leader). Apesar do título 'líder', exercia, na realidade, o papel de organizador das atividades do grupo. Além desses papéis, o pesquisador executou diversas ações de intervenção, acumulando também a função de membro do time, conforme descrito e sintetizado no Quadro 7. As atribuições do pesquisador nos papéis desempenhados foram: 
- Membro: responsável pelas atividades relacionadas com o domínio da sua área/Departamento de Arquitetura de Negócios nos ciclos, por exemplo, criação dos pilares e critérios de avaliação de startups;

- 'Líder do time' (Team Leader): administrador dos processos para o cumprimento dos objetivos de cada ciclo e dos prazos de execução de cada atividade acordada pelo grupo da intervenção. Responsável pela organização de reuniões de trabalho e pela ajuda aos demais participantes na resolução de problemas;

- Consultor: responsável pelo acompanhamento e pelas recomendações aos participantes dos grupos quanto aos direcionamentos do ciclo em andamento, sempre embasado em estudos teóricos e práticos.

Quadro 7 - Papéis Assumidos pelo Pesquisador

\begin{tabular}{|c|c|c|c|}
\hline & $\begin{array}{c}\text { Ciclo 1 - } \\
\text { Exploratório }\end{array}$ & $\begin{array}{c}\text { Ciclo 2 - Capacitação } \\
\text { Interna, Aculturamento e } \\
\text { Ferramental }\end{array}$ & $\begin{array}{c}\text { Ciclo 3 - Expansão do } \\
\text { Aculturamento e } \\
\text { Experimentação do } \\
\text { Ferramental }\end{array}$ \\
\hline $\begin{array}{c}\text { Objetivos do } \\
\text { Ciclo }\end{array}$ & $\begin{array}{c}\text { Diagnosticar os } \\
\text { problemas que } \\
\text { dificultam a empresa } \\
\text { para fazer negócios } \\
\text { com startups e propor } \\
\text { ações de melhoria. }\end{array}$ & $\begin{array}{c}\text { Melhorar o relacionamento da empresa XYZ com startups, } \\
\text { considerando-as como provedoras de solução para os } \\
\text { problemas de negócios. }\end{array}$ \\
\hline Período & $\begin{array}{c}\text { Dezembro de 2017 a } \\
\text { março de 2018 }\end{array}$ & $\begin{array}{c}\text { Abril de 2017 a } \\
\text { setembro de 2017 }\end{array}$ & $\begin{array}{c}\text { Outubro de 2017 a } \\
\text { novembro de 2017 }\end{array}$ \\
\hline Papel do & Membro e Consultor & Membro e Consultor & Membro e Líder do Time \\
Pesquisador & Team Leader) \\
\hline
\end{tabular}

Fonte: Elaborado pelo autor.

\subsection{ESTRUTURA DA PESQUISA-AÇÃO}

Apesar de não existir uma estrutura única para execução da Pesquisa-Ação, é possível encontrar similaridades nas estruturas estabelecidas por alguns autores. Ander-Egg (1990) propõe que a Pesquisa-Ação se aplique independentemente do campo de atuação, sendo, portanto, abrangente, focada na operacionalização do projeto e na estruturação da equipe que 
efetuará a pesquisa. Segundo ele, deve contemplar as seguintes etapas: definição de questões prévias; investigação; preparação do diagnóstico; preparação de um programa ou projeto; implementação de projetos e/ou programas; e controle operacional.

Coughlan e Coghlan (2002) propõem uma estrutura de Pesquisa-Ação aplicada ao gerenciamento de operações, contendo um passo inicial de compreensão do contexto e do propósito da mesma e outros seis passos cíclicos principais: coleta de dados; feedback dos dados; análise dos dados; planejamento da ação; implementação e avaliação - além da etapa de monitoramento que abrange toda a Pesquisa-Ação, chamada 'meta-passo: monitoramento'.

Coghlan e Brannick (2005) abordam a Pesquisa-Ação em organizações e propõem diretrizes partindo da perspectiva de que o pesquisador é membro permanente da organização. Eles defendem a estrutura da Pesquisa-Ação como um passo inicial de identificação do 'contexto e propósito da ação' e outros quatros passos cíclicos: diagnóstico; planejamento de ações; ações na prática; e avaliação do processo realizado. Além disso, Coghlan e Brannick (2005) incluem em sua estrutura, em paralelo ao processo da Pesquisa-Ação, a fase denominada 'Meta-Ciclo de Investigação' sobre todas as etapas.

Tripp (2005) propõe que a Pesquisa-Ação utilize quatro etapas. São elas: introdução; reconhecimento; ciclo (planejamento, implementação e geração de relatório) e conclusão. O foco da aplicação de Tripp (2005) é educacional e enfatiza a continuidade cíclica que a Pesquisa-Ação pode ter. Mello, Turrioni, Xavier e Campos (2012) propõem uma estrutura de Pesquisa-Ação contendo seis passos principais. São eles: planejamento da Pesquisa-Ação; coleta de dados; análise dos dados e planejamento das ações; implementação do plano de ação; avaliação dos resultados e geração de relatórios; e estabelecimento do ciclo de melhoria e aprendizagem. A estrutura proposta foi orientada para o âmbito da Engenharia de Produção.

Observa-se, nas abordagens de Pesquisa-Ação apresentadas, algumas variações na quantidade de fases/etapas (Quadro 8), no detalhamento das estruturas metodológicas, nas interpretações sobre os ciclos e nos campos de atuação. Foi possível identificar um padrão, 
que é a compreensão do lócus da pesquisa, do diagnóstico do problema, do planejamento das ações, da implementação das ações e da avaliação das ações executadas, e da reflexãoaprendizado sobre todo o processo.

Quadro 8 - Estruturas da Pesquisa-Ação

\begin{tabular}{|c|c|c|c|c|c|c|}
\hline \multirow[b]{2}{*}{ Autores } & \multicolumn{6}{|c|}{ Etapas da Pesquisa-Ação } \\
\hline & $\begin{array}{c}\text { Compreensão } \\
\text { do Contexto } \\
\text { (Lócus) }\end{array}$ & $\begin{array}{c}\text { Diagnóstico do } \\
\text { problema }\end{array}$ & $\begin{array}{c}\text { Planejamento } \\
\text { das ações }\end{array}$ & $\begin{array}{c}\text { Implementação } \\
\text { das ações }\end{array}$ & $\begin{array}{c}\text { Avaliação das } \\
\text { ações } \\
\text { executadas }\end{array}$ & \begin{tabular}{|c|} 
Reflexão- \\
aprendizado \\
sobre todo o \\
processo
\end{tabular} \\
\hline $\begin{array}{l}\text { Ander- } \\
\text { Egg } \\
(1990)\end{array}$ & $\begin{array}{l}\text { Questões } \\
\text { prévias }\end{array}$ & $\begin{array}{c}\text { A própria } \\
\text { investigação } \\
\text { Preparação do } \\
\text { diagnóstico }\end{array}$ & $\begin{array}{c}\text { Preparação de } \\
\text { um programa } \\
\text { ou projeto }\end{array}$ & $\begin{array}{l}\text { Implementação } \\
\text { de projetos e / } \\
\text { ou programas }\end{array}$ & $\begin{array}{l}\text { Controle } \\
\text { operacional }\end{array}$ & $\begin{array}{l}\text { Controle } \\
\text { operacional }\end{array}$ \\
\hline$\left|\begin{array}{c}\text { Coughlan } \\
\text { e Coghlan } \\
(2002)\end{array}\right|$ & $\begin{array}{l}\text { Pré-passo: } \\
\text { compreensão } \\
\text { do contexto e } \\
\text { do propósito }\end{array}$ & $\begin{array}{c}\text { Coleta de } \\
\text { dados } \\
\begin{array}{c}\text { Feedback de } \\
\text { dados }\end{array} \\
\begin{array}{c}\text { Análise de } \\
\text { dados }\end{array} \\
\end{array}$ & $\begin{array}{l}\text { Plano } \\
\text { de ação }\end{array}$ & Implementação & Avaliação & $\begin{array}{l}\text { Meta-passo: } \\
\text { monitora- } \\
\text { mento }\end{array}$ \\
\hline \begin{tabular}{|c|} 
Coghlan e \\
Brannick \\
$(2005)$
\end{tabular} & $\begin{array}{l}\text { Contexto / } \\
\text { Propósito }\end{array}$ & $\begin{array}{l}\text { Diagnóstico } \\
\text { (cíclico) }\end{array}$ & $\begin{array}{c}\text { Planejamento } \\
\text { de ações } \\
\text { (cíclico) }\end{array}$ & $\begin{array}{l}\text { Atuação } \\
\text { (cíclica) }\end{array}$ & $\begin{array}{l}\text { Avaliação da } \\
\text { ação (cíclica) }\end{array}$ & $\begin{array}{l}\text { Meta-ciclo da } \\
\text { investigação }\end{array}$ \\
\hline $\begin{array}{l}\text { Tripp } \\
(2005)\end{array}$ & Introdução & $\begin{array}{l}\text { Reconhe- } \\
\text { cimento }\end{array}$ & $\begin{array}{l}\text { Planejamento } \\
\text { (ć́clico) }\end{array}$ & $\begin{array}{l}\text { Implementação } \\
\text { (cíclica) }\end{array}$ & $\begin{array}{c}\text { Relatório de } \\
\text { pesquisa } \\
\text { sobre os } \\
\text { resultados da } \\
\text { melhoria } \\
\text { planejada } \\
\text { Conclusão }\end{array}$ & Conclusão \\
\hline \begin{tabular}{|c|} 
Mello, \\
Turrioni, \\
Xavier e \\
Campos \\
$(2012)$ \\
\end{tabular} & $\begin{array}{l}\text { Plane- } \\
\text { jamento da } \\
\text { Pesquisa- } \\
\text { Ação }\end{array}$ & $\begin{array}{l}\text { Coleta de } \\
\text { dados }\end{array}$ & $\begin{array}{l}\text { Análise dos } \\
\text { dados e } \\
\text { planejamento } \\
\text { das ações }\end{array}$ & $\begin{array}{l}\text { Implementação } \\
\text { do plano de } \\
\text { ação }\end{array}$ & $\begin{array}{l}\text { Avaliação dos } \\
\text { resultados e } \\
\text { geração do } \\
\text { relatório }\end{array}$ & $\begin{array}{c}\text { Ciclo de } \\
\text { melhoria e } \\
\text { aprendizagem }\end{array}$ \\
\hline
\end{tabular}

Fonte: Elaborado pelo autor.

Com base no contexto da intervenção desta dissertação, decidiu-se selecionar uma abordagem da Pesquisa-Ação com as seguintes características:

- Ter orientação para o ambiente organizacional;

- Considerar o pesquisador como observador participante, haja vista o fato de ele atuar na organização e de estar diretamente envolvido no processo da intervenção; 
- Prever arcabouço tanto para a 'Pesquisa-Ação Central' (que atenda ao contexto real), quanto para a 'Pesquisa-Ação Dissertação' (com subsídios para esta dissertação); e

- Apresentar os métodos de 'reflexão-aprendizado'.

Optou-se, assim, por utilizar a abordagem de Coghlan e Brannick (2005) como linha metodológica principal, por atender às características supra descritas, além de apresentar detalhadamente uma estrutura de dissertação baseada em Pesquisa-Ação, tendo por princípio os ciclos de ação.

Figura 12 - Etapas do ciclo principal da Pesquisa-Ação

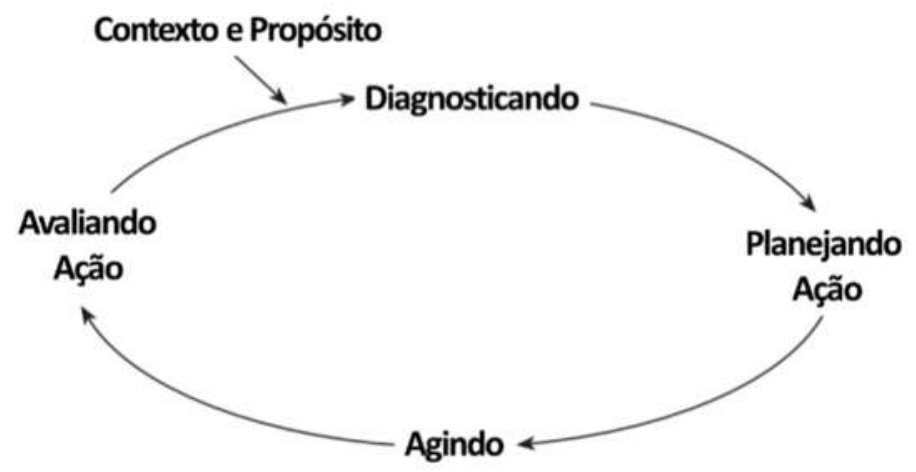

Fonte: Adaptado de Coghlan e Brannick (2005).

Coughlan e Coghlan (2002) e Coghlan e Brannick (2005) defendem que, além de cíclica, a abordagem da Pesquisa-Ação também deve ser espiral, ou seja, as etapas finais de cada ciclo podem dar início a outro e assim sucessivamente, conforme Figura 13. 
Figura 13 - Espirais dos Ciclos de Pesquisa-Ação

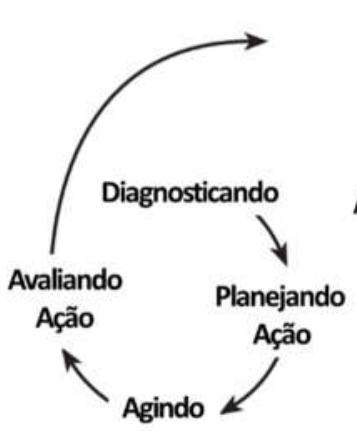

Cido 1

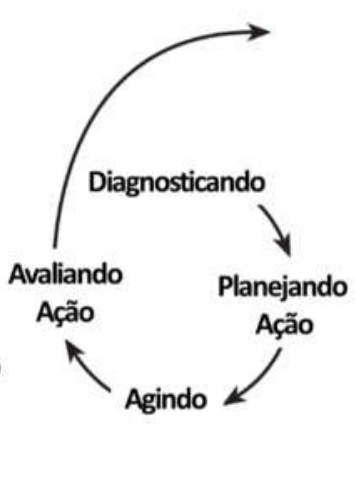

Ciclo 2

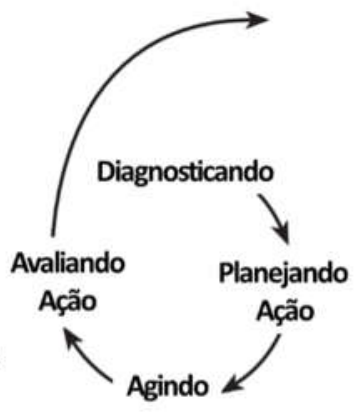

Cido3

Fonte: Adaptado de Coghlan e Brannick (2005).

Mesmo seguindo as orientações de Coghlan e Brannick (2005), ao longo da intervenção também foram utilizadas algumas fases citadas por outros autores como Mello, Turrioni, Xavier e Campos (2012) e Coughlan e Coghlan (2002), que complementam a abordagem, com procedimentos metodológicos e proposições de aplicação.

\subsection{USO DA FUNDAMENTAÇÃO TEÓRICA NA PESQUISA-AÇÃO}

A teoria é aplicada tanto na intervenção quanto na investigação do processo da PesquisaAção. Tripp (2005) afirma que é importante recorrer à teoria tradicional para compreender o contexto, planejar e explicar os resultados, embora ela não seja prioridade principal na Pesquisa-Ação. Coghlan e Brannick (2005) corroboram com a ideia de que um projeto de Pesquisa-Ação necessita adotar teorias estabelecidas ou estender a teoria.

Na fase de intervenção, a teoria é essencial para a construção do contexto e do propósito da Pesquisa-Ação, bem como para servir de insumo para efetuar os diagnósticos de problemas para proposição das ações em cada um dos ciclos (Mello, Turrioni, Xavier, \& Campos, 2012; Coughlan \& Coghlan, 2002). 
Durante a evolução da Pesquisa-Ação, pode haver revisão de teorias para atender às novas necessidades que eventualmente surjam. Segundo Coghlan e Brannick (2005), a teoria precisa ser revisitada durante o meta-ciclo, quando ocorrem reflexões e construção da narrativa da Pesquisa-Ação. Isso se deve aos descobrimentos de novos fatos sobre a pesquisa.

Uma característica que surge ao longo dos ciclos da Pesquisa-Ação é a existência de um processo de maturidade quanto aos objetivos e às teorias, partindo da difusão para a clareza (Gummesson, 2000). Na presente pesquisa, também houve um refinamento da teoria, na medida em que a 'Pesquisa-Ação Central' e a 'Pesquisa-Ação Dissertação' foram "evoluindo", conforme apresentado na Figura 14, a seguir.

Figura 14 - "Evolução" das teorias envolvidas na presente dissertação

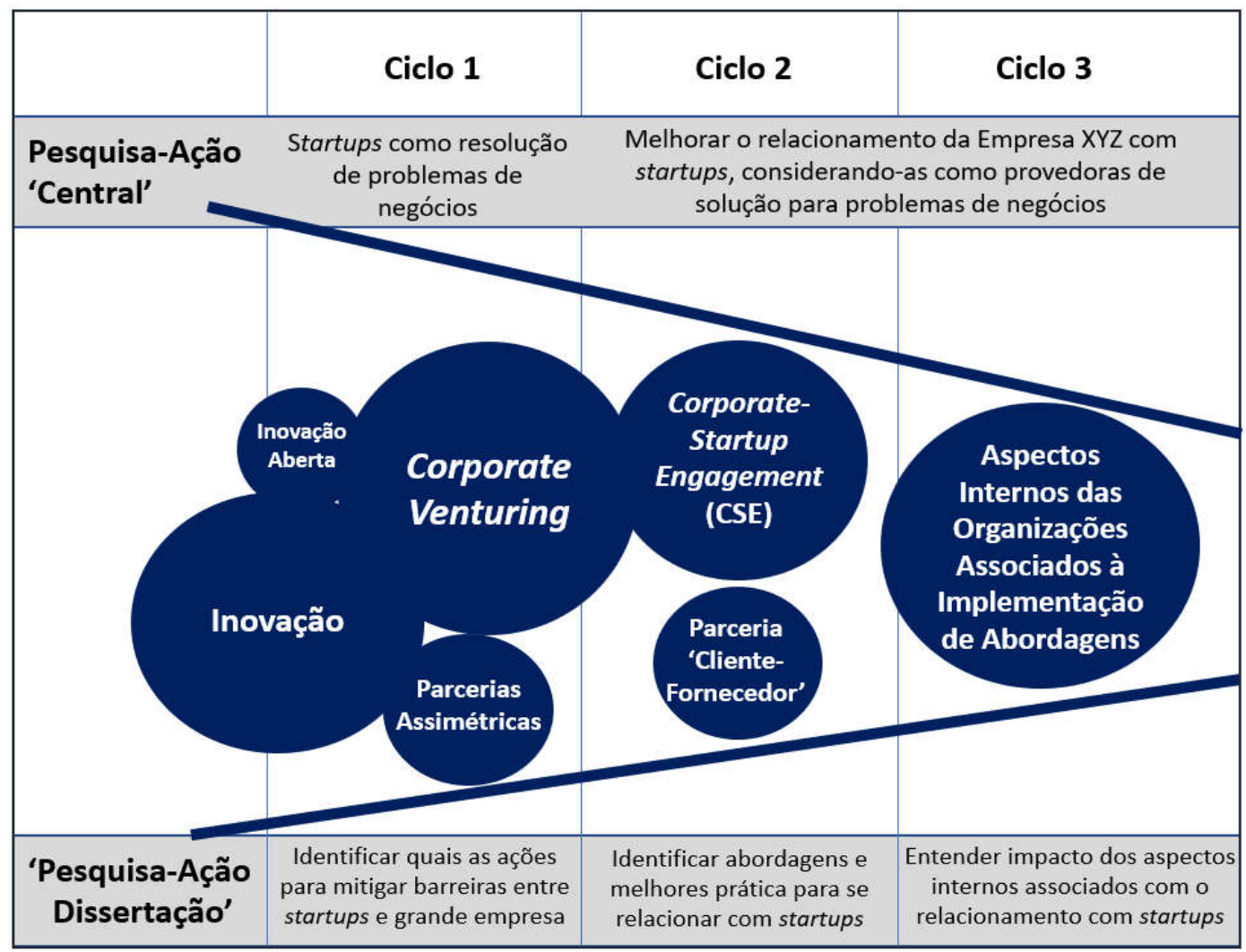

Fonte: Elaborada pelo autor. 
Coghlan e Brannick (2005, p. 126) denominam "literatura iniciada" aquela utilizada para fundamentar o contexto e a proposição da pesquisa para a organização. Na presente pesquisa, foram utilizadas como literatura inicial as teorias de Corporate Venturing, alguns aspectos de Inovação e de Inovação Aberta, além de parcerias assimétricas.

No decorrer dos ciclos, foram sendo incorporadas outras teorias para fundamentar novos acontecimentos, o que Coghlan e Brannick (2005, p. 130) consideram "literatura emergente". Assim, a presente pesquisa teve como literaturas emergentes as teorias de Corporate-Startup Engagement, as parcerias 'cliente-fornecedor' e os aspectos internos organizacionais, associados ao relacionamento de grandes empresas com startups. Essas teorias foram necessárias na medida em que os objetivos da intervenção foram sendo melhor definidos e novos problemas e/ou reflexões foram surgindo.

\subsection{DINÂMICAS DA PESQUISA-AÇÃO: 'CENTRAL' E 'DISSERTAÇÃO'}

Perry e Zuber-Skerritt (1992) explicitam que em uma Pesquisa-Ação há dois projetos acontecendo simultaneamente: um deles é a 'Pesquisa-Ação Central', focada na intervenção da organização na qual ocorrem os ciclos de ações; e o outro é a 'Pesquisa-Ação Dissertação', que visa a acompanhar e a avaliar todo o processo de intervenção, conforme Figura 15. Este último é o objetivo do presente estudo.

Coghlan e Brannick (2005) entendem que a 'Pesquisa-Ação Dissertação' é fruto da etapa de meta-ciclo. Pode-se, assim, afirmar que todo o projeto é um grande ciclo (meta-ciclo), desenvolvido a partir de ciclos centrais, conforme a estrutura do presente trabalho representada na Figura 16. 
Figura 15 - Relacionamento entre 'Pesquisa-Ação Central' e 'Pesquisa-Ação Dissertação'

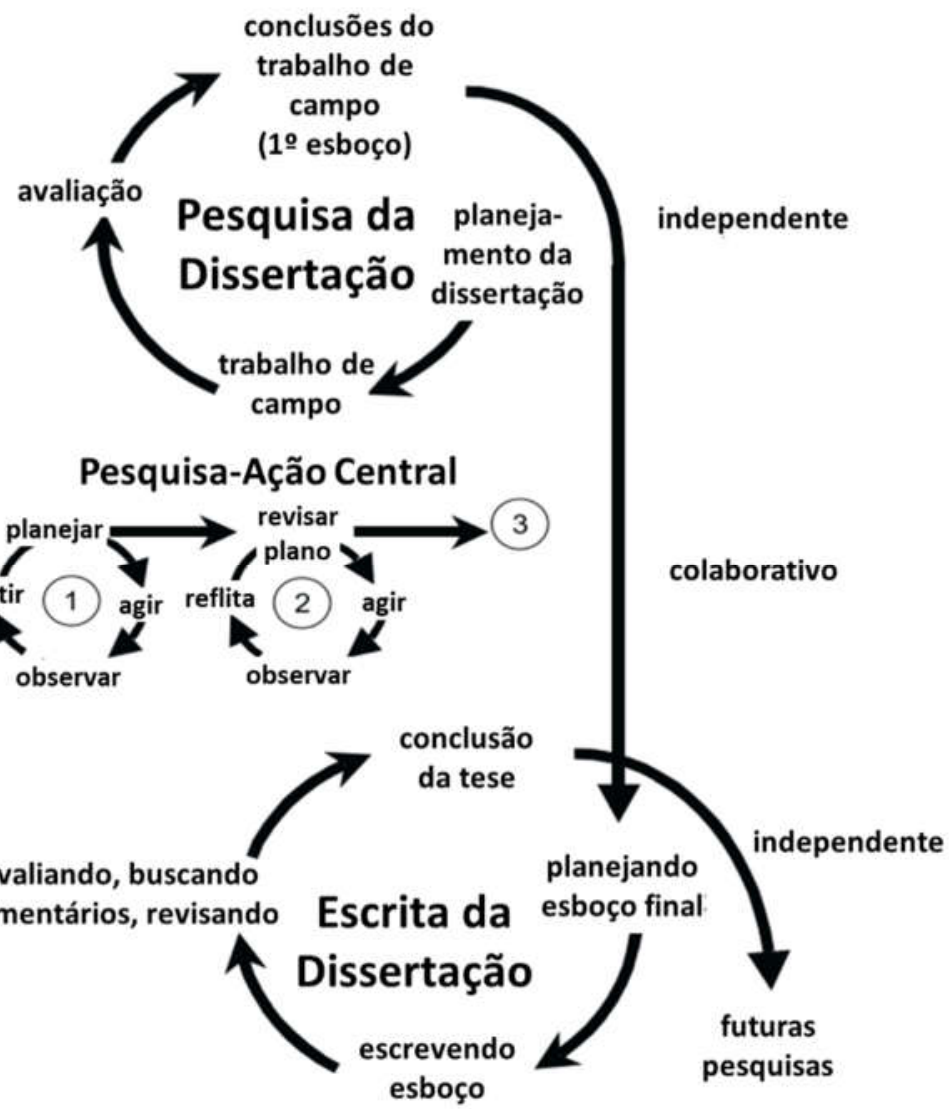

Fonte: Adaptada de Perry e Zuber-Skerritt (1992).

Figura 16 - Dinâmica entre os componentes da presente dissertação
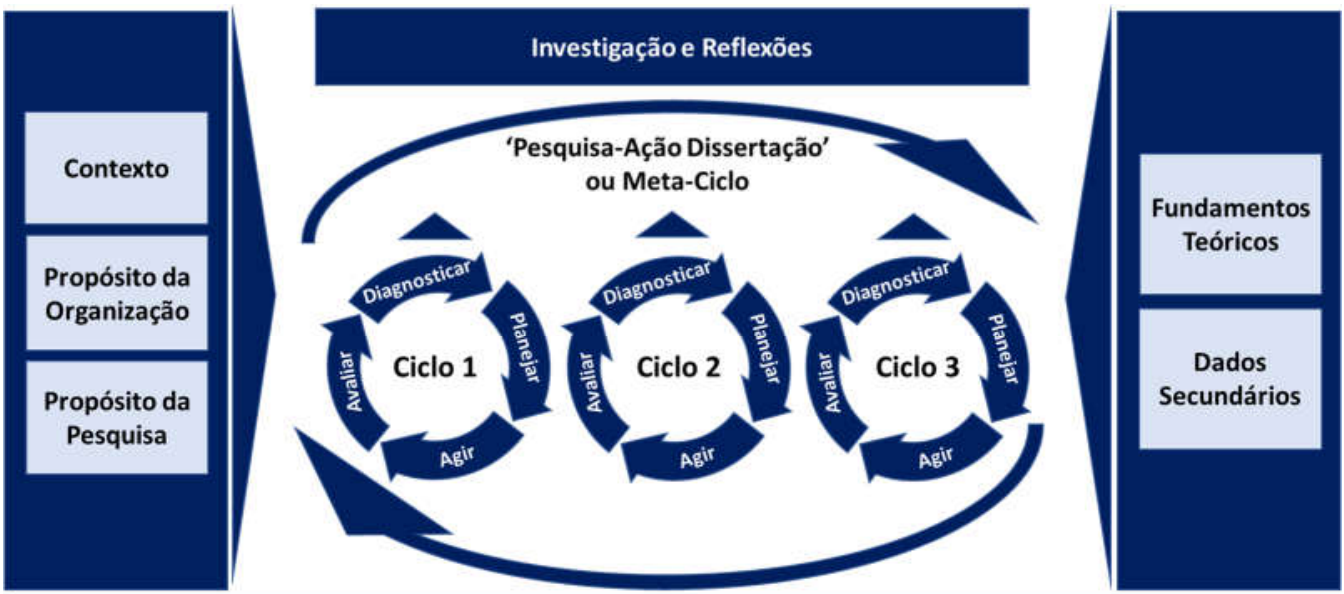

Procedimentos Metodológicos

Fonte: Elaborada pelo autor, com base em Coghlan e Brannick (2005). 
O meta-ciclo é a essência da dissertação e permeia toda a Pesquisa-Ação. Seu propósito é científico e visa a atender ao problema e aos objetivos de pesquisa, diferentemente dos ciclos de ação, orientados aos propósitos da organização (problemas e objetivos da organização).

Durante a Pesquisa-Ação deve haver sincronismo entre todas as atividades. Em cada um dos passos dos ciclos de ações está a reflexão. Os dados, análises e fundamentos - teóricos e práticos - utilizados nos ciclos de ações alimentam o meta-ciclo. Em contrapartida, toda a investigação e toda a análise do meta-ciclo retroalimentam a própria intervenção.

\subsection{ETAPAS E FASES DOS CICLOS DA 'PESQUISA-AÇÃO CENTRAL'}

Neste subitem apresentamos a forma como cada etapa do ciclo foi estruturada para a intervenção. É importante ressaltar que as etapas dos ciclos de ações diferem-se do procedimento metodológico utilizado para a 'Pesquisa-Ação Dissertação', a qual possui outra estrutura, conforme será apresentado a seguir, no subitem 3.6.

Para realizar a 'Pesquisa-Ação Central', o pesquisador juntamente com os grupos de colaboradores da empresa XYZ envolvidos no processo de intervenção buscaram cumprir as etapas sugeridas por Coghlan e Brannick (2005) quanto aos ciclos de ações: contexto/ propósito, diagnóstico, planejamento das ações, ação e avaliação.

Cabe destacar que a intervenção se realizou por meio de dois grupos de trabalho multidisciplinares, tendo este pesquisador participado de ambos. O Grupo 1 concentrou-se nas atividades do Ciclo 1, de caráter exploratório; enquanto o Grupo 2 atuou nos Ciclos 2 e 3, que exigiam características específicas, como fomento à mudança cultural e ferramentas para análise de startups.

Para o Grupo 1, foram designadas 13 (treze) pessoas das áreas de Arquiteturas de TI, Compras e Coworking, além deste pesquisador. Esse grupo teve como foco a identificação 
das barreiras que dificultam a relação da empresa com startups, a priorização dos temas e as primeiras ações efetuadas. Uma vez executado o Ciclo 1, foi realizada uma discussão com os executivos envolvidos, para a revisão dos objetivos. Esta discussão levou à delimitação do escopo do próximo ciclo da intervenção, direcionado para a área de tecnologia da organização. A partir de então, os times de Compras e de Coworking deixaram de atuar diretamente na pesquisa.

Para o início do Ciclo 2, foi constituído o Grupo 2, composto por 11 (onze) membros da Diretoria de Arquitetura de Tecnologia - Arquitetos de Negócios, de Solução, de Tecnologia e de Processos -, responsáveis pelos processos de avaliação das startups, integração com sistemas da organização e evolução tecnológica. A unidade definida como escopo da Pesquisa-Ação, portanto, foi a Diretoria de Arquitetura de TI, apresentada em detalhes no item referente ao lócus da pesquisa (Capítulo 4).

Na Tabela 1 e no Quadro 9, a seguir, apresentam-se a quantidade e as áreas dos integrantes dos grupos responsáveis pela intervenção em cada um dos ciclos, assim como as responsabilidades das áreas envolvidas em todo o processo, respectivamente.

Tabela 1 - Quantidade e área dos integrantes dos grupos responsáveis pela intervenção

\begin{tabular}{c|c|c|c}
\hline \multirow{2}{*}{ Áreas } & \multicolumn{3}{|c}{ Quantidade de Integrantes } \\
\cline { 2 - 4 } & Grupo 1 & Grupo 2 & $\begin{array}{c}\text { Integrantes do Grupo 1 que } \\
\text { também compuseram o Grupo 2 }\end{array}$ \\
\hline Arquitetura de Negócios & 2 & 4 & 2 \\
\hline Arquitetura de Solução & 2 & 2 & - \\
\hline Arquitetura de Tecnologia & 4 & 3 & - \\
\hline Arquitetura de Processos & 2 & 2 & - \\
\hline Compras & 1 & - & - \\
\hline Coworking & 3 & - & 2 \\
\hline Total de participantes & 14 & 11 & - \\
\hline
\end{tabular}


Quadro 9 - Responsabilidades dos integrantes dos grupos envolvidos na intervenção, por área

\begin{tabular}{|c|c|}
\hline Área & Responsabilidades dos integrantes \\
\hline $\begin{array}{c}\text { Arquitetura de } \\
\text { Negócios }\end{array}$ & $\begin{array}{c}\text { Responsáveis pela estratégia tecnológica e pela interface entre as áreas de negócios e } \\
\text { as de tecnologia. Efetuam a sondagem de startups e identificam necessidades das } \\
\text { áreas de negócios às quais as startups possam atender. Garantem que as parcerias não } \\
\text { fiquem apenas no campo das ideias, mas que de fato sejam formalizadas. }\end{array}$ \\
\hline $\begin{array}{c}\text { Arquitetura de } \\
\text { Solução }\end{array}$ & $\begin{array}{c}\text { Responsáveis pela avaliação da melhor forma de integrar a solução das startups com } \\
\text { o legado sistêmico da empresa. }\end{array}$ \\
\hline $\begin{array}{c}\text { Arquitetura de } \\
\text { Tecnologia }\end{array}$ & $\begin{array}{c}\text { Responsáveis pela avaliação técnica para definir se determinado produto ou serviço } \\
\text { de uma startup atende aos requisitos esperados pela organização. }\end{array}$ \\
\hline $\begin{array}{c}\text { Arquitetura de } \\
\text { Processos }\end{array}$ & $\begin{array}{c}\text { Responsáveis pela criação e gestão dos processos que envolvem tecnologia da } \\
\text { informação. }\end{array}$ \\
\hline Compras & $\begin{array}{c}\text { Responsáveis pela criação e gestão dos processos que envolvem aquisição de } \\
\text { produtos ou contratação de serviços provenientes de startups. }\end{array}$ \\
\hline Coworking & $\begin{array}{c}\text { Responsáveis pelo suporte operacional ao coworking. Uma das principais atividades } \\
\text { é prover a interação entre a empresa, o coworking e as startups. }\end{array}$ \\
\hline
\end{tabular}

Fonte: Elaborado pelo autor.

\subsubsection{Etapa 1 - Contexto / Propósito}

O 'contexto / propósito' é o primeiro passo do processo de intervenção que, segundo Coghlan e Brannick (2005), busca apresentar a relevância de execução da Pesquisa-Ação. A seleção do propósito está associada a alguma expectativa da organização. Nesta etapa da 'PesquisaAção Central' duas questões devem ser ponderadas ${ }^{4}$ :

- Por que este projeto é necessário / desejável?

- Qual é a razão para a realização desta pesquisa?

\subsubsection{Etapa 2 - Diagnóstico}

A segunda etapa, de acordo com Coghlan e Brannick (2005), prevê o diagnóstico, identificando quais questões devem serem resolvidas e qual tema de trabalho deve ser

\footnotetext{
${ }^{4}$ Neste estudo, essas questões estão respondidas parcialmente no Capítulo 1 (Introdução) e no Capítulo 4 (Relato da 'Pesquisa-Ação Central').
} 
utilizado como base para o planejamento e execução das ações. Envolve, ainda, a coleta e a geração de dados e a fundamentação teórica para dar suporte às ações. Os diagnósticos ocorrem a cada ciclo e, portanto, os temas de atuação podem eventualmente ser alterados, de acordo com os resultados obtidos nos ciclos anteriores. Outro aspecto considerado crítico na etapa de diagnóstico é a colaboração dos membros da intervenção, principalmente durante a análise dos dados.

Coughlan e Coghlan (2002) dividem a etapa de diagnóstico em três subetapas: a coleta, o feedback e a análise dos dados. No entanto, esses procedimentos ocorrem durante todo o processo da intervenção.

É importante ressaltar que, embora os insumos gerados durante o diagnóstico possam servir para a 'Pesquisa-Ação Central', também o podem para a 'Pesquisa-Ação Dissertação'. Esta última, por sua vez, possui processos de coleta de dados, análises e discussões próprias, condizendo com uma pesquisa científica e não diretamente com a intervenção, conforme será apresentado nos subitens de 3.5 a 3.9 .

A coleta dos dados na etapa de diagnóstico pode ser feita de diferentes formas, dependendo do contexto. No caso da 'Pesquisa-Ação Central', que serviu de base para essa dissertação, os dados foram coletados a partir de workshops, entrevistas com organizações externas, levantamentos documentais, reuniões e seminários. Para realizar a intervenção, os tipos de instrumentos de coleta e de geração de dados variaram em função dos objetivos de cada um dos ciclos, a saber:

- Workshops - dinâmicas de workshops foram importantes geradoras de dados para o diagnóstico dos problemas, pois aconteceram com a participação democrática dos membros do grupo. As dinâmicas de grupo envolveram dialogar, compartilhar as informações em artigos e relatórios, além de catalogar em pequenas notas adesivas as barreiras e primeiras ações para que a empresa começasse a repensar o processo de relacionamento com startups. Os workshops também serviram como evento para analisar os dados de forma colaborativa; 
- Entrevistas Abertas com Organizações Externas - durante o Ciclo 2, foram efetuadas 12 (doze) entrevistas com grandes empresas, startups e instituições fomentadoras do ecossistema de startups. Para realizá-las, o grupo baseou-se no referencial teórico cabível naquele momento e nas necessidades observadas em relação às startups. É importante ressaltar que essas entrevistas não são as mesmas utilizadas para a investigação científica da 'Pesquisa-Ação Dissertação', apresentadas no subitem 3.7, realizadas com membros da intervenção, com objetivo de resolver o problema da pesquisa em si;

- Documentos - foram coletados na organização ou gerados pelo grupo da intervenção durante os ciclos. Os coletados na empresa incluem casos de startups e relatórios de portfólio de projetos. Os gerados pelo grupo consistem em planilhas de atividades, relatórios e artefatos de entregas das ações;

- Reuniões - parte importante dos dados de pesquisa foram coletados em reuniões formais para acompanhamento e discussão das atividades;

- Seminários - ao longo do Ciclo 2, foram realizados seminários com apresentação de artigos científicos e relatórios de consultorias associados ao tema 'relacionamento entre startups e grandes empresas'. Ao todo, foram realizados três seminários, cada qual com aproximadamente 90 minutos de duração.

Mello, Turrioni, Xavier e Campos (2012) e Coghlan e Brannick (2005) ressaltam que a análise dos dados da etapa de diagnóstico deve ser feita com a participação dos membros dos grupos. Na presente pesquisa, além de analisar, eles também foram os responsáveis pela estruturação dos dados coletados para análise durante a intervenção.

Segundo Tripp (2005), durante a intervenção de uma Pesquisa-Ação, o mais importante é obter dados e analisá-los à medida que forem sendo encontrados, do que aguardar a integralidade de informações baseadas em um protocolo de pesquisa determinado previamente. Segundo Tripp (2005, p. 448), na Pesquisa-Ação busca-se "fazer julgamentos baseados na melhor evidência que se possa produzir". 
Nesse sentido, para as ações da presente Pesquisa-Ação, foram utilizados ferramentas e procedimentos de análise adequados às dinâmicas da empresa, mantendo a essência participativa, conforme recomendam Coghlan e Brannick (2005) e Mello, Turrioni, Xavier e Campos (2012). As ferramentas e procedimentos variaram de acordo com as análises necessárias em cada um dos ciclos e, para manter o sigilo da empresa, elas não estão apresentadas integralmente nesta dissertação.

Os dados coletados nos workshops, no primeiro ciclo, foram discutidos e categorizados por temas, utilizando a análise de conteúdo manualmente, sem uso de ferramenta computacional. Todos os dados obtidos foram sistematizados por meio de notas adesivas (post-its) e, posteriormente, foram apresentados em discussões realizadas com o grupo, utilizando o Diagrama de Ishikawa.

No segundo ciclo, as análises partiram das transcrições das entrevistas com organizações externas, revisadas pelos membros dos grupos. Posteriormente, essas entrevistas também passaram por análise de conteúdo, sendo extraídas as boas práticas. A seguir, foram analisadas as anotações obtidas nos seminários, a fim de extrair melhores práticas dos artigos teóricos e relatórios práticos apresentados. Todas essas boas práticas foram codificadas, agrupadas por similaridades e quantificadas. A seguir, elas foram associadas aos problemas identificados no Ciclo 1 ou classificadas como oportunidades (Diagrama de Ishikawa). As melhores práticas identificadas receberam notas em função dos graus de dificuldade de implementação e de relevância, de acordo com os objetivos da organização.

Para a análise do Ciclo 3, foram utilizadas como base as informações analisadas no Ciclo 2, incluindo dados da avaliação final.

Coughlan e Coghlan (2002) recomendam que o pesquisador e o grupo da intervenção se envolvam também com a etapa de feedbacks. No primeiro ciclo de pesquisa, o feedback foi realizado somente pelos membros do grupo envolvidos com a intervenção. A partir do segundo ciclo, no entanto, o feedback passou a envolver também executivos de tecnologia 
por meio de comitês. As informações das reuniões executivas foram coletadas a partir das atas e anotações do grupo.

Toda a construção dessas análises dos dados ocorreu nas sessões de discussão entre os membros do grupo e foram concebidas para o uso prático, embora parte desses dados possa ser utilizada para a 'Pesquisa-Ação Dissertação'.

\subsubsection{Etapa 3 - Planejamento das Ações}

Para Coghlan e Brannick (2005), o planejamento das ações é reflexo do encadeamento que parte do propósito da Pesquisa-Ação desde o diagnóstico. Segundo eles, as ações devem ser propostas de forma participativa, assim como nas etapas anteriores. Quanto à estrutura de atividades, o planejamento pode conter um conjunto de ações, dependendo das avaliações, análises, progresso e objetivos do grupo para cada ciclo.

Embora haja certa liberdade para estruturação dos planos, Coughlan e Coghlan (2002) ressaltam a importância de se fazer alguns questionamentos, tais como:

- Quais mudanças são desejáveis com a intervenção?

- Como formalizar a intenção dessas mudanças?

- Quais poderiam ser os impeditivos para executar as ações?

Para a construção das ações da presente pesquisa, foram utilizadas ferramentas de domínio da empresa. No Ciclo 1, utilizou-se o método de planejamento denominado Objectives and Key-Results (OKR), desenvolvido pela Intel e pelo Google, que estabelecem um prazo para implantação de tais ações (Niven \& Lamorte, 2016).

Para os Ciclos 2 e 3, utilizou-se para o planejamento das intervenções a metodologia de gestão de projetos Scrum, que estabelece um processo de planejamento e execução de atividades iterativo e incremental. 


\subsubsection{Etapa 4 - Ação}

Nesta etapa, ocorreu a implementação das ações planejadas. Devido ao volume de ações nos ciclos, para executá-las, os membros dos grupos de intervenção foram divididos em duplas ou trios, exceto em dois eventos de grande porte que contaram com a participação conjunta de todos eles.

Como forma de controle, o grupo reunia-se semanalmente para discutir como havia sido as ações realizadas na semana; quais ações seriam realizadas na semana seguinte; quais eram os possíveis impedimentos; e qual a necessidade de apoio em relação aos mesmos.

\subsubsection{Etapa 5 - Avaliação}

Segundo Coughlan e Coghlan (2002), nesta etapa deve haver uma avaliação da ação. O grupo precisa verificar se o diagnóstico está correto, se as ações são adequadas, se a forma como estão sendo executadas é correta, quais são os pontos de melhoria e quais dados podem ser utilizados nos ciclos seguintes. É o momento de revisão do processo de 'Pesquisa-Ação Central' para se beneficiar do aprendizado em relação às experiências obtidas no ciclo.

Na presente Pesquisa-Ação, as avaliações ocorreram de forma colaborativa e democrática. A avaliação do Ciclo 1 ocorreu em uma reunião com os membros designados para a intervenção. A partir do Ciclo 2, envolveu também uma apresentação dos resultados ao Comitê Executivo, que contava com patrocinadores das ações. Além das formas de avaliação interna nos ciclos, após o encerramento de todos eles, foi realizada uma reunião de avaliação geral. 


\subsection{META-CICLO - 'PESQUISA-AÇÃO DISSERTAÇÃO'}

Meta-ciclo ou meta-passo consiste na proposição de 'Pesquisa-Ação para a dissertação'. De acordo com Coughlan e Coghlan (2002), o meta-ciclo é fundamentado nas reflexões sobre as ações tomadas durante cada etapa de um ciclo: diagnóstico, planejamento, ação propriamente dita e avaliação da mesma. Sua execução ocorre de forma concorrente a cada uma dessas etapas.

No meta-ciclo, o pesquisador deve investigar cada uma dessas quatro etapas, questionando sobre qual a melhor conduta e consistência para atender aos objetivos propostos. Nesse ponto, há certa dicotomia, pois enquanto o grupo da intervenção concentra-se nos resultados práticos, o pesquisador tem uma tarefa adicional com o meta-ciclo, a de investigar um problema de pesquisa, considerando que este está "investigando dentro da investigação" (Coughlan \& Coghlan, 2002, p. 233).

Durante a interpretação, buscam-se respostas para as experiências práticas, que podem refletir em melhorias nos ciclos subsequentes (Coghlan \& Brannick, 2005). Cabe destacar que o processo de reflexão é a base sobre a qual o meta-ciclo se sustenta. Esse processo não é neutro, pois exige que o pesquisador reflita sobre o grupo e sobre a organização.

A reflexão, segundo Coghlan e Brannick (2005), consiste em recuperar, processar e analisar as experiências obtidas para planejar futuras ações. Eles propõem que o pesquisador exercite, criticamente, três formas de reflexão: sobre o conteúdo, sobre o processo e sobre as premissas. Esses aspectos devem ser apresentados na dissertação, para garantir a qualidade dos dados obtidos e das reflexões e extrapolações derivadas da prática para a teoria e viceversa:

- Reflexão sobre o conteúdo: busca refletir sobre o conteúdo diagnosticado,

planejado, realizado e avaliado, sob o ponto de vista dos problemas causados por eles e seus desdobramentos; 
- Reflexão do processo: abrange as estratégias tomadas, os processos estabelecidos para suportar cada uma das etapas da Pesquisa-Ação e como cada qual está sendo conduzida;

- Reflexão de premissa: considera as suposições e perspectivas subjacentes que governam as atitudes e o comportamento dos envolvidos na pesquisa. Por exemplo, a falta de experiência sobre um determinado assunto pode influenciar o grupo a tomar uma decisão errada. As perspectivas subjacentes permitem ao pesquisador ser instrumento na geração de dados, ao questionar e observar os membros participantes sobre as contribuições conceituais e analíticas.

Na presente pesquisa, o desenvolvimento do meta-ciclo utilizou as três formas de reflexão, aplicadas em cada uma das etapas dos ciclos, conforme representado na Figura 17, adaptada de Coghlan e Brannick (2005).

Figura 17 - Meta-ciclo de investigação associado aos ciclos de ações

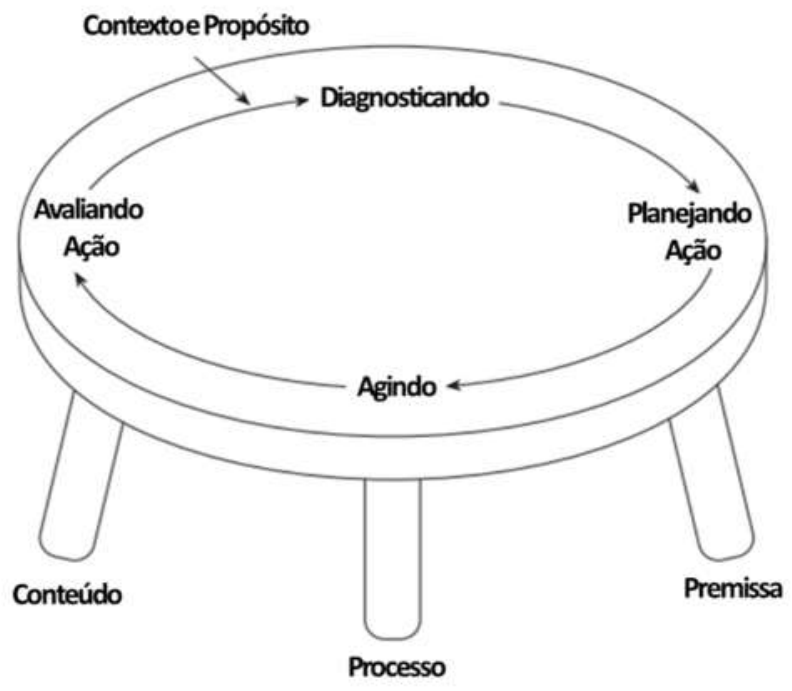

Fonte: Adaptada de Coghlan e Brannick (2005).

Embora para efetuar as reflexões para o meta-ciclo fosse possível considerar apenas as observações do pesquisador, buscou-se eliminar certos vieses, priorizando como dado principal da investigação científica, a percepção dos membros participantes dos ciclos. 
Alguns deles foram entrevistados com o objetivo de avaliar os aprendizados e de apreciar as reflexões sobre a intervenção, além de obter proposições de melhorias para os ciclos futuros. Assim, a partir dos dados coletados junto àqueles que participaram da intervenção, o pesquisador complementou com suas observações e dados documentais, procurando mitigar falsas suposições.

Com base nesses procedimentos, o meta-ciclo de investigação sobre a Pesquisa-Ação busca atender à qualidade e ao rigor exigidos neste trabalho científico-profissional.

\subsection{COLETA DE DADOS PARA A 'PESQUISA-AÇÃO DISSERTAÇÃO’}

Para garantir a lisura ética da pesquisa, Coghlan e Brannick (2005) propõem um conjunto de questões a serem resolvidas antes do início da coleta dos dados, que deve ser negociado com as autoridades e com os colaboradores, sobre o uso das informações e documentos da organização. Dentre eles, o compromisso de informar as partes interessadas sobre o andamento da pesquisa; a garantia da confidencialidade das informações e anonimato dos participantes; e o esclarecimento aos responsáveis pela empresa da forma como o trabalho será publicado. Para garantir o cumprimento das questões supramencionadas, foram utilizados, neste projeto, dois mecanismos:

- Solicitação para uso de informações e menção da empresa: visa a esclarecer a finalidade da pesquisa e a solicitar às autoridades da organização o uso de documentos, dados e a divulgação do nome da empresa. O regimento interno da empresa XYZ permite o uso de informações internas e o uso do nome da empresa, desde que haja uma comunicação formal via correio eletrônico (e-mail) ao diretor e ao superintendente responsáveis pelas informações. Seguindo o protocolo interno, foi cumprido tal procedimento, tendo sido encaminhado um documento eletrônico (por e-mail) contendo a justificativa do projeto, as categorias de informações necessárias e os fins para quais seriam utilizadas, assim como a permissão para utilização do nome da empresa na pesquisa. 
Essa solicitação foi aprovada em 8 de dezembro de 2017. No entanto, o pesquisador optou por não divulgar o nome da organização para ter maior liberdade para analisar os dados e discutir os resultados crítica e imparcialmente, o que é coerente com a ética exigida para trabalhos acadêmicos. $O$ pesquisador levou em consideração o pensamento de Coghlan e Brannick (2005), que consideram que apresentar interpretações ou resultados críticos pode ser percebido negativamente dentro e fora da organização. $\mathrm{O}$ anonimato foi, portanto, uma ação mitigadora.

- Termo de Consentimento Livre e Esclarecido: os participantes da Pesquisa-Ação, que contribuíram com dados para o projeto, assinaram esse tipo de documento. Não houve recusas. Dentre as principais disposições do Termo constavam o esclarecimento dos objetivos da pesquisa; a solicitação do uso dos dados gerados pelos participantes ao longo da intervenção; a garantia de confidencialidade e o anonimato daqueles que dela participaram; e a garantia de livre acesso aos dados da pesquisa, caso solicitado. O modelo do documento assinado pelos entrevistados foi adaptado de Pedroso (2010) e consta no Apêndice 2.

Para reforçar as medidas de confidencialidade e preservar o anonimato dos participantes e da organização, foram adotados códigos ao longo das análises desta dissertação, nos casos em que houve necessidade de mencionar algum comentário particular.

A fim de realizar uma investigação holística para a 'Pesquisa-Ação Dissertação', foram definidos dois conjuntos de fontes de dados, a saber:

- Dados coletados durante a própria intervenção: observação direta, reflexões e documentos (diário do pesquisador);

- Dados de entrevistas com membros que atuaram na intervenção; sendo essa a fonte mais relevante em torno desta pesquisa.

Segundo Coughlan e Coghlan (2002), a observação direta permite coletar dados em momentos formais, como em reuniões, ou informais, como em um almoço ou em outras 
atividades recreativas. Na prática, isso costuma ser eficaz, pois o pesquisador está envolvido no dia a dia dos processos da Pesquisa-Ação.

Seguindo a recomendação de Coghlan e Brannick (2005), foi utilizado um diário como instrumento de coleta da observação direta, registrando-se relatos e anotações curtas para reflexões posteriores. Cada evento registrado contém uma anotação descritiva do ocorrido e uma anotação reflexiva, conforme trecho apresentado no Apêndice 3. Os eventos foram catalogados por datas, pessoas envolvidas, assunto, ciclo da ocorrência e eventualmente documentos ligados ao evento. A agregação de dados a esses eventos também inclui dados da intervenção (workshops, entrevistas, documentos, reuniões formais efeedbacks), descritas no subitem 3.5.2. Ao todo, foram contabilizados 180 (cento e oitenta) blocos de registros, ao longo dos doze meses de pesquisa.

As entrevistas foram realizadas no final da Pesquisa-Ação, para obter as percepções dos respondentes em relação a todo o processo da pesquisa. Elas proporcionaram ao pesquisador a vantagem de capturar reflexões dos membros da intervenção com mais tempo e sem julgamentos dos pares. O objetivo era compreender a efetividade das ações, as dificuldades, as lições aprendidas e as proposições de melhorias para ações futuras.

É importante ressaltar que as entrevistas realizadas para o meta-ciclo ou 'Pesquisa-Ação Dissertação’ não são as mesmas que as feitas com organizações externas durante os ciclos de ações (etapa de diagnóstico), que tinham cunho prático.

O roteiro para a pesquisa qualitativa foi elaborado a partir de embasamento teórico e prático, sendo composto por 46 (quarenta e seis) perguntas, conforme detalhado no subitem 3.8 a seguir. Algumas variaram de acordo com o grupo ao qual o entrevistado pertencia, como se pode constatar no Apêndice 1.

Segundo Gil (1991), utilizar-se de uma amostra intencional para a realização de entrevistas é adequado para abordagens qualitativas, pois permite selecionar uma população que traga maior riqueza de elementos associados à pesquisa. Seguindo esse referencial, para esta 
pesquisa, foram selecionados 8 (oito) indivíduos dos dois grupos de participantes da Pesquisa-Ação, cujo perfis encontram-se no Quadro 10.

- Grupo 1 (participantes do Ciclo 1): 3 entrevistados de um total de 13 pessoas (excluindo-se o pesquisador);

- Grupo 2 (participantes dos Ciclos 2 e 3): 5 entrevistados de um total de 10 pessoas (excluindo-se o pesquisador).

Quadro 10 - Situação geral das iniciativas mapeadas pelo Comitê

\begin{tabular}{|c|c|c|c|c|c|c|}
\hline Grupo & $\begin{array}{l}\text { Código de } \\
\text { Referência }\end{array}$ & Cargo & $\begin{array}{l}\text { Formação } \\
\text { Superior }\end{array}$ & Pós-Graduação & $\begin{array}{l}\text { Tempo de } \\
\text { Empresa }\end{array}$ & $\begin{array}{l}\text { Duraç̧ão de } \\
\text { Entrevista }\end{array}$ \\
\hline 1 & GI & $\begin{array}{c}\text { Analista de } \\
\text { Relacionamento }\end{array}$ & $\begin{array}{l}\text { Sistemas de } \\
\text { Informação }\end{array}$ & & 6 anos & $\begin{array}{l}26 \text { minutos e } \\
54 \text { segundos }\end{array}$ \\
\hline 1 & SA & Arquiteto de Solução & $\begin{array}{l}\text { Sistemas de } \\
\text { Informação }\end{array}$ & $\begin{array}{c}\text { Especialização em } \\
\text { Finanças de TI }\end{array}$ & 9 anos & $\begin{array}{l}26 \text { minutos e } \\
6 \text { segundos }\end{array}$ \\
\hline 1 & FA & Strategic sourcing & $\begin{array}{l}\text { Sistemas de } \\
\text { Informação }\end{array}$ & $\begin{array}{l}\text { Especialização } \\
\text { Administração }\end{array}$ & 6 anos & $\begin{array}{l}24 \text { minutos e } \\
58 \text { segundos }\end{array}$ \\
\hline 2 & VI & $\begin{array}{l}\text { Coordenador de } \\
\text { Arquitetura Corporativa }\end{array}$ & $\begin{array}{c}\text { Processamento } \\
\text { de Dados }\end{array}$ & $\begin{array}{c}\text { Especialização em } \\
\text { Gestão da } \\
\text { Informação }\end{array}$ & 10 anos & $\begin{array}{l}47 \text { minutos e } \\
56 \text { segundos }\end{array}$ \\
\hline 2 & $\mathrm{AD}$ & $\begin{array}{c}\text { Coordenador de } \\
\text { Arquitetura de Solução }\end{array}$ & $\begin{array}{l}\text { Sistemas de } \\
\text { Informação }\end{array}$ & $\begin{array}{l}\text { MBA Estratégia de } \\
\text { Negócio }\end{array}$ & 11 anos & $\begin{array}{l}42 \text { minutos e } \\
54 \text { segundos }\end{array}$ \\
\hline 2 & CA & $\begin{array}{c}\text { Coordenador de } \\
\text { Arquitetura Corporativa }\end{array}$ & $\begin{array}{l}\text { Administração } \\
\text { de Empresas }\end{array}$ & $\begin{array}{l}\text { MBA Executivo } \\
\text { em Finanças }\end{array}$ & $\begin{array}{c}2 \text { anos e } 4 \\
\text { meses }\end{array}$ & $\begin{array}{l}40 \text { minutos e } \\
12 \text { segundos }\end{array}$ \\
\hline 2 & FE & $\begin{array}{c}\text { Especialista de } \\
\text { Arquitetura de Solução }\end{array}$ & $\begin{array}{l}\text { Sistemas de } \\
\text { Informação }\end{array}$ & $\begin{array}{c}\text { Especialização em } \\
\text { Arquitetura de } \\
\text { Solução }\end{array}$ & 7 anos & $\begin{array}{l}51 \text { minutos e } \\
28 \text { segundos }\end{array}$ \\
\hline 2 & RO & $\begin{array}{c}\text { Especialista de } \\
\text { Arquitetura Corporativa }\end{array}$ & $\begin{array}{l}\text { Ciências } \\
\text { Econômicas }\end{array}$ & $\begin{array}{l}\text { Especialização em } \\
\text { Gestão de Projetos }\end{array}$ & 12 anos & $\begin{array}{l}73 \text { minutos e } \\
6 \text { segundos }\end{array}$ \\
\hline
\end{tabular}

Fonte: Elaborado pelo autor.

Reforça-se que para a análise de dados não foram utilizadas apenas as 8 entrevistas, mas sim a triangulação delas com os registros do diário de bordo do pesquisador. Tal procedimento também permite que haja saturação de dados para análise. A triangulação de dados de campo e entrevistas segue a recomendação de Thompson e Perry (2004), como forma de obter dados suficientes e de qualidade como insumos para construção da 'Pesquisa-Ação Dissertação'.

As entrevistas foram presenciais, realizadas entre dezembro de 2017 e janeiro de 2018, e foram agendadas de acordo com a disponibilidade dos entrevistados. Elas foram gravadas e transcritas para posterior análise. 


\subsection{ELABORAÇÃO DO ROTEIRO DE ENTREVISTAS}

Para elaboração do roteiro de entrevista, foi desenvolvido um processo de cinco etapas, conforme apresentado na Figura 18, visando a garantir a consistência das perguntas para atender aos objetivos propostos:

- Referencial: foram utilizados referenciais teóricos e práticos sobre aspectos internos, barreiras e boas práticas associadas ao relacionamento de grandes empresas com startups. O referencial utilizado possui escopo reduzido em relação aos fundamentos apresentados no Capítulo 2, pois a compreensão e a complexidade dos problemas envolvidos evoluíram durante a realização das ações, fato comum em uma Pesquisa-Ação cíclica. Apesar disso, não afetou a obtenção de dados para continuidade da pesquisa;

- Categorização: identificação das categorias presentes em cada referencial e identificação dos principais aspectos de cada categoria;

- Correlação e Sintetização: identificação dos significados de cada categoria e, quando possível, unificação e/ou reagrupamento dos significados similares, permitindo estabelecer e eliminar aspectos não associados com a realidade do problema;

- Complemento de Contexto: além dos aspectos levantados pelos referenciais, alguns aspectos gerais da Pesquisa-Ação, como o perfil dos membros dos grupos e o entendimento geral da ação, contribuem para atingir os objetivos propostos;

- Roteirização: criação do roteiro de perguntas baseado em todos os aspectos relevantes para atingir os objetivos propostos. 
Figura 18 - Procedimentos para Elaboração do Roteiro de Entrevista

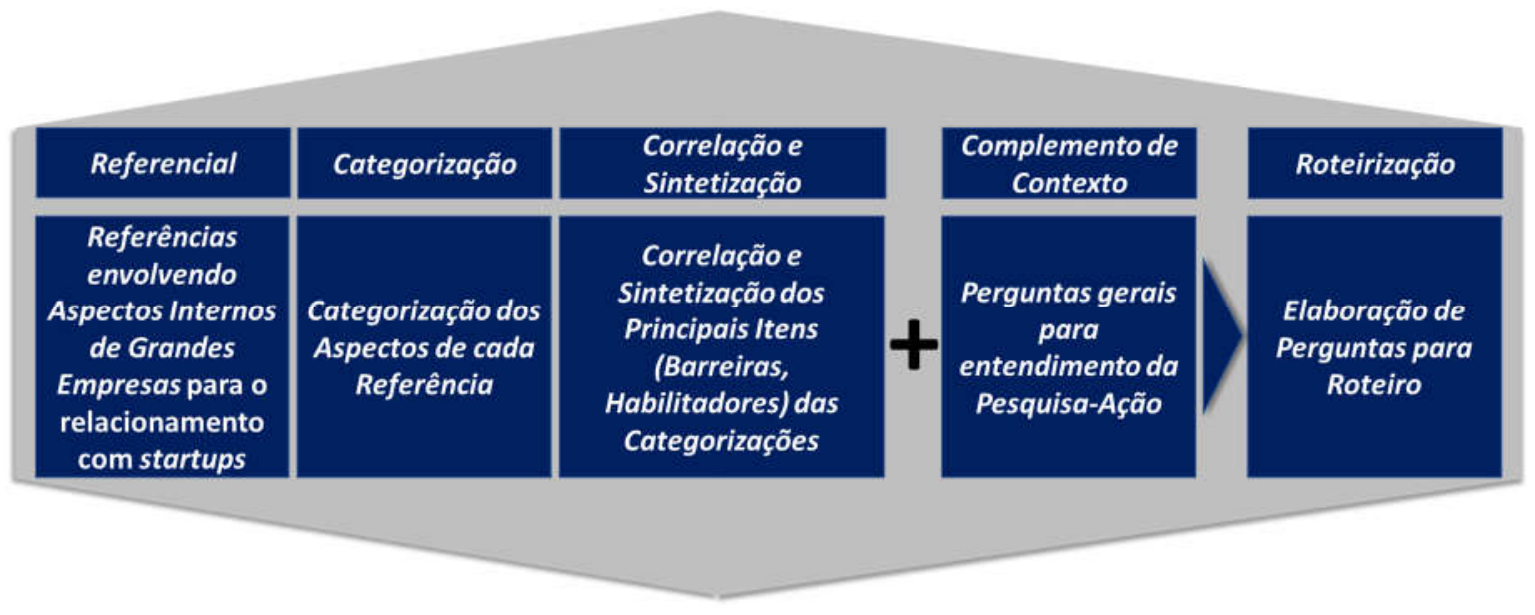

Fonte: Elaborada pelo autor.

A resultante dessas etapas está sintetizada no Quadro 11 e o roteiro proposto para a entrevista consta no Apêndice 1. Ele foi ordenado com base nas cinco etapas de um ciclo de ação. 


\section{Quadro 11 - Resultado das Categorizações e Sintetização para Elaboração de Roteiro de Perguntas}

\begin{tabular}{|c|c|c|}
\hline rizações & Sintetização de Tópicos & Autores \\
\hline $\begin{array}{l}\text { Objetivo e } \\
\text { Estratégia }\end{array}$ & 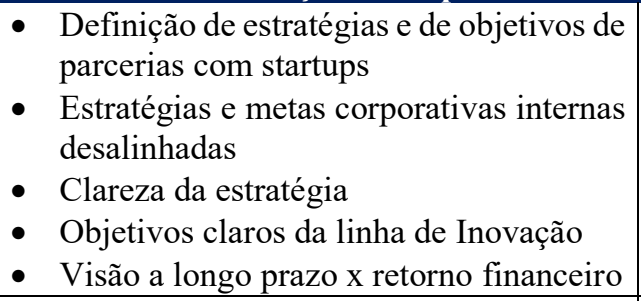 & $\begin{array}{l}\text { Morris \& Kuratko, 2002; Kuratko \& Goldsby, 2004; } \\
\text { Shah, Zegveld, \& Roodhart, 2008; Minshall, Mortara, } \\
\text { Napp, \& Probert, 2010; Mortara \& Minshall, 2011; } \\
\text { Battistini, Hacklin, \& Baschera, 2013; Mocker, Bielli, } \\
\text { \& Haley, 2015; Bannerjee, Bielli, \& Haley, 2016; } \\
\text { Kohler, 2016; Prats, Amigó, Ametller, \& Batlle, 2017; } \\
\text { De la Tour et al., 2017; Thieme, 2017; WEF, } 2018 .\end{array}$ \\
\hline Cultura & $\begin{array}{l}\text { - Arquétipos de cultura: cargo, poder, } \\
\text { realização e suporte } \\
\text { - Ausência de cultura empreendedora } \\
\text { - Sentimento 'Não foi inventado aqui' } \\
\text { - Aversão a Risco } \\
\text { - Colaboradores com espírito } \\
\text { - } \text { Açproendedor de aculturamento }\end{array}$ & $\begin{array}{l}\text { Ahmed,1998; Martins \& Terblanche, 2003; Freeman } \\
\text { \& Engel, 2007; Mortara, Napp, Slacik, \& Minshall, } \\
\text { 2009; Minshall, Mortara, Napp, \& Probert, 2010; } \\
\text { Kuratko, Hornsby, \& Covin, 2014; Mocker, Bielli, \& } \\
\text { Haley, 2015; Bannerjee, Bielli, \& Haley, 2016; } \\
\text { Kohler, 2016; Thieme, 2017; Prats, Siota, Canonici, \& } \\
\text { Contijoch, 2018; Rundquist \& Österling, 2018; Das, } \\
\text { Verburg, Verbraeck, \& Bonebakker, 2018. }\end{array}$ \\
\hline Alta Liderança & $\begin{array}{l}\text { - Apoio da alta gerência } \\
\text { - Incentivos e metas dos executivos } \\
\text { - Liderança próxima das iniciativas/ações } \\
\text { - Equívoco sobre o conceito de startups } \\
\text { - Conflito de interesses }\end{array}$ & $\begin{array}{l}\text { MacMillan, Block, \& Narasimha, 1986; Rumelt, 1995; } \\
\text { Ahmed, 1998; Hill \& Rothaermel, 2003; Dombrowski } \\
\text { et al., 2007; Freeman \& Engel, 2007; Minshall, } \\
\text { Mortara, Napp, \& Probert, 2010; Mortara, Napp, } \\
\text { Slacik, \& Minshall, 2009; Battistini, Hacklin, \& } \\
\text { Baschera, 2013; Mocker, Bielli, \& Haley, 2015; } \\
\text { Bannerjee, Bielli, \& Haley, 2016; Bonzom \& } \\
\text { Netessine, 2016; Kohler, 2016; Thieme, 2017; De la } \\
\text { Tour et al., 2017; Prats, Amigó, Ametller, \& Batlle, } \\
\text { 2017; Das, Verburg, Verbraeck, \& Bonebakker, 2018. }\end{array}$ \\
\hline Equipe & \begin{tabular}{ll|} 
- & Conhecimento dos colaboradores \\
- Habilidades necessárias para & \\
- & Dimplementar iniciativas \\
- & Membribilidade das pessoas com espírito empreendedor \\
- & Capacitação dos colaboradores \\
- Motivação, incentivos e recompensas do & \\
& 'agentes de mudança' \\
\end{tabular} & $\begin{array}{c}\text { Martins \& Terblanche, 2003; Dombrowski et al., } \\
\text { 2007; Minshall, Mortara, Napp, \& Probert, 2010; } \\
\text { Mortara \& Minshall, 2011; Kuratko, Hornsby, \& } \\
\text { Covin, 2014; Mocker, Bielli, \& Haley, 2015; } \\
\text { Bannerjee, Bielli, \& Haley, 2016; Kohler, 2016; } \\
\text { Schättgen \& Mur, 2016; Prats, Amigó, Ametller, \& } \\
\text { Batlle, 2017; Thieme, 2017; Das, Verburg, Verbraeck, } \\
\text { \& Bonebakker, 2018. } \\
\end{array}$ \\
\hline $\begin{array}{c}\text { Estrutura } \\
\text { Organizacional } \\
\text { e Processos } \\
\text { Internos }\end{array}$ & 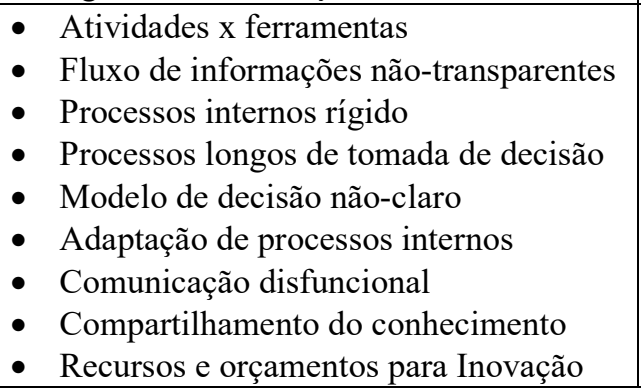 & $\begin{array}{c}\text { Morris \& Kuratko, 2002; Kuratko \& Goldsby, 2004; } \\
\text { Dombrowski et al., 2007; Mortara \& Minshall, 2011; } \\
\text { Minshall, Mortara, Napp, \& Probert, 2010; Mocker, } \\
\text { Bielli, \& Haley, 2015; Bannerjee, Bielli, \& Haley, } \\
\text { 2016; Thieme, 2017; Prats, Amigó, Ametller, \& } \\
\text { Batlle, 2017; De la Tour et al., 2017; Mind the Bridge } \\
\text { \& Nesta, 2017; Das, Verburg, Verbraeck, \& } \\
\text { Bonebakker, 2018. }\end{array}$ \\
\hline
\end{tabular}

Fonte: Elaborado pelo autor. 


\subsection{ANÁLISE DE DADOS PARA A 'PESQUISA-AÇÃO DISSERTAÇÃO'}

A forma de análise no meta-ciclo é conduzida apenas pelo pesquisador. Coghlan e Brannick (2005) afirmam que a análise do meta-ciclo precisa extrair sentido dos dados. Não basta simplesmente descrevê-los, pois precisam ser refletidos a partir de evidências. Durante o processo, além dos objetivos da pesquisa, é comum surgirem temas não previstos e que precisem ser apresentados e discutidos na dissertação.

Nesta pesquisa, para estruturação da análise qualitativa, também foram utilizadas as recomendações de Creswell (2007) e as de Mello, Turrioni, Xavier e Campos (2012). Creswell (2007) sugere seis passos para extrair o sentido dos dados de uma pesquisa qualitativa: organização e preparação dos dados; leitura de todos os dados; análise inicial detalhada para o processo codificação; descrição dos cenários e das pessoas e categorias/temas de análise; prevenção como a descrição e temas representados na narrativa; e interpretação ou extração de significados dos dados.

O início do processo de análise do meta-ciclo consistiu na conversão dos dados coletados para formatos digitais a fim de serem lidos por softwares de análise qualitativa. O documento gerado a partir do diário foi criado em formato de planilha eletrônica, facilitando sua utilização. Os documentos, como apresentações, e-mails e atas, foram convertidos para arquivos eletrônicos do tipo portable document format (pdf) e seus nomes foram catalogados em planilha eletrônica para posterior controle. Por fim, as gravações das entrevistas foram transcritas para texto e estruturadas igualmente para o formato de planilha eletrônica.

Mello, Turrioni, Xavier e Campos (2012) indicam que os dados de pesquisa devem ser triangulados, com vistas a dar consistência para as análises. Sendo assim, faz-se importante reforçar mais uma vez que, para a presente pesquisa, houve essa triangulação, ou seja, as 8 entrevistas foram cruzadas com os 180 registros oriundos do diário de bordo do pesquisador, buscando assim a saturação dos dados a serem analisados. 
Após a preparação dos dados, foi iniciada a sua análise, com apoio do software de análise qualitativa, NVivo - versão 11. Optou-se por criar uma estrutura inicial de unidades de contexto, baseada na teoria inicial e nos ciclos realizados como forma de balizar as primeiras análises. Posteriormente, com a exploração das fontes, foi possível reformular e reorganizar as codificações e unidades de contexto.

As primeiras unidades de contexto e codificações pós-teoria surgiram da leitura exploratória dos trechos das entrevistas e do diário do pesquisador. As etapas posteriores foram iterativas, contando com a revisitação e a reformatação das unidades de contexto, codificações, categorias e temas, à medida que as demais fontes de informação foram sendo incorporadas à análise. Em paralelo às análises, agregaram-se novos referenciais teóricos e práticos que as subsidiaram. Ao final, foi possível reorganizar os diversos agrupamentos e subagrupamentos de codificações em dois grandes eixos (Eixo Y e Eixo X), baseados na teoria e na prática, facilitando a busca pela resolução do problema de pesquisa.

- Eixo $\mathbf{Y}$ - Aspectos internos organizacionais associados ao relacionamento entre grandes empresas e startups: Cultura; Equipe; Objetivos e estratégia; Alta liderança; Estrutura organizacional e Processos internos.

- Eixo $\mathbf{X}$ - Temas transversais que direcionavam a análise para obtenção dos dados à luz do objetivo de 'Pesquisa-Ação':

- Barreiras para aproximação da empresa XYZ com as startups;

- Elementos habilitadores da aproximação da empresa XYZ com as startups;

- Novas ações e melhorias.

Ao todo, foram contabilizadas 40 categorias ou unidades de registros que, por sua vez, tiveram 398 codificações associadas, conforme apresentado na Tabela 2. 
Tabela 2 - Codificações dos temas versus aspectos pesquisados

\begin{tabular}{|c|c|c|c|c|c|c|}
\hline & Barreiras & $\begin{array}{l}\text { Quanti- } \\
\text { dade de } \\
\text { Codifi- } \\
\text { cações }\end{array}$ & Habilitadores & $\begin{array}{l}\text { Quanti- } \\
\text { dade de } \\
\text { Codifi- } \\
\text { cações }\end{array}$ & $\begin{array}{l}\text { Novas ações e } \\
\text { melhorias }\end{array}$ & $\begin{array}{l}\text { Quanti- } \\
\text { dade de } \\
\text { Codifi- } \\
\text { cações }\end{array}$ \\
\hline \multirow{4}{*}{ Cultura } & $\begin{array}{c}\text { Ausência de cultura } \\
\text { empreendedora/ startups }\end{array}$ & 16 & Eventos de aculturamento & 17 & \begin{tabular}{|c|} 
Continuidade das ações \\
de aculturamento
\end{tabular} & 17 \\
\hline & $\begin{array}{c}\text { Falta de conhecimento } \\
\text { sobre startups e } \\
\text { empreendedorismo }\end{array}$ & 8 & Rede social & 6 & $\begin{array}{c}\text { Continuidade da 'rede } \\
\text { social' interna }\end{array}$ & 4 \\
\hline & Aversão a risco & 9 & & & $\begin{array}{c}\text { Iniciativas de imersão } \\
\text { cultural }\end{array}$ & 6 \\
\hline & $\begin{array}{c}\text { Modelo operacional com } \\
\text { retorno financeiro }\end{array}$ & 8 & & & & \\
\hline \multirow{5}{*}{ Equipe } & $\begin{array}{c}\text { Baixo conhecimento } \\
\text { sobre o tema - falta de } \\
\text { capacitação }\end{array}$ & 19 & Autonomia & 4 & $\begin{array}{l}\text { Time dedicado em } \\
\text { tempo integral }\end{array}$ & 18 \\
\hline & $\begin{array}{c}\text { Falta de tempo para } \\
\text { dedicação ao processo de } \\
\text { intervenção }\end{array}$ & 21 & $\begin{array}{l}\text { Motivação pessoal dos } \\
\text { membros do time }\end{array}$ & 12 & Definição de 'Líder' & 2 \\
\hline & Falta de incentivos & 5 & $\begin{array}{l}\text { Aprendizagem na } \\
\text { intervenção }\end{array}$ & 53 & $\begin{array}{c}\text { Maior tempo } \\
\text { alocado/dedicado }\end{array}$ & 4 \\
\hline & $\begin{array}{c}\text { Instabilidade com troca } \\
\text { de membros da } \\
\text { intervenção }\end{array}$ & 3 & & & $\begin{array}{c}\text { Redução do tamanho } \\
\text { da equipe }\end{array}$ & 3 \\
\hline & & & & & $\begin{array}{c}\text { Aumento da } \\
\text { representatividade das } \\
\text { metas - bônus }\end{array}$ & 3 \\
\hline \multirow{2}{*}{$\begin{array}{l}\text { Objetivo e } \\
\text { Estratégia }\end{array}$} & $\begin{array}{l}\text { Estratégia indefinida em } \\
\text { relação às startups }\end{array}$ & 12 & $\begin{array}{c}\text { Definição do objetivo e } \\
\text { estratégia para a } \\
\text { intervenção } \\
\end{array}$ & 13 & $\begin{array}{c}\text { Ações de aproximação } \\
\text { com áreas de negócio e } \\
\text { executivos }\end{array}$ & 7 \\
\hline & $\begin{array}{c}\text { Morosidade na definição } \\
\text { do escopo e estratégia } \\
\text { para a intervenção }\end{array}$ & 12 & & & & \\
\hline \multirow{3}{*}{$\begin{array}{c}\text { Alta } \\
\text { Liderança }\end{array}$} & Falta de apoio entre pares & 6 & $\begin{array}{l}\text { Apoio do diretor- } \\
\text { patrocinador }\end{array}$ & 8 & \begin{tabular}{|c|} 
Apresentação de casos \\
internos (Piloto, \\
Experimento)
\end{tabular} & 3 \\
\hline & $\begin{array}{l}\text { Conflito de prioridades } \\
\text { dos times de apoio }\end{array}$ & 11 & & & $\begin{array}{c}\text { Compartilhamento de } \\
\text { metas com executivos } \\
\text { parceiros }\end{array}$ & 6 \\
\hline & $\begin{array}{c}\text { Comunicação esporádica } \\
\text { com os executivos }\end{array}$ & 7 & & & & \\
\hline $\begin{array}{l}\text { Estrutura } \\
\text { Organi- } \\
\text { zacional }\end{array}$ & $\begin{array}{l}\text { Hierarquia rígida e } \\
\text { verticalizada }\end{array}$ & 14 & & & & \\
\hline \multirow{4}{*}{$\begin{array}{l}\text { Processos } \\
\text { Internos }\end{array}$} & $\begin{array}{l}\text { Processos internos } \\
\text { complexos }\end{array}$ & 15 & Cartilha & 2 & Processo de fast-track & 11 \\
\hline & $\begin{array}{l}\text { Processos longos de } \\
\text { tomada de decisão }\end{array}$ & 9 & $\begin{array}{c}\text { Ferramenta de critérios de } \\
\text { avaliação para soluções de } \\
\text { startups }\end{array}$ & 4 & Experimentação/ piloto & 9 \\
\hline & & & & & \begin{tabular}{|c|} 
Flexibilização dos \\
processos/governança
\end{tabular} & 9 \\
\hline & & & & & $\begin{array}{c}\text { Melhoria contínua nos } \\
\text { processos }\end{array}$ & 6 \\
\hline
\end{tabular}

Fonte: Elaborada pelo autor. 
Uma síntese da etapa de análise e da discussão dos resultados está representada na Figura 19, a seguir.

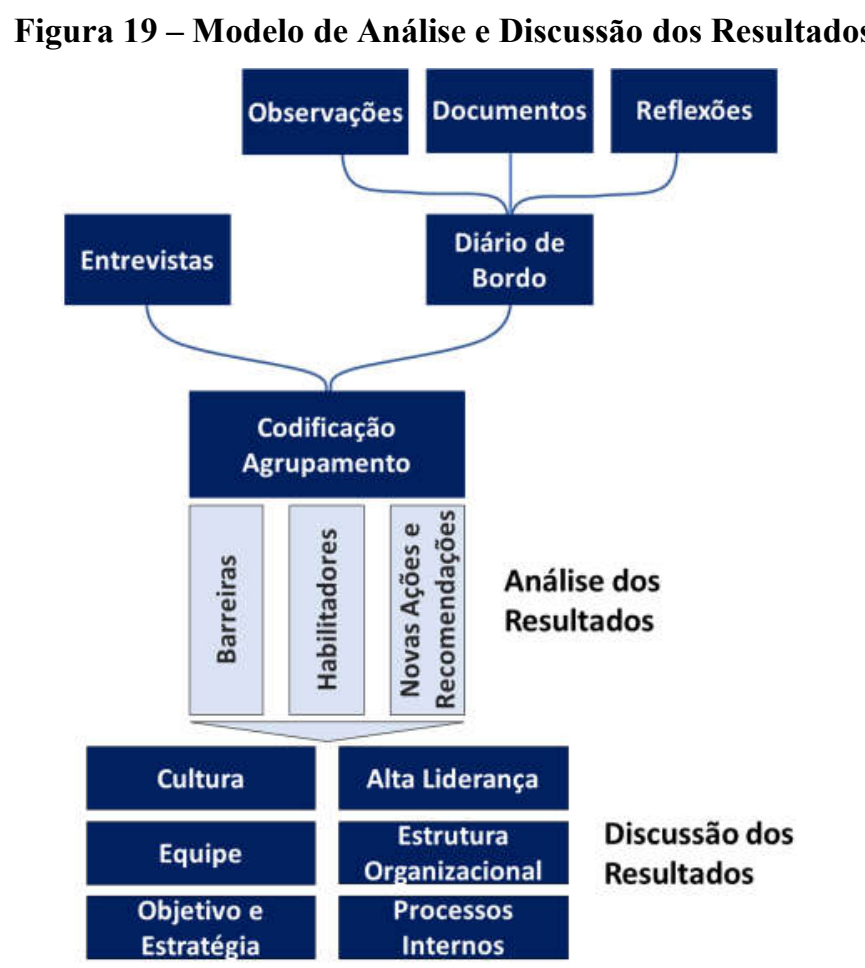

Fonte: Elaborada pelo autor.

Os resultados das análises apresentam-se no Capítulo 5. Foram estruturados utilizando-se os três temas do Eixo Y, a saber: Barreiras, Habilitadores, Novas Ações e Recomendações. Para garantir uma exposição mais concisa e produtiva do resultado dessas análises, buscou-se destacar as codificações mais representativas.

O Capítulo 6 - Discussão dos Resultados, por sua vez, foi organizado associando as referências teóricas ao Eixo $\mathrm{X}$ - aspectos internos organizacionais no relacionamento entre grandes empresas e startups: Cultura, Equipe, Objetivos e Estratégia, Alta Liderança, Estrutura Organizacional, Processos Internos. 


\section{RELATO DA 'PESQUISA-AÇÃO CENTRAL'}

O presente capítulo contém a narrativa fruto da observação do pesquisador e os resultados práticos obtidos pelo grupo da intervenção. Sendo assim, o objetivo é sobretudo contextual, para que haja melhor compreensão da análise e discussão dos resultados.

\subsection{LÓCUS DA PESQUISA}

A organização envolvida no projeto foi denominada 'empresa XYZ', por questões de sigilo. Ao longo de sua história, desenvolveu mais de trinta negócios estratégicos entre aquisições, fusões, joint-ventures e parcerias.

Por ser uma instituição financeira e possuir capital aberto, a empresa XYZ tem forte estrutura de Governança Corporativa e de Sustentabilidade. A estrutura de Governança, cujo primeiro nível é gerido por uma Sociedade Anônima com controle organizacional possui o papel de provisionar a visão estratégica a longo prazo. O segundo nível, composto pelo Conselho de Administração, é responsável pela gestão profissional e pela definição dos parâmetros operacionais. O terceiro e último nível, composto pelo Comitê Executivo, é responsável pela implementação das estratégias e pela gestão do 'dia a dia'. A empresa também possui uma estrutura composta pela gestão de riscos dos negócios, gestão de riscos de mercado, operacional, crédito e auditagem interna.

Em 2017, a empresa XYZ exercia uma presença marcante na América Latina e seu quadro era composto por dezenas de milhares de colaboradores, distribuídos em dezenas de diretorias. Nesse mesmo ano, sua carteira era constituída por dezenas de milhões de clientes entre pessoas físicas e jurídicas, que lhe renderam um lucro bilionário, algo que vem acontecendo há quase duas décadas. 
Além da forte presença em canais digitais, como mobile e internet banking, até setembro de 2018, a empresa XYZ possuía agências e caixas eletrônicos em todos os estados e principais cidades do Brasil.

Na década de 1970, a empresa XYZ passou a utilizar a tecnologia como um propulsor de seus negócios, o que tem se intensificado nos últimos anos. Em 2015, a empresa XYZ iniciou uma agenda de transformação digital, que passou pela contratação de talentos com perfis digitais, como cientistas de dados, e pela adoção de metodologias de trabalho orientadas a ágil e lean.

Nesse contexto, a área de Tecnologia gerencia a maior parte dos projetos denominados estratégicos e é considerada parte do core business da organização. Uma das principais diretorias envolvidas no movimento de 'transformação digital' é a Diretoria de Arquitetura de Tecnologia, escolhida para ser a unidade da presente pesquisa. Essa diretoria possuia papel relevante na definição de evolução tecnológica da organização, incluindo o processo de 'transformação digital'. A área foi o principal alvo das ações propostas durante os diversos ciclos.

Parte do movimento de 'transformação digital' da empresa XYZ diz respeito à aproximação e à conexão com o universo do empreendedorismo tecnológico, mais precisamente com as startups. Nesse sentido, duas ações concretas ocorreram em 2015, a saber:

- criação da área de Arquitetura de Negócios dentro da empresa XYZ, responsável pela estratégia tecnológica e por fazer a interface entre as áreas de negócios e a de tecnologia;

- cocriação de um espaço compartilhado para startups, externo à organização, em parceria com uma empresa de investimentos de riscos.

Em 2016, entre as atividades estratégicas da área de Arquitetura de Negócios constava a sondagem de startups, tanto no Brasil quanto no exterior, e ocorria por diversos propósitos, dentre eles, a avaliação de novos habilitadores de modelos de negócios, os testes de hipóteses, 
pilotos e a habilitação de entregas de grandes projetos. O mapeamento dessas startups ocorria por demanda das áreas de negócios ou por pesquisas de tendência de mercado. A empresa XYZ possuía políticas robustas para avaliar questões de segurança, jurídicas e de riscos. Embora houvesse adversidades, a maioria das iniciativas implementadas tinha repercussão positiva entre os executivos da organização.

Até dezembro de 2016, não existia nenhum processo diferenciado para habilitar startups como solução para as iniciativas dentro da empresa XYZ. Essa situação fazia com que as startups sofressem com barreiras internas, tais como condições não previstas em processos internos e aprovações em diversos níveis hierárquicos. Outro fato recorrente era o acesso das áreas de negócios diretamente com as startups, sem avaliação prévia sobre a viabilidade de negócios ou a técnica em relação à necessidade que a startup poderia suprir, causando, em certos momentos, problemas de comunicação, morosidade nas avaliações e divergências de expectativas por parte dos envolvidos.

\subsection{PROPOSTA DE 'PESQUISA-AÇÃO' 5}

Em meados de 2016, o presente pesquisador constatou a oportunidade de propor a metodologia de 'Pesquisa-Ação', demonstrando seu interesse profissional e acadêmico em melhorar o 'relacionamento da empresa XYZ com startups'.

A proposição inicial de 'relacionamento entre a empresa

\section{Comentário 1:}

No momento em que foi feita a proposição da 'Pesquisa-Ação' ainda não se tinha clareza de que o 'relacionamento da empresa XYZ com startups' restringir-se-ia ao uso de soluções de startups para resolver problemas de negócios.

XYZ e startups' dizia respeito às 'parcerias' que, naquela ocasião, eram acordos comerciais que geravam vantagens mútuas. Naquele momento, utilizou-se para a apresentação parte da teoria e dados secundários também utilizados nesta dissertação (Mortara, Napp, Slacik, \& Minshall, 2009; Minshall, Mortara, Napp, \& Probert, 2010; Bannerjee, Bielli, \& Haley,

\footnotetext{
${ }^{5}$ Alguns comentários são apresentados ao longo deste capítulo em 'caixas de texto' para não interferirem nas análises apresentadas, conforme orientam Coghlan e Brannick (2005).
} 
2016), além de pesquisa documental que partiu de alguns dados da empresa sobre dois casos internos de avaliação de startups, sendo um deles, de sucesso, e outro, de fracasso.

O pesquisador foi designado para fazer parte de um grupo que seria criado em dezembro de 2016, com a finalidade de executar uma força-tarefa, visando ao aprimoramento da relação da empresa XYZ com startups.

Em 5 de dezembro de 2016, este pesquisador enviou ao executivo o resumo do projeto e a solicitação formal para execução da pesquisa. Após dois dias, recebeu a autorização formal para prosseguir com ela.

\subsubsection{Ciclo 1 - Preparação e Definição de Propósito}

O grupo designado para iniciar a intervenção era heterogêneo, composto por profissionais das áreas de Compras, de Arquiteturas de TI e do espaço compartilhado fomentado pela organização - doravante nominado de Coworking. Totalizavam quatorze profissionais experientes e com vivência nos processos internos, acionados quando da necessidade de avaliar uma startup.

A primeira reunião formal ocorreu na manhã de 29 de dezembro de 2016, quando foi explicado ao grupo o porquê do encontro. Naquele momento, o objetivo foi diagnosticar os problemas que dificultavam a empresa a fazer negócios com startups e, consequentemente, a propor ações de melhoria. Cada integrante discursou sobre o papel de suas respectivas áreas em relação às startups. O pesquisador apresentou-se como consultor e membro com expertise em Arquitetura de Negócios e afirmou poder orientar e fornecer informações e melhores práticas oriundas do mercado e da academia a todos os membros da Pesquisa-Ação. Aproveitou-se a oportunidade para esclarecer, inclusive, qual era o propósito de uma Pesquisa-Ação. O pesquisador explicou ainda que, além de atuar na intervenção juntamente com o grupo, também faria uma investigação acadêmica sobre todo o processo. 
No período da manhã daquele dia, foi proposta a utilização do framework de Objectives and Key Results (OKR), como forma de organizar os trabalhos do ciclo. Optou-se por fazer um conjunto de três workshops: o primeiro, para definir o propósito da pesquisa-ação; o segundo, para diagnosticar os problemas; e o terceiro, para planejar as ações, conforme apresentado no Quadro 12, a seguir.

Quadro 12 - Marcos do Ciclo 1

Fonte: Elaborado pelo autor.

\begin{tabular}{|c|l|}
\hline \multicolumn{1}{|c|}{ Datas } & \multicolumn{1}{c|}{ Eventos } \\
\hline $29 /$ dez/2016 & $\begin{array}{l}1^{\circ} \text { Workshop - primeira reunião formal para definição do } \\
\text { propósito da 'Pesquisa-Ação Central' }\end{array}$ \\
\hline $05 /$ jan/2017 & $2^{\circ}$ Workshop - levantamento dos impedimentos \\
\hline $18 /$ jan/2017 & $3^{\circ}$ Workshop - priorização das ações \\
\hline $24 /$ jan/2017 & Planejamento das Atividades \\
\hline $25 /$ jan/2017 & Aprovação do Plano pelo Comitê Executivo \\
\hline $01 / \mathrm{mar} / 2017$ & Entrega - Modelo de evolutivo para avaliação de startups \\
\hline $23 / \mathrm{mar} / 2017$ & Entrega - Comitê para avaliação de projetos de startups \\
\hline $20 / \mathrm{mar} / 2017$ & Entrega - Cartilha de processos \\
\hline $31 / \mathrm{mar} / 2017$ & Reunião para Avaliação do Ciclo \\
\hline
\end{tabular}

A partir de então, deu-se início às discussões para se definir o objetivo principal da intervenção. A participação de todos era visível. Muitos comentários foram apresentados, pois membros da organização tinham vivência sobre o assunto. O [Participante GI1] afirmou: "muitas empresas nos enxergam como referência em inovação e temos o desafio de continuar

Comentário 2:

'Tornar a empresa XYZ referência em fazer negócios com startups' embora fosse um objetivo amplo, era o que se pretendia em termos de negócios. No entanto, deve-se evidenciar que esse não é o objetivo da 'Pesquisa-Ação Dissertação'. a ser". O [Participante UT1] ressaltou: "não queremos somente contratar os serviços das startups, eventualmente queremos ser parceiros, como somos de grandes empresas". A discussão durou cerca de 90 minutos. Ao final, o grupo decidiu que o objetivo macro da intervenção seria: 'Tornar a empresa XYZ referência em fazer negócios com startups'.

O grupo concordou que aquele seria o objetivo a longo prazo, o 'sonho grande', que Coghlan e Brannick (2005, p. 95) nomeiam "estado futuro". As próximas atividades da dinâmica consistiam em analisar qual era a situação naquele momento e em definir um horizonte de 
ações. O executivo de processos de Tecnologia da Informação [Participante CE1] sugeriu que fossem elaboradas entregas a curto prazo, para serem implementadas em até três meses, conhecidas internamente como quickwins, que significa ganhos rápidos, em inglês. $\mathrm{O}$ grupo consentiu, ainda, que durante a priorização e o planejamento consideraria essa abordagem.

\subsubsection{Ciclo 1: Diagnóstico}

Em 5 de janeiro de 2017, ocorreu o segundo workshop. O objetivo foi avaliar a situação da organização naquele momento no que se referia ao relacionamento com startups. No início da sessão, o pesquisador apresentou dois artigos que haviam servido de base para o projeto de pesquisa (Mortara, Napp, Slacik, \& Minshall, 2009; Minshall, Mortara, Napp, \& Probert, 2010).

O objetivo não era teorizar, mas dar insumos para extrair o melhor das competências do grupo tanto para a coleta quanto para a análise das informações. $\mathrm{Na}$ apresentação, foram dados exemplos das principais dificuldades encontradas nas parcerias entre grandes empresas e startups ao fazer negócios, conforme ilustra a Figura 20.

Os membros do grupo identificaram-se com os exemplos apresentados. O feedback do time foi positivo. O Participante GI1, que atuava no Coworking, comentou que as dificuldades apresentadas se assemelhavam com alguns desafios internos da empresa XYZ. 
Figura 20 - Principais dificuldades encontradas pelas startups em fazer negócios com grandes empresas

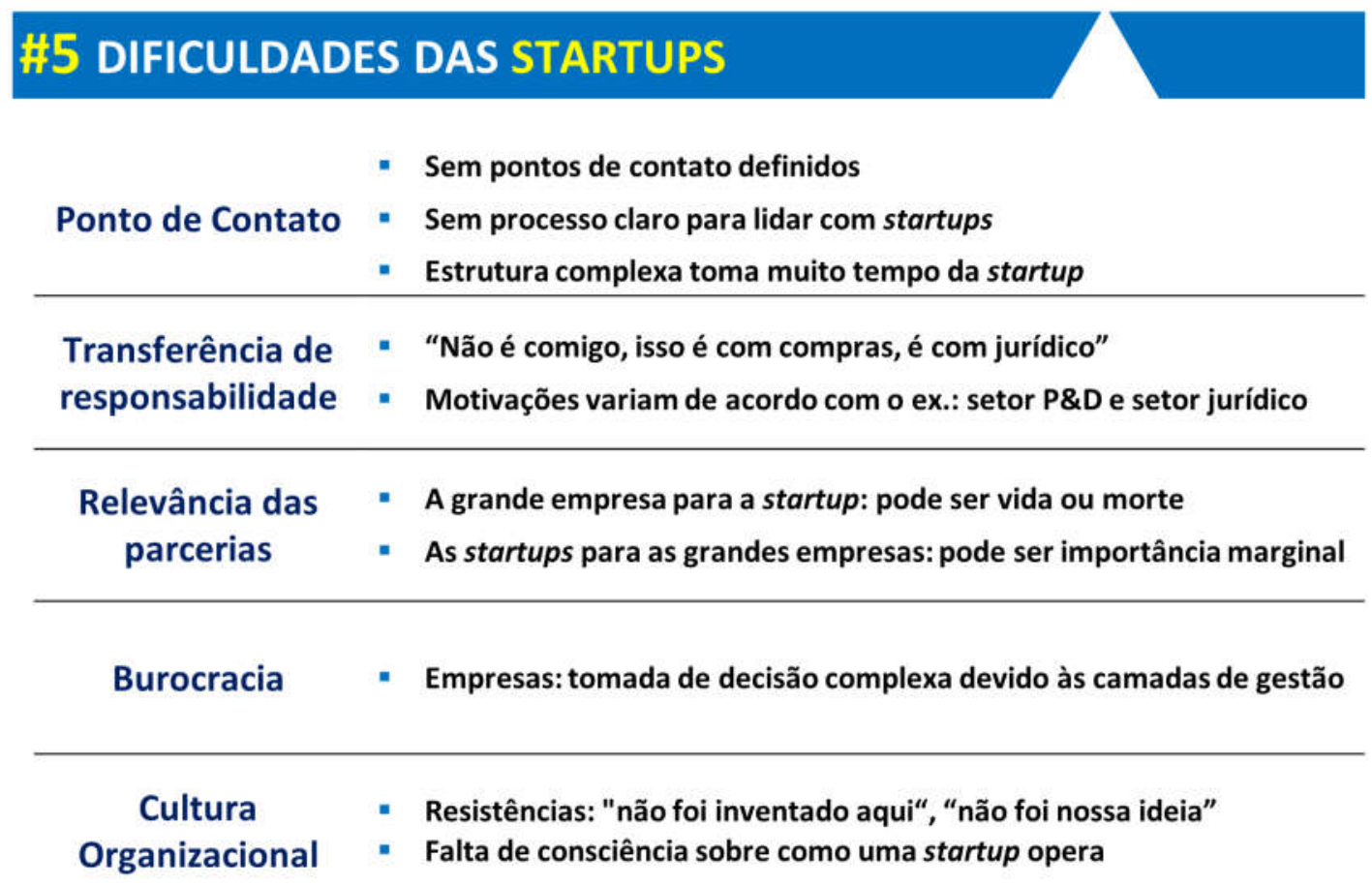

Fonte: Elaborada pelo autor, baseado em Minshall, Mortara, Napp e Probert (2010).

A atividade seguinte, do segundo workshop, foi identificar quais eram os principais fatores existentes na organização que dificultavam ou impediam a realização de negócios com startups. Foi feita, então, uma dinâmica colaborativa que levou em consideração a percepção e a experiência dos membros da equipe. Para possibilitar a coleta desses dados, cada membro envolvido teve dez minutos para elencar os impedimentos, escrevendo-os em pequenas notas adesivas. A seguir, cada um deles apresentou seus próprios argumentos para que todo o grupo discutisse e refletisse.

Ao final da atividade, obteve-se o levantamento de 33 (trinta e três) impedimentos, classificados pelo grupo de trabalho em cinco categorias:

- Engajamento Cultural = 9 (nove) impedimentos;

- Avaliação de Riscos = 5 (cinco) impedimentos;

- Metodologia e Avaliação técnica = 5 (cinco) impedimentos; 
- Transparência $=5$ (cinco) impedimentos;

- Governança/Processos $=9$ (nove) impedimentos.

Uma vez levantados os impedimentos, o passo seguinte foi identificar as principais ações que deveriam ser tomadas para eliminá-los ou mitigá-los. Para realizar esse trabalho, semelhantemente à etapa de identificação de impedimentos, o grupo teve 10 (dez) minutos. Cada membro teve 5 (cinco) minutos para apresentar as propostas de ações e mais 5 (cinco) minutos para que cada uma delas fosse analisada e discutida em grupo.

Deste modo, o resultado do segundo workshop foi a consolidação dos impedimentos e das ações em um documento, que seria enviado a todos os membros do grupo.

A atividade resultou na proposição de 20 (vinte) ações, conforme demonstra a Figura 21. A quantidade de ações foi menor do que os 33 (trinta e três) impedimentos levantados, pois algumas delas destinavam-se a solucionar mais de um impedimento. Por ser uma quantidade de ações extensa, discutiu-se se todas realmente precisariam ser resolvidas pela intervenção.

O pesquisador recomendou ao grupo que fossem definidas ações factíveis de serem implementadas em até três meses, conforme acordado na primeira reunião. $\mathrm{O}$ grupo concordou em refletir sobre as ações propostas e em revisálas ou até mesmo em eliminá-las na medida do possível, até a próxima sessão, que seria realizada duas semanas após

Comentário 3: Essa orientação seguia a sugestão de Coghlan e Brannick (2005) quanto à "gestão de transição", ou seja, uma evolução gradual das ações para atingir o "estado futuro", no caso, "ser referência em fazer negócios com aquele encontro. $\mathrm{O}$ objetivo do próximo encontro seria, portanto, priorizar as atividades e definir os responsáveis por cada uma das ações.

Durante as duas semanas seguintes, as interações foram feitas por e-mails e por telefone. Houve críticas sobre a falta de clareza dos descritivos das ações e sugestões de redefinição delas, bem como sobre os responsáveis. Foi possível perceber um forte engajamento dos membros das áreas de Compras, de Coworking, de Arquitetura de Negócios e de Solução, 
enquanto os participantes das demais áreas não tinham dado nenhum tipo de feedback seja por e-mail, seja por telefone.

Durante o intervalo, o pesquisador enviou ao time de intervenção os resumos dos dois artigos apresentados na primeira interação do grupo, os quais abordavam o relacionamento entre grandes empresas e startups. O objetivo foi possibilitar a reflexão sobre os temas e definir as atividades importantes. No entanto, não houve feedback por parte dos integrantes.

Figura 21 - Apresentação das ações inicialmente propostas pela equipe da força-tarefa

\section{draft key results}

\begin{tabular}{|l|l|l|l|l|l|l|}
\hline $\begin{array}{l}\text { criar kit de } \\
\text { negócio com } \\
\text { startup: } \\
\text { processo, poc, } \\
\text { conceito }\end{array}$ & $\begin{array}{l}\text { ter orçamento } \\
\text { claro para } \\
\text { fazer negócio } \\
\text { com startups }\end{array}$ & $\begin{array}{l}\text { novo modelo } \\
\text { de negócios } \\
\text { com startups } \\
\text { para aliança } \\
\text { estratégica } \\
\text { (assimétrica) }\end{array}$ & $\begin{array}{l}\text { modelo de } \\
\text { desenvolvi- } \\
\text { mento de } \\
\text { startups como } \\
\text { fornecedoras }\end{array}$ & $\begin{array}{l}\text { fortalecer } \\
\text { processo de } \\
\text { relacionamen- } \\
\text { to de negócios } \\
\text { com startups }\end{array}$ & $\begin{array}{l}\text { adequar o } \\
\text { ritmo dos } \\
\text { processos } \\
\text { internos aos } \\
\text { negócios com } \\
\text { startups }\end{array}$ & $\begin{array}{l}\text { radar de } \\
\text { tecnologia das } \\
\text { startups que } \\
\text { tem negócios } \\
\text { com o } \\
\text { [empresa XYZ] }\end{array}$ \\
\hline $\begin{array}{l}\text { modelo } \\
\text { colaborativo } \\
\text { de avaliação } \\
\text { técnica }\end{array}$ & $\begin{array}{l}\text { cultura de } \\
\text { startups entrar } \\
\text { na agenda de } \\
\text { marketing }\end{array}$ & $\begin{array}{l}\text { captar de } \\
\text { forma } \\
\text { estruturada o } \\
\text { roadmap dos } \\
\text { produtos das } \\
\text { startups }\end{array}$ & $\begin{array}{l}\text { realizar } \\
\text { periodicamen- } \\
\text { te comitês com } \\
\text { todas partes } \\
\text { envolvidas } \\
\text { para gerar } \\
\text { alinhamento } \\
\text { estratégico } \\
\text { time }\end{array}$ & $\begin{array}{l}\text { critério e } \\
\text { alçada claros }\end{array}$ & $\begin{array}{l}\text { tracking para } \\
\text { as startups e } \\
\text { para os } \\
\text { negócios }\end{array}$ & $\begin{array}{l}\text { expor APIs } \\
\text { para viabilizar } \\
\text { negócio com } \\
\text { startups }\end{array}$ \\
\hline $\begin{array}{l}\text { mapa de } \\
\text { investimento } \\
\text { com startups }\end{array}$ & $\begin{array}{l}\text { alta liderança } \\
\text { alinhada com } \\
\text { modelo de } \\
\text { fazer negócio } \\
\text { com startups }\end{array}$ & $\begin{array}{l}\text { matriz de } \\
\text { riscos }\end{array}$ & $\begin{array}{l}\text { time dedicado } \\
\text { adequado a } \\
\text { tecnologias de } \\
\text { ponta }\end{array}$ & $\begin{array}{l}\text { mercado de } \\
\text { requisitos para } \\
\text { startups }\end{array}$ & “crunchbase" \\
das startups & & & & & \\
\hline
\end{tabular}

Fonte: Elaborada pelo grupo da intervenção, com base nas discussões internas.

\subsubsection{Ciclo 1: Planejamento}

Em 18 de janeiro de 2017, ocorreu o terceiro workshop. O objetivo do grupo foi identificar as ações mais relevantes para o ciclo e definir a quem caberiam as responsabilidades.

Estiveram presentes apenas 6 (seis) dos 14 (quatorze) colaboradores que haviam participado do primeiro e do segundo workshops. 
O pesquisador sugeriu que as 20 (vinte) ações inicialmente propostas fossem reformuladas a partir da reflexão sobre a prioridade de assuntos e mudanças. Essa reformulação estava baseada em Coughlan e Coghlan (2002). Para dar início à discussão, o pesquisador levantou novamente as mesmas barreiras apontadas no segundo encontro do grupo e o objetivo da Pesquisa-Ação. Após longa discussão, o grupo entendeu que as primeiras mudanças necessárias estavam associadas aos seguintes itens:

- Transparência: permitir que os colaboradores da empresa XYZ conhecessem como funciona uma startup e que as startups compreendessem os processos internos da empresa XYZ;

- Governança: ter acompanhamento adequado das iniciativas que envolvessem startups;

- Processo: revisar os processos atuais que envolvessem a avaliação de startups.

Com base nessas reflexões, foram definidas três ações, considerando-se a razoabilidade para implantação e o potencial benefício a ser obtido. Essa avaliação foi feita pela percepção do grupo e resultaram em:

Comentário 4:

Analisando as ações propostas, percebeu-se que o 'fazer negócios com startups' teve seu escopo focado em utilizar as soluções de startups para resolver problemas de negócios.

- Elaboração do processo de contratação de startups: elaborar cartilha para que tanto as áreas de negócios quanto as startups entendessem o processo de avaliação;

- Comitê quinzenal de acompanhamento de projetos envolvendo startups: estruturar um comitê periódico com o objetivo de compreender a situação dos projetos e de resolver de forma mais ágil os problemas envolvendo a avaliação de startups;

- Modelo evolutivo para avaliação de startups: estruturar um plano evolutivo com as áreas internas da organização para avaliação mais eficaz das startups. 
Uma vez definidas as ações, o pesquisador solicitou ao grupo que refletisse sobre os possíveis impedimentos para realizá-las e sobre as formas de validá-las com os diretores envolvidos. O grupo entendeu que o não estabelecimento de prioridades e o não engajamento dos demais membros envolvidos poderiam ser um forte impedimento para viabilização da PesquisaAção.

\subsubsection{Ciclo 1: Ações}

As ações começaram a ser implementadas no início de fevereiro de 2017. Apesar de existirem três frentes, as mesmas 6 (seis) pessoas envolvidas no planejamento foram as que se mantiveram ativas durante as ações. Os demais membros também participaram pontualmente. Na dinâmica de grupo, embora houvesse responsáveis pelas atividades, não havia uma liderança formal. O grupo tomava decisões colegiadas.

No decorrer do processo, a comunicação passou a ser um fator crítico. Para melhorá-la, o pesquisador agendou conversas semanais recorrentes. As dificuldades relatadas diziam respeito ao tempo de dedicação para execução das atividades, pois os membros não estavam imersos nas ações em tempo integral, uma vez que todos tinham atividades paralelas. Com base na conversa com três membros, pode-se concluir que o tempo médio de dedicação era de 12 (doze) horas semanais, cerca de $30 \%$ da capacidade.

Em 25 de janeiro de 2017, o plano das ações foi apresentado aos Executivos de Tecnologia da empresa XYZ. Logo após a reunião, a percepção do grupo foi que a ideia tinha sido bem aceita pelos executivos. No entanto, passadas duas semanas, as pessoas solicitadas ainda não haviam sido alocadas na intervenção. Na terceira semana após a reunião com o comitê, foi realizada a segunda ação do grupo - um pedido formal por e-mail para que fossem designadas as pessoas que deveriam fazer parte das ações. Desta vez, positivamente, pois houve aceno para alocar mais uma pessoa, que passou a atuar pontualmente. A interpretação por parte dos 6 (seis) membros mais envolvidos foi que, apesar do interesse dos executivos, havia outras

prioridades no cotidiano da empresa. Esse reflexo podia ser observado nos incentivos dos 
membros para executar as ações. Com exceção dos Participantes GI1 e FA1 (do Coworking e de Compras, respectivamente), os demais membros não tinham metas associadas às implementações. Se eles não as tinham, seus superiores também não. As ações desenvolvidas serão detalhadas a seguir.

\section{Ação 1: Cartilha com processo de contratação de startups}

A elaboração da cartilha (que naquele momento ainda não tinha sido assim nomeada) foi iniciada logo após a formalização do plano, em um workshop realizado em 1 de fevereiro de 2017. Esse evento foi conduzido por um analista do time de processos de tecnologia, que não fazia parte da intervenção, mas tinha sido convidado pontualmente para aquele workshop. Nesse evento, foi contextualizado a todos os participantes o objetivo de se desenvolver um macroprocesso para realizar a contratação de alguma startup como fornecedora de solução.

No decorrer da apresentação de abertura, foi explicado, inclusive, que as áreas ali presentes eram necessárias para mapear detalhadamente cada um dos processos e, assim, vinculá-las ao desenho do macroprocesso.

Passados dois dias da realização dos workshops detalhando os processos, o progresso havia sido de cerca de 10\%. Mesmo assim, os representantes das áreas ainda tinham dúvidas sobre as regras e as exceções dos processos.

Após estudos, o grupo da intervenção decidiu mudar de estratégia. Ao invés de efetuar detalhamentos exaustivos de processos, sem nem sequer saber se funcionariam, decidiu-se mantê-los como estavam e simplificar a maneira como eles seriam comunicados aos colaboradores e às startups. Toda essa simplificação seria apresentada diretamente em uma 'Cartilha'.

\section{Comentário 5:}

De acordo com Bannerjee, Bielli e Haley (2016, p. 21), apresentar os processos da empresa de forma menos complexa entrega um valor positivo e rápido. Eles afirmam que a abordagem é semelhante a "esconder todo o emaranhado de fiações atrás da parede" de uma sala de TV e deixar apenas os plugs à vista. 
Para um diagnóstico inicial, o grupo resolveu coletar informações básicas dos processos por meio de um questionário simples enviado por e-mail aos envolvidos nos workshops de mapeamento de processos, conforme Quadro 13. As respostas foram analisadas e serviram para confeccionar o primeiro protótipo da cartilha. Em seguida, foi realizada uma reunião com os representantes para refinamento e explicações gerais. Após interações por e-mail, por telefone e presenciais, a cartilha foi concluída em 20 de março de 2017 (Figura 22).

Quadro 13 - Questionário base para criação da Cartilha

\section{Questionário base para criação da Cartilha}

- Qual o papel da sua área na contratação de uma startup?

- De forma macro, como funcionam os processos de sua área?

- Qual o SLA - tempo previsto - médio para cada uma das etapas?

- Existem ferramentas de controle para cada etapa do processo? Quais? Como funcionam?

- Atualmente, existem responsáveis e pontos focais para cada etapa do processo?

- Como você avalia a transparência do processo de contratação de startup?

- Como é feita a comunicação das etapas para as áreas com as quais você interage?

Fonte: Elaborado pelo grupo da intervenção, baseado em discussões internas. 
Figura 22 - Detalhe da Cartilha de processos de contratação de startups

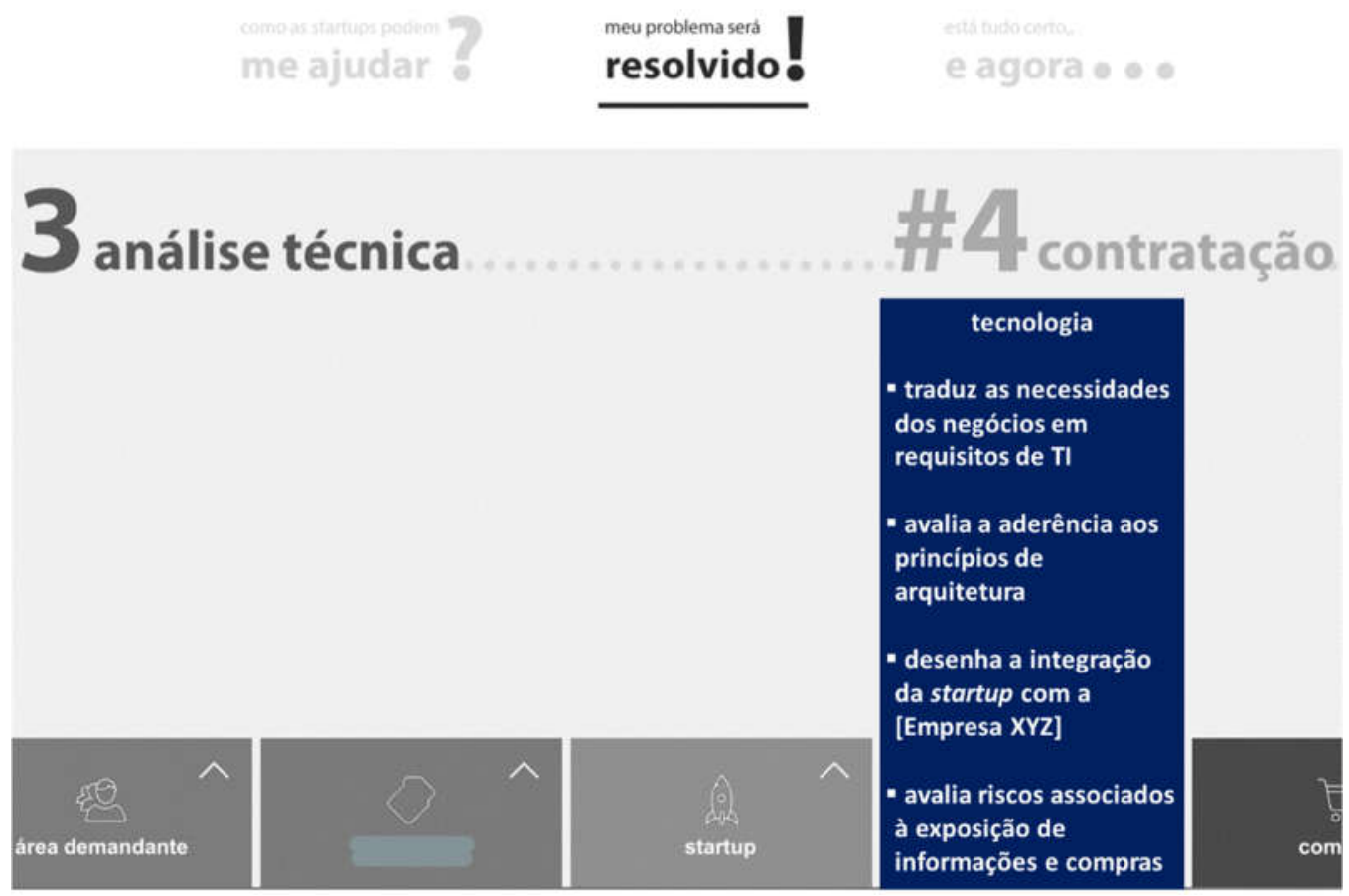

Fonte: Elaborado pelo grupo da intervenção.

\section{Ação 2: Comitê quinzenal de acompanhamento de projetos envolvendo startups}

O comitê quinzenal foi criado em 24 de janeiro de 2017, antes mesmo de o plano ter sido oficializado aos executivos. Esperava-se com isso melhorar o relacionamento das startups com a empresa XYZ por duas razões: dar visibilidade à organização sobre o andamento dos projetos e compreender os pontos mais críticos das avaliações das startups para gerar novas ações.

A atividade inicial para estabelecer a governança sobre as demandas foi mapear as iniciativas que envolviam startups. Foi, então, necessário efetuar uma varredura nos 8 (oito) pontos de contato de cada uma das áreas. No entanto, antes de conversar com cada uma delas, foi preciso confeccionar uma planilha eletrônica destacando os campos necessários para obter uma governança adequada, como: responsáveis, etapas, observações, motivos de 
cancelamento e PoC - Prova de Conceito. No final das rodadas de comitê, a planilha foi substituída por uma ferramenta virtual e Kanban ${ }^{6}$.

Ao finalizar a etapa de mapeamento, foi estabelecido o comitê de acompanhamento dos projetos com periocidade quinzenal, liderado pelo Participante GI1 (de Coworking). Logo no início, foi acordado o papel exercido por cada um deles no Comitê. O pesquisador e mais dois arquitetos - de Solução e de Negócios - foram os responsáveis por responder às questões de Tecnologia. Coube ao analista de compras responder às questões de processo comercial e ao Participante GI1, às pendências das áreas de Negócios demandantes e das startups.

As pendências de Compras, Negócios e Startups foram respondidas em um prazo de uma semana e as de Tecnologia demoravam de uma a três semanas. Muitas das pendências de Tecnologia não diziam respeito à área de Arquitetura e tiveram que ser encaminhadas para outras equipes, não sendo respondidas dentro do prazo esperado ou até mesmo nem sendo respondidas. $\mathrm{O}$ esforço semanal para atualizar as demandas era excessivo. Ao final de dois meses, o grupo resolveu cancelar o comitê, devido ao grande esforço em mantê-lo e ao baixo retorno.

\section{Ação 3: Modelo evolutivo para avaliação de startups}

Estabelecer um novo processo para avaliação de startups vinha sendo uma ambição da área de Tecnologia desde 2016. Em 13 de fevereiro de 2017, foi iniciada a elaboração de um modelo de avaliação de startups. Foi a ação que mais tardou a começar. Nela, o presente pesquisador exerceu o papel de líder.

Para fazer o levantamento de mudanças no processo, era necessário obter insumos de quatro áreas: de Arquitetura de Solução, de Arquitetura de Tecnologia, de Arquitetura de Negócios

\footnotetext{
${ }^{6}$ Kanban é uma ferramenta que indica de forma visual o andamento de determinados fluxos de atividades. Alguns exemplos de indicação de atividades são: 'a iniciar', 'em andamento' e 'finalizado'.
} 
e de Segurança da Informação. A preocupação do time era com relação às alocações de pessoas capazes de representar essas áreas pois, apesar de terem designado os pontos focais, sofriam com a concorrência de outras atividades paralelas. A opção do grupo foi assumir premissas quando da falta de pessoas e, posteriormente, validá-las com os profissionais. Houve longo período de revisões e validações com as áreas e morosidade nos retornos, o que acabou atrasando ainda mais a entrega da proposta.

Para efetuar a proposição dos ciclos, levou-se em consideração as diretrizes obtidas em documentos da organização, as lições aprendidas com outros projetos, as recomendações de consultorias e as teorias identificadas no início do ciclo. As atividades foram organizadas obedecendo a um cronograma e compartilhadas com todos os envolvidos.

Após as discussões ocorridas em fevereiro de 2017, em $1^{\mathrm{o}}$ de março, uma proposta de implementação do modelo de avaliação de startups foi apresentada aos superintendentes das equipes envolvidas, que aprovaram a continuidade do plano, sem alterações ou ressalvas.

A proposta possuía um plano de evolução em três etapas (Figura 23). A primeira, sugeria uma experimentação de algumas práticas de open innovation com startups. A ideia era que, ao término de três meses, se compreendesse o que deu certo e o que poderia ser melhorado. A segunda, dizia respeito à criação de ferramentas para avaliação de solução de startups baseadas na experiência adquirida na primeira etapa. A terceira, seria estabelecer um processo formal, consolidando todo o aprendizado.

A intenção do grupo era concluir o processo proposto até o final de março de 2017, mas não foi possível, pois dois dos três membros designados para aquela ação foram realocados para outras atividades, inviabilizando a

Comentário 6: A saída dos profissionais deu um sinal de 'alerta' em relação às futuras perdas de conhecimento, conquistadas pelo time. implementação da proposta. 
Figura 23 - Detalhes da apresentação do modelo de processo para avaliação de startups

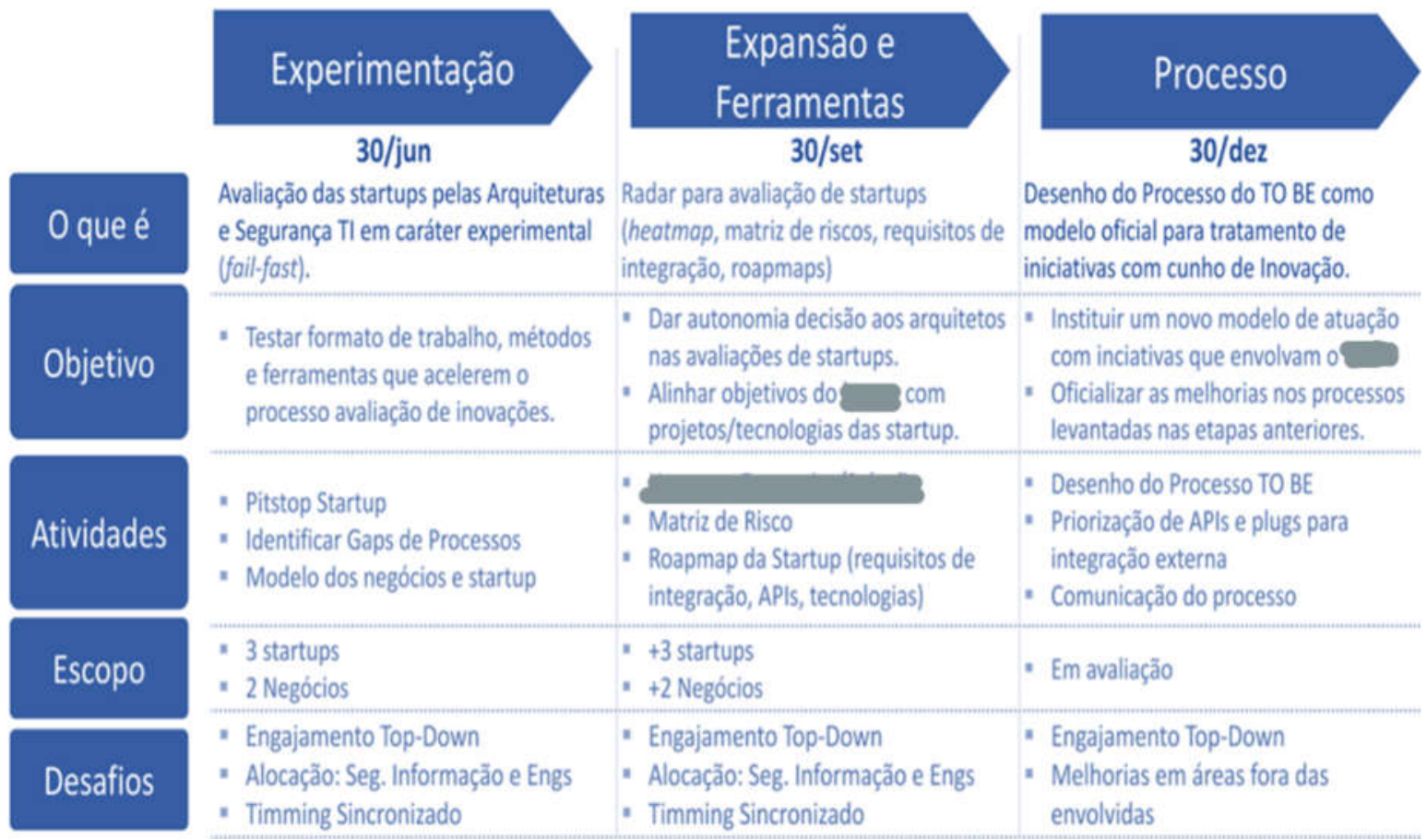

Fonte: Elaborada pelo grupo da intervenção, com base em discussões internas. ${ }^{7}$

\subsubsection{Ciclo 1: Avaliação}

Em 31 de março de 2017, ao finalizar as atividades de intervenção do Ciclo 1, 8 (oito) profissionais, entre os 14 (quatorze) inicialmente alocados, saíram do grupo: 4 (quatro) deles pertencentes ao núcleo mais ativo, composto por seis pessoas. Em compensação, 9 (nove) novos integrantes ingressaram no Ciclo 2, permanecendo como remanescentes apenas o pesquisador e um membro da área de Arquitetura de Negócios.

$\mathrm{Na}$ reunião de avaliação, além dos membros participantes do Ciclo 1, foram convidados também os membros que executariam o ciclo seguinte. $O$ pesquisador adotou essa medida para mitigar os riscos de perda de conhecimento durante a transição. O quórum de membros

\footnotetext{
${ }^{7}$ Essas figuras foram geradas pelo grupo da intervenção, estando sujeitas a eventuais erros ortográficos ou gramaticais.
} 
do Grupo 1 era baixo, apenas 4 (quatro) dos 14 (quatorze) iniciais, enquanto os representantes presentes do Grupo 2 eram 7 (sete).

Na reunião, conduzida pelo pesquisador, foi apresentado o resumo de cada uma das etapas do ciclo, diagnóstico, planejamento e ações. Na etapa de diagnóstico, ao apresentar os envolvidos nos workshops, houve indagação por parte do Participante CA2, integrante do novo time, sobre a não participação de startups durante o processo. O Participante GI1 (de Coworking) respondeu que tinha consciência de que aquilo era uma limitação do diagnóstico. Porém, afirmou que no decorrer da discussão, eventuais informações poderiam ser divulgadas e não poderiam ser expostas a startups naquele momento. Ele ressaltou que o time de Coworking tinha capacidade para reproduzir os "pontos de dores" das startups. A seguir, o pesquisador apresentou os resultados de cada uma das entregas do Ciclo 1.

\section{Ação 1: Cartilha com processo de contratação de Startups}

A entrega da 'Cartilha' foi a ação realizada. Houve consenso entre os presentes que o material era relevante interna e externamente.

O Participante FA1 (de Compras) afirmou que "a cartilha trouxe [tinha trazido] uma visão abrangente dos papéis e passos envolvidos na contratação de uma startup" e que isso se deu graças à participação das 8 (oito) áreas envolvidas nos processos de contratação de startups.

Na sequência, o Participante MA1 fez uma crítica à Pesquisa-Ação.

Ele temia que a cartilha desestimulasse a melhoria dos processos que impactavam as startups. O Participante LU12 (de Arquitetura de Negócios) afirmou que, independentemente da 'Cartilha', seriam realizadas sessões de melhoria dos processos atuais por meio dos Kaizens.

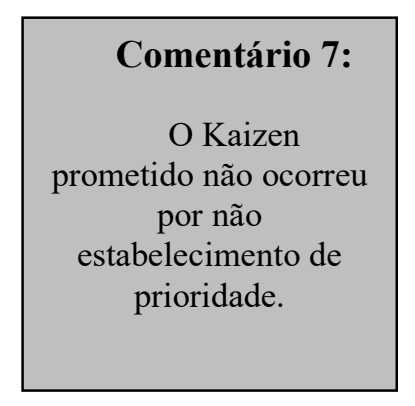


O Participante CA2 (de Arquitetura de Negócios), comentou sobre a ausência de prazos estimados nas etapas apresentadas na 'Cartilha'. O Participante GI1 (de Coworking) afirmou que era inviável fazer estimativas, pois os prazos variavam de acordo com a complexidade de cada demanda.

\section{Ação 2: Comitê quinzenal de acompanhamento de projetos envolvendo startups}

O pesquisador apresentou o último painel de status dos projetos que envolviam startups. No último levantamento feito havia um total de quatorze demandas envolvendo startups, cujas situações foram sintetizadas no Quadro 14.

Quadro 14 - Situação geral das iniciativas mapeadas pelo grupo no período da intervenção

\begin{tabular}{|c|c|c|}
\hline Grupo Situacional & Fase das Iniciativas & $\begin{array}{c}\text { Quantidade de } \\
\text { Demandas }\end{array}$ \\
\hline Aprovada & Execução & 6 \\
\hline Cancelada (negócio) & $\begin{array}{c}\text { Ideação / Prova de } \\
\text { Conceito }\end{array}$ & 3 \\
\hline Cancelada (startup) & Anteprojeto & 1 \\
\hline Reprovada & Prova de Conceito & 3 \\
\hline Reprovada & Ideação & 1 \\
\hline
\end{tabular}

Fonte: Elaborado pelo autor, a partir de dados da intervenção.

Foram quatro as demandas reprovadas, assim como também foram quatro as canceladas por desistência das áreas de negócios ou da própria startup. As reprovações estavam associadas ao não atendimento dos requisitos técnicos, por exemplo, volumetria de transações e riscos de exposição de informações. Quanto às desistências não se conseguiu especificar as razões.

Em relação às seis iniciativas aprovadas, duas foram por alçadas executivas; as outras quatro estavam relacionadas com os canais de comunicação, ou seja, não estavam diretamente relacionadas à atividade central da empresa. 
O Participante GI1 (de Coworking) afirmou que o comitê contribuiu para a compreensão da forma como os processos internos e a cultura da organização afetavam as iniciativas envolvendo as startups. Apesar dessa visão, segundo ele, seria inviável continuar o acompanhamento pela falta de recursos dedicados a mapear e a acompanhar todas as demandas e pela penetração das áreas para obter informação sobre a situação dos projetos.

Na opinião do Participante GI1, para tornar viável o acompanhamento dessas demandas, seria necessário a alocação de pessoas dedicadas em cada um dos departamentos. Essas pessoas deveriam estar 'empoderadas' para transpor suas áreas departamentais. Uma sugestão dada pelo pesquisador foi que os responsáveis por essas atividades tivessem metas e incentivos a serem cumpridos, do contrário, ficariam sufocados em atividades de rotina. A atividade de acompanhamento não teve continuidade nos ciclos seguintes.

\section{Ação 3: Modelo evolutivo para avaliação de startups}

A última entrega apresentada foi a proposta de avaliação das startups. O pesquisador apresentou tanto o referencial teórico como os dados de consultorias externas que serviriam como embasamento para a elaboração do plano e de suas três fases. A sugestão do pesquisador foi que essas três fases se tornassem os próximos ciclos a serem executados até o final de 2017.

No momento em que fazia a exposição dessas fases, o Participante CA2 (de Arquitetura de Negócios) indagou se a proposição apresentada realmente seria o melhor caminho para executar os ciclos subsequentes. Ele complementou, a seguir, que "gostaria que o grupo revisse as ações dos próximos ciclos". Na sequência, dois novos membros do grupo afirmaram não ter conhecimento suficiente sobre as startups para poder executar aquelas ações. 
O Participante CA2 e os novos integrantes demonstraram interesse em se aprofundar nos embasamentos. Por aclamação, decidiram que iriam rever os próximos planejamentos dos ciclos.

Durante os dois primeiros workshops, o pesquisador percebeu o quanto a experiência pregressa dos envolvidos e a colaboração contribuíram para uma visão ampla dos problemas a serem enfrentados pela organização. A vivência dos colegas com startups e a coletividade das discussões também trouxeram qualidade ao conteúdo coletado, muito difícil de ser obtida individualmente. Coghlan e Brannick (2005) corroboram com essa visão, ao afirmarem que a Pesquisa-Ação possui abordagem colaborativa; que os clientes ou colaboradores conhecem melhor do que ninguém os problemas; e que ações podem funcionar.

\subsubsection{Autorreflexões sobre o Processo do Ciclo 1}

Quanto aos processos, o framework de OKR utilizado para organizar o trabalho do grupo participante do Ciclo 1 foi aderente à abordagem de Pesquisa-Ação. A sequência: (1) definir um objetivo; (2) levantar impedimentos; e (3) propor posteriormente ações é compatível com as etapas: (1) contexto/propósito; (2) diagnóstico; e (3) planejamento de ações, de Coghlan e Brannick (2005). Em adendo, a abordagem de Pesquisa-Ação e de framework de OKR trabalham a definição de um objetivo inicial amplo e a proposição de atividades a serem executadas para atingi-lo.

Com base na reflexão sobre a maneira como foi executada a etapa de diagnóstico, foi possível constatar que houve uma decisão tácita entre definir um problema específico ou ser abrangente no levantamento dos problemas. Foi escolhida a segunda opção. O pesquisador entendeu que isto ocorreu em função de duas questões: o grupo possuía uma visão gerencial da organização, pois 10 dos 14 envolvidos possuíam cargos de gestão; e a própria dinâmica adotada previa tempos pré-determinados justamente para que o grupo não se estendesse nas discussões. 
Na etapa de diagnóstico, constatou-se a percepção positiva do grupo durante os workshops, capturada pela observação, por conversas informais e pelas entrevistas. No entanto, apesar de a dinâmica dos workshops ter provocado certo entrosamento e engajamento, não foi suficiente para manter todos os 14 (quatorze) envolvidos até o final do Ciclo 1.

Outro fato perceptível no Ciclo 1 foi o baixo interesse dos membros do grupo nos conteúdos teóricos e nos materiais de consultorias enviados por e-mail. A experiência mostrou que essa abordagem não gerou engajamento. O pesquisador questionou dois membros sobre o $e$-mail enviado. Um deles afirmou que "não havia percebido o e-mail na caixa [de mensagens]". O outro disse que havia visto o e-mail, porém não havia tido tempo para lê-lo. Como aprendizado, na fase de diagnóstico do ciclo seguinte, o pesquisador propôs realizar seminários para estimular a compreensão dos membros sobre as informações teóricas e práticas e, a seguir, compará-las com os dados coletados na empresa XYZ. Essa sugestão destacou a questão participativa do grupo nas etapas da Pesquisa-Ação, principalmente na de diagnóstico (Coghlan \& Brannick, 2005).

O processo para identificação dos impedimentos e proposições de ações gerou valor para o Ciclo 1 e para os posteriores. Essa percepção foi obtida pelas entrevistas com membros dos Grupos 1 e 2. No entanto, as críticas sobre o risco de vieses nos impedimentos levantados fizeram sentido, pois não houve envolvimento direto das startups durante as discussões. O Grupo 1 poderia tê-las inserido, usando, por exemplo, mecanismos de confidencialidade, como ‘acordo de não divulgação’ (Minshall, Mortara, Napp, \& Probert, 2010).

Na etapa de 'Planejamento' do Ciclo 1, percebeu-se que orientar o planejamento do ciclo com perguntas baseadas em necessidades foi uma decisão acertada (Coughlan \& Coghlan, 2002). Se tal atitude não fosse tomada logo no início dessa etapa, não seria possível a associação das ações com o objetivo proposto, o que aumentaria o risco de a Pesquisa-Ação fracassar.

Quanto à elaboração das ações, surgiu ainda uma outra reflexão, desta vez, sobre o seu processo. A discussão aberta utilizada foi suficiente para elaborar as ações, pois apenas três 
temas seriam abordados: transparência, governança e processos. Porém, no caso de haver maior quantidade de temas, ficaria inviável definir ações em discussão aberta. Nessas situações, para facilitar a tomada de decisão, melhor seria utilizar um método baseado em indicadores, conforme recomendam McNiff, Lomax e Whitehead (1996).

Outra situação que o pesquisador e parte do grupo consideraram preocupante foi a falta de engajamento de alguns membros, que passou a ocorrer a partir da etapa de planejamento das ações.

No decorrer do ciclo, o pesquisador constatou que o fato de possuir um e-mail de um executivo afirmando estar 'de acordo' com a execução das ações e com a alocação de seus subordinados não era suficiente para que houvesse engajamento. Segundo estudos como os de Bannerjee, Bielli e Haley (2016) e Mortara, Slacik, Napp e Minshall (2010), uma das recomendações para mitigar esse problema seria a proposição de incentivos e metas, visando a realmente obter comprometimento. Isso foi comprovado na prática, pois os membros mais engajados no ciclo tinham metas associadas às ações.

Em relação à etapa de 'Ações implementadas', o 'Comitê quinzenal de acompanhamento de projetos envolvendo startups' foi o que apresentou melhor compreensão da cultura da empresa em relação às startups. O principal aprendizado sobre as iniciativas foi em relação à falta de relevância da comunicação quando necessária, principalmente a externa, por exemplo, ao tornar o motivo da desistência ou reprovação para as startups, uma reclamação comum dessas empresas com relação às corporações (Minshall, Mortara, Napp, \& Probert, 2010).

Outro resultado do Comitê que chamou a atenção foram as características das demandas aprovadas; duas delas por alçada de diretores e outras duas por não estarem relacionadas à atividade principal de empresa. A primeira situação está relacionada à morosidade dos processos e a segunda, ao fato de as demandas envolvendo atividades não-core terem menor resistência. Essas são ideais também para se executar pilotos (Mortara, Napp, Slacik, \& Minshall, 2009; Prats, Amigó, Ametller, \& Batlle, 2017). 
Outra entrega que trouxe reflexões foi o 'Modelo evolutivo para avaliação de startups'. Apesar de esse processo ter sido construído utilizando referenciais teóricos e de consultorias (Mortara, Napp, Slacik, \& Minshall, 2009; KPMG, 2015; Schättgen \& Mur, 2016), em conversa informal com os Participantes CA2 e VI2 - membros do Ciclo 2 -, foi constatado que a proposição não foi comunicada adequadamente. Esse fato gerou resistências do Grupo 2 em aceitar a proposta. Essa situação deixou como aprendizado que é preciso explicar de maneira bastante clara as propostas para reduzir desconfortos sobre os alinhamentos com os times, principalmente os que não tiverem participado de fases anteriores no processo de intervenção. Ficou comprovado que a inconstância de membros do time prejudicava a ação de iniciativas voltadas à inovação, por não terem conhecimento prévio (Schättgen \& Mur, 2016; Weiss \& Hoegl, 2016).

Ainda sobre a estruturação do 'processo para avaliação de startups', o pesquisador percebeu que, por mais que fosse construída uma proposta de avaliação, a baixa adesão de alguns perfis necessários à intervenção enfraqueceu a legitimidade do modelo. Ficou o aprendizado que é necessário identificar os assuntos críticos previamente e reivindicar junto ao sponsor representantes que fiquem disponíveis integralmente para o grupo. Nesse sentido, Mortara, Napp, Slacik e Minshall (2009) e Prats, Amigó, Ametller e Batlle (2017) ressaltam a importância de se ter um time multifuncional e dedicado para executar ações voltadas à inovação e à Corporate Venturing.

Uma das primeiras reflexões quanto às ações desenvolvidas foi sobre o quanto a redução da equipe ao longo do processo afetou o rendimento do grupo. A falta de recursos com expertise impossibilitou a viabilidade do modelo de avaliação de startups, por exemplo.

Ainda sobre a questão da equipe, questionou-se sobre qual era a importância da intervenção para os convocados e seus líderes. Um forte indicador seria o quanto suas metas estariam associadas à intervenção. Baseado nesse indicador, havia apenas dois membros no grupo com metas associadas à intervenção. Kuratko e Goldsby (2004) e Morris e Kuratko (2002) identificam a ausência de metas como uma das principais barreiras para gerar cultura 
empreendedora nas organizações. De forma complementar, Martins e Terblanche (2003) reforçam que os incentivos adequados são habilitadores para uma cultura de inovação em organizações.

Outro indicador para engajamento de lideranças, na visão de Thieme (2017) e Mortara, Slacik, Napp e Minshall (2010), é ter uma estratégia bem definida de relacionamento com startups. Apesar de o grupo possuir um objetivo macro a ser alcançado na Pesquisa-Ação 'ser referência em fazer negócios com startups' -, no Ciclo 1, ainda não se tinha clareza de como a organização construiria esse relacionamento, o que dificultou a criação de engajamento com as lideranças pares do diretor-patrocinador. Cabe considerar que não existia uma visão compartilhada quanto ao real interesse no relacionamento com startups.

A confecção da cartilha também trouxe aprendizados importantes: primeiramente quanto à ponderação entre reestruturar processos organizacionais complexos versus melhorar a forma de como comunicá-los. Avaliando o objetivo da ação - dar transparência aos colaboradores -, e as boas práticas recomendadas por Bannerjee, Bielli e Haley (2016) e Minshall, Mortara, Napp e Probert (2010), foi possível perceber que simplificar a comunicação era a melhor alternativa.

O 'Comitê quinzenal de acompanhamento de projetos envolvendo startups' apresentou também situações desafiadoras, dentre elas, a ausência de um processo claro e a inexistência de pessoas formalmente designadas para resolver os problemas desse tipo de iniciativa. O principal aprendizado foi que a falta de procedimento estabelecido e de incentivos corretos dificulta a condução dos projetos envolvendo startups. A situação oposta, no entanto, é corroborada por Kuratko, Hornsby e Covin (2014) e Dombrowski et al. (2007), que afirmam que os incentivos e a extensão dos limites dos departamentos são essenciais para uma mudança interna caminhar em direção ao empreendedorismo corporativo e à inovação, como exige a atuação com startups.

Ao refletir sobre a construção de um engajamento junto as lideranças, o pesquisador constatou que não houve estratégia nesse sentido. $\mathrm{O}$ grupo poderia ter proposto reuniões 
intermediárias ou uma governança formal, como sugerem Prats, Amigó, Ametller e Batlle (2017) e Mortara, Napp, Slacik e Minshall (2009), o que poderia ter sido utilizado para sinalizar o impacto do número insuficiente de pessoas para as atividades e até mesmo para garantir o compromisso de metas dos executivos.

Por fim, a etapa de ‘Avaliação' também gerou conhecimentos. A apresentação dos resultados ocorreu durante uma hora e meia e não foi suficiente para conquistar o engajamento do Grupo 2. Em primeiro lugar, pelo desconforto pelo fato de o grupo não ter referência de como outras organizações atuavam com startups. Em segundo, por membros do grupo terem manifestado que não estavam habituados a lidar com startups. E, em terceiro, pelo pouco tempo para ambientação dos novos participantes quanto às atividades da intervenção, haja vista o fato de eles terem entrado no processo apenas no Ciclo 2.

Estes fatos fizeram com que o pesquisador refletisse sobre as maneiras de como mitigar futuras perdas de experiência do time e de como capacitá-lo, visto que a manutenção do conhecimento e a capacitação do time são essenciais para executar ações internas voltadas à inovação (Mortara, Napp, Slacik, \& Minshall, 2009; Ahmed, 1998; Rumelt, 1995; Fasnacht, 2009). Apesar do ruído gerado, a experiência adquirida no Ciclo 1 foi utilizada como subsídio nos ciclos seguintes.

O Quadro 15, apresentado a seguir, sintetiza todos os procedimentos, ações e resultados decorrentes do Ciclo 1.

\section{Quadro 15 - Síntese do Ciclo 1: Exploratório}

\begin{tabular}{|c|c|}
\hline Período & Ciclo 1 - Exploratório \\
\hline $\begin{array}{c}\text { Papel do } \\
\text { Pesquisador }\end{array}$ & Membro e Consultor. \\
\hline $\begin{array}{c}\text { Escopo no momento } \\
\text { do Ciclo }\end{array}$ & 'Diagnosticar os problemas que dificultam a empresa a fazer negócios com startups e a \\
propor ações de melhoria'.
\end{tabular}




\begin{tabular}{|c|c|c|}
\hline \multicolumn{2}{|c|}{ Diagnóstico } & $\begin{array}{l}\text { - Objetivo: Identificar o propósito e o objetivo da intervenção (workshops). } \\
\text { - Coleta: Identificar quais seriam os principais problemas ao se relacionar com startups } \\
\text { e os dados secundários de artigos (workshops). } \\
\text { - Análise: Fazer anotações em post-its e, posteriormente, organizá-las em slides e em } \\
\text { planilhas eletrônicas (workshops). } \\
\text { - Resultados: Discutir conjuntamente em workshop. }\end{array}$ \\
\hline \multicolumn{2}{|c|}{ Planejamento } & $\begin{array}{l}\text { - O grupo deve estabelecer priorização em workshops e em planejamento feito em } \\
\text { planilha: } \\
\text { ○ Time dedicado e autônomo; } \\
\text { ○ Transparência dos processos internos envolvendo startups; } \\
\text { ○ Governança dos projetos com startups; } \\
\text { ○ Revisão dos processos envolvendo startups. }\end{array}$ \\
\hline \multicolumn{2}{|c|}{ Entregas Realizadas } & $\begin{array}{l}\text { - Cartilha com processo de contratação de startups. } \\
\text { - Comitê quinzenal para acompanhamento de projetos envolvendo startups; } \\
\text { - } \quad \text { Modelo evolutivo para avaliação de startups. }\end{array}$ \\
\hline \multirow{3}{*}{ 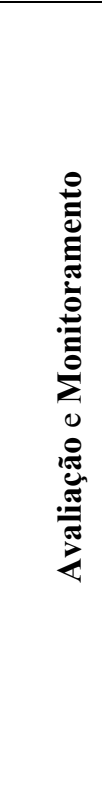 } & $\begin{array}{l}\text { Pontos } \\
\text { Positivos/ } \\
\text { Habili- } \\
\text { tadores }\end{array}$ & $\begin{array}{l}\text { - Apoio inicial do diretor-patrocinador. } \\
\text { - Pequeno núcleo do grupo de intervenção engajado. } \\
\text { - Visão geral dos processos, dores, problemas na contratação de uma startup. } \\
\text { - Conscientização sobre os problemas entre as fronteiras departamentais do processo. }\end{array}$ \\
\hline & $\begin{array}{l}\text { Pontos } \\
\text { Negativos/ } \\
\text { Barreiras }\end{array}$ & $\begin{array}{l}\text { - } \text { Falta de clareza quanto ao objetivo do grupo (visão abrangente). } \\
\text { - Visão simplista (superficial) dos problemas internos. } \\
\text { - } \text { Falta de prioridade (e ausência) de alguns participantes. } \\
\text { - } \text { - } \text { - Conficuldades dos membros em dedicar tempo para realização das atividades. } \\
\text { - Falta de incentivo/metas entre os membros (apenas dois membros com bônus } \\
\text { - } \text { - Troca de membros dos times envolvidos (perda de conhecimento e legitimidade). } \\
\text { - } \text { Dificuldade de comunicação entre departamentos. } \\
\text { - Falta de visão holística dos processos internos da empresa. } \\
\text { - Visão interna sobre projetos de startups não estruturada. }\end{array}$ \\
\hline & $\begin{array}{l}\text { Melhorias } \\
\text { propostas } \\
\text { pelo } \\
\text { grupo }\end{array}$ & $\begin{array}{l}\text { - Estabelecer incentivos e metas para os colaboradores envolvidos na intervenção. } \\
\text { - Definir as pessoas dedicadas para executar as atividades. } \\
\text { - Aprofundar o conhecimento dos membros da equipe sobre o ecossistema de startups. }\end{array}$ \\
\hline
\end{tabular}

Fonte: Elaborado pelo autor. 


\subsubsection{Ciclo 2 - Capacitação Interna, Aculturamento e Ferramental}

Após apresentação dos resultados do Ciclo 1, para o Ciclo 2, foram estabelecidas novas diretrizes pelos executivos envolvidos. A primeira, referia-se à dedicação do time: os membros passariam a dedicar $10 \%$ de suas cargas de trabalho semanais para a execução da intervenção, no entanto, sem datas fixas. A segunda, referia-se aos incentivos: ao menos 5\% do contrato de metas dos membros deveria estar associado à intervenção. A terceira, referiase ao aferimento da meta com os resultados: deveria ocorrer no final da intervenção por especialistas de tecnologia da organização.

Por fim, em relação à amplitude do escopo da Pesquisa-Ação, foi estabelecido que o grupo deveria diminuir a dependência de outras áreas além da de Tecnologia, focando a atuação das ações prioritariamente nesta. Os impeditivos sobressalentes, identificados no Ciclo 1, como modificar processos de compras, passariam a ser descentralizados entre as diretorias da empresa XYZ, ficando a execução de planos prioritários a critério de cada uma das diretorias envolvidas.

Esses direcionamentos reforçaram a não realocação para o próximo ciclo de pessoas com conhecimento no coworking e em compras, o que levou à saída dos membros das áreas não envolvidas ao final do Ciclo 1.

Em 3 de abril de 2017, foi realizada a primeira reunião do grupo responsável pelo Ciclo 2, conforme apresentado no Quadro 16, no qual constam, inclusive, os demais marcos desse ciclo. No evento, estiveram presentes 7 (sete) dos 11 (onze) membros designados para a intervenção, incluindo este pesquisador, que, inclusive, foi o mediador das discussões. $\mathrm{O}$ foco da reunião foi definir a nova forma de interagir durante o andamento do ciclo, buscando assimilar a cultura de metodologias ágeis em gestão de projetos implementada há doze meses na organização. Após as discussões, definiu-se por consenso dos presentes, que os membros encontrar-se-iam semanalmente, idealmente às sextas-feiras, e compartilhariam suas atividades utilizando as seguintes pautas: (1) quais foram as atividades realizadas no decorrer 
da semana; (2) quais seriam as atividades previstas para a semana seguinte; e (3) quais eram os impedimentos para realizar tais atividades. Esse formato de interação passou a ser aplicado desde a etapa de 'Diagnóstico' do Ciclo 2.

\section{Quadro 16 - Marcos do Ciclo 2}

\begin{tabular}{|c|l|}
\hline Data & \multicolumn{1}{|c|}{ Eventos } \\
\hline $03 /$ abr/2017 & $1^{\text {o }}$ Reunião do grupo \\
\hline $24 /$ abr/2017 & Revisão do diagnóstico do Ciclo \\
\hline $04 / \mathrm{mai} / 2017$ & Benchmarks (Início) \\
\hline $19 / \mathrm{mai} / 2017$ & Seminários (Início) \\
\hline $02 / \mathrm{jun} / 2017$ & Seminários (Fim) \\
\hline $26 / \mathrm{jun} / 2017$ & Benchmarks (Fim) \\
\hline $12 / \mathrm{jul} / 2017$ & Planejamento das atividades e definição dos responsáveis \\
\hline $14 / \mathrm{jul} / 2017$ & Apresentação do plano em Comitê Executivo \\
\hline $20 / \mathrm{jul} / 2017$ & Revisão do planejamento, com base na revisão da estratégia \\
\hline $24 / \mathrm{jul} / 2017$ & Entrega: 'Rede social' \\
\hline $26 /$ ago/2017 & Entrega: Critérios de avaliação para soluções de startups \\
\hline $06 / \mathrm{set} / 2017$ & Entrega: Evento de aculturamento \\
\hline $08 / \mathrm{set} / 2017$ & Reunião para avaliação do Ciclo \\
\hline
\end{tabular}

Fonte: Elaborado pelo autor.

\subsubsection{Ciclo 2: Diagnóstico}

Com base nas reflexões sobre as ocorrências do Ciclo 1, em 24 de abril de 2017, o pesquisador propôs uma revisão dos procedimentos de diagnóstico complementares aos workshops realizados. O primeiro item proposto foi a inclusão de benchmarks externos no diagnóstico, com a inclusão de participantes do ecossistema empreendedor nacional: incubadoras, aceleradoras, grandes empresas e startups. Essa medida visou a reforçar esta etapa de 'Diagnóstico' com novas referências, aspecto levantado na avaliação do Ciclo 1. Devido ao bom trânsito do Participante LU12 por esse meio, ficou a cargo dele a seleção e o agendamento de contatos.

Outra proposição foi fazer nova revisão de artigos e relatórios sobre o relacionamento entre grandes empresas e startups, considerando-se que boa parte dos membros não havia participado do Ciclo 1. No entanto, diferentemente do que havia ocorrido no ciclo anterior, para que houvesse uma melhor compreensão por parte dos membros, foi proposto pelo 
pesquisador que os artigos e relatórios fossem apresentados pelos próprios membros em um seminário. Esta proposta estava associada à intenção de evitar a perda de conhecimento do Ciclo 2 e na forma como seria possível engajar o time.

\section{Seminários}

Em 15 de maio de 2017, foi dado o primeiro passo para realização dos seminários. O pesquisador encaminhou por e-mail uma seleção de 10 (dez) artigos/relatórios sugeridos para leitura e pediu aos membros que se reunissem em duplas para escolherem um dos documentos para ser lido e apresentado o resumo de seu conteúdo, juntamente com as melhores práticas identificadas como possíveis de serem aplicadas na empresa XYZ. Os quatro relatórios/artigos selecionados foram: Ernst e Young (2016); Mortara, Napp, Slacik e Minshall (2009); KPMG (2015); Mocker, Bielli e Haley (2015); e Bannerjee, Bielli e Haley (2016). Cada dupla dispôs de 45 (quarenta e cinco) minutos para apresentar suas sínteses. Os

grupos tiveram liberdade para trocar os materiais escolhidos, caso avaliassem que não agregariam à intervenção em curso.

Os seminários ocorreram nos dias 19 e 26 de maio e 2 de junho. Nessas ocasiões, os membros dos grupos apresentaram a todos o levantamento feito e discutiram sobre as práticas encontradas. Foram coletadas as 30 (trinta) melhores práticas de organizações que atuavam com startups e que poderiam ser aplicadas à realidade da empresa XYZ, conforme detalhadas no Quadro 17 a seguir. 
Quadro 17 - Melhores práticas de organizações que atuam com startups, coletadas durante os seminários do Ciclo 2

\begin{tabular}{|c|c|c|}
\hline $\begin{array}{r}\text { Art } \\
\text { Rela }\end{array}$ & $\begin{array}{l}\text { lo } \\
\text { rio }\end{array}$ & $\begin{array}{l}\text { Melhores práticas de organizações que atuam com startups, coletadas } \\
\text { durante os seminários do Ciclo } 2\end{array}$ \\
\hline $\begin{array}{l}\text { Mortara, } \\
\text { Napp, } \\
\text { Slacik e } \\
\text { Minshall } \\
(2009)\end{array}$ & $19 / 05 / 2017$ & $\begin{array}{l}\text { - Definir o portfólio de projetos que possam ser compartilhados com as startups. } \\
\text { - Possuir um roadmap de tecnologias a serem implementadas pela empresa -Technology } \\
\text { Roadmap (TRM). } \\
\text { - Avaliar o nível de prontidão da startup com que se deseja fazer negócios. } \\
\text { - Definir o grupo de pessoas ou os indivíduos responsáveis pela implementação do } \\
\text { programa. } \\
\text { - Iniciar os primeiros relacionamentos com startups por meio de um piloto/ } \\
\text { experimentação. } \\
\text { - Comunicar os processos internos de forma adaptada às startups. }\end{array}$ \\
\hline & $26 / 05$ & $\begin{array}{l}\text { - Promover eventos de conexão entre startups e a empresa XYZ. } \\
\text { - } \text { Definir pilotos de Mínimos Produtos Viáveis (MVP - Minimum Viable Product) com } \\
\text { - Obter orçamento para experimentação. } \\
\text { - Fornecer feedback às startups durante e após as avaliações. } \\
\text { - Desenvolver um 'mapa de processos' para startups. } \\
\text { - Planejar a trajetória para o início da colaboração. } \\
\text { - Identificar e selecionar iniciativa de relevância e com resultados mensuráveis. } \\
\text { - Alinhar as expectativas sobre o relacionamento com as startups. } \\
\text { - Training). } \\
\text { - Definir o orçamento para atuar com startups considerando os propósitos de cada } \\
\text { estratégia e os valores pré-aprovados. }\end{array}$ \\
\hline & $26 / 05$ & $\begin{array}{l}\text { - Definir etapas de maturidade para cocriação com startups (Define, Discover, Incubate, } \\
\text { - Scale). } \\
\text { - Definir cases claros a serem resolvidos pelas startups. }\end{array}$ \\
\hline $\begin{array}{l}\text { Mocker, } \\
\text { Bielli e } \\
\text { Haley } \\
(2015)\end{array}$ & $02 / 06$ & $\begin{array}{l}\text { - Obter patrocínio dos altos executivos. } \\
\text { - Efetuar um piloto antes de definir o programa de atuação com startups. } \\
\text { - Selecionar os programas de acordo com objetivos. } \\
\text { - Alocar um líder com poder sobre o orçamento. } \\
\text { - Ter incentivos específicos para inovação (ex.: alocação de tempo e metas } \\
\text { diferenciadas). } \\
\text { - Simplificar a comunicação dos processos internos para as startups. }\end{array}$ \\
\hline $\begin{array}{l}\text { Bannerjee, } \\
\text { Bielli e } \\
\text { Haley } \\
(2016)\end{array}$ & $02 / 06 / 2017$ & $\begin{array}{l}\text { - Definir claramente os objetivos do Programa relacionado com as startups (por exemplo: } \\
\text { renovação da cultura, posicionamento, problemas e expansão de mercado). } \\
\text { - Possuir critérios claros para avaliar os resultados das iniciativas que envolverão as } \\
\text { startups. } \\
\text { - Acompanhar os resultados do Programa para tomadas de decisão (por exemplo, escalar } \\
\text { as startups, cancelar o programa e outros). } \\
\text { - Promover e incentivar trocas de experiências entre colaboradores e startups. } \\
\text { - Avaliar o uso de ferramentas/processos para combinar a necessidade da empresa XYZ } \\
\text { com as startups. }\end{array}$ \\
\hline
\end{tabular}

Fonte: Elaborado pelo autor, a partir de dados da intervenção. 
Ao analisar as boas práticas identificadas, foi possível perceber alguns conjuntos em função de similaridades e sobreposições. Dentre eles, estava a necessidade de definir um objetivo claro para o relacionamento entre a empresa e as startups, presente em diversos estudos, como os da KPMG (2015); de Mocker, Bielli e Haley (2015); de Ernst e Young (2016); e de Bannerjee, Bielli e Haley (2016). Esse conjunto de boas práticas consistia em definir o objetivo da empresa, sua estratégia em relação às startups e a estruturação das fases de implementação. $\mathrm{O}$ ponto mais crítico desse conjunto foi definir uma estratégia de relacionamento com as startups, algo que o grupo ainda não tinha clareza e que, segundo os autores estudados, deveria ser o primeiro item em qualquer trabalho nesse sentido. Os participantes decidiram que esse ponto deveria ser mais explorado na apresentação do 'Diagnóstico', pois ainda não estava claro. Era preciso obter um direcionamento do diretor patrocinador.

Outro conjunto de aprendizagem que chamou a atenção foi o relacionado com o aculturamento da organização para se relacionar com startups. Essas aprendizagens estavam presentes nos materiais de Mortara, Napp, Slacik e Minshall (2009); da KPMG (2015); e de Bannerjee, Bielli e Haley (2016) e incluíam: a promoção de eventos de conexão entre colaboradores de grandes empresas e startups; o fornecimento de feedback durante as avaliações das startups; a adoção de critérios de avaliação e ferramentas de combinação entre as necessidades da grande empresa e soluções das startups.

Também foi possível identificar um conjunto de melhores práticas relacionadas com a necessidade de definir claramente os problemas de negócios que as startups deveriam resolver, tema presente nos estudos da KPMG (2015); de Ernst e Young (2016); e de Bannerjee, Bielli e Haley (2016), que compreendiam escolher problemas relevantes para a organização.

Além dos itens destacados, foi possível identificar nos materiais selecionados outros conjuntos de melhores práticas, como a adoção de piloto e experimentos para avaliar solução de startups, provisionamento de orçamento dedicado para atuar com startups, definição de 
pessoas dedicadas ao relacionamento 'empresa-startups', incentivos exclusivos para os times envolvidos, definição de portfólio de projetos que poderiam ser abertos para startups e simplificação de processos internos para startups.

Houve certa empolgação do time quanto à possibilidade de usar as melhores práticas identificadas. No entanto, o pesquisador deixou claro que essas práticas não necessariamente resolveriam os problemas que a empresa XYZ gostaria de tratar. Era necessário fazer um alinhamento das melhoras práticas com os impedimentos identificados no Ciclo 1, mas isso só seria feito após as entrevistas com entidades do ecossistema de startups.

\section{Comentário 8:}

É importante ressaltar que alguns artigos e relatórios utilizados pelo grupo durante a intervenção serviram como referencial desta dissertação, tais como os de: Mocker, Bielli e Haley (2016); Minshall, Mortara, Napp e Probert (2010), Mortara, Slacik, Napp e Minshall (2010); e KPMG (2015). No entanto, outros foram descartados, dentre os quais os de Ernst e Young (2016). Também é importante ressaltar que a quantidade de documentos utilizados como referencial da dissertação foi maior do que a utilizada na intervenção.

\section{Entrevistas com entidades do ecossistema de startups}

Em 2 de maio de 2017, deu-se início às atividades envolvendo entrevistas com organizações atuantes no ecossistema de startups. Os objetivos do grupo consistiam em identificar as melhores práticas aplicáveis, entender como as entidades lidavam com as startups/grandes empresas e compartilhar de forma abrangente os desafios da empresa XYZ em relação a esse tema.

O pesquisador propôs um roteiro inicial para as entrevistas que, posteriormente, foi enriquecido pelos membros do grupo, com o objetivo de garantir a obtenção das informações necessárias e de manter um padrão de entrevista independentemente de quais membros a aplicassem. Apesar de o grupo não ter sido totalmente fiel ao roteiro, o mesmo serviu como balizador das conversas. 
Ao todo foram realizadas 12 (doze) entrevistas, entre 04 de maio e 26 de junho de 2017, com profissionais das empresas Microsoft, Accenture, Endeavor, Google Campus, ABStartups, ACE, StartSE, Wayra, Liga Ventures e Porto Seguro, além de duas startups. A duração das entrevistas variou entre 20 e 40 minutos, dependendo da disponibilidade de tempo dos entrevistados e da quantidade de pessoas envolvidas. Para cada entrevista, havia um membro responsável por centralizar as anotações, criar uma ata e disponibilizá-la a todos para avaliação. O pesquisador sistematizou as melhores práticas registradas nas atas, compartilhadas com o grupo em 28 de junho de 2017.

\section{Comentário 9:}

Alguns membros do grupo fizeram perguntas técnicas, sem percepção de aspectos como estratégia, cultura e relacionamento. Uma das razões para isso era a falta de conhecimento de alguns deles sobre o ecossistema de startups.

Ao final das discussões foram identificadas as 28 (vinte e oito) melhores práticas, coletadas a partir das entrevistas com benchmarks, conforme apresentado no Quadro 18.

\section{Quadro 18 - Melhores práticas coletadas a partir das entrevistas com benchmarks}

\begin{tabular}{|c|c|c|}
\hline $\begin{array}{c}\text { Tipo de } \\
\text { Entidade }\end{array}$ & $\begin{array}{c}\text { Data da } \\
\text { Entrevista }\end{array}$ & Melhores Práticas Coletadas \\
\hline Startup A & $04 / 05 / 2017$ & - Criar laboratório para piloto/experimentos entre a startup e a empresa. \\
\hline $\begin{array}{c}\text { Grande Empresa } \\
\text { A }\end{array}$ & $11 / 05 / 2017$ & $\begin{array}{l}\text { - Alocar time escalável que atue na intermediação entre a empresa e a startup. } \\
\text { - Ver as startups como parcerias. }\end{array}$ \\
\hline $\begin{array}{c}\text { Intermediadora/ } \\
\text { Consultoria A }\end{array}$ & $16 / 05 / 2017$ & - Promover encontros de startups com departamentos da empresa. \\
\hline Aceleradora A & $24 / 05 / 2017$ & $\begin{array}{l}\text { - Separar o ambiente do 'dia a dia' do ambiente de inovação e criatividade. } \\
\text { - Organizar o orçamento por categorias e com valores definidos para aplicação } \\
\text { em pilotos ou experimentos. }\end{array}$ \\
\hline $\begin{array}{l}\text { Grande Empresa } \\
\text { B }\end{array}$ & $26 / 05 / 2017$ & $\begin{array}{l}\text { - Definir time dedicado para atuação com startups. } \\
\text { - Possuir uma estratégia bem definida de atuação com as startups. }\end{array}$ \\
\hline $\begin{array}{l}\text { Intermediadora/ } \\
\text { Consultoria B }\end{array}$ & 29/05/2017 & $\begin{array}{l}\text { - Designar um patrocinador forte para atuar nos programas envolvendo } \\
\text { startups. } \\
\text { - Realizar meetups de startups com departamentos. } \\
\text { - Desenvolver/elencar um time para atuar entre empresa e startups que tenha } \\
\text { mentalidade empreendedora. } \\
\text { - Desenvolver fluxo simplificado para avaliação de soluções de startups. }\end{array}$ \\
\hline Aceleradora B & $30 / 05 / 2017$ & $\begin{array}{l}\text { - Desenvolver modelo de funil tanto para avaliação das startups, quanto para } \\
\text { as demandas da empresa. } \\
\text { - Utilizar piloto/experimentação como primeira interação com startups. }\end{array}$ \\
\hline
\end{tabular}




\begin{tabular}{|c|c|c|}
\hline $\begin{array}{c}\text { Tipo de } \\
\text { Entidade }\end{array}$ & $\begin{array}{c}\text { Data da } \\
\text { Entrevista }\end{array}$ & Melhores Práticas Coletadas (continuação) \\
\hline $\begin{array}{c}\text { Grande Empresa } \\
\text { C }\end{array}$ & $31 / 05 / 2017$ & $\begin{array}{l}\text { - Designar 'padrinhos' que adotem as startups dentro da empresa. } \\
\text { - Designar times dedicados/focados nas atividades de inovação. } \\
\text { - Selecionar iniciativas relevantes e com propósito claro. } \\
\text { - Selecionar oportunidades de problemas mais acessíveis (low hanging fruits) } \\
\text { e impactantes para as startups. }\end{array}$ \\
\hline Startup B & $31 / 05 / 2017$ & $\begin{array}{l}\text { - Dar insumos e autonomia para as equipes dos projetos terem poder de decisão } \\
\text { nas reuniões com startups. } \\
\text { - Possuir orçamento pré-aprovado para realizar Provas de Conceito (PoCs). }\end{array}$ \\
\hline $\begin{array}{c}\text { Intermediadora/ } \\
\text { Consultoria C }\end{array}$ & $01 / 06 / 2017$ & $\begin{array}{l}\text { - Desenvolver portal interno para promoção de conteúdo sobre ecossistema de } \\
\text { startups. } \\
\text { - Realizar eventos com convidados do ecossistema de startups. }\end{array}$ \\
\hline $\begin{array}{c}\text { Intermediadora/ } \\
\text { Consultoria D }\end{array}$ & $09 / 06 / 2017$ & - Realizar meetups entre startups e representantes de departamentos. \\
\hline Aceleradora $\mathrm{C}$ & $26 / 06 / 2017$ & $\begin{array}{l}\text { - Ter políticas ou mecanismos para mensurar o nível de prontidão e maturidade } \\
\text { da startup. } \\
\text { - Preparar as startups para apresentação aos negócios interessados (Pitch } \\
\text { Training). } \\
\text { - Designar time para oferecer mentoria às startups. }\end{array}$ \\
\hline
\end{tabular}

Fonte: Elaborado pelo autor, a partir de dados da intervenção.

Ao analisar as entrevistas realizadas nas instituições, foi possível identificar alguns conjuntos de melhores práticas, como o de aculturamento, que continha 7 (sete) distintos aprendizados, tais como: a realização de eventos entre a empresa e as startups; treinamento de pitch para startups; portal interno para divulgação de conteúdos sobre o ecossistema de startups; e ações internas para analisar startups como parceiras.

Outro conjunto de 6 (seis) boas práticas diziam respeito à formação do time interno que atuaria com as startups. As instituições recomendaram que os times fossem formados por pessoas com perfil empreendedor, cuja alocação poderia ser dedicada ou com tempo suficiente para executar as ações. Além disso, seria importante que os times tivessem autonomia para tomada de decisão.

Quatro boas práticas relacionadas ao modo de avaliação das startups também foram identificadas. A recomendação é que houvesse um funil de avaliação tanto para as startups 
quanto para as empresas. Em relação às startups, o funil permitiria avaliar se os níveis de prontidão e de maturidade estariam aderentes com o que a empresa esperava. Quanto à empresa, seria necessário avaliar se os propósitos das iniciativas estavam claros e se os significados e seus objetivos seriam possíveis de serem mensurados.

A Aceleradora B, por exemplo, enfatizou a importância de as empresas terem propósitos bem definidos, exemplificando que em um evento promovido para desafiar startups a resolverem problemas de um governo estadual, apenas um projeto conseguiu perdurar, dos quinze propostos inicialmente. Nesse caso, o projeto sobrevivente possuía um patrocinador participativo, além do propósito e dos indicadores de sucesso bem definidos.

Outras boas práticas foram identificadas durante as conversas com representantes das organizações e também foram encontradas nos estudos realizados pelo grupo, tais como: a obtenção de um patrocinador forte; a necessidade de alinhamento de estratégias da empresa com as startups; a definição de um orçamento dedicado para atuar com startups; a criação de estruturas apropriadas para pilotar e experimentar projetos com startups; e a simplificação do processo envolvendo startups.

Durante a reunião de discussão sobre as melhores práticas, membros do grupo constataram a lacuna de conhecimento que tinham em relação ao ecossistema de startups, dentre eles o Participante FE2 que afirmou que "não fazia ideia da quantidade de coisas que podem [poderiam] ser feitas para nos aproximar [aproximá-los] de startups".

\section{Consolidação e Apresentação do Diagnóstico}

Em 30 de junho de 2017, iniciou-se a última etapa da fase de 'Diagnóstico', a saber: a consolidação das melhores práticas e a proposição das ações à luz dos impedimentos. O processo de consolidação envolvia 5 (cinco) etapas: 
(1) categorizar as melhores práticas: consistiu em associar as melhores práticas a um padrão de categorias. O time utilizou o formato utilizado por Bannerjee, Bielli e Haley (2016), que propõe que a grande empresa atue em 4 (quatro) perspectivas ao se relacionar com startups: estratégica, cultural, estrutural e processual;

(2) unificar boas práticas: consistiu em unificar boas práticas redundantes ou similares;

(3) associação aos problemas/oportunidades: cruzamento das melhores práticas com as barreiras identificadas no Ciclo 1, a partir de um Diagrama de Ishikawa. As melhores práticas, que não tinham associação com esses impedimentos, foram classificadas como oportunidades;

(4) priorizar as ações: esse processo iniciou-se a partir da seleção das ações que poderiam ser feitas pela área de Tecnologia, seguindo orientação do diretorpatrocinador, para então atuar em ações sobre as quais a equipe tinha poder de decisão. Posteriormente, para priorizar as ações restantes, o grupo atribuiria pontuação a cada uma delas;

(5) documentação dos resultados: elaboração de apresentação executiva e materiais detalhados com os principais aspectos priorizados.

O processo de consolidação teve formato de oficinas com duração média de 180 minutos. O fato de ainda não existir um direcionamento estratégico claro fez com que algumas vezes os encontros fossem acalorados e pouco produtivos. Além disso, a presença sazonal de alguns membros fez com que o grupo voltasse a alguns aspectos já discutidos anteriormente. Esses fatos levaram o grupo a necessitar de quase duas semanas para realizar essas cinco etapas, impactando o início das ações.

Em 12 de julho de 2017, foi realizada a priorização das 'Ações'. Apesar de esta fase ser de 'Diagnóstico', a proposta é que houvesse uma recomendação aos executivos quanto às ações a serem desenvolvidas no Ciclo 2 , a fim de facilitar o processo de decisão durante a etapa de planejamento. O grupo decidiu, por aclamação, que as ações seriam ranqueadas por aspectos 
de impacto versus esforço. Ambos os aspectos tinham peso de 1 a 3 , o que gerou uma pontuação para cada ação. No total, 34 (trinta e quatro) ações foram relacionadas, sendo que 10 (dez) delas foram propostas aos executivos. Foi utilizado como justificativa para o corte a capacidade dos membros para executar as ações, conforme explicitado na Figura 24.

Ao todo, foram 7 (sete) ações associadas a processos: 2 (duas) relacionadas aos aspectos estruturais e uma associada à estratégia. Por ordem, as 5 (cinco) primeiras foram eleitas para serem executadas no Ciclo 2, enquanto as demais poderiam ser revisitadas no Ciclo 3. 


\section{Figura 24 - Ações propostas para o Ciclo 2}

\begin{tabular}{|c|c|c|c|c|c|}
\hline Númer & Épico & Tag & Estória & nro $P$ & Oport \\
\hline 5 & Processo & Políticas e Critérios & $\begin{array}{l}\text { Eu como Arquitetura preciso de Direcionadores/critérios/métodos e/ou ferramentas para que eu } \\
\text { possa ter autonomia na avaliação (maturidade, risco funcional, alinhamento com estratégia do } \\
\text { se a solucão de uma startup pode ser (e como Dode ser) utilizada para atender uma necessidade }\end{array}$ & 8 & 25 \\
\hline 3 & Processo & Mapear processo & Eu como startup desejo conhecer o processo atual para me relacionar com o & 21 & 4 \\
\hline 16 & Estratégia & Sponsor & $\begin{array}{l}\text { Eu como envolvido no processo de habilitação de Startups, preciso de um sponsor (com clareza de } \\
\text { objetivos) para habilitar as ações envolvendo startups na Tecnologia e Área de Negócio. (Considerar } \\
\text { apoio de consultor externo no board / Comite de Inovação) }\end{array}$ & 20 & 10 \\
\hline 4 & Processo & Dashboard & $\begin{array}{l}\text { Eu como área de negócio preciso de critérios claros (ex Maturidade, Risco Funcional) para avaliar se } \\
\text { startups do mercado atendem minha necessidade }\end{array}$ & 34 & 6 \\
\hline 43 & Processo & & & 14 & 10 \\
\hline 31 & Processo & Painel Status & Eu como Arquitetura quero saber o status atual e evolução da demandas que envolvam startups & 14 & 8,5 \\
\hline 1 & Processo & Guia Startups & $\begin{array}{l}\text { Eu como startup desejo um material para me auxiliar na tratativa dos processos de aprovação de } \\
\text { Tecnologia }\end{array}$ & 28 & 2 \\
\hline 14 & Processo & (- & Eu como startup quero um processo de avaliação de Segurança de Informação mais ágil & 29 & 4 \\
\hline 22 & Estrutura & Catálogo & $\begin{array}{l}\text { Eu como Arquiteto gostaria de ter uma base de conhecimento de startups para que possa oferecer } \\
\text { opçōes para que o meus clientes como potencial solução a suas necessidades }\end{array}$ & 25 & 5 \\
\hline 29 & Estrutura & Time & $\begin{array}{l}\text { Eu como preciso definir os Times / pontos focais dentro para resolver problemas } \\
\text { envolvendo startups. }\end{array}$ & 30 & 5 \\
\hline
\end{tabular}

Fonte: Elaborada pelo grupo da intervenção. 


\section{Elaboração da apresentação e estruturação de Comitê para feedback do diagnóstico}

Ao dar início à elaboração da apresentação que seria feita ao diretor-patrocinador, o grupo refletiu sobre qual seria o tipo de relacionamento que a empresa XYZ estava buscando com as startups, e como as ações propostas entregariam esse valor. O grupo concluiu, então, que apresentaria ao diretor a proposição de Bannerjee, Bielli e Haley (2016), estudada durante o 'Diagnóstico', que sugere decidir os programas de engajamento possíveis com startups - Corporate-Startup Engagement (CSE), a partir dos objetivos da empresa, que poderiam ser: o rejuvenescimento da cultura corporativa, a inovação da marca, a solução de problemas de negócios e a expansão para mercados futuros.

Para que o modelo não fosse apresentado ao diretor-patrocinador de forma passiva, o pesquisador propôs ao grupo que identificasse a melhor abordagem possível de 'relacionamento com startups' para sugerir ao executivo. O grupo, baseando-se no histórico de interações que a organização já tinha com startups, concluiu que a motivação mais provável para que a empresa se relacionasse com startups seria a de 'resolução de problemas de negócios', culminando então na abordagem sugerida de 'parceria' e corroborando com o fato de que as ações mais lembradas pelo grupo foram as de contratação de startups como fornecedoras de solução. O grupo entendeu que, mesmo que não fosse a visão corporativa sobre startups, aquela sugestão de abordagem seria a mais familiar à Área de Tecnologia.

$\mathrm{Na}$ apresentação executiva, que ocorreu em 14 de julho de 2017, o grupo expôs as possíveis motivações para as empresas se relacionarem com startups, de acordo com o estudo de Bannerjee, Bielli e Haley (2016). Posteriormente, apresentou-se a sugestão de que o objetivo a ser atingido pela intervenção seria a 'solução de problemas de negócios'. Sendo assim, a abordagem de 'parcerias' ou a contratação de startups como fornecedoras de soluções seria a forma mais apropriada para orientar as ações da intervenção, mesmo que não representasse a estratégia global da organização. Tal suposição foi confirmada pelo executivo e por seus colaboradores diretos presentes.

Apesar da concordância inicial, ao apresentar as ações propostas para o Ciclo 2, a resposta obtida foi diferente da esperada. O feedback do diretor para o grupo foi de que ao invés de atuar em ações estruturais e de processos, o grupo precisaria priorizar ações voltadas 
ao aculturamento e ferramental, pois traria maiores benefícios no curto-médio prazo. A equipe comprometeu-se a assimilar a proposição do diretor durante as reuniões de planejamento, que se iniciariam na semana seguinte.

\subsubsection{Ciclo 2: Planejamento}

Em 20 de julho de 2017, o grupo da intervenção reuniu-se para revisar as ações baseadas no feedback do diretor-patrocinador e para planejar as respectivas atividades. Essa revisão causou desânimo a alguns membros devido a retrabalhos, porém, a maioria do grupo considerou o direcionamento como necessário e estratégico, pois acabou dando ainda mais foco ao grupo, ao priorizar as ações de aculturamento e por desconsiderar as ações de aspecto processual e estrutural.

A partir desses direcionadores, o grupo discutiu sobre a necessidade de possuir um modelo visual que tratasse do relacionamento com startups considerando as melhores práticas identificadas durante o diagnóstico. Essa visão ajudaria a compreender quais componentes estariam envolvidos para habilitar esses relacionamentos. O Participante CA2 dispôs-se a conduzir as conversas com o time, que duraram 3 dias e culminaram no

Comentário 10: A elaboração do modelo de relacionamento com startups foi uma ferramenta essencial para o grupo apresentar sua proposta de atuação durante os Ciclos 2 e 3 .

modelo apresentado na Figura 25. 
Figura 25 - Modelo de relacionamento considerando startups como provedoras de solução para problemas de negócios

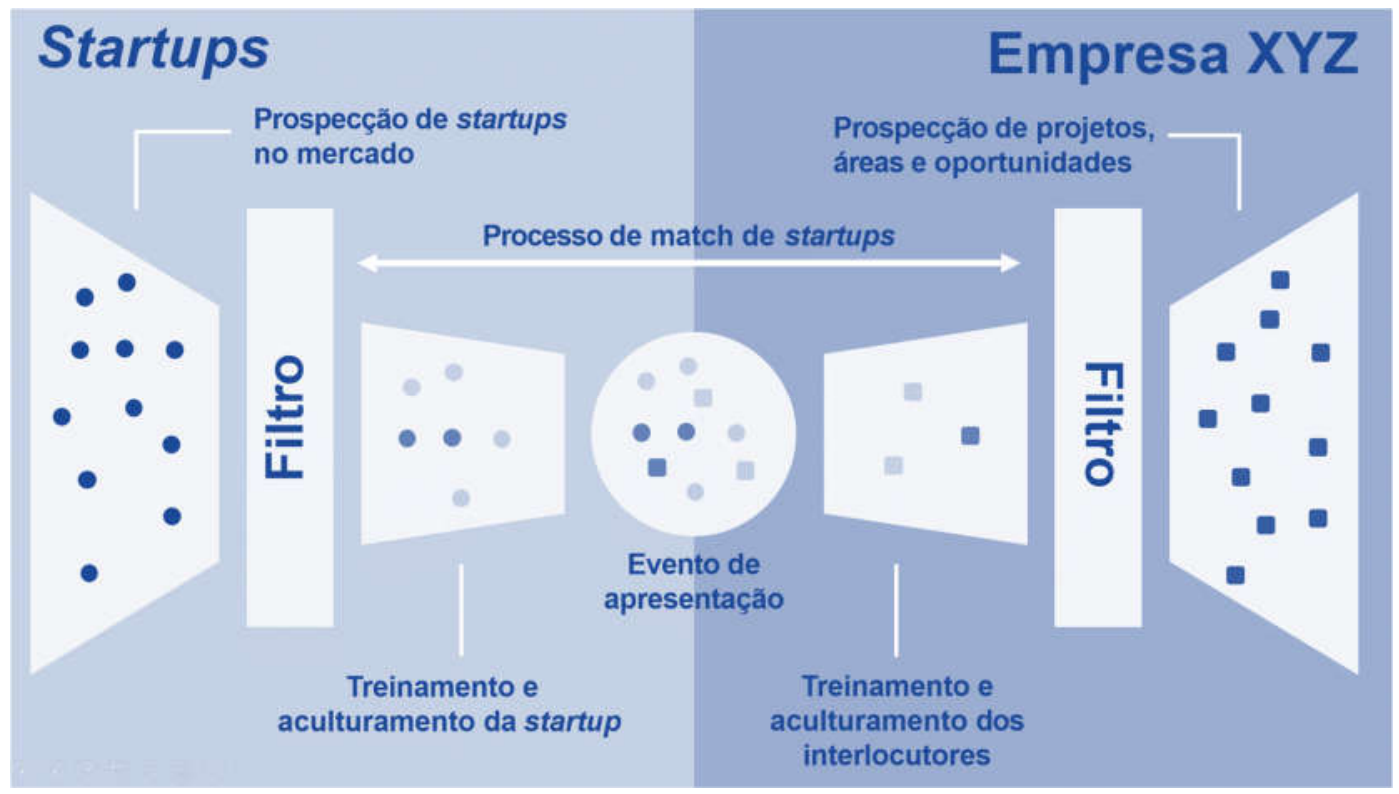

Fonte: Elaborada pelo grupo da intervenção.

Os membros do grupo combinaram que as ações deveriam ser realizadas no prazo de até três meses, finalizando, portanto, em setembro de 2017, para que, a partir de então, pudesse ser realizado um novo e último ciclo. O grupo também submeteria os resultados ao diretor-patrocinador e, após a etapa de avaliação interna, aos seus executivos.

Ao fazer a revisão das ações propostas na etapa de diagnóstico, a partir do redirecionamento executivo e da avaliação da capacidade do time, as ações selecionadas para o Ciclo 2 foram: 'rede social' - portal interno para divulgação de conteúdos relacionados às startups; 'critérios de avaliação' para soluções de startups; e 'Startup Day' - evento de aculturamento sobre relacionamento com startups.

Para realizar essas atividades, os membros foram divididos em grupos. Apesar do baixo quórum nessa reunião, apenas 7 (sete) dos 11 (onze) membros estavam presentes, o grupo foi dividido em duplas e trios. A única atividade não passível de divisão foi o 'Startup Day', devido ao grande volume de atividades.

A atividade 'rede social' foi designada aos Participantes VI2 e CA2, pois ambos tinham domínio sobre a plataforma tecnológica adquirida pela empresa para gestão de conteúdo. 
O desenvolvimento dos 'critérios de avaliação' para soluções de startups ficou a cargo deste pesquisador, juntamente com os Participantes RO2 e AD2. Quanto ao 'Startup Day', executado em grupo, foi a ação mais complexa no que tange ao 'Planejamento', pois abrangeu toda a organização do evento: pauta, local, refeições e contato com potenciais palestrantes.

\subsubsection{Ciclo 2: Ações}

A seguir, serão detalhadas as ações desenvolvidas: 'rede social', 'critérios de avaliação' para soluções de startups e 'Startup Day' - evento de aculturamento e relacionamento com startups.

\section{Ação 4: 'Rede Social'}

Em 21 de julho de 2017, foi iniciada a criação da 'rede social' interna focada inicialmente no compartilhamento de conteúdo sobre o ecossistema de startups como um todo, cujas soluções pudessem fazer sentido à organização. Lançada em apenas 3 dias, em 24 de julho, a partir de um portal de conteúdo que a empresa já possuía, a 'rede social' (Figura 26) foi mantida a princípio apenas com postagens de relatórios de consultorias e artigos relacionados ao tema startups. 
Figura 26 - 'Rede Social'

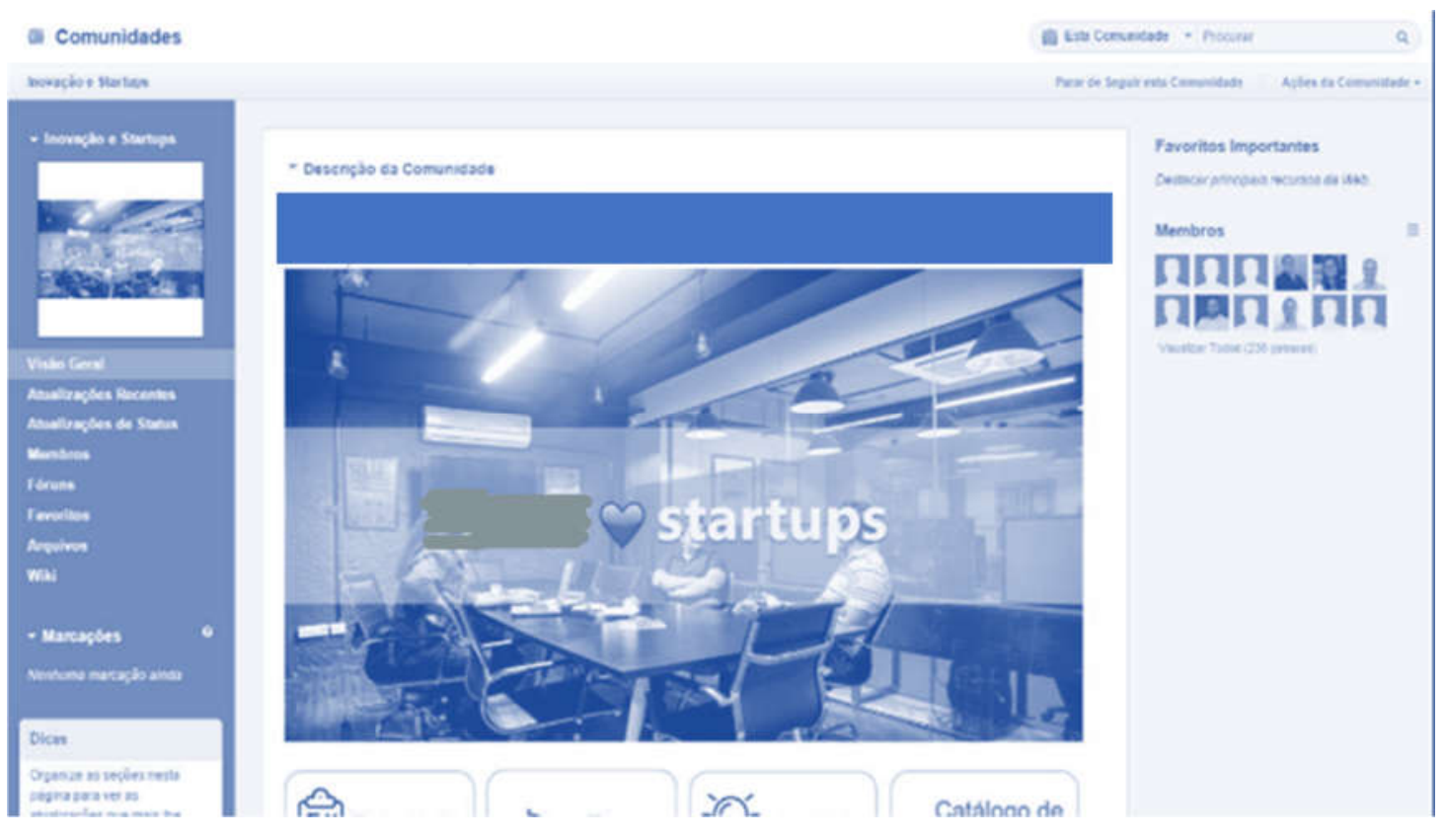

Fonte: Elaborada pelo grupo da intervenção.

Ao desenvolver essa 'rede social', o grupo refletiu sobre qual deveria ser o seu real objetivo. De acordo com o Participante FE2, a 'rede social' era "o canal para gerar familiaridade sobre as startups" e "uma forma de gerar confiança para conversar com elas". Ao longo da discussão, o grupo consentiu que, além de compartilhar materiais relacionados ao tema startups, a rede também poderia ser utilizada para divulgar as ações realizadas nos ciclos.

O pesquisador mencionou também que o objetivo dessa rede era esclarecer aos colaboradores o propósito daquela intervenção de aproximação com startups, a saber: 'a resolução de problemas de negócios'. Sendo assim, ao sintetizar as reflexões, o objetivo final da 'rede social' ficou definido da seguinte maneira: “(...) compartilhar conteúdos relacionados com as startups e incentivar a utilização de soluções tecnológicas fornecidas por elas, como forma de evoluir as capacidades de negócios da organização. Aqui [Nela] divulgaremos [seriam divulgadas] também algumas das iniciativas que visam [visavam] a melhorar o nosso relacionamento com as startups."

Em 4 de agosto de 2017, por meio de divulgação boca a boca e pelo envio de e-mails pelos integrantes do grupo, a 'rede social' atingiu-se mais de 5 mil inscritos. O grupo 
entendeu que havia uma demanda reprimida e grande interesse em relação ao tema 'startups' dentro da organização.

O crescimento repentino da rede levou à necessidade de revezar a curadoria do conteúdo a ser disponibilizado, o que foi intensificado a partir da criação de um fórum de discussão sobre temas relacionados às startups.

Em 11 de agosto de 2017, uma página contendo a cartilha com o processo de contratação das startups foi acrescentada à rede social e, até o final dos ciclos, foram acrescidas outras ações do grupo como os 'critérios de avaliação para soluções de startups'.

\section{Ação 5: Critérios de Avaliação para Soluções de Startups}

Em 9 de agosto de 2017, ocorreu a primeira reunião de trabalho para desenvolvimento dos 'critérios para avaliação de soluções envolvendo startups'. Essa 'ação' foi realizada pelo pesquisador, juntamente com os Participantes RO2 e AD2. Durante a reunião, questionou-se se a ação de ‘critérios de avaliação' possuía viés de aculturamento ou de processos. Após longo debate, o grupo consentiu que os 'critérios' eram ferramentais para o aculturamento, haja vista o fato de servirem de apoio aos colaboradores de tecnologia, em especial aos arquitetos de tecnologia da informação, para observar e avaliar as startups. Em seguida, o grupo definiu o objetivo dos 'critérios de avaliação', a saber: “Apoiar os Arquitetos nas decisões quanto a utilizar startups para atender às necessidades de negócios".

Para estruturar os pilares (fundamentos) e critérios de avaliação, o grupo decidiu utilizar como insumo o conhecimento capturado nos seminários, entrevistas e nas próprias experiências vividas.

Durante a reunião realizada em 11 de agosto de 2017, cada membro do grupo em particular propôs uma série de fundamentos e, num momento seguinte, o grupo em conjunto definiu uma lista unificada. Considerado o pilar mais disruptivo adotado pelo grupo, o Propósito de Negócios surgiu a partir da necessidade, identificada nos 
seminários e entrevistas, de definir claramente o problema que os interessados nas startups gostariam de resolver.

Ao todo, foram identificados 5 (cinco) pilares a serem observados durante a avaliação da solução de uma startup:

- Estratégia: avaliar o nível de alinhamento da estratégia de evolução tecnológica e cultural da startup em relação à empresa XYZ e mensurar o quanto a startup poderia contribuir para as capacidades de negócios da organização;

- Equipe: avaliar o perfil e a experiência da equipe da startup, a fim de identificar a capacidade de entrega esperada pela empresa XYZ;

- Empresa: avaliar a capacidade de diferenciação da startup, sua capacidade de sustentabilidade e seu potencial de evolução no mercado em que atua;

- Solução: avaliar tecnicamente a solução proposta pela startup para determinar seu grau de aderência à arquitetura alvo da organização;

- Propósito de Negócio: avaliar se a necessidade de negócios justifica a solução de utilização de startups. Neste caso, deveria ser verificado itens como a clareza do problema e as oportunidades almejadas pelos negócios envolvidos.

Em 16 de agosto de 2017, de forma similar ao ocorrido no segundo encontro, o grupo apresentou sugestões quanto aos critérios de avaliação para cada um dos pilares identificados, os quais foram discutidos em função do significado de cada qual até chegar à definição dos critérios definitivos. A partir desses, o grupo discutiu a forma de mensuração que seria utilizada, estruturando os dados em formato de questionário, conforme demonstra a Figura 27. 
Figura 27 - Detalhe do questionário de avaliação - Pilar da Empresa

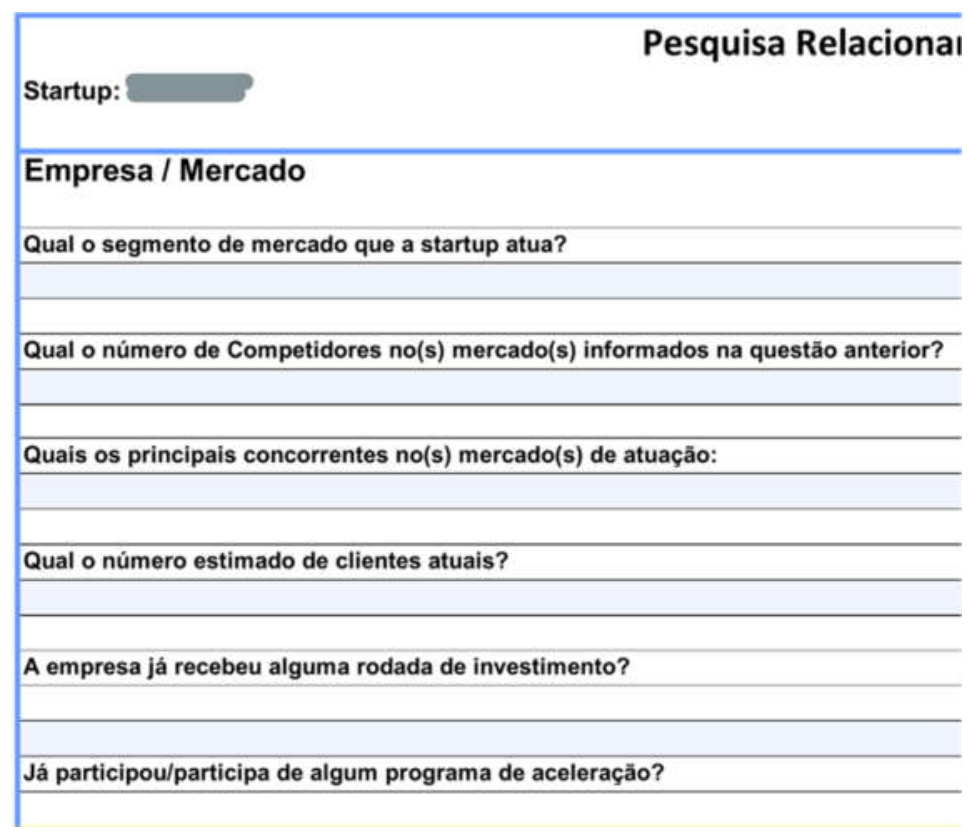

Fonte: Elaborada pelo grupo da intervenção.

Para que houvesse um alinhamento das expectativas com o público que utilizaria os critérios de avaliação, o pesquisador escreveu uma introdução, incorporada ao documento. O texto explicava que o instrumento de critérios de avaliação era uma "ferramenta de apoio à decisão" e seu propósito não era o de avaliar uma startup isoladamente, mas sim o de confrontar sua solução com o propósito do negócio envolvido, mais precisamente, com o problema que se esperava resolver. O texto também explicava que, ao se valer do material, esperava-se que os colaboradores pudessem defender de forma mais embasada e segura a posição de utilizar ou não uma startup para solucionar problemas de negócios. Por fim, os colaboradores não poderiam deixar de dar retorno quanto aos resultados da avaliação para as startups o mais rápido possível, para que pudessem ser desenvolvidos.

Em 26 de agosto de 2017, a primeira versão do instrumento de critérios de avaliação estava finalizada, porém o material ainda não tinha sido nem testado e nem divulgado para uso. 


\section{Ação 6: Startup Day - Evento de Aculturamento}

A produção do evento de aculturamento começou na semana seguinte à da revisão do planejamento do Ciclo 2. Na reunião de abertura, o pesquisador propôs que os interlocutores externos convidados para o evento fossem preferencialmente os parceiros da empresa XYZ e que estivessem enfrentando desafios de relacionamento no ecossistema de startups, fossem eles startups, grandes empresas ou mesmo intermediadores. Ao longo das discussões sobre como poderia ser o evento, o Participante LU12 mencionou que havia um consultor atuando na geração de negócios entre startups e grandes corporações e que o mesmo já tinha proferido uma palestra sobre "Inovação Aberta com Startups". O grupo entendeu, por consenso, que essa palestra faria sentido e poderia causar impacto nos colaboradores. Somou-se a isto, a proposta do Participante FE2 de criar um painel de discussão composto por colaboradores da empresa e entidades externas, o que também foi incluído na elaboração do evento. Toda a divulgação sobre ele foi feita via correio eletrônico (e-mail).

Em 6 de setembro de 2017, foi realizado o evento de aculturamento que teve início com uma palestra de 40 minutos de duração. Posteriormente, houve um painel de discussão, composto pelo consultor palestrante, pelo fundador de uma startup especializada em força de vendas e pelo responsável pela gestão do Coworking. Estavam presentes no auditório cerca de 80 (oitenta) pessoas, dentre as 120 (cento e vinte) previstas. O evento durou 2 horas e o público alvo foi, prioritariamente, os colaboradores de tecnologia.

\subsubsection{Ciclo 2: Avaliação}

Em 8 de setembro de 2017, o grupo realizou uma reunião interna para avaliação dos resultados do Ciclo 2.

Além de refletir sobre os aprendizados do ciclo atual, o objetivo do encontro também foi identificar quais ações poderiam ser realizadas no ciclo seguinte. Tanto o resultado do Ciclo 2, quanto a proposição das ações para o próximo ciclo seriam levados ao conhecimento do diretor-patrocinador e de seus executivos, no início do Ciclo 3. 
No encontro de avaliação, estiveram presentes apenas 7 (sete) participantes dos 11 (onze) oficialmente alocados nesse ciclo da Pesquisa-Ação. Essas 7 (sete) pessoas foram as que efetivamente executaram as ações do Ciclo 2. Por e-mail, o pesquisador questionou os que não haviam comparecido sobre o porquê da ausência; apenas dois deles alegaram concorrência de agenda, os demais nem mesmo deram resposta.

$\mathrm{O}$ pesquisador iniciou a reunião questionando o grupo sobre qual foi a principal dificuldade encontrada durante as ações do Ciclo 2. Os Participantes mencionaram a sobrecarga de atividades e a concorrência com atividades fora do grupo, como sendo as dificuldades mais impactantes na performance do grupo. O Participante CA2 sugeriu, então, que fosse reduzido o volume de ações para o Ciclo 3, para que o grupo pudesse concluir o próximo ciclo com qualidade nas entregas.

O grupo discutiu cada uma das ações a ser adotada e concluiu por consenso que as realizadas no Ciclo 2 tiveram um impacto positivo quanto ao aculturamento, apesar da subjetividade dos resultados.

\section{Ação 4: 'Rede Social'}

A ação referente à criação da 'rede social' teve uma avaliação positiva sob o ponto de vista do aculturamento, pois funcionava como um ponto central para divulgação massificada e trocas de mensagens relacionadas ao tema startups. Um dos membros expôs sua reflexão sobre a 'rede social': “(...) pensem que antes esse pessoal não tinha onde falar sobre startups, ou se falava era em pontos isolados. Conseguimos juntá-los, já é um começo".

Com mais de cinco mil membros inscritos, o grupo entendeu que deveria ser intensificada a divulgação dos conteúdos que contribuíssem com a temática envolvendo o relacionamento de grandes empresas com as startups, além da publicação de projetos dos quais as startups participassem dentro da organização. 


\section{Ação 5: Critérios de Avaliação para Soluções de Startups}

A entrega dos critérios para avaliação de solução envolvendo startups foi vista como um ativo positivo, porém sem resultado prático. A crítica dos Participantes foi que o modelo precisaria ser testado com startups para verificar qual seria a real utilidade e o formato mais adequado para operacionalizá-lo, pois o documento era um questionário estruturado em uma planilha eletrônica. O Participante CA2 indagou: "será que uma startup, que quase não possui integrantes, vai ter tempo de responder tudo isso que está aqui? " Em seguida, o Participante RO2 também recomendou que o material fosse divulgado àqueles que iriam utilizá-lo, ou seja, aos arquitetos de tecnologia da informação, caso contrário, segundo ele, "o documento poderia ficar guardado 'na gaveta' para sempre e todo mundo se esqueceria dele".

\section{Ação 6: Startup Day - Evento de Aculturamento}

O grupo avaliou positivamente o evento ‘Startup Day', embora o público presente tivesse sido inferior ao esperado. A visão positiva deveu-se ao fato de o grupo não ter conhecimento de outro evento anterior que tivesse sido focado no relacionamento com startups e de ter trazido entidades externas. Além disso, o Participante CA2 ressaltou a oportunidade do diálogo direto entre o público e os convidados do painel, isto é, entre as pessoas envolvidas nos desafios do relacionamento de grandes empresas com startups.

O pesquisador destacou outra contribuição associada ao evento de aculturamento: a construção de rede de contatos. Na semana seguinte ao evento, o pesquisador contabilizou duas solicitações de contato de áreas internas com entidades participantes do evento: a primeira, foi um pedido de avaliação de ferramenta de força de vendas, solicitada pela rede de agências; e a seguinte, foi um pedido de apresentação de programas de colaboração com startups feito ao consultor palestrante pelo escritório de TI localizado no exterior. 
A abertura de diálogo proposta pelo evento e a possibilidade de construção de rede de contatos foram resultados considerados satisfatórios pelo grupo, pois ajudaram a gerar sinergia no contexto cultural relacionado a startups.

Dentre as falhas do evento, a que mais chamou a atenção foi a baixa audiência. O principal motivo identificado pelo grupo foi a divulgação inadequada, causada pela falta de mensagens de reforço após o envio dos convites por e-mail, e a restrita lista de destinatários composta apenas por colaboradores de tecnologia.

Houve outras sugestões de melhoria. O Participante FE2 criticou a diversidade do evento, que poderia ser aprimorada trazendo startups como palestrantes e não apenas como participantes do painel de discussão. O Participante VI2 comentou que o evento poderia ter sido útil para divulgação das ações da intervenção, uma vez que os participantes eram formadores de opinião e seriam eles que utilizariam os artefatos da intervenção, dentre eles, os critérios de avaliação de soluções provenientes de startups.

\subsubsection{Autorreflexões sobre o Processo do Ciclo 2}

$\mathrm{Na}$ etapa de 'Diagnóstico', durante as entrevistas com as entidades externas, o pesquisador percebeu que parte do grupo ainda não tinha conhecimentos suficientes sobre o ecossistema de startups. As perguntas feitas tinham pouca aderência ao relacionamento com startups, por exemplo, eram feitos questionamentos sobre a tecnologia que as empresas utilizavam. A falta de entendimento sobre o que é o ecossistema de startups é uma situação comum, considerando que, para Minshall, Mortara, Napp e Probert (2010) e Bannerjee, Bielli e Haley (2016), uma das principais deficiências das grandes empresas quanto ao relacionamento com startups é a falta de compreensão sobre a forma como elas funcionam. Porém, foi justamente os benchmarks associados aos seminários que permitiram ao grupo adquirir mais conhecimento sobre o tema durante a etapa de diagnóstico.

Ainda refletindo sobre a etapa de diagnóstico, o pesquisador percebeu a vantagem de uma intervenção democrática, pois não seria possível levantar todas as melhores práticas se 
não houvesse diversidade de percepções dos participantes envolvidos. Agrega-se, ainda, o fato de que a identificação do diagnóstico em conjunto fez com que o time construísse engajamento e equalizasse o conhecimento por meio de discussões. Coughlan e Coghlan (2002) corroboram com esse ponto de vista, ao afirmarem que o trabalho colaborativo no diagnóstico é um fator crítico para a qualidade da Pesquisa-Ação.

Outra constatação do pesquisador durante o Ciclo 2 foi que o alinhamento tardio sobre a estratégia e o escopo das ações trouxe retrabalho para o time. Um alinhamento prévio, no início da etapa de 'Diagnóstico', poderia ter melhorado o entendimento dos membros envolvidos e teria reduzido os esforços durante as etapas subsequentes (Coghlan \& Brannick, 2005).

Outro ponto relevante, na perspectiva do pesquisador, foi o papel do diretor-patrocinador que, embora não pudesse definir de forma isolada a estratégia da organização quanto à atuação com startups, suas decisões e as de seus executivos, no âmbito da diretoria, ajudaram a dar andamento ao processo de intervenção. O pesquisador elencou algumas dessas decisões:

- delimitação da intervenção aos colaboradores da área de Tecnologia;

- definição que a motivação de relacionamento com as startups, no caso da intervenção em curso, era para solução de problemas de negócios;

- definição que para a intervenção, a forma de relacionamento com as startups seria sob a ótica de fornecedora de solução;

- definição que as ações da intervenção eram focadas nos aspectos de aculturamento e ferramental.

Em relação à etapa de 'Planejamento', o pesquisador percebeu o quanto o time mantevese a par dos principais acontecimentos da intervenção e como pôde colaborar quando algum membro tinha dificuldades de execução de suas tarefas. Essa dinâmica era muito diferente da ocorrida no Ciclo 1, no qual houve maior dispersão dos membros. Segundo Schättgen e Mur (2016) e Weiss e Hoegl (2016), a unidade de um time e sua estabilidade são elementos importantes para que ele possa ter eficiência em tarefas internas envolvendo assuntos de inovação e de empreendorismo, como é o caso da intervenção. Esse formato de interação pôde ser seguido nas demais etapas dos Ciclos 2 e 3 . 
Com base no evento de aculturamento, o pesquisador registrou três considerações. A primeira, diz respeito ao instrumento de conscientização que o evento possibilitou, pois, por meio do painel de discussão, permitiu que os colaboradores e as startups discutissem abertamente, promovendo um senso de pertencimento e de proximidade entre eles. Essa aproximação dos colaboradores é a razão principal pela qual Bannerjee, Bielli e Haley (2016) e Bonzom e Netessine (2016) sugerem a realização de eventos de aculturamento.

A segunda reflexão diz respeito à legitimidade e à provocação construídas com o público ao agregar pessoas de fora da organização. Essa tática foi identificada como sendo a melhor prática durante os benchmarks, assim como nas referências analisadas pelo grupo. A presença de entidades externas mostrou que 'o desafio não acontece só nesta empresa'. Considerou-se que deveria haver ampliação desse tipo de evento no Ciclo 3, abrindo espaço para essas instituições.

A terceira consideração está relacionada com a ausência dos executivos no evento organizado. Fato que levou o pesquisador a questionar sobre qual seria a relevância do relacionamento com startups para as lideranças. A resposta a essa pergunta seria importante, pois, como abordam Shah, Zegveld e Roodhart (2008) e Bannerjee, Bielli e Haley (2016), o suporte dos executivos é um dos principais fatores de sucesso para implantação desse tipo de programa, não sendo suficiente apenas o engajamento dos colaboradores. Porém, o quórum baixo de participantes no evento foi uma falha de planejamento por parte dos membros do grupo e poderia ser corrigida no ciclo seguinte.

Durante a etapa de 'Avaliação', o pesquisador refletiu sobre a maturidade do grupo. Apesar da baixa adesão dos participantes - apenas 7 (sete) dos 11 (onze) membros participaram de fato das intervenções -, a permanência deles foi decisiva durante as ações, permitindo o entrosamento do time e o compartilhamento dos conhecimentos obtidos nas etapas dos ciclos, e propiciando, assim, maior maturidade a todos os envolvidos.

A seguir são apresentados os procedimentos, ações e resultados decorrentes do Ciclo 2 (Quadro 19). 
Quadro 19 - Síntese do Ciclo 2 - Capacitação Interna, Aculturamento e Ferramental

\begin{tabular}{|c|c|c|}
\hline \multicolumn{2}{|c|}{ Período } & $03 / 04 / 2017-08 / 09 / 2017$ \\
\hline \multicolumn{2}{|c|}{ Papel do Pesquisador } & Membro e Consultor \\
\hline \multicolumn{2}{|c|}{$\begin{array}{l}\text { Escopo no momento do } \\
\text { Ciclo } \\
\end{array}$} & $\begin{array}{l}\text { 'Melhorar o relacionamento da empresa XYZ com startups, considerando-as } \\
\text { como provedoras de solução para problemas de negócios. }\end{array}$ \\
\hline \multicolumn{2}{|c|}{ Diagnóstico } & $\begin{array}{l}\text { - Coleta: pesquisa teórica, seminários e entrevistas com atores do } \\
\text { ecossistema de startups. A etapa de coleta também serviu como } \\
\text { capacitação do time. } \\
\text { - Análise: categorização e unificação de boas práticas; associação de boas } \\
\text { práticas com problemas e oportunidades. Nesta fase, foram utilizados o } \\
\text { Diagrama de Ishikawa e planilha eletrônica. } \\
\text { - Resultados: discussão conjunta em reunião e apresentação executiva com } \\
\text { motivações, referencial teórico, fases, necessidades de recursos e pontos } \\
\text { de atenção. }\end{array}$ \\
\hline \multicolumn{2}{|c|}{ Planejamento } & $\begin{array}{l}\text { - Revisão estratégica com o diretor patrocinador: ambiente de tecnologia e } \\
\text { viés de aculturamento das ações; e abordagens de startups como } \\
\text { provedoras de solução. } \\
\text { - Priorização feita pelo grupo em workshops, baseados em ranqueamento e } \\
\text { na capacidade do time acerca de: } \\
\text { o aculturamento dos colaboradores sobre startups; } \\
\text { ○ ferramental de suporte para avaliação de startups. }\end{array}$ \\
\hline \multicolumn{2}{|c|}{ Entregas Realizadas } & $\begin{array}{l}\text { - 'Rede Social'; } \\
\text { - Critérios de avaliação para soluções de startups; } \\
\text { - Startup Day - evento de aculturamento. }\end{array}$ \\
\hline \multirow{3}{*}{$\begin{array}{l}\text { Avaliação e } \\
\text { Monito- } \\
\text { ramento }\end{array}$} & $\begin{array}{c}\text { Pontos } \\
\text { Positivos/ } \\
\text { Habilitadores }\end{array}$ & $\begin{array}{l}\text { - Definição do objetivo da intervenção: aculturamento e critérios de } \\
\text { avaliação considerando startups como provedoras de soluções. } \\
\text { - Atribuição de metas e incentivos aos membros da intervenção. } \\
\text { - Atribuição de dedicação parcial do time. } \\
\text { - Capacitação dos membros; diagnóstico. } \\
\text { - Capacitação do grupo: passam a ter noção da lacuna de conhecimento; } \\
\text { - discussões sobre artigos, revistas, trocas de experiências e benchmarks. } \\
\text { - Coco no aculturamento. } \\
\text { - Colaboração e engajamento dos funcionários pela 'rede social'. } \\
\text { e empreendedorismo. }\end{array}$ \\
\hline & $\begin{array}{l}\text { Pontos } \\
\text { Negativos/ } \\
\text { Barreiras }\end{array}$ & $\begin{array}{l}\text { - Falta de conhecimentos e experiências sobre melhores práticas em relação } \\
\text { ao tema. } \\
\text { - Dificuldades da equipe em priorizar as atividades; concorrência com } \\
\text { atividades de rotina. } \\
\text { - Falta de interação rápida com os executivos gerando retrabalho em } \\
\text { algumas ações. } \\
\text { - Falta de engajamento de alguns membros. }\end{array}$ \\
\hline & $\begin{array}{l}\text { Melhorias } \\
\text { Propostas } \\
\text { pelo grupo }\end{array}$ & $\begin{array}{l}\text { - Intensificar a divulgação de conteúdos na rede social. } \\
\text { - Divulgar, de forma planejada, as ações realizadas: critérios de avaliação } \\
\text { das startups e eventos. } \\
\text { - Testar os critérios de avaliação. }\end{array}$ \\
\hline
\end{tabular}

Fonte: Elaborado pelo autor. 


\subsubsection{Ciclo 3 - Expansão de Aculturamento e Experimentação do Ferramental}

Após os resultados e avaliações internas do grupo sobre o Ciclo 2, deu-se a continuidade da intervenção - o Ciclo 3. Oficialmente, o novo ciclo foi composto pelo mesmo número de pessoas que finalizou o Ciclo 2, ou seja, 10 (dez), além do pesquisador. No entanto, no decorrer do Ciclo 3, assim como no anterior, o engajamento - frequência e realização de ações - ocorreu com apenas 7 (sete) pessoas.

Em 12 de setembro de 2017, foi realizada a primeira reunião do grupo responsável pelo Ciclo 3, conforme apresentado no Quadro 20, no qual constam, inclusive, os demais marcos desse ciclo.

Quadro 20 - Marcos do Ciclo 3

\begin{tabular}{|c|l|}
\hline Data & \multicolumn{1}{c|}{ Evento } \\
\hline 12/set/2017 & $1^{\circ}$ Reunião do grupo no Ciclo 3 \\
\hline $15 /$ set/2017 & Apresentação do diagnóstico do Ciclo 3 aos executivos \\
\hline 19/set/2017 & Planejamento das atividades e definição dos responsáveis \\
\hline 20/out/2017 & Entrega: Piloto e divulgação dos critérios de avaliação para soluções de startups \\
\hline 4/dez/2017 & Entrega: Startup Day 2 - Evento de aculturamento \\
\hline $11 /$ dez/2017 & Reunião final para avaliação da intervenção \\
\hline
\end{tabular}

Fonte: Elaborado pelo autor.

\subsubsection{Ciclo 3: Diagnóstico}

Em reunião ocorrida em 12 de setembro de 2017, o grupo definiu a priorização das ações do Ciclo 3 e, em conjunto, decidiu pela continuidade das ações e concordou que a etapa de 'Diagnóstico' tivesse como principais insumos os resultados das ações realizadas no ciclo anterior.

Ao revisitar os resultados das ações do Ciclo 2, o grupo concluiu, inclusive, que durante o Ciclo 3 haveria a oportunidade de aprimorar significativamente as ações desenvolvidas, tais como os 'critérios de avaliação' e o 'Startup Day 2'. O grupo também entendeu que a ação 'rede social' estava estável e não necessitava de melhorias imediatas. Após ter decidido que havia a necessidade de aprimorar as duas primeiras ações supramencionadas - 'critérios de avaliação' e 'Startup Day 2' -, o grupo iniciou as discussões visando à adoção de melhorias para tais ações. 
O Participante RO2 reforçou que os 'critérios de avaliação' corriam o risco de serem ignorados pelos arquitetos ou pelas startups devido à falta de um 'teste prático'. Para aprimorá-los, foi sugerido um piloto com startups, o que daria maior robustez e prepararia os critérios para serem divulgados aos arquitetos. O grupo sugeriu, e todos os demais integrantes do grupo concordaram, que esse piloto deveria ser feito com três startups e que a atividade de divulgação dos critérios nas áreas impactadas deveria fazer parte do planejamento da ação.

Ao refletir sobre o novo evento de aculturamento - 'Startup Day 2' -, o pesquisador lembrou a sugestão feita durante a avaliação do Ciclo 2, para convidar um palestrante proveniente de startup, pois possibilitaria aos colaboradores a oportunidade de conhecerem mais sobre os desafios de relacionamento, sob a perspectiva de uma startup.

Outra sugestão de melhoria dada foi utilizar a 'rede social' criada pelo grupo para impulsionar o convite do evento, uma vez que os membros dessa rede constituíam seu público alvo. Por fim, o Participante VI2 reforçou a ideia de que um dos itens da pauta deveria ser a apresentação das ações realizadas na intervenção.

A etapa de 'Diagnóstico' teve seu fechamento formal em 15 de setembro de 2017, quando foram apresentados ao diretor-patrocinador e aos demais executivos os resultados do Ciclo 2 e a proposição das ações do Ciclo 3. Iniciou-se apresentação esclarecendo que os avanços obtidos nos ciclos anteriores, quanto ao escopo, aos levantamentos e aos resultados das ações desenvolvidas, assim como os aprimoramentos decorrentes das ações realizadas anteriormente, permitiram que o terceiro e último ciclo tivesse um foco em poucas ações, mas com maior eficácia. A escolha de duas ações para o ciclo: 'piloto e divulgação dos critérios de avaliação' e 'Startup Day 2', deu-se pelo fato de ambas as iniciativas darem continuidade ao objetivo de trabalhar os aspectos de aculturamento na organização, em especial com os colaboradores da área de Tecnologia. 


\subsubsection{Ciclo 3: Planejamento}

Em 18 de setembro de 2017, no início da etapa de 'Planejamento', o Participante FE2 pediu para não mais exercer o papel de team leader - responsável por organizar as reuniões e por apoiar as atividades dos demais -, voltando, então, a atuar somente na execução das ações. O pedido foi ocasionado devido à concorrência entre as atividades da intervenção e as de seu departamento, apesar da diminuição da quantidade de ações da intervenção. O papel de team leader foi colocado à disposição dos outros membros do grupo e, como não houve voluntários, o pesquisador acabou assumindo essa função.

Em 19 de setembro de 2017, o grupo reuniu-se para definir os responsáveis pelas duas ações previstas para o Ciclo 3. No encontro, estiveram presentes 7 (sete) membros da equipe, os mesmos que já haviam participado de forma ativa das etapas desenvolvidas ao longo do Ciclo 2.

O pesquisador juntamente com os Participantes RO2 e AD2 comprometeram-se a dar continuidade à ação do 'Piloto e Divulgação dos Critérios de Avaliação' de Startups, pois já tinham familiaridade com essa atividade.

Quanto ao 'Startup Day 2', todos os 7 (sete) membros comprometeram-se a contribuir com sua realização. Sendo assim, o pesquisador sugeriu que fosse realizada uma divisão por frentes de atuação. Os Participantes LU12 e CA2 ficariam responsáveis pelas agendas dos palestrantes e as dos demais participantes; o pesquisador e os Participantes RO2 e AD2 ficariam responsáveis pela divulgação do evento e pela preparação da apresentação das ações; e o Participante FE2 prontificou-se a reservar o local do evento e a atuar na logística do mesmo.

Ficou acordado que o grupo apresentaria semanalmente o status de suas atividades nas reuniões, algo que já vinha sendo realizado desde o Ciclo 2, mas que, a partir de então, passaria a ser organizado pelo pesquisador. 


\subsubsection{Ciclo 3: Ações}

As ações previstas para este ciclo serão apresentadas a seguir, a saber: revisão e geração de um 'piloto e divulgação dos critérios de avaliação' para soluções de startups e 'Startup Day 2', evento de aculturamento e relacionamento com startups.

\section{Ação 7: Piloto e Divulgação dos Critérios de Avaliação para Soluções de Startups}

Em 21 de setembro de 2017, foi iniciada a aproximação com as startups sobre os critérios de avaliação. Foram agendadas entrevistas com três startups para efetuar os pilotos: uma de mobilidade de força de vendas; uma de gestão de processos e uma de gestão de produtividade. Essas entrevistas foram realizadas presencialmente nos escritórios dessas startups, nos dias 26 e 27 de setembro de 2017. As três empresas foram avisadas que se tratava de um teste e, portanto, a avaliação não tinha valor real.

Para efetuar o piloto dos 'critérios de avaliação', os Participantes RO2 e AD2 atuaram como entrevistadores e, ao longo das entrevistas, foram anotando suas percepções. Em 28 de setembro de 2017, esses participantes-entrevistadores reuniram-se com o pesquisador para discutir suas percepções sobre as entrevistas realizadas. Um dos pontos identificados por ambos foi quanto à forma de avaliação utilizando questionário, pois não trazia nem naturalidade e nem fluidez à conversa. O Participante RO2 afirmou que "a impressão que dava é que estávamos fazendo um interrogatório". Outro ponto que causou incômodo a ambos foi quanto à longa duração das entrevistas, entre 90 e 110 minutos. A expectativa é que durassem entre 35 e 40 minutos. A principal justificativa para essa longa duração, segundo os participantes-entrevistadores, foi o número elevado de perguntas. 
Em 3 de outubro de 2017, com base nos dados obtidos pelo instrumento piloto, o pesquisador e os outros dois membros participantes iniciaram as modificações necessárias no documento de 'critérios de avaliação'. No decorrer do desenvolvimento, no entanto, a entrega do material acabou atrasando duas semanas, devido à concorrência com outras atividades, sendo então finalizada em 17 de outubro de 2017.

Comentário 11: Ao passo que o fim do ano se aproximava, a concorrência das atividades 'extra intervenção' intensificava-se e os $10 \%$ de dedicação combinados no início do processo foi difícil de ser cumprido. Por esse motivo, foi preciso revezar a atuação, principalmente em relação aos critérios de avaliação.

Outra tarefa associada aos 'critérios de avaliação' foi a sua divulgação. A primeira ação realizada nesse sentido foi a criação pelo grupo de uma seção na 'rede social', na qual, além do material, foi inserido um texto explicativo sobre a forma de sua utilização. Para potencializar seu uso, foi feita a apresentação desse documento em um dos Fóruns semanais de Arquitetura de Negócios, ocorrido em 20 de novembro de 2017. Ao público presente, composto por especialistas e gestores de arquitetura de negócios, foi solicitado que propagassem o uso aos seus pares e às suas equipes.

\section{Ação 8: Startup Day 2 - Evento de Aculturamento}

Em 29 de setembro de 2017, deu-se início às atividades referentes ao evento de aculturamento. O grupo decidiu que a edição do 'Startup Day 2' seria composta por duas preleções: uma apresentação sobre as ações do grupo e um painel de discussão entre duas startups e dois executivos da empresa XYZ, seguindo as decisões e encaminhamentos definidos pelo grupo, no final do Ciclo 2. Ao todo, o evento teria três horas de duração, uma hora a mais do que a edição anterior.

Para elencar as preleções, o Participante LU12 efetuou sondagens com algumas instituições envolvidas no ecossistema empreendedor. Após alguns contatos e negociações, ele conseguiu confirmar a participação de uma aceleradora de startups que abordaria o tema 'programas de inovação corporativa'.

A presença do palestrante convidado, proveniente de um startup, foi confirmada pelo Participante CA2. Esse convidado era fundador de uma startup que atuava em processamento de cartões de débito e crédito. O pesquisador sugeriu que ele abordasse 
'as dificuldades de se relacionar com grandes empresas' e quais 'recomendações daria às grandes empresas que desejam [desejassem] se relacionar com startups'.

Para composição do painel, além do representante dessa startup mencionada, também foi convidado o de uma outra, de força de vendas, que já havia participado do evento anterior. Foi confirmada, inclusive, a presença de dois executivos da empresa XYZ, sendo um da área de Customer Relationship Management (CRM) e o outro da área de Compras.

O evento também teve um momento reservado à apresentação das ações realizadas durante esta Pesquisa-Ação. O grupo concordou que, além de apresentar a visão geral de todo o processo de intervenção, também deveria abordar com mais destaque o 'modelo de relacionamento com startups proposto' e os ‘critérios de avaliação' desenvolvidos para melhoria desse relacionamento.

Durante as preparações desse evento, a atividade de maior apreensão foi com relação à forma de sua divulgação. Para essa tarefa, em 29 de outubro de 2017, foi realizada uma ação conjunta de disseminação do evento, enviando-se a mensagem com um link para que os destinatários pudessem fazer sua inscrição. A publicação foi divulgada através da 'rede social' para todos os inscritos e por e-mail para os colaboradores da organização considerados formadores de opinião - executivos de tecnologia e alguns diretores de negócios. 36 horas após a divulgação, as 180 vagas disponibilizadas haviam se esgotado. Prevendo-se ausências, foram abertos mais 100 convites, que se esgotaram em cerca de 6 horas.

Em 4 de dezembro de 2017, foi realizado o evento. O auditório estava lotado e algumas pessoas acabaram se sentando nos corredores, conforme ilustra a Figura 28 abaixo. 
Figura 28 - Startup Day 2

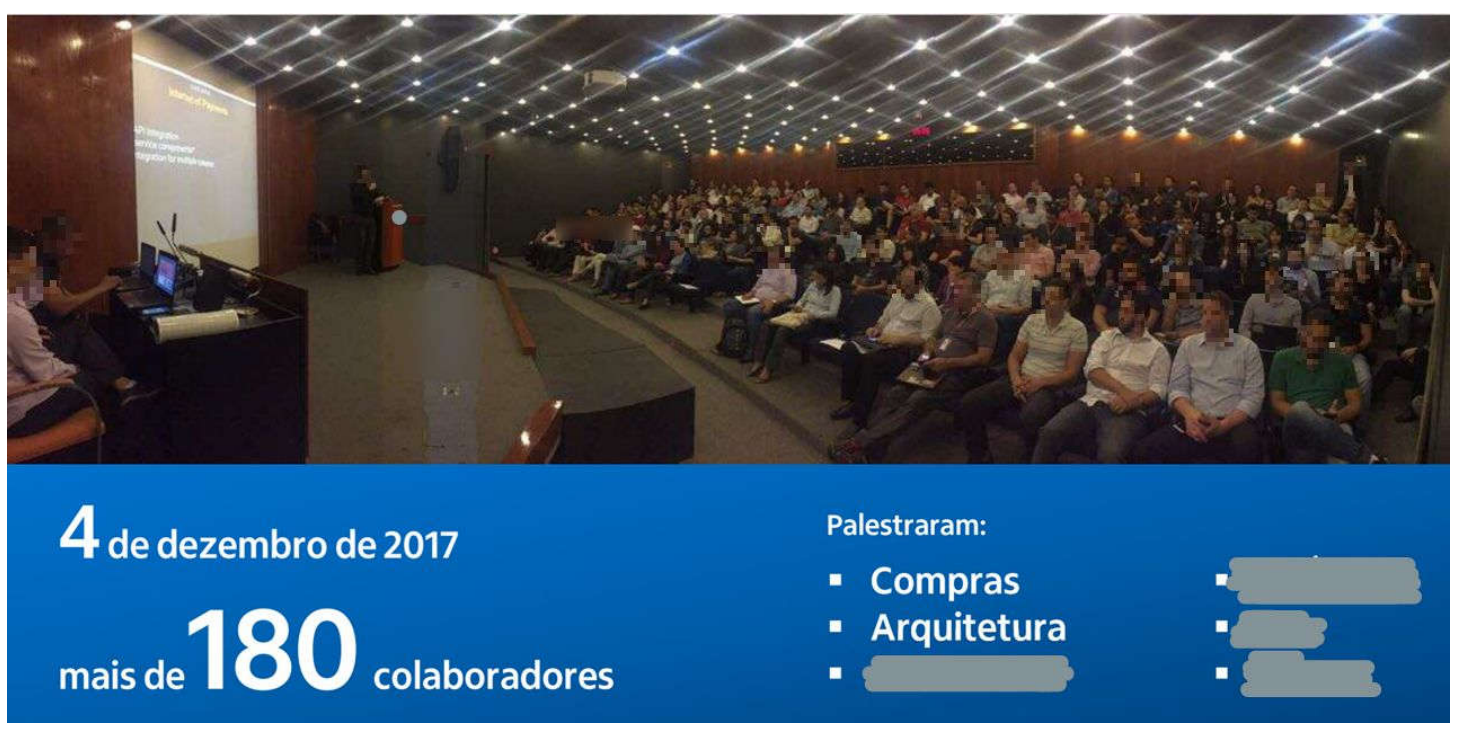

Fonte: Elaborada pelo autor.

Após as palestras e a apresentação das ações realizadas pelo grupo, deu-se início ao painel de discussão, desta vez conduzido somente com perguntas elaboradas pelo público presente. Foi possível responder àquelas referentes aos casos de sucesso e aos de insucesso de startups com a empresa XYZ, bem como fazer sugestões de aprimoramento.

Dentre as ocorrências do painel, destacou-se o compartilhamento da experiência do fundador de uma das startups, que teve que passar por provas de conceito antes de fechar o primeiro contrato com a empresa XYZ. Esse empreendedor destacou que, em contrapartida, como resultado positivo, após essa primeira aproximação, outros três contratos foram concretizados em menos de um ano. Enriquecendo ainda mais jornada, o fundador sugeriu que fossem realizados pilotos e provas de conceito remuneradas, a fim de estimular outras startups a trazerem inovação para a empresa.

Durante o painel, o executivo de CRM comparou dois casos de startups que tentaram prover soluções à organização: uma delas levou três meses entre a negociação e a entrega do seu primeiro projeto; e a outra demorou doze meses desde o primeiro contato até a elaboração do parecer negativo, dado pela área de Tecnologia. O executivo explicou que o primeiro caso foi entregue pois, diferentemente do segundo, o objetivo a ser alcançado pelo negócio e por ambas as equipes - tanto a da empresa XYZ como a da startup - era 
muito claro e elas atuaram boa parte do tempo fisicamente próximas. No segundo exemplo, a área de Negócios "queria apenas utilizar a startup como 'fábrica de software", segundo o executivo. Ou seja, não tinha nem propósito e nem critérios claros sobre como construir soluções com a startup.

Ao finalizar o evento, também foi possível perceber movimentos de construção de rede de contatos. Por exemplo, o pesquisador presenciou a conversa entre um diretor e o representante de uma das startups que havia proferido uma das palestras. Além disso, duas semanas após o evento, o grupo responsável pela intervenção foi convidado pela equipe de inovação de uma área de negócios para discutir um novo processo de 'inovação aberta' envolvendo startups. Esse interesse surgiu em função da participação no evento de um dos colaboradores dessa área.

\subsubsection{Ciclo 3: Avaliação}

Com o final do Ciclo 3, encerrou-se também a Pesquisa-Ação. Todos os 11 (onze) membros oficialmente inscritos possuíam em seus contratos $5 \%$ das metas do ano associadas à intervenção. Devido ao fato de essa formalização ter ocorrido no início do Ciclo 2, somente os membros que atuaram nos Ciclos 2 e 3 seriam avaliados. A avaliação foi feita pelos executivos diretamente ligados ao diretor-patrocinador e pelos especialistas de Tecnologia da organização.

A reunião de avaliação ocorreu em 11 de dezembro de 2017, portanto, sete dias após a conclusão da última ação, o evento 'Startup Day 2'. Estiveram presentes cerca de 50 (cinquenta) especialistas da área de Tecnologia e 4 (quatro) executivos. Nesse evento, foram apresentados brevemente os números da Pesquisa-Ação e todas as 9 (nove) ações realizadas durante os três ciclos, embora o Ciclo 1 não estivesse sendo avaliado.

Ao final, houve um tempo para comentários do público. Um dos especialistas questionou a eficiência da divulgação dos critérios de avaliação para solução de startups nas redes sociais e pontualmente nos fóruns, afirmando que os critérios seriam rapidamente “esquecidos”. O pesquisador, em particular, concordou com a crítica e sugeriu que essa 
avaliação utilizando os critérios fosse fornecida como um serviço prestado pela área de Arquitetura de Negócios, pois todas as iniciativas de tecnologia, incluindo as que envolviam startup, eram obrigatoriamente avaliadas por essa equipe.

\subsubsection{Autorreflexões sobre o Processo do Ciclo 3}

Durante a etapa de 'Planejamento' do Ciclo 3, ocorreu a terceira mudança no papel de líder do time (Team Leader). Isso fez com que o pesquisador refletisse sobre as frequentes trocas de papéis, resultantes das interferências do cotidiano, o que contrasta com a necessidade de dar suporte suficiente aos colaboradores para que consigam atuar com iniciativas de inovação (Dombrowski et al., 2007; Martins \& Terblanche, 2003).

A principal razão para as trocas repentinas, na visão do pesquisador, continuava a ser a concorrência com atividades fora da intervenção. As alternativas para mitigar tais pontos, na visão do pesquisador, seriam formalizar um tempo maior de dedicação aos membros do time e provisionar incentivos, este último incluindo os executivos. Estudos como os de Mortara, Napp, Slacik e Minshall (2009), e os de Kuratko, Hornsby e Covin (2014) sugerem apresentar incentivos específicos para equipes que atuem com inovação, como uma boa prática de mercado.

O pesquisador refletiu a respeito da importância de coletar informações das startups para efetuar melhorias nos critérios e nas ferramentas de avaliação de suas soluções. Esses testes trouxeram modificações importantes, como a redução da quantidade de perguntas e a simplificação dos textos. Sem que houvesse troca de experiência com quem participaria das avaliações, seria provável que os artefatos não fossem utilizados, por não agregarem valor.

Outra reflexão diz respeito à continuidade de divulgação dos 'critérios de avaliação'. O grupo sentiu a boa aceitação do público, mas alguns membros foram procurados por pessoas que tinham dúvidas sobre como seria a adoção dessa ferramenta, considerandose que não existia um processo pré-estabelecido. Como sugestão, o pesquisador propôs a criação de um serviço de consultoria, a ser prestado pela área de Arquitetura de Negócios, 
que permitiria mais incursões de mudança cultural na organização à medida que as avaliações fossem ocorrendo.

Em relação ao 'Startup Day 2', as reflexões estavam associadas ao futuro de eventos de aculturamento similares a serem realizados. Notou-se que os eventos trouxeram engajamento do público sobre o assunto e, em alguns casos, permitiram que relacionamentos fossem fomentados. No entanto, o pesquisador concorda com Bannerjee, Bielli e Haley (2016), que consideram que eventos isolados tendem a ser ‘impulsionadores' para uma cultura interna e não sustentadores dessa cultura. $\mathrm{Na}$ visão do pesquisador, os eventos são importantes para a empresa e deveriam ocorrer periodicamente, mas deveriam ser acompanhados de outras ações.

Ao comparar o Ciclo 3 com os anteriores, o pesquisador pôde perceber uma transição de ações exploratórias para ações de continuidade. Essa reflexão corrobora com a visão de Gummesson (2000) de que na Pesquisa-Ação os objetivos partem da confusão para a nitidez ao percorrerem seus ciclos espirais.

No caso da intervenção relatada nesta dissertação, o pesquisador credita o ganho de clareza e transparência do processo a duas principais razões: a primeira, diz respeito aos direcionamentos do diretor-patrocinador que balizaram o foco do grupo. Da mesma forma, Kuratko, Hornsby e Covin (2014), Prats, Amigó, Ametller e Batlle (2017) e Schättgen e Mur (2016) corroboram com essa visão, ao afirmarem que a alta liderança tem papel fundamental no engajamento, no direcionamento e no provisionamento de recursos e incentivos.

A segunda razão está relacionada com o amadurecimento da equipe quanto ao conhecimento sobre as limitações das empresas envolvidas, o ecossistema de startups, e as melhores práticas de mercado. Essa consideração corrobora com a visão de Mortara, Napp, Slacik e Minshall (2009) e com a de Rumelt (1995) que discorrem sobre a função primordial de capacitação e habilidades para execução de ações envolvendo inovação nas organizações. 
A síntese dos procedimentos, ações e resultados decorrentes do Ciclo 3 apresenta-se no Quadro 21 a seguir.

Quadro 21 - Síntese do Ciclo 3: Expansão de Aculturamento e Experimentação do Ferramental

\begin{tabular}{|c|c|c|}
\hline \multicolumn{2}{|c|}{ Período } & $12 / 09 / 2017-11 / 12 / 2017$ \\
\hline \multicolumn{2}{|c|}{ Papel do Pesquisador } & Membro e Líder do Time (Team Leader) \\
\hline \multicolumn{2}{|c|}{ Escopo no momento do Ciclo } & $\begin{array}{l}\text { 'Melhorar o relacionamento da empresa XYZ com startups, } \\
\text { considerando-as como provedoras de solução para problemas } \\
\text { de negócios'. }\end{array}$ \\
\hline \multicolumn{2}{|c|}{ Diagnóstico } & $\begin{array}{l}\text { - Coleta: foram utilizados os dados obtidos no ciclo anterior, } \\
\text { além das discussões de feedback dos membros do grupo. } \\
\text { - Análise: estruturação dos dados obtidos, além dos } \\
\text { feedbacks coletados na etapa de avaliação do Ciclo } 2 \text {. } \\
\text { - Resultados: discussão conjunta em reunião e avaliação de } \\
\text { todo o processo pelos colaboradores. }\end{array}$ \\
\hline \multicolumn{2}{|c|}{ Planejamento } & $\begin{array}{l}\text { - Priorização pelo aprimoramento das atividades do ciclo } \\
\text { anterior: } \\
\circ \text { aculturamento dos colaboradores sobre startups; } \\
\circ \text { ferramental de suporte para avalição de startups. }\end{array}$ \\
\hline \multicolumn{2}{|c|}{ Entregas Realizadas } & $\begin{array}{l}\text { - Piloto e divulgação dos critérios de avaliação para soluções } \\
\text { de startups. } \\
\text { - 'Startup Day 2' - evento de aculturamento. }\end{array}$ \\
\hline \multirow{3}{*}{$\begin{array}{c}\text { Avaliação e } \\
\text { Monitoramento }\end{array}$} & $\begin{array}{c}\text { Pontos Positivos/ } \\
\text { Habilitadores }\end{array}$ & $\begin{array}{l}\text { - Validação dos critérios de avaliação de startups, utilizando } \\
\text { a percepção de startups parceiras. } \\
\text { - Planejamento de divulgação do evento de aculturamento e } \\
\text { ferramental de critérios de avaliação. } \\
\text { - Estímulo à criação de rede de contatos entre colaboradores } \\
\text { e startups em função do evento }\end{array}$ \\
\hline & $\begin{array}{l}\text { Pontos } \\
\text { Negativos/ } \\
\text { Barreiras }\end{array}$ & $\begin{array}{l}\text { - Dificuldade da equipe em priorizar atividades (concorrência } \\
\text { com atividades do dia a dia) } \\
\text { - Falta de engajamento de alguns membros. }\end{array}$ \\
\hline & $\begin{array}{l}\text { Melhorias } \\
\text { Propostas pelo } \\
\text { grupo }\end{array}$ & $\begin{array}{l}\text { - Definição da condução dos 'critérios de avaliação' como um } \\
\text { serviço da área de Arquitetura de Negócios. } \\
\text { - Definição de pessoas dedicadas a realizar as atividades } \\
\text { resultantes da intervenção, em especial, a 'rede social'. }\end{array}$ \\
\hline
\end{tabular}

Fonte: Elaborado pelo autor.

Finalizou-se, assim, a 'Pesquisa-Ação Central', porém foi dada continuidade à 'PesquisaAção Dissertação'. Nas semanas posteriores a esse fechamento, o pesquisador entrou em contato com alguns dos membros que haviam participado das intervenções para entrevistá-los, com o objetivo de obter suas percepções sobre todo o processo. 


\section{ANÁLISE DOS RESULTADOS}

Conforme explicado no subitem 3.9, os resultados das análises apresentam-se por meio de temas transversais, como: barreiras, habilitadores e melhores práticas.

A fim de dar clareza aos fatos e de mitigar vieses, a análise apresenta-se tendo como fonte principal de discorrimento trechos de relatos dos membros entrevistados ${ }^{8}$. Complementarmente, ao longo deste capítulo, serão cotejadas evidências de observação do pesquisador e de dados documentais, quando estes fizerem sentido.

\subsection{BARREIRAS PARA APROXIMAÇÃO DA EMPRESA XYZ COM STARTUPS}

\subsubsection{Objetivos e Estratégias}

\section{Falta de clareza da estratégia em relação às startups}

Os entrevistados relataram que não conseguiram obter uma definição da estratégia da organização em relação às startups, mesmo indagando os altos executivos que tinham interface com a intervenção. Alguns entrevistados interpretaram essa posição como um sinal de cautela da organização.

A indefinição da estratégia fez com que os grupos nos Ciclos 1 e 2 discutissem e prolongassem o planejamento das ações com base em suposições de abordagem, dissipando sua produtividade.

Membro FE [Grupo 2]: Acho que nossa estratégia é indefinida, porque é dito para todo mundo que a empresa XYZ está se aproximando. Ela tem iniciativas, mas a gente consegue internalizar ainda pouco de tudo isso. Se fosse algo que a empresa XYZ realmente priorizasse, veríamos mais energia investida. Hoje diria que temos uma estratégia mais tácita.

\footnotetext{
${ }^{8}$ Omitiu-se as identificações dos respondentes, por questões éticas de pesquisa e para preservação do anonimato. As menções feitas por esses participantes foram mantidas na íntegra o que justifica eventuais repetições e/ou erros, típicos da oralidade.
} 
Membro RO [Grupo 2]: (...) ela [a empresa XYZ] está começando a tentar dar passos maiores no sentido de colaborar mais com startups, mas, ainda, a estratégia dela, eu acho que está pautada muito na observação... é uma estratégia descentralizada.

Membro GI [Grupo 1]: (...) a gente ficou discutindo em qual problema deveríamos focar. Tinha problema em todo canto... Mas qual a nossa prioridade? Não tínhamos uma prioridade no executivo, né? Isso era um problema, a gente se perguntava muito e discutia muito entre a gente.

Membro VI [Grupo 2]: A gente questionou inclusive muito isso no começo e a gente não conseguiu obter um framework estratégico. A gente tinha pensado em algo do tipo, "olha, se for dessa forma, vamos comprar essa [a startup], se for dessa outra forma, vamos usar aquela [a startup], se for dessa outra forma a gente não quer...".

\section{Morosidade na definição do escopo e estratégia para a intervenção}

Pelo fato de não existir uma estratégia da organização para startups, o grupo buscou junto com o diretor-patrocinador definir o objetivo e a estratégia para a intervenção, o que levou algumas semanas.

Até que o objetivo e a estratégia para a intervenção estivessem definidos, os membros ainda discutiam entre si e com as áreas parceiras quais seriam as ações prioritárias. $\mathrm{O}$ período de discussões provocou desgastes e, principalmente, atrasos na evolução das atividades, não permitindo que ações mais complexas pudessem ser realizadas, por falta de tempo.

Membro VI [Grupo 2]: Acho que a gente teve uma priorização clara a partir do momento em que a gente conseguiu voltar com o executivo, e isso, por algumas razões aqui operacionais, demorou um pouco para acontecer.

Membro FA [Grupo 1]: Faltou um norte mais claro de cima para a iniciativa. A gente perdeu muito tempo com isso. Por falta disso a gente se perdeu nos interesses, então, a gente de compras estava muito interessado em resolver o problema do processo, porque não conhecia o processo, e os da arquitetura acho tinham interesse na tecnologia.

Membro RO [Grupo 2]: A gente perdeu muito tempo definindo ou tentando definir o que a gente queria como entrega de valor, então, se a gente já soubesse disso em menos tempo, poderíamos ter realizado entregas mais complexas. 
Em suas anotações de 16 de junho de 2017, antes do redirecionamento da intervenção, o pesquisador relatou discussões dispersas que o grupo teve em torno do escopo das atividades. Um dos membros entendeu que o foco da intervenção deveria estar na contratação: "a gente precisa de uma estória mais clara do ponto de vista da área de negócios, desejando critérios e formas de aceleração na contratação de uma startup" [Participante FE2]. Outro membro [Participante CA2] ponderou: "Como saber se o que vamos fazer é de fato importante? Eu acho que o aculturamento é importante, mas não é sustentável sem estabelecer processos".

\subsubsection{Alta Liderança}

\section{Falta de apoio entre pares}

O desafio de engajar a alta liderança de áreas pares (diretores e superintendentes) foi outra das principais barreiras constatadas na intervenção.

Segundo os entrevistados, os executivos de áreas parceiras foram mobilizados pelo diretor-patrocinador, porém, alguns se mostraram céticos quanto à real capacidade de resolução de problemas das startups, diminuindo o comprometimento com o passar do tempo, o que refletiu na falta de prioridade em suas agendas, causando paralisações nas atividades da intervenção.

Membro SA [Grupo 1]: A nossa velocidade de grupo estava muito ruim... as agendas não estavam priorizadas. $\mathrm{Na}$ época, eu lembro que a gente tinha algumas dependências do [Superintendente X], e o [Superintendente $\mathrm{X}]$ não podia atender a gente, né?

De acordo com registros de e-mails, datados de 09 de março de 2017, foi possível constatar o interesse inicial de alguns executivos, buscando compreender o que era a intervenção e quais os recursos que ela necessitaria. Mas, uma mobilização efetiva dessas lideranças não chegou a ir adiante. Outro reflexo da falta de apoio dos executivos foi a baixa presença desse perfil no primeiro evento de aculturamento, executado em 06 de setembro de 2017, quando somente um alto executivo esteve presente. 


\section{Conflito de prioridades dos times de apoio}

$\mathrm{Na}$ opinião dos entrevistados, a falta de engajamento dos executivos estendeu-se aos times envolvidos na intervenção, gerando conflitos de prioridades entre as atividades da intervenção e as do dia a dia. Isso fez com que os colaboradores designados a participar das atividades ausentassem-se ou enviassem, em seu lugar, colegas que não tinham histórico das discussões. Esses problemas resultaram em desperdício de tempo, devido ao retrabalho das atividades, e à perda de qualidade ao fazer com que o grupo tomasse decisões com menos informações.

Membro RO [Grupo 2]: Eu acho que a falta de priorização foi um dos principais pontos críticos, porque nem todas as áreas tinham priorizado aquilo. Acho que faltou buy in de alguns gestores, pois, por exemplo, tinham analistas que não priorizavam as atividades...

Membro GI [Grupo 1]: Não sei se todos os executivos estavam alinhados no projeto, o gerente ia numa reunião e na seguinte ele não ia mais, mandava outro no lugar, não era prioridade para ele. Então, tinha algumas áreas que não eram prioridades... Então, isso atrapalhou a sequência.

Membro FA [Grupo 1]: Em várias reuniões que a gente fazia, cada hora um faltava ou mudava uma pessoa, então... aquilo que a gente discutiu na reunião anterior você tinha que meio que explicar para a nova pessoa, ou ela não tinha a mesma bagagem...

Em 18 de janeiro de 2017, data do $3^{\circ}$ workshop do Ciclo 1, já era evidente a queda no engajamento dos participantes. Em um trecho do e-mail enviado a todos os 14 (quatorze) convidados, o pesquisador ressaltou que apenas " 2 aceitaram, 2 recusaram e a maioria não enviou resposta". Ainda assim, o grupo decidiu continuar o workshop, que contou com a presença de 6 (seis) pessoas, incluindo o pesquisador.

Levantamentos documentais também corroboraram com os relatos dos entrevistados. Foi possível identificar que quatro reuniões com áreas parceiras tiveram que ser reagendadas por conflito com outras atividades. Em uma dessas ocasiões, em 13 de fevereiro de 2017, o pesquisador tentou negociar com um gestor de uma área parceira, para conseguir a participação de uma pessoa do seu time: "Precisamos muito do apoio do seu time para 
evoluir as conversas, mas entendo a quantidade de demandas em paralelo que têm. O que acha de alinharmos as expectativas? ”

\section{Comunicação esporádica com os executivos}

A irregularidade de comunicação com com os executivos envolvidos no projeto não permitiu que fossem discutidas questões estratégicas de forma mais direta. A irregularidade de discussões com executivos fez com que o time, às vezes, atuasse com poucos subsídios, o que acabava gerando retrabalho após novas conversas com eles, atrasando, assim, os cronogramas.

Membro RO [Grupo 2]: Eu acho que a comunicação foi falha somente entre o time e os executivos, no sentido de frequência. Tirando a autonomia, não teve nem insights nem ajudas vindas de cima.

Membro FE [Grupo 2]: Teve uma questão de pouco contato, a gente deveria ter tido mais contato com os executivos para eles nos ajudarem mesmo a manter o foco nesses pontos estratégicos que eles colocaram no começo, até de forma a manter o foco no trabalho. Acho que faltou um pouco mais de contato.

\subsubsection{Cultura}

\section{Ausência de Cultura Empreendedora / Startups}

A ausência de cultura empreendedora foi identificada como a barreira com mais associações em torno das ações de aproximação da empresa XYZ com startups. Os entrevistados atribuíram a origem dessa barreira à conveniência da organização em manter um modelo de negócios que vem dando resultados positivos subsequentes. A ausência da cultura empreendedora, no contexto da intervenção, foi composta por um comportamento de aversão aos riscos, seguido de baixo conhecimento sobre startups e cultura empreendedora. Na perspectiva dos entrevistados, os principais impactos da falta de cultura empreendedora, no processo da intervenção proposta, ajudaram a esclarecer o pessimismo dos membros envolvidos e das áreas parceiras, e a necessidade de um tempo mais longo para a construção do conhecimento por parte do grupo. 


\section{Modelo operacional com retorno financeiro}

No entendimento dos membros da empresa XYZ, o fato de a organização ter lucros subsequentes elevados, em um modelo de gestão e operação estável, desestimula a abertura de iniciativas voltadas à aproximação com startups, ainda mais por ser uma empresa de capital aberto. Um exemplo que comprova essa perspectiva é a priorização de projetos de tecnologia desenvolvida estritamente com base no retorno financeiro.

Membro SA [Grupo 1]: Acho que é um tema [colaboração com startups] importante, mas hoje não é uma coisa que dói para a empresa XYZ. A empresa XYZ é o pai rico, o pessoal brinca. Então, por mais que seja um problema, como instituição financeira, ela ainda não está preocupada, porque funcionando do jeito que está, está dando lucro.

Membro VI [Grupo 2]: Eles da empresa XYZ sempre deram resultado e ainda estão dando. No fim do dia, as empresas [que fazem parte da empresa XYZ] ainda obtêm lucro gigantesco, trabalhando dessa mesmíssima forma. Essa realidade que ainda não mudou, na conta do acionista não mudou ainda, acho que esse é o maior desafio que a gente tem, é de convencer as pessoas de que não vai dar tempo se elas esperarem para mudar de uma hora para outra.

\section{Aversão aos riscos}

A aversão aos riscos, no entendimento dos entrevistados, está enraizada na cultura da organização, por exemplo, resistência ou medo de efetuar mudanças. Tal cultura refletiuse na falta de proatividade e morosidade dos colaboradores em executar tarefas que saíam de suas atividades habituais.

Membro CA [Grupo 2]: A nossa doença, essencialmente é a empresa XYZ não estar preparada e não gostar de correr riscos, e boa parte dos sintomas que você encontra na falta de voluntariedade das pessoas, na velocidade lenta de fazer as coisas, coisas assim, têm a ver com a empresa não correr riscos.

Membro FE [Grupo 2]: Existe muito mindset que precisa ser alterado e que não é simples, porque são coisas muito enraizadas, deu certo até hoje, né? Então são modos de pensar que levaram a empresa aonde ela está hoje, por que mudar? Por que eu vou arriscar? 


\section{Falta de conhecimento do público sobre startups e empreendedorismo}

De acordo com os entrevistados, os colaboradores da organização possuem baixo conhecimento sobre o tema startups e empreendedorismo, devido ao baixo incentivo às interações com esses tipos de negócios. Esse baixo estímulo tem sido mantido ao longo do tempo e justifica o comportamento de alguns dos funcionários, principalmente dos que estão há mais tempo na organização.

Membro RO [Grupo 2]: Isso não é uma regra, obviamente, mas deu para perceber que, na média, os colaboradores mais antigos têm um nível de cultura empreendedora menor, porque não havia estímulo. Eles trabalharam anos e anos e anos sem esse estímulo.

Membro CA [Grupo 2]: Acho que até pelo perfil das pessoas, dos profissionais da empresa XYZ; o perfil, em geral, a cultura empreendedora é baixa. Temos um perfil que não está acostumado com empreendedorismo ou uma startup, que é um negócio exponencial.

\section{Impactos da falta de incentivos à cultura empreendedora/startups}

Na percepção dos entrevistados, a falta de incentivos à cultura empreendedora consolidou nas áreas parceiras da intervenção uma resistência à iniciativa, por acreditarem que não haveria mudanças na organização para uma aproximação de startups ou que a mudança não teria relevância.

Membro FA [Grupo 1]: Alguns diretores não acreditavam nisso; até um diretor falou assim: "Ah, me fala uma startup que resolve um problema sério aqui..." Mas eu acho que aquele grupo que estava lá, os 'caras' acreditavam que as startups podiam solucionar grandes problemas nossos.

Membro FE [Grupo 2]: Nós falamos para um grupo de pessoas que eles poderiam trabalhar com uma startup, mas é nítido o ceticismo deles diante da realidade, devido a todo aparato organizacional. 


\subsubsection{Equipe}

\section{Baixo conhecimento sobre o tema (falta de capacitação)}

A falta de capacitação dos membros da intervenção foi reconhecida pelos entrevistados como uma das principais dificuldades em se executar as ações. Esse fato foi agravado frente à expectativa do grupo em iniciar rapidamente a execução das ações.

Apesar de existirem pessoas com algum conhecimento prévio sobre startups, houve consenso entre os entrevistados que o conhecimento geral do grupo era predominantemente baixo. Mesmo os membros que já tinham alguma familiaridade com o tema, estavam limitados à perspectiva operacional das startups; sem visão estratégica em relação a esses negócios. Por exemplo, os benefícios e desafios da empresa XYZ em atuar próxima às startups.

Membro VI [Grupo 2]: O primeiro grande obstáculo foi o conhecimento das pessoas, né? Não havia, então, essa necessidade de formar a equipe, formar muito rápido para já conseguir produzir algum resultado, isso foi um obstáculo.

Membro RO [Grupo 2]: O time não era homogêneo, mas, no geral, o conhecimento era baixo, a gente tinha talvez duas ou três pessoas no time que conheciam o tema...

Membro AD [Grupo 2]: Eu percebi que o conhecimento do time no começo do trabalho era muito da relação do dia a dia, sem uma visão estratégica.

Membro FE [Grupo 2]: Eu acho que é muito naquele sentido de que a gente abordava... muitas startups como um fornecedor tradicional de tecnologia.

Segundo os entrevistados, a falta de capacitação e de experiência sobre o tema 'relacionamento de startups com grandes empresas' gerou, em alguns participantes, uma visão simplista de como as ações deveriam ser executadas, o que provocou discussões não assertivas em relação às atividades.

A falta de conhecimento sobre o assunto e discussões prolongadas acarretaram, segundo os entrevistados, em ampliação das fases iniciais para que a equipe pudesse se aprofundar no assunto. 
Membro FE [Grupo 2]: No começo, a maioria do grupo queria revolver na base do 'achismo'. Quando você não sabe nada você fala: "A gente tinha que abrir para startups, a gente tinha que abrir, começar a interagir com empresas assim, a gente tem que abrir o olho para essas coisas...". Mas quem conhecia um pouco [sobre o assunto] falava: "Não, espera aí, o buraco é mais embaixo... temos que ter um plano".

Membro CA [Grupo 2]: Eu lembro quando a gente chegou na primeira reunião e eu tive que falar: "“cara', vocês não fazem ideia do que vocês tão falando...".

Membro RO [Grupo 2]: Se todo mundo tivesse um conhecimento prévio do tema, teríamos poupado algumas discussões. A gente poderia ter definido de forma mais rápida as ações, os objetivos que a gente queria chegar, buscar mais rápido um alinhamento com a estratégia etc.

\section{Falta de tempo para se dedicar ao processo de intervenção}

A falta de tempo para realizar ações foi a barreira mais relatada nas entrevistas coletadas, sendo citada 21 (vinte e uma) vezes pelos 8 (oito) entrevistados.

Enquanto no Ciclo 1 não havia um tempo pré-determinado para as atividades, que se espremeram no cotidiano dos membros, no Ciclo 2, foi estabelecido cerca de quatro horas semanais, o que, mesmo assim, foi insuficiente para realizar as ações da intervenção. Essa disponibilização do tempo, segundo alguns entrevistados, não foi negociada, e sim estabelecida.

Segundo os entrevistados, na prática, muitos membros consumiam um tempo maior para conseguir realizar as atividades. Por não haver um tempo fixo, o grupo também sofreu com problemas para efetuar o agendamento conjunto.

Membro RO [Grupo 2]: Uma grande barreira que impediu que fizéssemos entregas melhores e mais complexas foi o tempo de dedicação, porque já foi dado desde o início e a gente se adequou a essa realidade, à nossa própria expectativa e a dos executivos.

Membro RO [Grupo 2]: Eu diria que a falta de tempo foi um dos maiores problemas que tivemos. Conciliar a agenda de todos os envolvidos para realizar as atividades exigiu um esforço a mais dos envolvidos. 
Membro AD [Grupo 2]: Acho que ao longo desse trabalho aqui, todo o grupo, acho que sem exceção, dividiu sua agenda com várias outras atividades.

Membro VI [Grupo 2]: A gente, oficialmente, a gente tinha que dedicar quatro horas semanais, né? Que não foi possível, porque as pessoas que fizeram isso acontecer, com certeza, se dedicaram mais do que quatro horas semanais, não teria como fazer diferente.

Corroborando com a visão dos entrevistados, o pesquisador constatou que as quatro horas disponibilizadas não foram sincronizadas com a agenda de todos, exceto uma hora por semana, quando o grupo se reunia para o encontro semanal. Em anotações efetuadas em 05 de maio de 2017, o pesquisador observou que, para melhorar a comunicação interna, foi criado um grupo de conversas em um aplicativo de mensagens de celular, a fim de atenuar as limitações de tempo.

Em 20 de setembro de 2017, o pesquisador registrou a seguinte anotação em seu diário de campo: "Durante essas últimas três semanas, tivemos que postergar as entregas comprometidas entre o time para efetuar entregas consideradas mais relevantes, como confecção de materiais executivos para outros comitês de projetos paralelos".

Reforçando os relatos dos entrevistados, coletas documentais demonstraram que alguns membros deixaram de atuar em papéis de liderança e passaram a executar apenas algumas atividades por falta de tempo: "Devido a conflitos de agenda, estou deixando o papel de Team Leader [do grupo]. O [pesquisador] ocupará esta função. Continuarei participando como membro do time" [Participante FE2, Grupo 2].

A falta de disponibilidade de tempo impactou na redução da capacidade de entrega dos participantes e na qualidade de algumas dessas entregas. Em contrapartida, os membros priorizaram a execução das atividades que mais agregariam valor ao objetivo proposto.

Membro CA [Grupo 2]: Um obstáculo que a gente teve aqui foi em relação à agenda, por ser uma quantidade pequena de horas. A gente poderia ter tido entregas muito mais consistentes e um número maior de entregas se não fosse isso.

Membro FE [Grupo 2]: Eu acho que os que estavam lá se dedicaram bastante e se revezaram, se esforçaram para cumprir as tarefas. No entanto, a concorrência com outros tipos de demanda prejudicou a qualidade. 
Membro RO [Grupo 2]: Teve um alinhamento do que era valor para nosso trabalho e teve também uma questão de avaliar o que poderia ser executado, porque o time não era um time focado somente neste trabalho... A gente teve que pesar também a nossa capacidade de entrega das tarefas para definir qual era a prioridade sem perder a escala de valor que elas poderiam entregar.

Durante o Ciclo 2, foi comum o sentimento de pouca produtividade pela dificuldade de reunir as pessoas. Em 05 de maio de 2017, ao presenciar o baixo quórum diante de atividades que exigiam diversos perfis, um dos membros ressaltou: "estamos cuidando de importantes direcionamentos... precisamos da participação de todos vocês para atingirmos nosso resultado" [Participante VI2].

\section{Falta de incentivos}

A falta de incentivos ou deficiência dos participantes foi apontada pelos integrantes dos dois grupos. Enquanto no Grupo 1 apenas dois membros possuíam metas atreladas à intervenção, os demais envolvidos no primeiro ciclo não tinham um comprometimento formal para realizar as intervenções. A falta de vínculo, na visão dos entrevistados, causou prejuízo no engajamento dos colaboradores envolvidos no Ciclo 1, fazendo com que as atividades que dependiam de múltiplas áreas perdessem força.

Em contrapartida, todos os membros do Grupo 2 tinham metas associadas à intervenção, cujo percentual era $5 \%$ do total do contrato. Isso significa que $5 \%$ do bônus - valor monetário - daquele colaborador seria proveniente do que entregasse ao final da intervenção. Apesar disso, a falta de engajamento teve continuidade nos Ciclos 2 e 3, principalmente por parte de pessoas externas ao grupo, exigindo maior esforço por parte dos membros para conduzir as ações.

Membro FA [Grupo 1]: Um parêntese aqui: só tinha duas pessoas com metas associadas a isso. Se você tem um negócio que você quer fazer, mas seu chefe não está nem aí, você vai se dedicar a fazer?

Membro GI [Grupo 1]: Na empresa XYZ ficamos muito amarrados no que está escrito na meta e aí a gente fica muito preso no que está ali, no que a gente vai ser cobrado no final do ano e dificilmente alguém pega alguma coisa para fazer com afinco, que não está escrito ali e cravado na meta. É difícil hoje alguém, falar: "não está na minha meta, mas eu 
acho que é uma coisa importante, eu vou fazer". No final do ano aquilo não vai contar, então a pessoa não vai fazer.

Membro CA [Grupo 2]: Todos nós tivemos meta formal diretamente relacionadas à iniciativa, mas só $5 \%$, ou seja, é muito pouco.

Durante a execução das atividades, foram comuns justificativas de ausência dos membros, devido a outros compromissos concorrentes, conforme comentário observado pelo pesquisador, após o envio de uma das atas de reunião, em maio de 2017: "Peço desculpas pela minha ausência nas reuniões... tive duas semanas bem difíceis, mas sei que, afinal todos têm compromissos...” [Participante AM2].

\section{Instabilidade devido à troca de membros da intervenção}

Apesar de não terem sido encontradas menções diretas nos relatos dos entrevistados, o pesquisador observou certa instabilidade no dia 03 de abril de 2017, durante a transição entre os Ciclos 1 e 2, relacionada à troca de pessoas da intervenção do Grupo 1 para o Grupo 2. Durante a reunião de avaliação do Ciclo 1, houve membros do Grupo 2 que questionaram sobre algumas ações realizadas, colocando em dúvida a legitimidade e o modo como foram feitas. A partir do Ciclo 2, o grupo manteve-se estável, por isso não houve esses tipos de observações, a não ser o já relatado baixo quórum de participantes.

\subsubsection{Estrutura Organizacional}

\section{Hierarquia Rígida e Verticalizada}

As influências da estrutura rígida e verticalizada apareceram mais claramente nos momentos em que o grupo validava as ações da intervenção e engajava as áreas de negócios da empresa. Tais ações só conseguiram ser feitas com o uso da hierarquia, na visão dos membros envolvidos com a intervenção. Os entrevistados apresentaram suas percepções sobre a situação geral e a necessidade de que as decisões fossem democratizadas para os colaboradores da base da organização. 
Membro RO [Grupo 2]: O fato de termos que levar nossas ações para validação em comitê, para mim, demonstra que ainda há um longo caminho para reduzir a burocracia da organização.

Membro FE [Grupo 2]: A gente acaba perdendo oportunidades por não ter um mindset aberto. Como que eu vou trazer uma startup para experimentar, sem um projeto e que não seja top-down, que seja mais bottom-up, que os times tomem iniciativa e mostrem?

Membro SA [Grupo 1]: Hoje temos uma hierarquia rígida. Hoje está muito ao contrário do que deveria ser, o diretor visualiza, sustenta isso, compartilha e aí vai descendo...

\subsubsection{Processos Internos}

\section{Processos internos complexos}

Mesmo com a presença de especialistas das áreas envolvidas, a complexidade dos processos não permitiu que os membros da intervenção entrassem em detalhes sobre os fluxos de decisão para diagnosticar os problemas processuais. A complexidade, segundo os membros, era proveniente das sobreposições ou lacunas de papéis e atribuições e da falta de conhecimento sobre os processos. As dificuldades em realizar o mapeamento dos processos fizeram com que o grupo modificasse a abordagem, focando na criação da cartilha de processos-macro.

Membro FA [Grupo 1]: Por exemplo, uma vez tentaram me explicar o fluxo de contratação para novas tecnologias. Tem um momento em que o comitê de investimento entra no meio do caminho da contratação, tem momento que não, aí quando entrava startup, aí virava uma bagunça, porque ninguém sabia o que fazer.

Membro FA [Grupo 1]: Quando a gente tentou ir nos detalhes dos problemas, a gente se perdeu porque ninguém sabia completamente um fluxo [completo]. Por exemplo, quando fomos definir como contratamos uma startup, chegava no meio do caminho e todo mundo se perdia.

Em 27 de janeiro de 2017, o pesquisador presenciou o momento em que o Participante

GI1 constatou que ainda não havia um processo totalmente elaborado para startups: "o grande ponto é que ainda não existe um 'processo de contratação de startups'. Se existe, é desconhecido pela maioria das pessoas". 


\section{Processos longos de tomada de decisão}

Ao efetuar ações de acompanhamento de algumas startups no Ciclo 1, o grupo percebeu que as longas e indefinidas cadeias de decisão da organização desestimulavam-no a continuar nos processos. Além disso, os entrevistados envolvidos no comitê de acompanhamento dos projetos com startups relataram a demora para obter informações sobre os trâmites das iniciativas. Também relataram reclamações por parte das startups sobre conversas repetitivas com várias áreas.

Membro FA [Grupo 1]: Algumas vezes a gente não conseguia seguir adiante, batia em outras áreas da organização, (...) e ficava num limbo lá dos 'caras'... Algumas vezes, a gente conseguiu ter resposta ali, outras vezes não.

Membro SA [Grupo 1]: (...) a gente tem vários times e a gente tinha o contato com a startup em momentos diferentes, isso não estava em nenhum lugar. Nessas intervenções a gente recebeu [como feedback] das startups: "Poxa, com cada área que eu converso, eu preciso explicar o projeto desde o zero".

Membro FA [Grupo 1]: A gente não tinha nem gente para receber as startups, vinha o CEO da startup falar com o analista aqui. A gente deixava o 'cara' esperando na hora, o 'cara' lá ficava em várias reuniões, com várias áreas, o negócio não andava, não conseguia desenrolar.

Durante os acompanhamentos de projetos envolvendo startups no Ciclo 1, alguns pedidos de intermediação feitos ao pesquisador, pelo Participante GI1, demonstraram a dificuldade de se obter respostas ou informações de áreas parceiras, tais como: “[startup] está sem retorno de [área], enviei e-mail, cobrei, mas ainda estamos sem retorno. Preciso da ajuda de vocês" e "acredito que a iniciativa foi 'abandonada' [pelo negócio], acho importantíssimo termos mais detalhes; e o que for possível repassarmos para a startup como uma forma de feedback para ela entender os motivos de não estar aderente e como pode melhorar sua solução". 


\subsection{ELEMENTOS HABILITADORES DE APROXIMAÇÃO DA EMPRESA XYZ COM AS STARTUPS}

\subsubsection{Objetivos e Estratégias}

\section{Definição dos objetivos e estratégias para a intervenção}

Os entrevistados relataram a definição dos objetivos e das estratégias para a intervenção como um fator positivo, ao contrário da indefinição constatada na esfera da organização. Essas definições só foram possíveis a partir do retorno do grupo com o diretorpatrocinador.

O objetivo de melhoria do relacionamento com startups foi tê-las como provedoras de soluções para problemas de negócios. O direcionamento estratégico fornecido, por sua vez, foi realizar ações de aculturamento dos colaboradores, com auxílio de ferramental.

No entendimento dos participantes entrevistados, a definição do objetivo para a intervenção e o direcionamento estratégico trouxeram maior clareza ao time, permitindoo a atuar de forma mais assertiva, priorizando ações relevantes sob a ótica do executivo patrocinador.

Membro CA [Grupo 2]: A gente consegue quebrar a nossa estratégia em dois pilares: o pilar principal, que é o de aculturamento, iniciando um movimento de introdução do ecossistema de startups no cotidiano dos colaboradores; e o outro pilar, que é auxiliar, (...) é o questionário para avaliação das startups.

Membro AD [Grupo 2]: (...) só depois do direcionamento para ir pelo aculturamento, a gente teve foco e fomos mais assertivos.

Membro FE [Grupo 2]: (...) lembro em momentos de dúvida quanto às prioridades que o time se recordava do direcionamento. É assim que eu vejo a função mesmo de um diretor no direcionamento estratégico, ele te dá um driver e com esse driver você consegue realizar.

O pesquisador observou que, para obter apoio e direcionamento do diretor-patrocinador, houve um planejamento prévio do grupo, que se preparou para sugerir as possíveis estratégias que a empresa XYZ poderia adotar para fazer negócios com startups, dentre elas as parcerias. Uma das conversas, datada de 13 de julho de 2017, recupera parte da 
proposição de planejamento feita pelo Participante AD2, antes que fosse feita uma recomendação de objetivo: "Deveríamos fazer uma provocação quanto à estratégia e abordar todas as possibilidades de atuação com as startups".

\subsubsection{Alta Liderança}

\section{Apoio do diretor-patrocinador}

De acordo com os participantes, a atuação do diretor-patrocinador foi fundamental para que a intervenção ocorresse e tivesse continuidade. De acordo com os relatos dos entrevistados, o diretor foi decisivo para fortalecer o time, fornecendo autonomia, disponibilizando horas, estabelecendo metas e definindo objetivos e estratégias da intervenção, estes últimos já analisados anteriormente.

Membro CA [Grupo 2]: O apoio que ele [diretor-patrocinador] nos deu foi estabelecer a equipe, dar autonomia para o time fazer as atividades, dar a possibilidade das horas...

Membro RO [Grupo 2]: (...) a influência do [diretor-patrocinador] foi decisiva do ponto de vista de definição estratégica, porque foi ele que nos deu a meta estratégica do trabalho... 


\subsubsection{Cultura}

\section{Aculturamento da organização}

Na percepção dos entrevistados, as ações de aculturamento mostraram-se como um fator habilitador do relacionamento da empresa XYZ com startups, à medida que aproximava os colaboradores do conhecimento sobre o assunto. Os argumentos eram que:

- as ações de aculturamento permitiram que a organização transmitisse a mensagem que desejava que os colaboradores atuassem com startups.

Membro AD [Grupo 2]: O desafio que tínhamos com o aculturamento era disseminar, passar o sentimento de confiança de que a gente está numa organização que está aberta à inovação e eu entendo que a gente conquistou esse desafio também a partir do feedback que a gente recebeu como resultado das ações de aculturamento que foram realizadas.

- o público alvo das ações do aculturamento passou a ter consciência sobre startups/empreendedorismo e, por sua vez, passou a absorver conhecimentos básicos para lidar com startups.

Membro RO [Grupo 2]: O engajamento pareceu ser bastante bom, porque foram feitos dois eventos durante a execução do trabalho (...) até no final, eu sinto que foi criada uma agenda para o tema dentro da empresa XYZ, então, eu acho que a comunicação funcionou.

Membro FE [Grupo 2]: Colocar esses colaboradores em contato com o ecossistema de startups gerou um apetite por informação sobre o tema.

- os canais de comunicação de baixo para cima na organização, ou seja, fora do padrão hierárquico, estimularam um comportamento protagonista dos colaboradores.

Membro CA [Grupo 2]: (...) nossa cultura top-down, por si só não se sustenta mais. Esse tipo de mudança mais sistêmica tem que acontecer de forma bottom-up, as pessoas que de fato executam. A empresa XYZ precisa ter noção de que o mundo está mudando. E aí entra o processo de aculturamento. É um começo. É demorado, mas ao menos começou a acontecer aqui dentro. 


\section{Aculturamento da organização - eventos}

Na percepção dos entrevistados, os eventos de aculturamento criaram na organização um clima propício para as ações seguintes de aproximação da empresa XYZ com as startups. Os membros do grupo entenderam que o número de pessoas interessadas e presentes nos eventos legitimaram o interesse dos colaboradores pelos assuntos 'startups' e 'empreendedorismo'. Os entrevistados atribuíram o interesse pelo tema à demanda reprimida pela falta de estímulos anteriores e pelo fato de os convidados atuantes nesse ecossistema, fundadores de startups e executivos de aceleradoras, abordá-los no momento da intervenção. $\mathrm{Na}$ perspectiva dos membros, os estímulos resultantes dos eventos transmitiram a mensagem de que é possível trabalhar com startups.

Membro RO [Grupo 2]: O tamanho da demanda que a gente descobriu era gigantesca, muitas pessoas se inscreveram, muita gente veio, ficaram de pé, sentaram no chão. Tem muita gente que já começou a ouvir falar disso, também muito por conta do trabalho do nosso grupo. A aceitação é gigantesca, as pessoas têm fome de conhecimento sobre esse assunto mesmo.

Membro CA [Grupo 2]: Os eventos realizados foram as ações mais importantes para gerar esse clima, para transmitir que têm pessoas preocupadas com o tema. Teve gente de fora, fundadores de startups, pessoas do ecossistema para trazer conhecimento, isso legitima que é um assunto além da empresa XYZ, e aí atrai as pessoas da empresa XYZ, né? Sem dúvida, foram essas ações para impactar clima, com certeza foram as maiores ações.

Membro VI [Grupo 2]: Eu acho bom que está vindo de fora para dentro, por isso que é importante o contato que esses eventos propiciam, para os colaboradores verem que é possível trabalhar de outra maneira e incentivar as pessoas.

Ao contrário do primeiro evento, o segundo engajou e trouxe benefícios aos executivos, permitindo, por exemplo, que eles entrassem em contato direto com as startups presentes para discutir potenciais negócios.

Membro FE [Grupo 2]: O feedback do primeiro [evento] foi positivo e, consequentemente, chamou a atenção [para o segundo workshop]. Senti uma ligeira participação [no primeiro], e um envolvimento maior dos executivos [no segundo]...

Documentos coletados pelo pesquisador também demonstram que os eventos de aculturamento deram visibilidade ao trabalho do grupo para outras áreas. De acordo com 
os registros, três áreas procuraram os membros para desenvolverem trabalhos voltados às startups, a exemplo de uma mensagem enviada ao pesquisador, em 04 de dezembro de 2017, por um membro de uma área de inovação interna, que havia participado do evento, e que gostaria de conversar sobre projetos futuros.

\section{Aculturamento da organização - 'rede social'}

A 'rede social', na visão dos membros da intervenção, serviu como instrumento para aculturamento, utilizado como difusor de informações sobre relacionamento de grandes empresas com startups, e permitiu ao público trocar informações em fóruns e receber divulgações de eventos relacionados ao tema, como foi o caso do segundo evento de aculturamento realizado pelo grupo da intervenção.

Membro FE [Grupo 2]: Ter uma comunidade [virtual] dentro da empresa XYZ, que é uma das mais seguidas, deixa claro que existe um interesse do outro lado e que também, de certa forma, o que a gente está fazendo está gerando algum valor.

Membro CA [Grupo 2]: A ['rede social' interna] contribuiu bastante. No segundo evento, a gente tomou mais rápida a decisão de divulgar para mais fóruns (...) e foi uma avalanche [de interessados].

\subsubsection{Equipe}

Os entrevistados relataram três elementos associados ao time que possibilitaram a aproximação da empresa XYZ com startups durante a Pesquisa-Ação: o processo de aprendizagem sobre os temas durante a intervenção (workshops, artigos, benchmarks e prática), a motivação e a autonomia dos membros envolvidos.

\section{Aprendizagem na intervenção}

$\mathrm{Na}$ opinião dos entrevistados, o processo de aprendizagem do time para construção de competências, habilidades e conhecimentos foi essencial para conduzir as atividades definidas na intervenção. 
A construção desse processo ocorreu por meio de análises de artigos, visitas a entidades externas, trocas de experiências em workshops, além da própria realização das atividades.

Conforme observações feitas pelo pesquisador em 24 de maio de 2017, no Ciclo 2, diferentemente do ocorrido no Ciclo 1, o grupo da intervenção já estava organizado para adquirir mais conhecimento sobre startups ao efetuar planejamento para visitar organizações externas, além de uma curadoria de artigos e seminários para compartilhamento do conhecimento entre os membros. Apesar de parte dos membros participar esporadicamente, outra parte do mesmo, cerca de sete dos onze, teve uma participação estável durante os Ciclos 2 e 3.

\section{Aprendizagem na intervenção - Workshops}

Os workshops para entendimento da situação atual na empresa XYZ, no início das atividades da intervenção, permitiram, segundo os membros da intervenção, um panorama mais amplo sobre as lacunas da organização em relação às startups, o que foi possibilitado pelas trocas de experiências com as áreas que tinham envolvimento com startups.

Membro FA [Grupo 1]: Eu acho que o levantamento das barreiras teve uma assertividade alta, porque todo mundo que estava lá convivia com os problemas no dia a dia.

Observações feitas em 26 de dezembro de 2016 e 05 de janeiro de 2017 corroboraram com a percepção dos entrevistados, ao avaliarem um bom engajamento e interação dos participantes nos primeiros dois workshops. No entanto, no último evento, realizado em 18 de janeiro de 2017, foi possível observar uma queda de cerca de $40 \%$, porque apenas seis dos quatorze participantes estiveram presentes. 


\section{Aprendizagem na intervenção - Artigos}

De acordo com os entrevistados, os artigos trouxeram embasamento teórico sobre o relacionamento de grandes empresas com startups, servindo como fundamento para a execução das atividades de diagnóstico durante os Ciclos 2 e 3 da intervenção.

Membro CA [Grupo 2]: A leitura dos artigos foi fundamental, porque eles davam um embasamento teórico para as pessoas entenderem os problemas de solução na atuação de grandes empresas e startups.

Membro RO [Grupo 2]: O onboarding do tema, por meio dos artigos, é que deixou o time com uma maturidade mínima de partir para as entrevistas com quem está em campo, com as aceleradoras, coworkings, startups etc. Então, para mim, foi decisivo.

\section{Aprendizagem na intervenção - Benchmarks}

A imersão por meio de benchmarks trouxe um entendimento dos desafios e soluções obtidos da prática por entidades que compõem o ecossistema de startups no Brasil. As conversas com as organizações de fomento ao empreendedorismo, aceleradoras, incubadoras, coworking e startups permitiram, segundo os entrevistados, engajar o grupo e criar uma melhor capacidade de absorção de conhecimentos.

Membro VI [Grupo 2]: Porque o benchmark jogou-nos cara a cara com alguém que vive aquilo. A gente conversou com empreendedores de startups. A gente conversou com diretores de grandes empresas que se relacionavam com startups, donos de espaços que promoviam esse relacionamento entre startups e todo esse tipo de conhecimento, de gente que está vivendo isso na prática. Foi muito rico, assim, isso foi essencial.

Membro AD [Grupo 2]: A partir do momento em que a gente foi lá consultar, ver a Endeavor, ver a Oxigênio, a Google, a Google Campus, como que eles trabalham com startups, é um engajamento do time de querer conhecer esse modelo. Então, a capacidade de absorver as informações, a gente conseguiu conquistar resultados e amadurecer bastante nesse assunto. De um time que estava muito cru estrategicamente, falando de startups, para um time muito engajado e com alta capacidade de absorver conhecimento.

O processo de aprendizado através dos workshops, artigos e benchmarks, de acordo com os entrevistados, impactou positivamente, trazendo equalização de conhecimentos dentro 
do grupo sobre startups e subsídios para estratégias de atuação, tomadas de decisão e priorização das atividades. Ademais, os entrevistados entenderam que esses três elementos trouxeram uma compreensão do potencial impacto das ações de aculturamento na organização.

Membro CA [Grupo 2]: O time começou a ter um conhecimento maior de como tratar a startup, de quais que eram os riscos e oportunidades que tínhamos com essas empresas. Acho que a partir do terceiro mês, todo mundo tinha um conhecimento mais ou menos equalizado.

Membro VI [Grupo 2]: A capacitação que os membros conseguiram com os artigos e benchmarks acabaram por ajudar a dinâmica do processo de decisão das atividades e ações que deveríamos escolher.

Membro RO [Grupo 2]: Eu nunca tinha trabalhado nesse ambiente, startups lidando com empresas grandes. Esse aprendizado pelos benchmarks foi essencial e daí, sim, teve um entendimento que passou a ser maior. De como que essa conversa acontece, da relação.

\section{Aprendizagem na intervenção - Prática}

De acordo com os entrevistados, ao passo em que o grupo ia imergindo nas práticas dos ciclos de intervenção, também ia se aprimorando em relação à execução das ações. Essa melhoria dizia respeito tanto à qualidade nas decisões quanto ao engajamento com os outros departamentos. Os eventos destacaram-se também pela eficiência, sendo que a realização do segundo evento de aculturamento teve maior divulgação e, consequentemente, maior quantidade de público.

Membro VI [Grupo 2]: A partir do momento em que a gente imigrou para um viés de cultura e de mindset, quebrar a resistência era o nosso principal objetivo. Então, a gente começou a lidar com tudo isso de uma forma muito mais diferente: "Vamos chamar o 'cara' de compras no meio do evento e é isso aí, porque a gente tem que fazer essa provocação mesmo".

Membro RO [Grupo 2]: (...) no final, a gente fez um evento que foi considerado de bastante sucesso aqui, e a gente já estava bem maduro como equipe sobre o tema, mais maduro quero dizer (...) a maturidade fez com que a gente planejasse e executasse um evento que levou as pessoas a se engajarem mais. 


\section{Motivação pessoal dos membros do time}

A motivação dos membros do time para realizar as atividades foi um dos fatores determinantes para efetivar as ações. Segundo os entrevistados, o fator motivacional transpassou a falta de conhecimento inicial, as limitações financeiras e as restrições de disponibilidade de tempo para que as pessoas realizassem as entregas.

Membro RO [Grupo 2]: Eu acho que teve muito de motivação do time para executar as tarefas. Claro, tivemos planejamento, nos capacitamos, mas a motivação foi o fator primordial.

Membro VI [Grupo 2]: Eu acho que os principais fatores foi realmente a vontade das pessoas de ter tido um desafio na mão e de querer sair do outro lado com alguma coisa mesmo. Foi maior do que o conhecimento que elas nem tinham sobre o assunto, isso é que permitiu mesmo que a gente conseguisse alguns resultados. A gente conseguiu muito por conta da determinação de algumas pessoas.

Membro FE [Grupo 2]: O compromisso dos participantes ativos foi o que permitiu que as ações fossem realizadas. A motivação e a atitude do time foram essenciais, sem esses pontos a gente não teria conseguido.

O levantamento documental feito pelo pesquisador demonstra que, a partir do Ciclo 2 , os membros melhoraram a forma como cooperar, demonstrando comprometimento e formação de time, conforme e-mail recebido pelo pesquisador, datado de 20 de setembro de 2017: "Conseguiu conversar com [RO1]? Precisa de algum apoio para efetuar a avaliação das startups? Posso te ajudar?”

As motivações relacionadas à efetivação das ações eram diversificadas, passando pela idealização de mudanças na organização, curiosidade e compreensão sobre o tema, potencial de evolução na carreira e histórico de interação com startups.

Membro GI [Grupo 1]: Pouquíssimas pessoas teriam isso como experiência passada, mas muitos tinham vontade, queriam entender o melhor daquele mundo, de fazer as coisas acontecerem.

Membro CA [Grupo 2]: Eu tinha uma experiência anterior com startups, isso me motivou, mesmo não sendo a mesma coisa, mas o assunto me motivou por essa participação.

Membro RO [Grupo 2]: A maioria de nós estava motivada pelo tema e em como esse conhecimento poderia influenciar nas nossas ações 
diárias aqui na empresa XYZ e, claro, como isso poderia ajudar a nossa carreira.

\section{Autonomia}

Os entrevistados também relataram um sentimento de autonomia no grupo, o que lhes deu liberdade para que pudessem executar as atividades da forma como julgassem mais adequadas. No entanto, um dos entrevistados declarou que esse sentimento de autonomia foi aflorado somente a partir do direcionamento dado pelo diretor-patrocinador para que as ações fossem focadas no aculturamento.

Essa autonomia, compensaria os impasses iniciais quanto às restrições de tempo e à proximidade dos executivos.

Membro VI [Grupo 2]: A execução dessas ações era totalmente a cargo do time e foi totalmente confiando no time. A gente estava como um time empoderado a executar todas essas ações. Isso só foi possível porque a gente tinha um driver muito forte de que a gente devia seguir a cultura e de que a gente devia seguir esse mindset.

Membro FE [Grupo 2]: Tudo que a gente decidiu fazer, conseguimos buscar e realizar. Apesar das limitações como tempo e proximidade com os executivos, a gente correu atrás e realizou.

Membro AD [Grupo 2]: [Destaco] a nossa autonomia de conduzir o trabalho da forma como a gente entendeu que era necessário para chegar em um resultado, então, por exemplo, a liberdade que nós tivemos de buscarmos as empresas, as startups, os cases, ninguém nos pediu isso, fomos e fizemos.

\subsubsection{Processos internos}

Embora não tenha sido possível cuidar de todos os problemas estruturais da organização, como os processuais, o grupo encontrou uma forma de abrandar as barreiras de complexidade de processos e a falta de direcionamentos sobre avaliação de startups, com o lançamento da cartilha e da ferramenta de avaliação de startups, respectivamente. 


\section{Cartilha}

Os entrevistados enxergaram a cartilha como algo capaz de mitigar a falta de clareza sobre os processos internos, por ser um instrumento de comunicação, tanto para os colaboradores quanto para as startups, sobre o caminho a ser percorrido para avaliar as startups. No entanto, houve também uma visão crítica sobre o resultado da cartilha. Os membros da intervenção entenderam que a cartilha dava uma visão subjetiva dos processos e que ainda não havia sido amplamente divulgada a ponto de impactar a todos.

Membro SA [Grupo 1]: Quando a gente viu que estava complicado mapear os processos no detalhe, aí o que a gente fez? A cartilha (...). Então, vamos lá, foi o melhor que a gente conseguiu fazer em termos de ajudar os processos. Estava macro[em alto nível]? Sim, mas foi um passo inicial.

\section{Ferramenta de critérios de avaliação para soluções de startups}

Os critérios de avaliação das startups, segundo os entrevistados, permitiram que a organização tangibilizasse as decisões de utilizar soluções dessas empresas emergentes, o que até então não era possível, por não se ter clareza de quais ações precisariam ser adotadas e nem de quem seriam os papéis e as responsabilidades abrangidos. Antes da ferramenta de avaliação, os times envolvidos não tinham insumos para a tomada de decisão sobre as soluções das startups. A proposta do time não era criar processos, mas estabelecer diretrizes para apoiar as decisões.

Embora houvesse um reconhecimento sobre o ativo deixado, também havia críticas sobre o aculturamento dos colaboradores para poder utilizar a ferramenta.

Membro VI [Grupo 2]: A gente propôs a ideia de critérios, como um grande guideline que explica para ele [colaborador] o que ele deve olhar, principalmente para as primeiras vezes em que for avaliar uma startup. Não queremos que seja um processo engessado, mas que sirva como guideline para ele [colaborador] ir aprendendo para depois seguir os critérios intuitivamente.

Membro CA [Grupo 2]: a gente entregou ferramentas muito poderosas para a empresa XYZ, que podem esclarecer, inclusive, quando a gente pode ou não usar uma startup. 
Alguns entrevistados acreditaram que os critérios de avaliação permitiriam que os colaboradores da organização pudessem tomar melhores decisões com relação às startups, mas enxergaram o uso massivo da ferramenta como um desafio cultural.

Membro VI [Grupo 2]: Então, acho que a gente se preocupou muito em dar ferramentas, para que eles [colaboradores] possam tomar as decisões, mas aqui a gente ainda tem um caminho para essas pessoas criarem uma cultura de uso. O caminho de autonomia. Eu acho que isso 'casa' com o desafio cultural que a empresa inteira terá.

A ferramenta de 'critérios de avaliação' foi desenvolvida também para serem preenchidas pelas startups. Foi a partir das primeiras validações com esses negócios que a ferramenta pôde ser aprimorada, conforme o pesquisador observou em registro de 21 de setembro de 2017: “depois que testamos com a [startup], notamos que precisávamos criar um kit para que elas pudessem responder sem que a gente ficasse explicando os critérios. Assim, criamos uma planilha e começamos a desenvolver as perguntas e esclarecimentos necessários, partindo do pilar estratégia e empresa".

\subsection{SUGESTÕES DE AÇÕES E MELHORIAS PARA OS PRÓXIMOS CICLOS}

\subsubsection{Objetivos e Estratégias}

\section{Ações de aproximação com áreas de negócios e executivos}

Nos relatos dos entrevistados, foram identificadas sugestões para aproximar a intervenção de outras áreas de negócios, uma vez que os impactos se concentraram em TI, com interações das áreas de apoio, como Compras e Segurança da Informação.

A incorporação de outras verticais de negócios ajudaria, na perspectiva dos entrevistados, e justificaria o prolongamento da equipe, além de gerar maior impacto, pois essas ações mais complexas dependeriam de outras áreas. Alguns entrevistados entenderam que essa 
proposição envolveria alinhamentos com outros executivos, mas que o ganho de experiência já obtido pelo time permitiria construir essa rede de colaboração entre eles.

Membro RO [Grupo 2]: Precisamos agora extrapolar o mundo de TI, porque quando a gente está falando sobre startups, como eu disse, é uma abordagem que precisa do negócio, só assim habilitaremos uma estratégia no nível da empresa XYZ. Se a gente restringir as ações ou as propostas de ações só para a área de TI da empresa, não teremos fôlego.

Membro FE [Grupo 2]: Faltava um pouquinho de 'liga', de juntar a estratégia (...) com outras áreas. Porque os executivos dessas áreas não são cobrados daquilo, não tem agenda comum.

Membro RO [Grupo 2]: Na próxima interação podemos utilizar os primeiros momentos, agora que todos nós [participantes da intervenção] temos um conhecimento prévio do tema, estamos mais maduros para propor objetivos e estratégias aos executivos sobre colaboração com startups, baseados no que ouvimos...

\subsubsection{Alta liderança}

\section{Apresentar casos internos (piloto, experimentos, casos)}

Por acreditarem que o distanciamento de casos reais de startups não permitiu que os executivos enxergassem valor em atuar com elas, alguns entrevistados sugeriram criar e apresentar casos internos com proposta de valores tangíveis. Essa proposição teria ajudado, na opinião de alguns entrevistados, a fomentar uma predisposição e comprometimento dos executivos.

Membro RO [Grupo 2]: Creio que mudar o mindset dos executivos é uma das chaves para a empresa XYZ mudar de patamar. Para alcançar esse alinhamento estratégico, falta mostrar esse valor para a instituição, com um piloto, um case. Tentar mudar o mindset, com real valor das oportunidades. Então, acho que falta isso.

\section{Compartilhamento de metas com executivos parceiros}

Alguns entrevistados entenderam que o engajamento dos líderes da empresa XYZ teria refletido na adesão de seus colaboradores durante a intervenção. $\mathrm{Na}$ opinião desses 
entrevistados, o comprometimento dos líderes poderia ter minimizado empecilhos comuns dentro da organização, como falta de recursos, conflitos de estratégia e concorrência com outros projetos.

Alguns entrevistados também destacaram que compartilhar as metas com os executivos parceiros em iniciativas futuras e aumentar a representatividade do bônus teria ajudado a manter os colaboradores engajados e próximos das atividades da intervenção.

Membro FA [Grupo 1]: Eu acho que é vir desde cima o apetite para a gente realmente mudar e fazer as coisas diferentes, a gente tem que ter ali uma predisposição de mudança de cultura.

Membro RO [Grupo 2]: Dentro do que se espera do 'cara' durante o ano, nas metas a participação no grupo tem que representar algo mais significativo, inclusive por parte dos executivos, porque aí comprometeria muito mais pessoas. Infelizmente nossa cultura é assim (...). Eu acho que eles têm que estar olhando mais de perto isso daí, que é interessante. É um tema que todos os executivos deveriam estar mais próximos, dar maior atenção.

Membro FE [Grupo 2]: (...) temos que engajar as pessoas a fazer, mas eu não consigo mudar isso, né? [risos]. A gente precisa dos executivos para dar essa 'puxada'. A gente precisa deles também para os incentivos, as metas, para dar fôlego e não ficar apenas no 'gogó'.

\subsubsection{Cultura}

\section{Iniciativas de imersão cultural}

A partir das entrevistas, é possível identificar proposições para que os colaboradores efetuem imersões culturais, a ponto de entenderem a realidade e desafios de uma startup e do ecossistema de empreendedorismo. Algumas proposições sugerem que os colaboradores ajudem com suas próprias experiências dentro das startups, semelhantemente a job rotation. Outras sugestões indicam que os colaboradores devam estruturar internamente seus modos de trabalhar semelhantemente aos de startups, grupos pequenos, com autonomia e escassez de recursos.

Membro RO [Grupo 2]: Uma forma de aculturar a meu ver é dar aos colaboradores a oportunidade de tomar contato com o modus operandi de uma startup. A empresa XYZ tem alguns programas internos de troca cultural, por exemplo, de job rotation em filiais estrangeiras. Acho 
que a empresa XYZ deveria fazer algo semelhante com colaboradores interessados em atuar com startups e isso seria ótimo para as próprias startups, porque estas têm escassez de recursos, e esse colaborador já ia se aculturando e seria um multiplicador. Poderia ser feito algum programa nesse sentido...

Membro AD [Grupo 2]: Deveríamos selecionar alguns projetos ou algumas iniciativas como se fossem startups dentro da empresa XYZ, para exercitar o modo como as startups pensam/agem. Estabelecer times pequenos, que é como a startup trabalha, com autonomia e com restrições financeiras, por exemplo.

\section{Continuidade das ações de aculturamento (eventos e 'rede social')}

O grupo compreendeu que as ações de aculturamento têm parcela fundamental na aproximação da organização com startups, a ponto de deixar assuntos como mudanças processuais em segundo plano nas próximas priorizações de ações.

A continuidade das ações traduziu-se na criação de conteúdo e de novos eventos de aculturamento, aproveitando os canais já criados e o público já engajado. Na percepção dos entrevistados, deixar de aproveitar os ativos construídos na organização pode causar um declínio de engajamento ou impedir que ações com ênfase em outros aspectos possam ser criadas.

Acompanhando as proposições de continuidade das ações de aculturamento está a falta de pessoas comprometidas para realizar tais atividades, demonstrando carência de pessoas para isso.

Membro AD [Grupo 2]: (...) tendo uma próxima interação, eu ainda continuaria nesse tema de cultura [interna]. Eu acho que ainda tem bastante espaço antes de começar a atacar processo ou o que quer que seja. Continuaria ainda nesse tema. A gente tinha ainda outras histórias nesse tema que não entraram ainda nesse release e eu acho que a gente ainda tem bastante espaço.

Membro VI [Grupo 2]: (...) que a parte da empresa, nesse caso, é incentivar a cultura empreendedora, então, se ela também não começar a incentivar e a aproveitar a energia com quem se sentiu atraído pela cultura, ela vai perder uma janela de oportunidade.

Membro RO [Grupo 2]: Sem mexer na questão cultural, você não consegue mexer em nada quando trata de startups, né? Eu acho que a questão cultural deve ser a atenção e esse tema deve ser mantido. 
Os entrevistados entenderam que há margem para engajar mais pessoas, principalmente pelo fato de as ações de aculturamento terem sido direcionadas para a área de tecnologia da organização. $\mathrm{O}$ maior engajamento não necessariamente ficaria a cargo exclusivamente do grupo da intervenção. No entanto, os colaboradores já engajados teriam potencial para se tornarem multiplicadores do tema na organização.

Membro FE [membro grupo 2]: Acordaram algumas pessoas... eu acho que é possível aumentar isso aí, acordar mais gente ainda. A minha percepção é positiva, mas acho que tem margem para um alcance maior, focamos mais em tecnologia.

Membro VI [Grupo 2]: Temos os 5 mil inscritos [na 'rede social'], e se esses 'caras' virarem multiplicadores a gente rapidamente atinge a maioria das áreas da empresa XYZ.

\section{Continuidade da 'rede social' interna}

Os membros da intervenção viam a 'rede social' interna como um importante ativo da intervenção, pois difundia as informações sobre relacionamento de grandes empresas e startups. No entanto, os entrevistados estavam preocupados com a perda de relevância da 'rede', por eventual falta de atualização. E isso tende realmente a acontecer pelo fato de não haver pessoas disponíveis no grupo para criação de conteúdo.

Como proposição para as próximas interações, o grupo recomendou a continuidade de publicações na rede, para que esta se mantenha ativa e com conteúdo relevante para manter o público engajado.

Membro CA [Grupo 2]: Apesar de ter uma comunidade, eu percebo que a gente é pouco ativo, e aí tem uma questão com relação ao tempo... Mas precisamos continuar alimentando, continuar capturando conhecimento sobre as startups que estão surgindo no mercado e as oportunidades que estão acontecendo dentro da empresa XYZ. É fundamental para a gente ter conteúdo e engajar as pessoas.

Membro VI [Grupo 2]: Na comunidade, gente, hoje tem 5 mil inscritos, o que é super legal ou irrelevante, se a gente não postar nada para esses 5 mil inscritos, se não mandarmos novos feeds. 


\section{Continuidade e diversidade dos eventos de aculturamento}

Os entrevistados propuseram a continuidade dos eventos como instrumentos de aculturamento, porém sugeriram modificações para que os formatos rígidos e pontuais não venham a causar prejuízos de relevância nos próximos ciclos.

As sugestões de melhorias em relação a essa atividade foi que os próximos eventos sejam organizados com novos formatos e mais frequentes. Esses novos formatos podem gerar maior interesse e a diversificação nas formas de comunicação pode atrair mais pessoas impactadas; ao passo que, o aumento de frequência agilizará a propagação de cultura empreendedora na instituição.

Membro RO [Grupo 2]: Se a gente não conseguir estabelecer frequência, continuidade e aumento cada vez maior da atratividade do evento, ele vai acabar sendo descontinuado. Sem isso, a gente não consegue fazer essa evolução.

A partir dos relatos, foi possível delinear, ainda, dois conjuntos de proposições. O primeiro, focalizado na criação de eventos de desafio para startups, como hackathons, o que promoveria competição de startups para resolver desafios direcionados à empresa XYZ. Essa proposição, de acordo com os entrevistados, traria mais pragmatismo ao objetivo de melhorar o relacionamento com startups, considerando que os problemas reais seriam apresentados e consistiriam em algo menos expositivo do que os eventos atuais.

Membro RO [Grupo 2]: Em relação às startups podemos ajudar a formular um evento de caráter de competição por mercado, como um hackathon, por exemplo.

Membro AD [Grupo 2]: Faria um hackathon. A gente poderia tentar realmente hackear [sic] o processo que a gente tem (...) Eu criaria um hackathon para a gente colocar em questionamento algumas coisas que a gente tem e como que as startups conseguem ajudar nisso. $\mathrm{O}$ hackathon, para mim, é uma forma de aculturamento.

O segundo conjunto proporia a criação de eventos com temas orientados para as linhas de negócios, para os quais seriam convidadas as startups que tivessem afinidade com os assuntos das áreas da empresa XYZ para interagir com seus colaboradores. A abordagem 
permitiria extrapolar a área de Tecnologia e engajar de forma direta outras linhas de negócios e departamentos da organização.

Membro RO [Grupo 2]: Talvez a gente não devesse focar somente em ações de comunicação baseadas em eventos, pelo próprio caráter descentralizado da estratégia da empresa XYZ em relação às startups... Podemos fazer algumas ações de comunicação descentralizadas, focadas em áreas de negócios, por exemplo, levar startups que possam falar sobre um tema bem específico, por exemplo, seguros, cartões e até mesmo atuar em áreas departamentais, como backoffice, jurídico etc.

\subsubsection{Equipe}

\section{Time dedicado em tempo integral}

Dentre as melhorias recomendadas para as próximas interações, foram recorrentes nos relatos dos entrevistados as menções para que fosse estabelecido um time dedicado em tempo integral, com 18 (dezoito) codificações associadas. Uma das razões para se ter pessoas dedicadas, na visão dos entrevistados, seria a necessidade de resolver problemas processuais e políticos, na medida em que estes fossem surgindo e, para resolvê-los de forma mais eficiente, despenderia tempo de uma equipe multidisciplinar.

Membro GI [Grupo 1]: Eu ainda acho que uma das principais [melhorias], e vários concordavam ali, era a gente ter criado um time para ficar 'tocando' essas ações como full job, o que pra mim era a coisa mais assertiva a se fazer.

Membro FE [Grupo 2]: Para a gente pensar aqui em futuro deste trabalho de modificações ou criações, primeiro é preciso partir do grupo de trabalho, é realmente tornar esse time alocado e estável, com uma participação mais ampla nesse assunto e uma prioridade maior.

Membro GI [Grupo 1]: (...) Então, a gente tinha que deixar as pessoas ali dedicadas a isso, porque pode parecer que se você deixar a pessoa alocada ela não vai ter nada para fazer. Só que cada termo que a gente tem que mudar, cada partezinha do processo era uma coisa muito grande que a gente tinha que envolver várias outras pessoas dentro da empresa XYZ. Então, a gente tinha que ter pessoas alocadas e responsáveis por algumas partes do processo para a gente realmente conseguir efetivar alguma mudança. 


\section{Maior tempo alocado}

Uma recomendação alternativa ao time alocado no processo, na visão dos entrevistados, foi disponibilizar mais tempo para que o time responsável priorize as atividades da intervenção nas suas agendas.

Membro CA [Grupo 2]: Acho que não precisa ser full time comprometido, mas com uma dedicação maior do que quatro horas por semana... Daí sim, creio que geraremos resultados mais tangíveis.

Membro VI [Grupo 2]: Se a gente tiver pessoas mais alocadas, com mais tempo, naturalmente as pessoas se prepararão mais e naturalmente as ações serão mais simples de serem executadas, porque o time inteiro é muito capaz. A gente que não estava priorizando isso.

\section{Time reduzido}

Uma das lições aprendidas pelos entrevistados foi que um grupo muito numeroso para realizar as tarefas acabava levando a menor produtividade na intervenção, principalmente pelo fato de que algumas pessoas designadas para a intervenção não atuavam especificamente naquelas atividades, ou atuavam de forma pontual, dando a falsa impressão que todos no grupo eram produtivos.

Alguns entrevistados sugeriram, então, o estabelecimento de um time menor, porém com mais horas exclusivas. Na opinião deles, essa nova formatação daria foco e aumentaria a produtividade na execução das ações.

Membro VI [Grupo 2]: Eu penso que seria mais efetivo um grupo menor de pessoas com um percentual de dedicação maior, porque a gente tinha muitas pessoas que juravam que iam ajudar e não ajudavam ou realmente nunca apareceram. $\mathrm{E}$ as horas dessas pessoas contavam na produtividade do grupo. Então, ao invés de ter horas de uma pessoa que nunca ia, talvez a gente devesse ter doze horas das pessoas que já estavam comprometidas. Então, eu acho que seria mais efetivo menos pessoas, mas mais dedicadas.

Membro GI [Grupo 1]: A gente mobilizou um monte de gente, mas, por outro lado, a gente não precisaria ter mobilizado tanta gente. Era melhor a gente ter focado em pessoas específicas de cada área responsável, uma 
equipe menor. Se deixássemos elas mais dedicadas, faríamos discussões com melhores resultados.

\section{'Líder'}

Outra proposição de melhoria sugerida por alguns entrevistados foi a definição de um 'líder' com conhecimento da organização, que ficasse responsável por ajudar na resolução de problemas envolvendo o relacionamento com startups. Dentre as atividades sugeridas a essa pessoa estariam o engajamento de outros departamentos com as startups e a redução de problemas burocráticos, especialmente, por onde tramitam as iniciativas envolvendo startups. Essas recomendações, assim como outras, estão presentes em referências estudadas pelo grupo, como Bannerjee, Bielli e Haley (2016) e Minshall, Mortara, Napp e Probert (2010), que afirmam que tal atribuição pode promover iniciativas de Corporate Venturing ou Corporate-Startup Engagement.

Membro FE [Grupo 2]: Deveríamos ter um facilitador aqui dentro da organização, para que qualquer problema envolvendo iniciativas com startups, essa pessoa pudesse saber o 'caminho das pedras', saber resolver a parte política e envolver as pessoas dos demais departamento. Então, acho que uma figura de um representante interno aqui das startups seria interessante, uma interface das startups com o mundo aqui dentro.

Conforme observações do pesquisador, durante a intervenção não haviam lideranças fixas dentro do grupo. Apesar do papel de 'líder de time', ele auxiliava na organização das tarefas do time, sem o compromisso de gestão exclusiva, hajam vista as decisões terem sido sempre definidas em colegiado.

\section{Aumento da representatividade das metas (bônus)}

O grupo associou a priorização das atividades de colaboração com startups à proporcionalidade de incentivos que os membros do time poderiam receber, o que também representaria um sinal de que a empresa $\mathrm{XYZ}$ dá relevância à utilização de solução de startups como uma das formas de resolver problemas de negócios. De acordo 
com essa perspectiva, foi sugerido pelos integrantes do time que houvesse aumento da representatividade das metas acima dos 5\% para os participantes da intervenção.

Membro AD [Grupo 2]: Para a gente pensar aqui em futuro desta iniciativa, partindo do grupo de trabalho (...) seria necessário um incentivo, adequado à priorização das atividades. Quando a gente fala da empresa XYZ, a agenda não pode ficar $100 \%$ flexibilizada à startup, mas a gente consegue tirar muitos frutos bons desse relacionamento se a empresa reconhecer que isso é relevante, parte disso deve vir de incentivos, metas e dedicação de tempo.

Membro AD [Grupo 2]: O compromisso dos participantes ativos foi o que permitiu que as ações fossem realizadas e o que isso poderia ser feito de diferente é associar metas maiores a todos os envolvidos para que o compromisso seja maior, entendeu?

\subsubsection{Estrutura Organizacional}

Apesar de terem sido identificadas barreiras associadas à estrutura organizacional, como rigidez hierárquica e verticalização, não foram localizadas proposições de melhorias diretamente associadas a esse aspecto, por parte dos entrevistados.

\subsubsection{Processos Internos}

\section{Aplicação de melhoria contínua nos processos}

Apesar da impossibilidade de mapear os procedimentos no início da intervenção, alguns entrevistados acreditavam que seria preciso retomar ações voltadas aos processos, como a aplicação de melhorias contínuas, utilizando metodologias como kaizen, em que os processos poderiam aos poucos ser simplificados. $\mathrm{Na}$ visão de alguns membros, a simplificação dos processos poderia ter trazido mais comprometimento dos executivos, uma vez que iniciativas envolvendo startups seriam implementadas de forma mais ágil.

Membro VI [Grupo 2]: Nas próximas ações, eu vejo que devemos estar focados nos processos e em meios de tornar possível tudo que for possível. Parte do público alvo se sentiu encorajado em viabilizar soluções envolvendo startups, agora eles precisam de meios para fazer isso, então eu acho que alguma energia em processo deveria ser investida. 
Membro FA [Grupo 1]: Acho que precisamos ainda voltar a insistir no mapeamento dos processos atuais, mas com uma abordagem de kaizen, melhorando aos poucos, mudando um prazo de entrega de documento, ou eliminando menos um documento. (...) Eu acho que os processos, uma vez que estejam bem estruturados são positivos, por exemplo, eu não posso deixar de envolver a área de compras, (...) isso precisa acontecer no momento correto. Agora, é processo servindo pessoas, e não o inverso, né? Então, tudo aquilo que, de fato, gera um desperdício, a gente precisa eliminar.

\section{Processo de fast-track}

Uma das sugestões para abrandar as limitações estruturais na empresa XYZ foi a criação de um processo segregado que partiria da avaliação à incorporação de startups, o que alguns membros do grupo denominaram fast-track. Esse processo apartado contaria com a participação de pessoas de todas as áreas envolvidas na decisão e a implementação das startups.

Membro FE [Grupo 2]: Quando a gente fala de processo, ele foi construído olhando o todo, e quando a gente fala de startup, ela tem algumas particularidades que precisam ser customizadas, ou seja, é preciso ter uma linha específica para trabalhar com as startups.

Membro CA [Grupo 2]: Eu tiraria elas [startups] do processo normal e tentaria rodar um fast track com todos os envolvidos na decisão de avaliação e implantação, no mesmo local físico ajudando a viabilizar.

Membro GI [Grupo 1]: Para mim era muito importante ter um processo apartado que tivesse um time total multidisciplinar, porque a gente precisa ter todas as contas, todas as partes do processo como um todo, olhando para aquilo, para todo mundo enxergar que, 'putz', eu não sou só o jurídico que ajuda a fazer o contrato. Na verdade, tem um monte de coisas que acontecem antes e um monte de coisas que acontecem depois.

\section{Experimentação/Piloto}

Alguns entrevistados também refletiram sobre o estabelecimento de experimentações ou projetos pilotos com as startups, como o passo seguinte após o estabelecimento da ferramenta de 'critérios de avaliação para soluções de startups'. As experimentações, na 
percepção dos entrevistados, seriam formas de flexibilizar as condições de contratação e a efetivação de soluções envolvendo startups.

Membro AD [Grupo 2]: A gente ainda não tem uma cultura de experimentação que eu entendo que é necessária para a gente pular para o próximo patamar aqui quando a gente fala de startups... A gente ainda tem essa oportunidade de evolução também.

Membro RO [Grupo 2]: É, realmente eu tenho uma esteira mais flexível, um contratual mais simplificado quando a gente fala de experimentação com startup... Chegar mais rápido nessa etapa.

O piloto ou experimentação poderia ter início após a avaliação da solução e do problema de negócios. A partir de então, seriam analisadas as condições que este oferece.

Membro RO [Grupo 2]: Devemos dar um passo a mais, além dos critérios de avaliação, conseguir também fazer propostas de utilização da startup, preparar condições prévias para orientá-las e promover uma forma de piloto para utilização.

Para outros entrevistados, a experimentação deve estar associada à permissão para que os colaboradores tenham a liberdade de tangibilizar propostas de valor para os negócios em um ambiente controlado.

Membro AD [Grupo 2]: A próxima ação deve tratar dessa questão de experimentação. Quando a gente fala de experimentação a gente traduz em colocar em prática a resolução de um problema por uma startup dentro de um ambiente controlado, mas com liberdade para executar do jeito que precisarmos. Isso dá oportunidade de cenários mais efetivos e em mostrar valor para a empresa XYZ.

Membro FE [Grupo 2]: Se ele [colaborador] puder explorar, se ele puder testar, se ele quiser fazer uso de soluções 'fora da caixa' aqui, tem que ter isso facilitado, hoje o 'cara' vai pra casa e testa lá.

A priorização do que poderia ser experimentado estaria ligada a alguns critérios, como criticidade ou escopo do problema. Além de apresentar valor agregado à organização, alguns membros enxergaram no experimento uma forma de aculturar e de preparar os colaboradores a interagirem com startups.

Membro FE [Grupo 2]: A gente deveria aumentar a permissividade para todos os envolvidos. Por exemplo, experimentar novas soluções, dado um escopo, a criticidade de um projeto, permitir usar como soluções alternativas. A utilização de ferramentas 'fora da prateleira' que a gente tem, já aumentaria esse interesse da organização e deixaria as pessoas mais preparadas. 
Boa parte das proposições feitas pelos entrevistados está também presente nos benchmarks realizados, além de relatórios e artigos estudados pelo grupo, tais como: Mortara, Napp, Slacik e Minshall (2009), KPMG (2015), Mocker, Bielli e Haley (2015) e Bannerjee, Bielli e Haley (2016). Dentre essas intersecções estão a necessidade de Champion, de time dedicado em tempo integral, do uso de fast-track, da realização de programas de imersão cultural, do uso de experimentação/piloto, do uso de metas e incentivos e dos eventos de aculturamento, além do uso de sistemas de informação para propagar comunicação. 


\section{DISCUSSÃO DOS RESULTADOS}

Conforme apresentado no subitem 3.9, as discussões sobre os resultados seguem a estrutura dos aspectos internos: 'Objetivos e Estratégia', Alta Liderança, Cultura, Equipe, Estrutura Organizacional e Processos Internos. A partir do objetivo principal estabelecido para a presente pesquisa - 'aproximar a empresa XYZ das startups' -, segue-se, neste capítulo, uma linha de raciocínio que busca discutir a relevância de cada um dos temas identificados, considerando-se as barreiras mais relevantes ou o conjunto delas, as ações realizadas e as sugestões de melhorias para ações futuras.

Pretende-se, a partir das sugestões dos participantes quanto às melhorias e às ações, acrescentar uma perspectiva crítica complementar aos subsídios teóricos e práticos utilizados nesta dissertação.

\subsection{OBJETIVOS E ESTRATÉGIAS}

Objetivos e estratégias em ações de colaboração com startups direcionam as equipes envolvidas para mobilizarem esforços e investimentos de forma correta, além de levarem ao comprometimento dos envolvidos com as execuções das ações e de mantê-los a par dos resultados.

No contexto da empresa XYZ, as indefinições quanto aos objetivos e à estratégia em relação às startups dissiparam forças e limitaram a produtividade das ações. No entanto, ao definir objetivos e estratégias para intervenção, o time pôde ser assertivo e focar seus esforços no aspecto de aculturamento.

Os entrevistados também viram benefícios em discutir o escopo e a estratégia junto com outras áreas de negócios, o que poderia aumentar o impacto das ações. 


\subsubsection{Barreiras: indefinição do escopo e da estratégia quanto a startups para organização e intervenção}

De acordo com os entrevistados, a empresa XYZ reflete uma posição de indefinição e de observação quanto aos objetivos e às estratégias envolvendo startups internamente, apesar de a empresa ter iniciativas públicas relacionadas com o tema, como o coworking.

Há casos de organizações que optam por não definirem uma estratégia como uma forma de aprenderem a atuar com startups, chamada 'estratégia emergente' (Thieme, 2017). No entanto, não há evidências indicando que a empresa XYZ teve essa intencionalidade, enfraquecendo, assim, essa alternativa.

Por outro lado, a indefinição ou inconsistência quanto à estratégia para atuar com startups na empresa XYZ encontra base nos elementos culturais gerados pelos bons retornos financeiros da mesma em um setor pouco fragmentado, conforme evidenciado pelos entrevistados e discutido neste capítulo sob o ponto de vista dos aspectos culturais. Essas causas são corroboradas por Rehder e Levi (2011), ao afirmarem que a indefinição ou inconsistência de estratégia para inovações é comum em instituições financeiras, pois buscam por resultados a menores riscos. Das et al. (2017) complementam que a estabilidade e a baixa concorrência do setor financeiro geram inércia quanto a mudanças voltadas à inovação.

Tais fatos corroboram, portanto, para cautela da organização, conscientemente ou não, sobre as mudanças que se aproximam da mesma, o que reforça, inclusive, a estratégia de realizar ações voltadas ao aculturamento, definidas pelo diretor-patrocinador.

Planejar ações ainda sem objetivos e estratégias claros foi considerado prejudicial pelos entrevistados, pois as discussões abertas consumiram parte do tempo disponível, reduzindo a quantidade de ações a serem executadas. Essas circunstâncias e impactos vão ao encontro da constatação de Prats, Amigó, Ametller e Batlle (2017), ao afirmarem que a falta de estratégia para atuar com startups abre caminho para a ineficiência, desperdiçando tempo, recursos humanos e também os financeiros. 
O prolongamento para definir o objetivo e a estratégia no âmbito da intervenção também gerou divergências e desgastes inclusive para outras áreas parceiras. A principal razão para isso é que os diversos interlocutores não possuem uma orientação comum da organização. WEF (2018), Thieme (2017) e Bannerjee, Bielli e Haley (2016) ressaltam que grandes organizações necessitam de uma estratégia sobre startups, caso contrário, áreas internas tenderiam a entrar em conflito quando as iniciativas emergissem.

\subsubsection{Elementos habilitadores - definição do objetivo e da estratégia da intervenção}

De acordo com os relatos dos entrevistados, as definições de objetivos e de estratégias foram reconhecidas como habilitadores da intervenção, pois trouxeram eficiência e eficácia nos ciclos, reduzindo o desperdício de tempo, a subjetividade nas decisões e as discussões improdutivas. Prats, Siota, Canonici e Contijoch (2017) recomendam que seja definida a intenção estratégica com startups para tornar as iniciativas mais eficientes e eficazes, pois, quando se iniciam interações sem objetivos e estratégias claros, há desperdício de tempo e retrabalho, como o ocorrido na intervenção, antes dessas definições. Além disso, as estratégias de iniciativas pontuais podem contribuir, no futuro, para a definição das estratégias corporativas de inovação com startups (Thieme, 2017).

Quando avaliada a abordagem dos direcionamentos fornecidos, vê-se que a definição do objetivo - melhorar o relacionamento com as startups, sendo elas provedoras de solução - é adequada à baixa presença de cultura empreendedora e de conhecimentos evidenciados sobre startups. Aproximar-se de startups, adotando-as como provedoras ou fornecedoras de solução, é uma estratégia considerada por Minshall, Mortara, Napp e Probert (2010), Mortara e Minshall (2011), Pekar e Magulis (2003) e Reuer, Olk e Arino (2011) como a de menor maturidade no relacionamento com startups, exigindo menor nível de comprometimento e de integração por parte da grande empresa. A abordagem pode ser considerada conservadora, porém, segundo Bannerjee, Bielli e Hale (2016), é adequada para resolver problemas internos da organização. Ademais, a estratégia de atuar com atividades de aculturamento também pode melhorar futuras definições de objetivos e estratégias, pois abrandaria a resistência cultural da organização, identificada pelos entrevistados. 


\subsubsection{Proposição de melhorias e novas ações}

As proposições dos entrevistados sobre os objetivos e as estratégias em relação às startups giraram em torno da aproximação do grupo em juntar as áreas de negócios e executivos da empresa para criarem ações comuns de colaboração. Pode-se também encontrar na prática e na teoria outras proposições que fortificariam os objetivos e as estratégias. Dentre elas, sugere-se o estabelecimento de governança para iniciativas envolvendo startups e o uso de experimentos como pré-requisito para apoiar os direcionamentos.

No entanto, independentemente das ações tomadas quanto à definição dos objetivos e das estratégias para atuar com startups, em todas há uma forte dependência de apoio da alta liderança e dos executivos para realizá-las (Martins \& Terblanche, 2003; Prats, Siota, Canonici, \& Contijoch, 2017; Bannerjee, Bielli, \& Hale, 2016).

\section{Ações de aproximação com áreas de negócios e executivos}

Essa proposição também é teórica e prática. Minshall, Mortara, Napp e Probert (2010) e WEF (2018) recomendam que as empresas trabalhem para ter uma abordagem corporativa sobre startups e para alinharem as prioridades e interesses, evitando conflitos e falta de comprometimento. Essa medida também caminha para a proposição de Kohler (2016), que afirma que a participação dos representantes das áreas de negócios é um 'fator altamente crítico' na estruturação de iniciativas de inovação voltados às startups.

Por serem múltiplas áreas, o desafio é deixar claros os objetivos e as estratégias para todos os envolvidos. Como forma de garantir o comprometimento, os entrevistados sugeriram que houvesse metas compartilhadas. Essa proposição, segundo Schättgen e Mur (2016) e Dombrowski et al. (2007), permitiria um maior envolvimento de colaboradores em iniciativas inovadoras. Essas medidas são importantes, pois ações que exigem o envolvimento de várias áreas também refletem em discussões, conflitos de interesses e transferências de responsabilidade (Minshall, Mortara, Napp, \& Probert, 2010; Mortara \& Minshall, 2011). 


\section{Governança para a intervenção em conjunto com áreas e executivos}

Mortara e Minshall (2011) afirmam que a estratégia para atuar com inovações externas, como as startups, deve ser constantemente alinhada e adaptada com os diferentes grupos da organização, em especial, o alinhamento com a alta liderança para garantir recursos, suporte e comprometimento. Para endereçar este ponto, Bannerjee, Bielli e Hale (2016) e De la Tour et al. (2017) sugerem o estabelecimento de uma governança próxima à alta liderança e aos executivos. A governança seria estabelecida em reuniões periódicas e permitiria a colaboração dos executivos na definição dos objetivos e das estratégias, além da ajuda em eventuais dificuldades durante as intervenções.

O estabelecimento da governança pode ser visto como uma medida em conformidade com a proposição de aproximação das áreas de negócios com os seus executivos, pois estabelece uma rotina de comunicação entre as pessoas que têm poder de decisão e as que têm interesses sobre o tema. Além disso, a criação de governanças para iniciativas complexas faz parte da cultura da empresa XYZ, encontrada também nos relatos, o que facilitaria a sua adoção.

\section{Uso da experimentação como forma de engajamento com startups}

Decidir intencionalmente adotar uma estratégia aberta pode fazer sentido para empresas que busquem reduzir riscos e aprender a atuar com startups (Bannerjee, Bielli, \& Hale, 2016; Thieme, 2017). Essa abordagem ganha força a partir de novos modelos de trabalho como o "ágil" e o "lean startup" (Thieme, 2017; Schättgen \& Mur, 2016). Esses aprendizados poderiam ser feitos por experimentos, o que permitiria testar formas de atuação com startups antes de estratégias definitivas (Bannerjee, Bielli, \& Hale, 2016; Thieme, 2017; Mocker, Bielli, \& Haley, 2015).

Na empresa XYZ, a adoção dos experimentos pode facilitar a definição de estratégias pelos executivos, pois reduz a exposição ao risco, ficando mais aderente à cultura organizacional. Essa abordagem pode ter sentido, desde que os executivos se aproximem 
dessas iniciativas, a ponto de avaliarem o retorno que elas podem prover, para assim clarificar suas decisões quanto aos direcionamentos de colaboração com startups.

\subsubsection{Resumo do aspecto 'Objetivos e Estratégias'}

Os objetivos e as estratégias demonstraram ser aspectos determinantes na intervenção, influenciando na velocidade e na eficiência da mesma. Constatou-se, na empresa XYZ, uma indefinição de objetivos e de estratégias para startups, fruto principalmente da cultura organizacional atual, o que gerou discussões e baixa produtividade ao planejar ações.

A partir da definição dos objetivos e das estratégias para a intervenção, o grupo pôde constatar que as decisões foram mais ágeis, trazendo mais eficiência no planejamento e andamento mais rápido das ações. Adotar startups como provedoras de solução reforçou a cautela da empresa. No entanto, é coerente com o propósito de resolver problemas de negócios.

Como proposição de ações futuras, o grupo entendeu que a aproximação das áreas de negócios com os executivos deve ser intensificada, a fim de buscar direcionamentos que englobem a organização. Essa proposição tem base teórica e empírica, no entanto, exige gerenciar as complexidades, alinhar os interesses com várias áreas e definir metas compartilhadas entre si.

Em complementação à proposição dos entrevistados, a experimentação pôde ser utilizada como abordagem prévia para construir direcionamentos definitivos, pois permitiu que os executivos pudessem avaliar o valor das startups de forma mais próxima e com menor exposição aos riscos. A outra proposição foi a estruturação de uma governança que ajudasse a definir e a acompanhar os objetivos e as estratégias para as startups, junto com os executivos da organização. A adoção de governança é, portanto, comum na empresa $\mathrm{XYZ}$ no que tange às iniciativas complexas. 
Independentemente das atividades executadas e propostas, foi possível constatar que para definir os objetivos e as estratégias, deve haver uma forte ligação com a alta direção e com os executivos.

\subsection{ALTA LIDERANÇA}

O apoio da alta liderança é um fator vital para a colaboração entre uma grande organização e startups (Thieme, 2017). Segundo Kuratko, Hornsby e Covin (2014), Minshall, Mortara, Napp e Probert (2010) e Mortara, Napp, Slacik e Minshall (2009), a alta liderança tem efeito direto nos resultados de inovação, uma vez que suporta, dá credibilidade e aumenta a aceitação dos colaboradores.

Nessa discussão, considerou-se como alta liderança os executivos que ocupam as posições de diretores e superintendentes. Os altos executivos tiveram papel de promotores e detratores das ações de aproximação com startups. O diretor-patrocinador, sendo um dos altos executivos da organização, pôde apoiar o time, direcionando-o no planejamento e na execução das ações. No entanto, a interação esporádica com o líder fez com que as orientações tardassem para ocorrer.

Por outro lado, os diretores e superintendentes parceiros, que possuíam colaboradores envolvidos na intervenção, apresentaram baixo comprometimento, o que refletiu na participação volátil dos altos executivos e de seus times.

\subsubsection{Barreiras: falta de apoio dos executivos pares, conflito de prioridades dos times de apoio e comunicação esporádica com os executivos}

\section{Comunicação esporádica com os executivos}

O grupo teve acesso ao diretor-patrocinador para discutir os desafios da intervenção e obteve as orientações para que pudesse conduzir com mais eficácia as ações. Porém, essa comunicação foi esporática, refletindo um distanciamento do grupo com seu líder em relação às atividades. 
O distanciamento do time que atua em ações de inovação e seus altos líderes podem causar falha ou paralisar iniciativas desse tipo (Bannerjee, Bielli, \& Hale, 2016; Dombrowski et al., 2007). Mortara, Napp, Slacik e Minshall (2009) e Shah, Zegveld e Roodhart (2008) complementam esse ponto de vista ao considerarem fundamental que a alta gerência acompanhe as atividades de Inovação e de Corporate Venturing, para obterem sucesso. Ademais, Ahmed (1998) ressalta ainda que a alta liderança deve fornecer não só recursos, mas também suporte emocional nas ações de inovação.

\section{Alta-administração: Falta de apoio entre pares}

A falta de engajamento e o estabelecimento de prioridade por parte dos demais altos líderes também eram notórios e foram evidenciados tanto pela ausência desses executivos em atividades como pela morosidade quando solicitadas suas alçadas de aprovação. Kuratko e Goldsby (2004), Dombrowski et al., (2007) e Thieme (2017) sugerem que a falta de engajamento dos líderes ocorra pela resistência natural a potenciais mudanças, sob o poder e os recursos que as inovações possam trazer. Hill e Rothaermel (2003) reforçam essa visão, ao afirmarem que a entrada de uma iniciativa de inovação é evitada, pois força a instabilidade nas estruturas de poder da organização, que têm recursos escassos e controlados.

A falta de engajamento dos líderes pares fez com que muitas atividades na intervenção ficassem estagnadas enquanto o grupo não recebia as aprovações ou as validações necessárias. Kuratko e Goldsby (2004) e Dombrowski et al. (2007) esclarecerem que a paralisação das atividades é comum quando grupos de colaboradores tentam executar iniciativas de baixo para cima, pois precisam submetê-las a vários líderes com alto poder de decisão.

É preciso ressaltar que nenhum dos líderes parceiros e nem seus colaboradores tiveram metas associadas às intervenções. Uma estruturação correta de incentivos e recompensas, segundo Dombrowski et al. (2007), Martins \& Terblanche (2003), Bannerjee, Bielli e Hale (2016), Kuratko, Hornsby e Covin (2014) e Mortara, Napp, Slacik e Minshall 
(2009), tem papel fundamental na construção de um comportamento empreendedor e criativo nas organizações. Ademais, de acordo com Minshall, Mortara, Napp e Probert (2010), os incentivos e recompensas também podem influenciar as organizações a engajarem e a motivarem seus colaboradores para que realizem mudanças associadas às inovações externas.

\section{Conflito de prioridades dos times de apoio}

Ao analisar a experiência do grupo da intervenção, foi possível compreender que a ausência dos líderes se refletiu na falta de comprometimento de seus colaboradores, com ausências e trocas de pessoas do grupo. Esses fatores causaram atrasos e riscos de perda de qualidade em algumas ações.

Quando se envolve iniciativas de inovação, o comportamento dos líderes afeta a maneira como seus liderados enxergam e aderem às iniciativas. Segundo Ahmed (1999), a alta gerência deve estar imersa na realidade das iniciativas voltadas às inovações, envolvendose diretamente a fim de legitimar e de engajar os colaboradores. Corroborando com essa visão, Mortara, Napp, Slacik e Minshall (2009), Kuratko, Hornsby e Covin (2014) e Shah, Zegveld e Roodhart (2008) afirmam que é o comprometimento dos líderes que traz a adesão dos colaboradores e facilita o seu engajamento.

À luz dos autores mencionados, a falta de engajamento dos colaboradores é reflexo da posição de seus altos executivos. Portanto, para que o engajamento dessas equipes seja potencializado, é necessária a realização de ações diretamente associadas com seus líderes.

\subsubsection{Elementos habilitadores - Patrocínio de um Alto Executivo}

\section{Patrocínio de um Alto Executivo}

O papel de um patrocinador é um elemento fundamental para viabilizar iniciativas empreendedoras (Simon, Houghton, \& Gurney, 1999). O diretor de tecnologia cumpriu 
esse papel, segundo os entrevistados, ao estabelecer diretrizes importantes, como a autonomia tática do time, o uso de horas semanais para executar as atividades, o bônus atrelado às entregas e a definição dos objetivos e das estratégias da intervenção.

Martins e Terblanche (2003) e Schättgen e Mur (2016) ressaltam a atuação dos altos líderes como um dos fatores críticos para a criação da cultura de inovação, pois eles definem os direcionadores estratégicos para as ações, habilitando entre outros elementos a autonomia dos grupos para implementá-las. Dombrowski et al. (2007), Kuratko, Hornsby e Covin (2014), Shah, Zegveld e Roodhart (2008) e Ahmed (1998) complementam, ao afirmar que os altos líderes devem fomentar iniciativas inovadoras por meio de elementos como disponibilização de tempo e criação de incentivos.

Sob essas perspectivas, dada a criticidade dos elementos fomentados pelo executivopatrocinador, constata-se que seu papel foi essencial para a intervenção, sem o qual possivelmente o grupo não teria sucesso na condução das ações.

\subsubsection{Proposição de melhorias e novas ações}

As proposições encontradas nos relatos dos entrevistados foram em torno de elementos associados ao aculturamento, tais como apresentar casos internos aos líderes e compartilhar metas com os executivos parceiros.

Além disso, outras proposições de estratégia podem ser encontradas na teoria e na prática para potencializar o apoio da alta liderança, como o gerenciamento dos interesses dos altos executivos, o apadrinhamento de startups e a utilização de 'líder' como ponto de contato com a alta liderança.

\section{Apresentação de cases e execução de piloto}

A proposição feita pelos entrevistados de apresentar casos ou pilotos buscava obter o engajamento dos líderes através de propostas de valor que se mostrassem factíveis e 
próximas de suas realidades. Bannerjee, Bielli e Hale (2016), Thieme (2017) e Bonzom e Netessine (2016) corroboram com essa visão, ao sugerirem que a grande empresa valide suas necessidades por meio de iniciativas menores, para provar valor de forma rápida. Essa abordagem pode permitir que os executivos consigam enxergar potenciais resultados que as startups possam oferecer.

Uma proposta de valor com retornos tangíveis leva ao comprometimento dos líderes a curto e a longo prazo, incentivando-os a tomarem decisões rápidas, ao mesmo tempo em que direcionam estrategicamente a organização na busca por benefícios em se atuar com startups (Schättgen \& Mür, 2013; Bozom \& Netessine, 2016). Bannerjee, Bielli e Hale (2016) recomendam ainda que os casos ou pilotos escolhidos sejam generalistas, a fim de que se possa engajar a maior quantidade possível de envolvidos da alta liderança.

No contexto da empresa XYZ, os casos e os pilotos podem se apoiar no convencimento da alta liderança. $\mathrm{O}$ fato de os altos executivos, incluindo os do setor financeiro, tenderem a investir em inovações quando há resultados tangíveis, reforça essa abordagem (Rehder \& Levi, 2011; Prats, Siota, Canonici, \& Contijoch, 2017). No entanto, cuidados devem ser tomados para que a comunicação com os líderes seja legitimada, pois, conforme relatos, a forte estrutura hierárquica da organização faz com que as propostas feitas por colaboradores tenham menor poder de convencimento. Nesse sentido, pode-se contar com o apoio do diretor-patrocinador para construir essa abordagem.

\section{Metas compartilhadas com executivos parceiros e, posteriormente, com seus liderados}

Para atuar no engajamento dos altos executivos, foi proposto criar metas compartilhadas, utilizando-se como incentivo a bonificação financeira, modelo adotado pela organização no período da intervenção. Segundo Makri, Lane e Gomez-Mejia (2006), a recompensa aos altos executivos, mesmo monetária, apresenta resultados positivos no desempenho de iniciativas envolvendo inovação em toda a organização.

Além de incentivar os executivos, os entrevistados acreditaram que o compartilhamento de metas refletiria no engajamento dos demais colaboradores, dada a orientação 
hierárquica da organização no período da intervenção. Dombrowski et al. (2007) e Freeman e Engel (2007) reforçam a percepção dos entrevistados, ao concluírem que o engajamento e o comprometimento de colaboradores são obtidos a partir da criação de incentivos, atribuição dada aos executivos.

Devido ao fato de a cultura hierárquica na empresa XYZ possuir metas compartilhadas com executivos e seus colaboradores, é possível equalizar os vários interesses envolvidos. No entanto, em uma organização como a empresa XYZ, em que há ausência de cultura empreendedora, ações devem ser tomadas para que os incentivos de realizar as iniciativas com startups sejam suficientemente maiores do que a exposição a riscos, principalmente aos colaboradores, para que se sintam confortáveis para realizarem as atividades (Thieme, 2017).

Além das sugestões efetuadas pelos membros da intervenção, outras ações encontradas na teoria e na prática podem fortalecer o apoio da alta liderança, no contexto da intervenção.

\section{Gerenciar os interesses dos altos executivos}

Uma das proposições encontradas na teoria para engajar os altos líderes é monitorar suas necessidades em relação às iniciativas de inovação, buscando administrar seus interesses.

Mortara e Minshall (2011) e Battistini, Hacklin e Baschera (2013) sugerem que as equipes que atuam com iniciativas inovadoras fiquem próximas dos executivos, para adaptarem suas estratégias, a fim de garantirem o melhor direcionamento das atividades e de evitarem cortes ou perda de engajamento em iniciativas envolvendo startups. Minshall, Mortara, Napp e Probert (2010) ainda sugerem que os grupos responsáveis pela intervenção sejam ativos, indo até os executivos e suas áreas para compreenderem suas expectativas em relação às iniciativas.

Além da proatividade dos membros, a gestão dos interesses pode contar com a atuação de um 'líder' (Howell \& Boies, 2004). Criar uma agenda formal com os executivos 
também ajudaria a estruturar a comunicação. A governança, apresentada no subitem anterior, é um exemplo dessa estruturação (De la Tour et al., 2017; Shah, Zegveld, \& Roodhart, 2008).

Ao entender os interesses dos altos executivos no âmbito da intervenção, vê-se a possibilidade de potencializar o apoio desses líderes e, ao mesmo tempo, reduzir o risco de perda de engajamento, causados, por exemplo, pelas paralisações para efetuar alinhamentos.

\section{Convidar executivos da alta liderança para serem 'padrinhos'}

Convidar executivos da alta liderança para serem padrinhos é uma forma de buscar, por meio do engajamento e da empatia, a realização das iniciativas inovadoras dentro de organizações que possuem forte estrutura hierárquica. Os formatos dessa atuação podem variar. Mocker, Bielli e Haley (2015) sugerem a boa prática de os executivos serem padrinhos de startups, desde o início das interações. Outra variação do apadrinhamento é apresentada na pesquisa de Linna (2017), na qual executivos-chave foram convidados para serem patrocinadores de eventos de inovação. Além de se engajarem na realização dos eventos, eles puderam realizar mudanças internas para facilitar a inovação e engajarem também seus liderados na promoção dessas iniciativas. Os executivos também receberam publicidade interna ao serem homenageados durante os eventos de aculturamento.

No âmbito da intervenção, além do patrocínio do diretor de tecnologia, tornar padrinhos os demais executivos-parceiros permitiriam aumentar as chances de sucesso das ações dentro da empresa XYZ, visto que a influência seria de cima para baixo, mitigando as resistências criadas pela hierarquia rígida e legitimando o interesse da organização. As proposições encontradas por Linna (2017) parecem ter aderência à necessidade da empresa XYZ, visto que a estratégia atual da intervenção tem como uma das ações justamente os eventos de aculturamento.

\section{Atuação de um 'líder'}


O papel de aculturamento do 'líder', apresentado anteriormente no subitem 6.2 - Equipe, envolve também o engajamento dos altos executivos.

Howell e Boies (2004) apresentam o ‘champion' como um líder capaz de influenciar e de gerenciar as expectativas da alta liderança quanto ao valor estratégico das iniciativas, incluindo na criação o senso de urgência quanto ao necessário, além de monitorar as mudanças políticas e de valorar os benefícios das iniciativas. Bannerjee, Bielli e Hale (2016) sugerem também que esse 'líder' possa engajar os executivos a realizarem programas com startups, incluindo a realização de pilotos.

Para que a influência sobre os altos líderes tivesse melhor eficácia na empresa XYZ, o 'líder' deveria ser um executivo sênior conhecido, a exemplo dos casos apresentados por Thieme (2017), pois teria maior capacidade de atravessar os silos hierárquicos da organização (Simon, Houghton, \& Gurney, 1999).

\subsubsection{Resumo do aspecto alta liderança}

A atuação da alta liderança foi fundamental para que a própria intervenção pudesse existir, uma vez que as principais diretrizes foram fornecidas por um diretorpatrocinador. Sem essas diretrizes, o escopo não seria definido e nem mesmo o time seria formado, o que demonstra a forte necessidade dos altos líderes na condução de iniciativas envolvendo startups dentro da organização.

Os altos executivos também influenciaram negativamente a intervenção. Líderes parceiros da intervenção não se engajaram de forma ativa e nem mesmo os seus colaboradores. A falta de engajamento desses líderes está ligada à manutenção da cultura organizacional atual. Soma-se a isso o fato de os executivos e seus colaboradores não terem tido metas associadas às entregas da intervenção, fator que influenciou no engajamento das áreas envolvidas. 
Vislumbrando os futuros ciclos, ações propositivas voltadas ao aculturamento foram encontradas nos relatos dos entrevistados, na teoria e na prática, como a criação de cases e pilotos e o apadrinhamento de iniciativas pelos executivos. Ações para o desenvolvimento de incentivos compartilhados e para a gestão dos interesses dos executivos também foram proposições que caminharam para potencializar o apoio dos altos líderes.

A manutenção dos habilitadores e a realização das ações propostas requerem a ocorrência de pré-requisitos importantes, como a aproximação do diretor-patrocinador da intervenção e a designação de um 'líder' para apoiar na articulação com os altos executivos.

\subsection{CULTURA EMPREENDEDORA}

A cultura empreendedora fomenta distintos comportamentos, como a busca por novas oportunidades, a tomada de riscos, a inovação, a proatividade e a autonomia para decisão (Lee \& Peterson, 2000; Leal-Rodriguez, Albort-Morant, \& Martelo-Landroguez, 2016). Essas caraterísticas são fundamentais para que as empresas consigam vantagens competitivas, ao mesmo tempo em que administram suas capacidades atuais (Tushman \& O'Reilly, 1996; He \& Wong, 2004).

\subsubsection{Barreiras: ausência de cultura empreendedora}

A ausência de cultura empreendedora desestimula os colaboradores a buscarem por iniciativas disruptivas, tal qual a atuação com startups (Thieme, 2017) e, em geral, ela ocorre pela predominância comportamental da organização em administrar suas capacidades atuais (Tushman \& O'Reilly, 1996).

A ausência de cultura empreendedora, na empresa XYZ, é caracterizada pela aversão aos riscos e pela falta de proatividade em atuar em oportunidades inovadoras externas à organização. A principal razão para a existência desses traços de cultura organizacional é a situação confortável diante dos resultados positivos que a empresa conquistou no 
mercado, por meio de seu modelo de negócios solidamente estabelecido. Tais fatos estimulam a organização a se desenvolver sobre suas competências existentes e a se manter eficiente.

A empresa XYZ mantém uma posição consolidada no setor financeiro, que possui alta barreira de entrada e concentração de mercado com poucas empresas de grande porte. Rehder e Levi (2011) e Das, Verburg, Verbraeck e Bonebakker (2018) destacam que as empresas do setor financeiro, em geral, seguem uma regulamentação densa e rígidos requisitos de conformidade, o que faz com que elas preservem o estilo conservador e a aversão aos riscos. Arriscar com soluções inovadoras é algo desestimulado, haja vista a desestabilização das estruturas atuais, focalizadas em usar todos os recursos para manter a empresa em ritmo constante (Freeman \& Engel, 2007; Stringer, 2000; Tushman \& O'Reilly, 1996).

De acordo com os relatos dos membros integrantes desta intervenção, a ausência de cultura empreendedora impactou também na falta de conhecimento sobre empreendedorismo e na adoção de inovações que algumas startups estão desenvolvendo.

\subsubsection{Falta de conhecimento sobre empreendedorismo/startups}

Assumindo a ótica de Long e Fahey (2000), que afirmam que o conhecimento é fruto da reflexão e experiência sobre determinado assunto, é possível constatar que, na empresa $\mathrm{XYZ}$, o conhecimento sobre empreendedorismo e startups ainda tem sido mantido à distância dos colaboradores, sobretudo em situações que envolvam as startups e o ecossistema empreendedor. Apenas recentemente, houve um ensaio para mudar tal contexto, a partir das sinalizações de mudanças no setor financeiro brasileiro e no coworking que a organização mantém de forma cooperada.

A falta de conhecimento gera um efeito que reforça a permanência da cultura corporativa atual, pois os colaboradores não se capacitam para atuar de forma distinta. Segundo Rumelt (1995), a falta de capacitação dos colaboradores inibe a ocorrência de mudanças organizacionais. Mortara e Minshall (2011) reforçam a limitação da mudança da cultura 
organizacional, ao afirmarem que, para gerar mudanças culturais em organizações que desejam trabalhar com startups, é preciso gerar contexto e identificação nos colaboradores, com novas perspectivas a serem almejadas. Essa percepção é consonante com a pesquisa de Minshall, Mortara, Napp e Probert (2010) que afirmam que um dos principais problemas culturais para gerar relacionamento de grandes empresas com startups é justamente a falta de conhecimento por parte dos colaboradores de grandes organizações sobre a forma como as startups funcionam.

A aversão aos riscos é também um dos elementos frutos da ausência de cultura empreendedora na empresa XYZ. Essa constatação reforça a opinião de Bannerjee, Bielli e Haley (2016), que afirmam que a aversão aos riscos é produto do acúmulo da cultura corporativa estabelecida. A cultura corporativa, segundo Stringer (2000) e Leifer, O'Connor e Rice (2001), funciona como mecanismo gerado pelas organizações para manterem controle eficiente sobre os riscos e, por consequência, acaba estabelecendo um baixo estímulo em relação às mudanças disruptivas.

Bannerjee, Bielli e Haley (2016) e Ahmed (1998) reforçam que a aversão aos riscos também desestimula a execução de iniciativas inovadoras, despertando a cultura do medo do fracasso e gerando tomadas de decisões mais lentas para atenuar as incertezas. $\mathrm{O}$ quadro de aversão aos riscos na empresa XYZ caminhou nesse sentido, ao gerar impactos no estabelecimento da cultura pró-startups e empreendedora, pois o risco de falhar é negativamente avaliado.

\subsubsection{Elementos habilitadores - eventos de aculturamento e 'rede social'}

Durante a intervenção na empresa XYZ, os eventos de aculturamento e o desenvolvimento da 'rede social' levaram à propagação dos temas startups e empreendedorismo dentro da organização.

Dentre os benefícios constatados das ações de aculturamento destaca-se a sinalização que a organização está aberta a startups e que os colaboradores podem proativamente promover atividades em prol dessa aproximação. Ahmed (1998) ressalta que a comunicação é importante, pois a organização precisa apresentar com clareza aos 
colaboradores a sua intenção no que se refere ao empreendedorismo e à inovação para que, de fato, comecem a ocorrer mudanças culturais nesse sentido.

Para compreender os efeitos habilitadores e as limitações dessas ações, é importante ter conhecimento sobre os resultados obtidos com os eventos e com a 'rede social'.

Os eventos de aculturamento foram considerados bem-sucedidos em relação à aproximação da empresa XYZ com startups, por terem provocado em grande número de colaboradores e em líderes o engajamento e a conscientização sobre startups. A disposição dos colaboradores, em participar, demonstrou também que eles tinham interesse sobre o assunto, mas reprimido pela falta de canais sobre o tema na organização, até a ocorrência da intervenção.

Os eventos de aculturamento são considerados formas iniciais de engajar as organizações na relevância das startups, promovendo um contato mais próximo com essas novas empresas (Bonzom \& Netessine, 2016; Bannerjee, Bielli, \& Haley, 2016; KPMG, 2015; Mocker, Bielli, \& Haley, 2015).

Segundo Mocker, Bielli e Haley (2015), os eventos têm capacidade de ser um passo inicial no sentido da mudança cultural interna, ao atingirem um amplo público, a baixo custo, o que torna as iniciativas acessíveis, como meio de apresentar aos colaboradores o compromisso da organização para com o empreendedorismo e a inovação (Mind the Bridge \& Nesta, 2017).

Os principais valores coletados a partir dos eventos de aculturamento foram a conscientização dos colaboradores sobre as startups e a legitimação da possibilidade de utilizá-las para alavancar capacidades na organização. Esses valores são fundamentais para que os colaboradores possam exercitar o comportamento empreendedor, como proatividade e inovação, à medida que passam a considerar as startups como soluções possíveis para resolver problemas de negócios (Kuratko, Hornsby, \& Covin, 2014; Bannerjee, Bielli, \& Haley, 2016). 
Os eventos também propiciaram oportunidades de negócios para as startups e serviram para que outras áreas da organização se interessassem pela realização de novos eventos de aculturamento. Destaca-se que esses resultados não tinham sido previstos pelo grupo, no entanto, são comuns nesse tipo de iniciativa (Bannerjee, Bielli, \& Haley, 2016).

Embora os eventos tenham gerado resultados positivos, não necessariamente esses efeitos irão perdurar como uma mudança cultural estabelecida. Ahmed (1998) afirma que apenas comunicar o interesse do tema à organização, como é o caso desses eventos, não é suficiente para desenvolver uma cultura, visto que sua construção é complexa e depende de diversos fatores. Mind the Bridge e Nesta (2017) corroboram com essa visão, ao sugerirem que os eventos não podem ocorrer de forma isolada; devem estar associados a um plano de comunicação e estratégias de inovação, sob risco de não gerarem mudanças mais profundas dentro das corporações.

A 'rede social' é uma plataforma de interação, comunicação e colaboração que permite às pessoas criarem e compartilharem conhecimentos (Kaplan \& Haenlein, 2010). A 'rede social' na empresa XYZ teve um crescimento exponencial, atingindo cerca de 5 (cinco) mil integrantes e os permitiu validar, criticar, construir e trocar experiências para gerar conhecimento sobre os temas startups e empreendedorismo, por terem tido à disposição uma gama de mídias - documentos, artigos, relatórios e fóruns. A criação da 'rede social' é convergente com a pesquisa de Dombrowski et al. (2007), na qual sugerem que o uso de sistemas de informação para compartilhar conhecimento é uma forma de democratizar a comunicação e, por consequência, de disseminar a cultura inovadora. Angehrn, Luccini e Maxwell (2009) corroboram com esse entendimento, ao afirmarem em sua pesquisa que as redes sociais funcionam como meios de impulsionar os processos de inovação, aumentando o engajamento dos colaboradores.

Os resultados e as percepções da implantação da 'rede social' nesta intervenção fizeram dela um instrumento potencial para melhorar o relacionamento da empresa XYZ com startups, na medida em que possibilitou aos colaboradores melhor compreensão sobre startups. Ademais, a concentração de pessoas permitiu que a rede atuasse como catalizadora de eventos de aculturamento, divulgando-os para toda a organização, o que reforça ainda mais sua utilidade. Alinhados a essa constatação, Martins e Terblanche (2003) afirmam que o uso de sistemas de informações, como a 'rede social' por exemplo, 
funciona como um mecanismo de suporte, permitindo o compartilhamento de conhecimento e contribuindo para a criação de uma cultura organizacional orientada à inovação.

\subsubsection{Proposição de melhorias e novas ações}

\section{Continuidade dos Eventos de Aculturamento}

As sugestões de melhorias dadas pelos entrevistados quanto aos eventos estão relacionadas com a diversificação, no caso, com a criação de competições, como hackathons, e de eventos temáticos para os departamentos da organização. Essas sugestões têm embasamento empírico. Mind the Bridge e Nesta (2017) e Bonzom e Netessine (2016) recomendam hackathons, como uma das possibilidades de eventos e apresentam outros, tais como competição de startups e conferências.

Esses formatos poderiam ser adotados pela empresa XYZ. No entanto, para habilitar esses eventos, é preciso primeiramente avaliar alguns pontos em questão, tais como: recursos financeiros, expertise dos times envolvidos e disponibilidade das pessoas que participarão dos eventos. Esses itens são críticos para a empresa XYZ, visto que os relatos dos entrevistados apontam falta de recursos financeiros e de disponibilidade das pessoas e limitações quanto ao conhecimento do time.

\section{Continuidade da 'rede social'}

Os membros da intervenção também propuseram que fosse dada continuidade à 'rede social' nos próximos ciclos. No entanto, apesar de poder contar com a contribuição dos participantes, a continuidade da rede iria requerer pessoas dedicadas exclusivamente à elaboração de conteúdo, como ressaltado pelos membros da intervenção. Durante as entrevistas, o número elevado de menções quanto à necessidade de pessoas destinadas tanto para a 'rede social' como também para outras atividades é fundamentado pela teoria e pela prática. Schättgen e Mür (2013) reforçam que não basta que os empreendimentos 
internos tenham capacidades relevantes, é necessário também ter pessoas dedicadas para realizá-los. Minshall, Mortara, Napp e Probert (2010) e Mortara e Minshall (2011) sugerem que sejam designadas pessoas exclusivamente para impulsionar a cultura inovadora dentro da organização.

\section{Iniciativas de imersão cultural}

O desenvolvimento de imersão comportamental sobre startups é uma nova proposta de ação sugerida pelo grupo como forma de desenvolver uma cultura empreendedora na organização. O conjunto de proposições divide-se entre a imersão dos colaboradores em atuações junto com as startups e a construção de projetos internos com pequenas equipes autônomas e orçamentos enxutos, semelhantemente ao que ocorre nas startups. Essas propostas garantiriam que os colaboradores pudessem se colocar na perspectiva das startups para entenderem seus desafios ao se relacionarem com uma grande empresa, ao passo que também desenvolveriam uma mentalidade empreendedora.

Segundo pesquisa de Gobble (2018), a aproximação do trabalho com as startups busca estabelecer nas grandes organizações novos aspectos culturais, semelhantes aos das startups, tais como tomada de decisão rápida, construção de processos mais ágeis e maior apetite a risco. Bannerjee, Bielli e Haley (2016) e De la Tour et al. (2017) afirmam que o encorajamento dos funcionários das grandes empresas para trabalharem com startups dá início à uma mudança de mentalidade e cultura de colaboração empreendedora dentro da empresa. Trabalhar em conjunto com startups permite trocar experiências, além de promover um processo de aprendizado de ambos os lados. Bannerjee, Bielli e Haley (2016) sugerem, ainda, que haja uma dedicação de tempo mensal para o grupo de colaboradores interessados nessa função ou elegíveis para essas iniciativas.

A imersão cultural no ambiente das startups está em sintonia com exemplos capturados da prática e da teoria. Minshall, Mortara, Napp e Probert (2010) e De la Tour et al. (2017) apresentam em suas pesquisas grandes empresas nas quais os funcionários dedicam 
tempo para estreitar relacionamento com startups, ajudando a cumprir as atividades profissionais e até mesmo as extraprofissionais.

Bannerjee, Bielli e Haley (2016) apresentam também eventos para construção de cultura e engajamento, os chamados Startups Weekends. Trata-se de eventos internos nos quais os colaboradores trabalham em pequenos grupos, como uma startup, para resolver problemas da organização. Abordagem muito semelhante à proposição feita pelos entrevistados por ocasião desta intervenção.

\subsubsection{Resumo do aspecto cultura empreendedora/orientação empreendedora}

O desafio de aproximar a empresa XYZ com as soluções de startups para resolver problemas de negócios passa pelo aculturamento dos colaboradores quanto às startups $\mathrm{e}$ ao empreendedorismo, visando a eliminar a aversão aos riscos e a falta de proatividade, ambos identificados nas análises.

O aculturamento passa pela conscientização, difusão e discussão desses temas pela organização. Os eventos de aculturamento e a 'rede social', por exemplo, cumpriram esse papel, obtendo resultados positivos. Portanto, poderiam ser continuados, mas com adaptações.

Como proposição de novas ações, os entrevistados sugeriram o desenvolvimento de imersões, as quais favoreceriam o desenvolvimento do comportamento empreendedor e maior conhecimento e engajamento sobre startups. Ações semelhantes são encontradas na teoria e na prática.

As proposições de melhorias e novas ações de aculturamento, no entanto, podem não encontrar viabilidade, caso sejam feitas isoladamente dentro da empresa XYZ. Essas atividades dependem do apoio da alta liderança, de recursos financeiros e da dedicação de pessoas com expertise. Esses aspectos precisam ser trabalhados conjuntamente, para que as ações de aculturamento possam ter efeito. 


\subsection{EQUIPE}

A estruturação da equipe é um dos principais elementos para se estabelecer iniciativas de aproximação com startups. Os grupos de intervenção foram a força motriz, durante o processo de intervenção na empresa XYZ, para execução das atividades. 


\subsubsection{Barreiras: falta de capacitação/conhecimento e falta de tempo}

A intervenção enfrentou duas principais barreiras quanto à equipe: a falta de tempo para dedicação exclusiva dos colaboradores e a falta de capacitação inicial dos mesmos.

\section{Falta de tempo}

A falta de tempo foi o limitador de avanço das ações, com maior número de menções durante as entrevistas. O pouco tempo dispensado, apenas quatro horas semanais, fez com que o time enfrentasse problemas ao priorizar ações, selecionando-as em função do tempo disponível e não necessariamente em função do maior impacto causado. Para Schättgen e Mür (2013), não basta que o time responsável por gerar iniciativas de inovação tenha um conjunto de habilidades para efetuar as ações, pois também deve ter disponibilidade adequada de tempo para imergir nessas atividades. Segundo Mortara e Minshall (2011), a disponibilidade de tempo mitiga os obstáculos para realizar mudanças em prol de inovações externas, pois permite melhor absorção de conhecimento e de aprendizado durante as ações.

Os membros da intervenção dispunham de um curto espaço de tempo para realizar as atividades, que não eram fixas na agenda, e, desse modo, eram pressionados por outras tarefas cotidianas. Além disto, o tempo não compatível com a complexidade e o esforço exigidos para realizar certas atividades, fizeram com que o time extrapolasse o tempo de quatro horas semanais acordado para efetuar entregas com qualidade. Kuratko, Hornsby e Covin (2014) sugerem aos grupos que pretendem atuar em atividades voltadas à inovação, que disponibilizem um tempo adequado para executar essas atividades, caso contrário, elas serão suprimidas por outras consideradas prioritárias. Essa estruturação se faz ainda mais necessária quando há metas organizacionais envolvidas (Kuratko, Hornsby, \& Covin, 2014).

Segundo relatos dos entrevistados, a equipe não teve margem para negociar o tempo definido pela alta liderança. Mocker, Bielli e Haley (2015) ressaltam que, para realizar 
atividades voltadas ao relacionamento de grandes empresas com startups, o tempo destinado deve ser definido antes de se dar início à execução das iniciativas, sob risco de posteriormente não conseguir dar andamento às tarefas.

Ao confrontar a barreira da falta de tempo da empresa XYZ com os insumos da teoria e da prática, percebe-se que os efeitos nocivos da falta de tempo são vistos em função da importância de disponibilizar períodos coerentes com a complexidade e o esforço exigidos, além de uma agenda fixa. Além disso, um trabalho prévio de negociação com executivos ajudaria a legitimar um tempo adequado para o time.

\section{Falta de Capacitação}

A falta de capacitação para executar as atividades caracterizou-se pelo pouco conhecimento sobre startups e sobre seus os desafios de relacionamento com grandes empresas. A barreira da falta de capacitação fez com que o time prolongasse o tempo de execução das atividades iniciais e tomasse decisões equivocadas por falta de entendimento.

Diversos autores afirmam que a capacitação é essencial, especialmente, para times que atuam em cenários envolvendo mudança cultural em prol de inovação e soluções externas. Rumelt (1995) e Fasnacht (2009) afirmam que a falta de capacitação pode provocar a inércia em ações de mudança de cultura e até causar falhas ao tentar implementar inovações. Mortara e Minshall (2011) complementam essa perspectiva explicando que a lacuna de um conjunto de habilidades é um obstáculo para empresas que desejem atuar com soluções tecnológicas externas.

O aprendizado que a equipe extrai quanto à falta de capacitação é que, caso o time tivesse se preparado melhor, teria tomado decisões mais assertivas e teria executado as ações com maior velocidade. Mortara e Minshall (2011) corroboram com essa visão, ao afirmarem que a experiência limitada de um time pode provocar custos extras e prolongamento das atividades. 


\section{Falta de Incentivo}

O principal impeditivo para execução das ações quanto aos incentivos e recompensas foi a baixa representatividade da meta ou a ausência desta para os colaboradores direta e indiretamente envolvidos na intervenção e para os executivos.

Enquanto no Grupo 1, apenas dois colaboradores tinham metas estabelecidas; no Grupo 2 , todos possuíam metas associadas à intervenção. A baixa proporção nas metas $-5 \%$ do total -, no entanto, ocasionou pouco interesse de alguns membros, acarretando um distanciamento deles quanto às atividades do grupo.

Um baixo incentivo pode fazer com que os colaboradores não se sintam desafiados a atuar em mudanças. Segundo Thieme (2017) e Martins e Terblanche (2003), não se pode esperar que colaboradores e executivos assumam a responsabilidade de empreender e de gerar mudanças significativas, se não há recompensa proporcional aos riscos que eles estão expostos. Esse cenário desenha-se na empresa XYZ, onde há um desnivelamento dos incentivos e recompensas, tanto no alcance dos envolvidos, quanto na proporcionalidade.

\subsubsection{Elementos habilitadores - aprendizado, motivação e autonomia}

As características encontradas na equipe que permitiram realizar as ações dentro da empresa XYZ foram o aprendizado, a motivação, e a autonomia dada.

\section{Aprendizado}

O aprendizado do time ocorreu pela experiência adquirida na prática das ações e por meio de estudos, workshops e benchmarks realizados durante a intervenção.

As atividades de benchmarks permitiram a aquisição de conhecimento empírico sobre startups, empreendedorismo, ecossistema de startups, desafios e melhores práticas 
quanto ao relacionamento de grandes empresas com startups. Os workshops também levaram conhecimento empírico, mas nas perspectivas dos colaboradores da organização, por meio da troca de experiências. Os estudos realizados pelo time tiveram, por sua vez, embasamentos em artigos científicos e em relatórios de consultorias. Esses estudos foram posteriormente compartilhados com o grupo através de seminários. Esse processo de aprendizado permitiu ao time refletir e entender a relevância das ações de aculturamento e como ela afeta outros aspectos necessários para propiciar um melhor relacionamento da empresa XYZ com startups. Como reflexo do aprendizado, o grupo teve mais assertividade nas tomadas de decisão e passou a executar as atividades da intervenção com mais qualidade e eficiência.

Além do conhecimento exposto, a própria prática da intervenção também serviu como fonte de aprendizado para o time, que passou a adaptar técnicas à realidade da organização, evidenciado pelo aperfeiçoamento na execução dos eventos, e pelo uso de 'rede social' como difusora de informações. $\mathrm{O}$ aprendizado da prática estimulou o time a refletir, compreender e gerar conhecimento que foi novamente aplicado. Esse resultado corrobora com as boas práticas identificadas por Bannerjee, Bielli e Haley (2016) e Martins e Terblanche (2003), que afirmam que o aprendizado contínuo contribui para o comportamento que encoraja a inovação e que gera a mudança de cultura dos colaboradores envolvidos.

A aprendizagem, no caso da intervenção, reflete o Ciclo de Kolb (1984), no qual o conhecimento é desenvolvido através da experiência, por meio de uma contínua transformação. Schön (1983) corrobora com essa visão, ao afirmar que o aprendizado pela prática se caracteriza por situações únicas, complexas e incertas, que se distanciam do conhecimento técnico.

\section{Motivação (pessoal)}

A segunda característica relacionada com a habilitação do time foi a motivação pessoal e as limitações quanto à capacitação sobre o tema 'relacionamento entre grandes empresas e startups', permitindo que as atividades fossem executadas desde o início. 
Ahmed (1998) e Amabile (1998) relatam que as motivações podem ser intrínsecas ou extrínsecas. Exemplificando, as intrínsecas referem-se ao desafio pessoal e à busca por novos conhecimentos; enquanto as extrínsecas referem-se às recompensas financeiras. Osterloh e Frey (2000) afirmam que as motivações intrínsecas possuem mais eficácia do que as extrínsecas, quando aplicadas em iniciativas de inovação.

Ao analisar a intervenção na empresa XYZ sob a ótica desses autores, é possível perceber que as motivações do grupo eram mistas, contendo tanto fatores externos como os internos. Os relatos de motivadores internos, no entanto, superaram os externos, dentre eles o desejo de transformação da organização e a busca por novos conhecimentos. É importante ressaltar que esses fatores não nasceram do incentivo da organização, mas dos próprios membros.

\section{Autonomia}

A autonomia pode ser definida como um habilitador para a intervenção, porém, com ressalvas. A autonomia permitiu aos membros da intervenção decidir a forma como as ações seriam executadas, porém, o time não teve autonomia plena para definir nem o objetivo e nem a abordagem da intervenção. Segundo Ahmed (1998), há dois tipos de autonomia para mudança de clima e cultura para inovação: uma, quando se dá liberdade total ao time para definir estratégia e executar ações; e outra, focada na permissão para executar as ações de forma livre, mediante a uma estratégia definida. No caso da intervenção na empresa XYZ, entende-se que foi aplicada o segundo tipo de autonomia, pois a estratégia foi definida pelos executivos, cabendo ao time apenas a decisão sobre como executá-la.

A autonomia dada ao time foi importante para executar as ações, no entanto, as limitações, associadas a outros fatores, contribuíram para que o time fosse ineficiente durante os dois primeiros ciclos. Todavia, não se pode afirmar que uma autonomia plena dada ao time, tornaria a intervenção mais eficiente, haja vista diversos fatores, dentre eles a falta de maturidade sobre os temas. 


\subsubsection{Proposição de melhorias e novas ações}

Entre as sugestões dadas pelo grupo para os próximos ciclos estão a formação de um time com dedicação exclusiva; a disponibilização de mais tempo para os membros da intervenção, alternativo para um time dedicado; a redução do time da intervenção; e a definição de um 'líder' para implantação das ações. As recomendações têm amparo em elementos empíricos ou científicos.

\section{Time dedicado}

A proposta do time dedicado, feita pelos membros da intervenção, permitiria que o conhecimento ficasse restrito ao time, o que ajudaria a criar um portfólio mais completo de ações, sendo possível escolher ações mais complexas e longas como aquelas voltadas a mudanças culturais e processuais, que exigem maior esforço e mais tempo para execução. O estabelecimento de um time dedicado é considerado essencial, na visão de Minshall, Mortara, Napp e Probert (2010), Bannerjee, Bielli e Haley (2016) e Mortara, Napp, Slacik e Minshall (2009), para conduzir ações voltadas para o relacionamento com startups.

Na percepção do grupo, além do aculturamento, o time dedicado também ajudaria a realizar ações mais tangíveis, como alteração de processos e experimentações. Essa abordagem faz sentido para a empresa XYZ, caso adote como estratégia para as próximas ações uma aproximação pragmática com as startups, considerando-se que os três ciclos da intervenção tiveram como foco principal o aculturamento. Se o grupo tivesse se mantido estável, desde o começo das ações, poderia ter contribuído mais para aliviar os atritos e dúvidas sobre a legitimidade das ações, como foi observado pelo pesquisador na transição do Ciclo 1 para o Ciclo 2.

Mortara e Minshall (2011), Weiblen e Chesbrough (2015), Minshall, Mortara, Napp e Probert (2010), Mocker, Bielli e Haley (2015) e Prats, Amigó, Ametller e Batlle (2017)

apresentam exemplos em conformidade com as sugestões dos entrevistados, como 
equipes dedicadas para realizar eventos de disseminação de conhecimento, experimentações, pilotos e resoluções de problemas envolvendo áreas internas.

Além dos casos com retorno positivo, o estabelecimento de um time com dedicação exclusiva requer também certos cuidados. O relatório da KPMG (2015) apresenta uma pesquisa na qual os times dedicados passam muito tempo em busca de legitimidade e aprovações orçamentárias e, muitas vezes, sucumbem na tentativa de estabelecer as mudanças na organização.

Logo, o estabelecimento de um time alocado deve ser acompanhado de fatores que o sustente, com um mandato de atuação claro, orçamento pré-estabelecido e alinhamento com a alta liderança da organização.

\section{Tempo disponibilizado}

Em alternativa a um time dedicado, alguns entrevistados sugeriram que fosse disponibilizado um tempo mais longo para os membros da intervenção para que executassem as atividades. Maior tempo de dedicação, diminuiria a concorrência das atividades da intervenção com as atividades do cotidiano.

A sugestão de disponibilizar um tempo maior, fixo e proporcional aos desafios encontra embasamentos teóricos e empíricos (Dombrowski et al., 2007; Kuratko, Hornsby, \& Covin, 2014; Mocker, Kuratko, \& Covin, 2015; Miles \& Covin, 2002). No entanto, o dimensionamento de tempo deve ser bem avaliado, considerando-se que as atividades que envolvem mudanças organizacionais tomam mais tempo exigem que o time se concentre para executá-las (Schättgen \& Mür, 2013).

\section{Time reduzido}

O número de pessoas designadas para a intervenção era visualmente maior do que o de pessoas que realmente participavam das atividades. Isso motivou os membros a proporem 
a redução da quantidade de participantes, pois entenderam que deixaria o grupo mais perene, sendo mantidos apenas os comprometidos.

Um time compacto tende a ter melhor resultado em ações voltadas à inovação e ao empreendedorismo, porque aumenta a eficiência, a motivação e a responsabilidade dos membros (Weiss \& Hoegl, 2016; Schättgen \& Mur, 2016). Sendo assim, no contexto da empresa XYZ, um time menor para a implantação de ações voltadas à aproximação com startups poderia entregar maior produtividade e mais assertividade nas ações.

Apesar de a redução do time ter potencial para entregar valor positivo, deve-se ter cuidado para que tenha um tamanho adequado e perfis capazes para entregar os desafios estabelecidos. O subdimensionamento ou a falta de perfis necessários podem comprometer as entregas voltadas à inovação, como é o caso da empresa XYZ, que deseja se aproximar das startups (Weiss \& Hoegl, 2016).

\section{'Líder'}

Por fim, os membros da intervenção entrevistados sugeriram a definição de um 'líder' [Champion para Thieme (2017) e Kohler (2016)], ou ponto focal para resolução de problemas relacionados à intervenção. Essa sugestão foi influenciada pelos estudos durante a intervenção.

Thieme (2017) e Kohler (2016) consideram 'líderes' como ‘fabricantes de pontes' que fazem a conexão entre as grandes empresas e as startups. Minshall, Mortara, Napp e Probert (2010), por sua vez, entendem que o 'líder' atua como ponto focal que blinda as startups da burocracia da organização. Bannerjee, Bielli e Haley (2016) o definem como um "líder de torcida" que busca aculturar, entusiasmando a organização para atuar com startups.

Os entrevistados entenderam que esse 'líder' pode atuar em casos específicos de startups ou em programas de engajamentos com startups, servindo como um articulador que resolveria entraves burocráticos. Entretanto, ao analisar os desafios atuais da intervenção, seu papel como agente de aculturamento interno é mais adequado. 
Quando se trata de selecionar o potencial 'líder' (Champion) para a intervenção, é preciso procurar por alguém que tenha apoio da alta liderança, poder de decisão sob recursos e sob execução de projetos (Dombrowski et al., 2007; Bannerjee, Bielli, \& Haley, 2016; De la Tour et al., 2017). Além disso, o candidato deve conhecer a política da empresa e possuir poder de penetração nos silos da organização (Mortara \& Minshall, 2011; Bannerjee, Bielli, \& Haley, 2016). Caso a proposição seja acatada pela empresa XYZ, é mais provável que o candidato venha de fora e não de dentro do grupo da intervenção, pela pouca representatividade política que os membros do time possuem.

No âmbito da empresa XYZ, o 'líder' pode ser catalisador para as ações da aproximação com startups. No entanto, este papel pode ser evolutivo, ou seja, iniciar com uma atuação voltada ao aculturamento e, ao longo do tempo, ir assumindo a gestão de pilotos e experimentações com startups.

Independentemente da estratégia adotada, o 'líder' deve ter apoio político da alta liderança e ser conhecedor do ambiente organizacional para defender as atividades da intervenção. Seguindo a lógica hierárquica da organização, esse 'líder' deve ser um alto executivo, o que conferiria maior apoio e legitimidade ao abordar outros departamentos da organização, ao passo que poderia facilitar a obtenção de recursos em futuras evoluções.

\section{Aumento da representatividade das metas}

Uma maior proporção de bonificação, na visão dos membros, faria com que os colaboradores se comprometessem mais, pois os valores monetários sinalizariam a importância que a organização estaria dando ao tema.

De acordo com Dombrowski et al. (2007), os incentivos devem ser coerentes com o propósito almejado pela organização. Portanto, aumentar a proporção da bonificação sobre as ações realizadas tenderia a incentivar uma participação maior dos envolvidos. Essa proposição também está em sintonia com a visão de Freeman e Engel (2007) e de 
Martins e Terblanche (2003), que defendem que as recompensas incentivam a predominância do comportamento desejado.

No entanto, os benefícios extrínsecos como valores monetários, em geral, têm efeito temporário, fazendo com que seja necessário fomentar os incentivos intrínsecos, pois engajariam os colaboradores a longo prazo (Martins \& Terblanche, 2003; Ahmed, 1998).

\section{Incentivos não financeiros (tempo)}

Segundo Martins e Terblanche (2003) e Ahmed (1998), as recompensas intrínsecas são as formas mais eficientes de engajar colaboradores na construção da mentalidade criativa/empreendedora e na condução de iniciativas inovadoras. Inúmeros exemplos de recompensas criadas pela organização são encontrados na teoria e na prática, tais como a disponibilidade de tempo e de recursos financeiros, a autonomia, o acesso aos executivos e a participação em programas de inovação e em treinamentos (Ahmed, 1998; Mind the Bridge \& Nesta, 2017; Martins \& Terblanche, 2003).

Entre todos os exemplos supramencionados, a proposição de recompensar os colaboradores com maior disponibilidade de tempo parece ter mais aderência à realidade da intervenção, visto que por diversas vezes a mesma foi mencionada como um problema.

Martins e Terblanche (2003) e Dombrowski et al. (2007) exemplificam casos de organizações que incentivam a cultura de empreendedorismo, permitindo que seus colaboradores possam reservar tempo para se dedicarem a outras atividades voltadas à inovação e aos projetos pessoais.

O uso da recompensa de maior disponibilidade de tempo poderia ser adotado no âmbito da intervenção como um experimento e, dependo de seus resultados, poderia ser posteriormente aplicado no âmbito da organização. Como regra, os resultados alcançados seriam revertidos em tempo para atuar em iniciativas envolvendo startups. 


\subsubsection{Resumo do aspecto da equipe}

$\mathrm{O}$ aspecto da equipe mostrou-se determinante para a intervenção, impactando o escopo, o ritmo e a qualidade das ações. A equipe influenciou positiva e negativamente a realização das ações através de fatores como a motivação pessoal, a aprendizagem, a autonomia, a capacitação e a disponibilidade de tempo.

A motivação pessoal causou efeito positivo, permitindo o engajamento dos membros que tinham aspirações de mudança cultural na organização e de novos conhecimentos. A autonomia permitiu que o time pudesse executar atividades com celeridade, mas apenas a partir do direcionamento estratégico do diretor-patrocinador.

O aprendizado do time, por sua vez, foi positivo durante a intervenção, pois contribuiu para o ganho de maturidade e de assertividade das ações, contrabalanceando com a falta de capacitação inicial, fator negativo que tinha afetado a eficiência do time nos primeiros ciclos.

Junto com a falta de capacitação, a falta de tempo também inibiu a equipe na execução das ações, impactando a qualidade e o escopo das ações.

A partir das experiências e dos aprendizados da equipe, proposições de melhorias foram feitas para contribuir com a aproximação da empresa XYZ com as startups nos próximos ciclos, tais como: criar um time dedicado, disponibilizar mais tempo aos membros, reduzir o tamanho do time e definir um 'líder'. Muito embora essas proposições tenham fundamento teórico e prático, elas dependem de outros aspectos, como o apoio da alta liderança e os recursos financeiros.

\subsection{ESTRUTURA ORGANIZACIONAL E PROCESSOS INTERNOS}

Diferentemente do ocorrido na Análise dos Resultados, os aspectos de Estrutura Organizacional e os Processos Internos serão discutidos conjuntamente, pois os desafios 
dos elementos processuais identificados na intervenção são provocados principalmente pela estrutura organizacional da empresa XYZ. 


\subsubsection{Barreiras: estrutura organizacional rígida e processos complexos e longos}

\section{Estrutura Organizacional Rígida}

Os entrevistados apontaram que, devido à hierarquia rígida da empresa, as atividades da intervenção tiveram velocidade reduzida e o escopo da intervenção foi limitado.

A necessidade de validar direcionadores em comitês com os executivos foi relatada como um dos elementos que causava diminuição da velocidade de implementação das atividades. Outro impacto associado à hierarquia rígida foi a abrangência da intervenção, que contemplou apenas a área de tecnologia pois, segundo relatos dos entrevistados, o diretor-patrocinador teria pouca influência sobre as demais áreas.

Segundo Hill e Rothaermel (2003), a rigidez hierárquica e suas estruturas burocráticas surgem da busca pelo crescimento estável, tendo como base inovações incrementais. No entanto, num ambiente que necessita de dinamismo, a rigidez dificulta as mudanças nas competências da organização.

$\mathrm{Na}$ empresa XYZ, também foi possível evidenciar problemas com processos complexos e longos períodos para a tomada de decisão, quando se tratava de iniciativas envolvendo startups. Esses problemas estão associados à rigidez das estruturas organizacionais, que necessitam de processos extensos e não conseguem compartilhar informações entre os silos organizacionais (Kuratko \& Goldsby, 2004; Minshall, Mortara, Napp, \& Probert, 2010; Bannerjee, Bielli, \& Hale, 2016).

\section{Processos Complexos}

As sobreposições, as lacunas e a falta de conhecimento, identificados no decorrer do mapeamento dos processos envolvendo startups da intervenção, impediram a identificação das causas raízes dos problemas processuais na organização. Segundo Nagano, Stefanovitz e Guimarães (2015), entre os principais desafios para realizar 
inovação na organização está a dificuldade em gerir os processos internos e em equalizar o conhecimento dos colaboradores.

A complexidade dos processos também dificultou a definição dos limites dos papéis e das responsabilidades dentro da empresa XYZ. Os reflexos dessas dificuldades foram a omissão de ajuda e a transferência de responsabilidade entre as áreas, quando se tratava de responder aos problemas das startups. Dombrowski et al. (2007) e Minshall, Mortara, Napp e Probert (2010) sugerem que a falta de colaboração entre fronteiras departamentais ocorre por não haver direcionadores ou incentivos que permitam assumir ações em zonas dúbias. Assim, os colaboradores preferem truncar a comunicação ou transferir a responsabilidade dos problemas.

\section{Processos longos para tomada de decisão}

$\mathrm{Na}$ empresa XYZ, as dificuldades em definir as responsabilidades também geraram períodos extensos para a tomada de decisão, o que foi evidenciado na intervenção. Bannerjee, Bielli e Hale (2016), Minshall, Mortara, Napp e Probert (2010) e Morris e Kuratko (2002) entendem que as camadas hierarquizadas diminuem a velocidade de decisão, o que é potencializado nos casos de busca por inovações, quando se tem exposição ao risco e proposição de mudanças nas competências organizacionais.

Os múltiplos pontos de contato que as startups tiveram com a empresa XYZ, durante a intervenção, consumiram tempo de ambos os lados, muitas vezes sem gerar resultados. De acordo com Minshall, Mortara, Napp e Probert (2010), essas experiências geram desistências e até mesmo podem repelir as startups a se aproximarem de outras grandes empresas no futuro. 


\subsubsection{Elementos habilitadores - cartilha e ferramenta para avaliação de startups}

\section{Cartilha}

A cartilha sobre os processos macros teve como objetivo simplificar a visão dos processos internos da organização para startups. Bannerjee, Bielli e Hale (2016, p. 21) chamam essa abordagem de 'esconder a fiação', pois a grande empresa não modifica os processos, apenas tenta mapeá-los e apresentá-los de forma mais clara. Esse tipo de ação também encontra amparo em Minshall, Mortara, Napp e Probert (2010), que recomendam o uso de mapas de processo para apresentar às startups como as decisões são tomadas dentro da organização.

Apesar de ter respaldo teórico e empírico, a ação não foi amplamente divulgada dentro da organização, sofrendo pela falta do aspecto mais intensificado pelo grupo da intervenção, o aculturamento.

\section{Ferramenta para avaliação de startups}

Outra ação no âmbito processual foi a elaboração de uma ferramenta para avaliar soluções provenientes de startups versus as necessidades de áreas de negócios. A ferramenta elaborada buscou, por meio de critérios e de definição de papéis/responsabilidades, dar clareza na tomada de decisão sobre como utilizar uma startup ou não para resolver problemas de negócios.

Traitler, Watzke e Saguy (2011) afirmam o que desenvolvimento de ferramentas é essencial para diminuir o peso da decisão dos colaboradores que desejem atuar com iniciativas de inovação na organização. Minshall, Mortara, Napp e Probert (2010) recomendam que as grandes empresas avaliem o nível de prontidão das startups, a fim de averiguarem à luz de sua estratégia e necessidade se o discurso apresentado pela startup tem amparo na realidade e se há alguma limitação de capacidade que precise ser trabalhada ou seja impeditiva. A utilização de critérios de avaliação acelera a tomada de 
decisão, pois, segundo Linna (2017), evita que as decisões de utilizar startups sejam feitas de forma emocional, podendo posteriormente causar frustações ou confusões em etapas futuras.

Embora a justificativa de criar uma ferramenta de avaliação, como a criada pelo grupo da intervenção, tenha amparo teórico e empírico, a ferramenta foi apenas testada e pouco divulgada na organização, como lembraram os membros. Sendo assim, somente a utilização massiva da ferramenta permitirá avaliar a sua efetividade no contexto da empresa XYZ.

\subsubsection{Proposição de melhorias e novas ações}

Não foi possível identificar, nas entrevistas, evidências suficientes sobre proposições associadas à estrutura organizacional. Para O'Reilly e Tushman (2008), a resposta para atuar com novas capacidades na organização depende primeiramente da atuação das lideranças, que posteriormente irão derivar para visões estratégicas e readequações organizacionais. Os autores reconhecem que não é uma solução definitiva, pois, em certos momentos, os conflitos são inevitáveis. Bannerjee, Bielli e Hale (2016, p. 15) corroboram com essa visão, ao afirmarem que "barreiras estruturais são notoriamente difíceis de superar, especialmente em empresas bem estabelecidas".

Apesar de não haver uma resposta clara e definitiva, na teoria e na prática é possível encontrar ações mitigatórias à rigidez hierárquica e à verticalização da empresa, parte delas apresentada anteriormente em aspectos de equipe e da alta liderança: segregar o ambiente de inovação do cotidiano (Dombrowski et al., 2007), Time dedicado, Gestão dos interesses dos altos executivos e definição de 'líder'. Esses dois últimos estão em concordância com a proposição de O'Reilly e Tushman (2008) de mitigar as barreiras estruturais por meio das lideranças.

Os entrevistados da intervenção também propuseram novas ações relacionadas aos aspectos processuais. As ações propostas foram a aplicação de melhoria nos processos atuais, a via rápida (fast-track) para avaliar as startups e a criação de experimentações ou pilotos. 


\section{Segregação do ambiente do dia a dia da inovação}

Uma das abordagens encontradas na literatura para mitigar influência das estruturas hierárquicas é apresentada por Dombrowski et al. (2007, p. 194) como "locais seguros". Segundo os autores, esses locais podem ser espaços físicos segregados do cotidiano da organização e que tenham liberdade e acesso a recursos para que seja possível materializar ideias, materializá-las e testá-las. Essa proposta relaciona-se bem com a criação de experimentações e de pilotos, de forma que o grupo interno e as startups envolvidas sintam-se seguros para interagir de forma rápida, até que pilotos ou experimentos estejam prontos para serem apresentados.

A proposição também está em linha com os benchmarks da intervenção. A aceleradora C recomendou que o ambiente para desenvolver iniciativas com startups fosse segregado do cotidiano da empresa. Ao usar uma analogia, um dos representantes da aceleradora deu o exemplo que manter a startup exposta a toda a empresa seria o mesmo que deixar 'um bebê e um monstro na mesma sala'.

\section{Aderência a proposições apresentadas anteriormente}

Outras ações anteriormente sugeridas pelo time da intervenção possuem amparo teórico e empírico para serem aplicadas na mitigação das barreiras estruturais e processuais da empresa XYZ:

- Gerenciamento dos interesses dos executivos: Bannerjee, Bielli e Hale (2016) e Mortara e Minshall (2011) propõem entender as necessidades dos executivos envolvidos a fim de obter o comprometimento e o apoio deles em relação às mudanças organizacionais necessárias para viabilizar a colaboração com startups. Essa proposição é detalhada no subitem 6.4 - Alta Liderança;

- Definição de 'líder': a alocação dos 'líderes' (champions) na visão de Bannerjee, Bielli e Hale (2016), Thieme (2017) e Minshall, Mortara, Napp e 
Probert (2010) simplifica os processos, suaviza problemas de comunicação e reduz os pontos de contato para startups. Para que o 'líder' possa efetuar esse trabalho, ele deve ter poder de decisão, acesso a um orçamento e, principalmente, força política para transitar entre os departamentos da organização (Bannerjee, Bielli, \& Hale, 2016; Mocker, Bielli, \& Haley, 2015). No contexto da empresa $\mathrm{XYZ}$, não foi identificado nenhum líder que pudesse atuar nessa abordagem, com exceção do diretor-patrocinador;

- Time dedicado: Dombrowski et al. (2007) e Minshall, Mortara, Napp e Probert (2010) sugerem que, para enfrentar os problemas de comunicação entre os silos de organização, sejam formadas equipes dedicadas e multidisciplinares com o papel de ter uma visão holística da empresa. Segundo Bannerjee, Bielli e Hale (2016), o time deve estar muito próximo dos altos executivos para que as ações tenham eficácia. No contexto da empresa XYZ, o relacionamento do time com os altos executivos necessitaria ser mais próximo para se adequar a essa recomendação.

\section{Aplicação de melhoria nos processos}

Uma das abordagens de melhoria dos processos atuais proposta pelos entrevistados foi a utilização do método Kaizen, que permite fazer modificações nos processos de forma incremental. No entanto, o Kaizen é adequado quando se busca eficiência, pois a metodologia padroniza os processos (Khan et al., 2013). Essa intenção é contrária à flexibilidade, propósito da empresa XYZ, que busca adaptar os processos internos às startups. Sendo assim, a adoção do Kaizen pode limitar a reformulação dos fluxos para tratar com startups.

No entanto, a intencionalidade do grupo de efetuar mudanças processuais, é legítima. Segundo Ahmed (1998), para habilitar a inovação, é necessário que algumas burocracias internas sejam eliminadas. Rundquist e Österling (2018) corroboram com essa visão, ao afirmarem que a fluidez interna dos processos tende a atrair mais startups. 
De la Tour et al. (2017), Bannerjee, Bielli e Hale (2016) e Mind the Bridge e Nesta (2017) sugerem prioridade de modificações processuais para colaborar com startups nas áreas de compras, jurídica e financeira. A razão por trás dessa prioridade é que essas áreas são as primeiras a exigirem controle dentro da organização, quando se trata de avaliação de soluções externas.

No entanto, no âmbito da empresa XYZ, que é uma organização financeira, o assunto Segurança da Informação também é crítico, conforme relatos dos entrevistados, fazendose necessário também revisitar esses processos.

Ademais, alinhar os interesses com os executivos parceiros e seus times também é essencial para realizar as modificações nos processos. A ausência desse alinhamento pode inviabilizar essas mudanças devido às divergências de interesses, ao medo de perda de poder e à perda de recursos (Kuratko \& Goldsby, 2004; Mortara, Napp, Slacik, \& Minshall, 2009). Esse ponto de atenção retoma as proposições das ações de gerenciar os interesses dos executivos, apresentadas no subitem 6.4 - Alta Liderança.

\section{Fast-track}

Frente a um cenário no qual os gargalos processuais da organização são difíceis de serem removidos, Bannerjee, Bielli e Hale (2016), Mocker, Bielli e Haley (2015) e De la Tour et al. (2017) sugerem criar processos paralelos simplificados, adaptados à realidade das startups. Essa abordagem é chamada 'fast-track' ou 'via rápida' (Bannerjee, Bielli, \& Hale, 2016). Segundo Bannerjee, Bielli e Hale (2016), a criação de um processo paralelo como o fast-track pode ser menos intrusivo do que a modificação dos processos atuais.

Entre os exemplos recorrentes de fast track está a criação tanto de equipe jurídicas dedicadas a avaliar acordos com startups como a de canais preferenciais para aquisição de soluções provenientes de startups (De la Tour, 2017; Bannerjee, Bielli, \& Hale, 2016; Linna, 2017). 
Apesar do fast-track ser uma abordagem atrativa sob o ponto de vista de agilidade, a empresa XYZ, assim como outras empresas, pode encontrar conflitos de interesse. Linna (2017) relata uma tentativa frustrada de criar um processo de fast-track por conflitar com interesses de outros departamentos. Sendo assim, reforça-se a necessidade de gerenciar os interesses dos executivos e das áreas parceiras.

\section{Experimentação (piloto)}

O piloto a curto prazo, na percepção de Minshall, Mortara, Napp e Probert (2010), ajuda a empresa a avaliar a startup e, ao mesmo tempo, permite a remuneração. Bannerjee, Bielli e Hale (2016) e Prats, Siota, Canonici e Contijoch (2017) recomendam o uso de pilotos como forma inicial de cooperar com startups, pois permite testar produtivamente soluções técnicas, identificar oportunidades de melhoria e provar valor às áreas demandantes. Apesar disso, para realizar pilotos com sucesso, é necessário que haja pessoas dedicadas, um orçamento prévio, critérios claros e prazo estabelecido para continuidade ou encerramento das iniciativas (Mocker, Bielli, \& Haley, 2015; Prats, Siota, Canonici, \& Contijoch, 2017).

A abordagem de piloto vai ao encontro da cultura de aversão a riscos da empresa XYZ, uma vez que evita grandes investimentos prematuros em startups sem que primeiramente tenha sido provado o seu valor. No entanto, mesmo para a realização de pilotos, é necessário ter garantias de recursos financeiros e humanos prévios, algo ainda não conquistado pela intervenção.

\subsection{SUGESTÕES PARA FUTURAS AÇÕES}

Considerando-se os resultados obtidos a partir da teoria e da prática, as barreiras identificadas durante a intervenção, a experiência dos integrantes na Pesquisa-Ação e a análise desses elementos ante aos desafios apresentados na empresa XYZ, apresenta-se, a seguir, um conjunto de proposições, representadas visualmente na Figura 29.

Objetivos e Estratégias: Quanto ao aspecto 'objetivos e estratégias', na empresa XYZ, recomenda-se primeiramente a compreensão do conceito desses dois elementos em si, 
além do alinhamento com áreas parceiras de negócios e respectivos executivos, o que pode levar à última ação, garantindo recursos para executá-las:

- Definição de objetivos corporativos para startups: sugere-se estabelecer objetivos e estratégias corporativas (Morris \& Kuratko, 2002; Bannerjee, Bielli, \& Haley, 2016). No entanto, tem-se consciência da complexidade dessa atividade em uma grande organização, como é o caso da empresa XYZ (Battistini, Hacklin, \& Baschera, 2013; Thieme, 2017), o que leva à recomendação seguinte;

- Ações de aproximação com áreas de negócios e executivos: sugere-se executar ações voltadas às áreas parceiras da diretoria-patrocinadora, que poderiam ser geridas por meio do estabelecimento de uma governança, conforme mencionado anteriormente no Aspecto Alta Liderança;

- Garantia de acesso aos recursos financeiros: subsequentemente, recomenda-se estabelecer um orçamento próprio e com fácil acesso da equipe, para execução de ações que promovam a aproximação com startups (Martins \& Terblanche, 2003; Shah, Zegveld, \& Roodhart, 2008).

Alta liderança: É a força motriz para iniciar a própria intervenção, desenvolver o aspecto da alta liderança na empresa XYZ e fortalecer o relacionamento com startups. Envolve mitigar o distanciamento dos líderes das ações e buscar o comprometimento das lideranças-pares, bem como o de seus liderados. Para contrapor essa situação, na empresa XYZ propõem-se ações voltadas ao aculturamento dos líderes, à transmissão da proposta de valor que as startups podem trazer, à gestão dos interesses dos executivos envolvidos e à clara proposição de metas. Soma-se a essas ações, a continuidade do patrocínio de algum executivo:

- Patrocínio de algum alto executivo: as análises demonstraram a importância de ter um alto líder para a execução das ações, tanto na concepção, quanto no direcionamento, o que é corroborado, inclusive, por referências teóricas e práticas (Shah, Zegveld, \& Roodhart, 2008; Kuratko, Hornsby, \& Covin, 2014). Essa medida deve ser continuada e pode ser aperfeiçoada com maior frequência de comunicação (Mortara, Napp, Slacik, \& Minshall, 2009). O estabelecimento de governança e de um 'líder', comprovado na literatura, pode contribuir para um 
melhor relacionamento de ações, envolvendo inovação e empreendedorismo corporativo (Prats, Amigó, Ametller, \& Batlle, 2017; Dombrowski et al., 2007; Howell \& Boies, 2004);

- Metas compartilhadas com camadas: recomenda-se a adoção de metas e incentivos associados às iniciativas de aproximação com startups, o que tende não só a engajar os executivos habituados aos mecanismos de recompensas financeiras, como também a estender naturalmente o engajamento aos seus times (Kuratko, Hornsby, \& Covin, 2014; Schättgen \& Mur, 2016). No entanto, essas metas só podem ser estabelecidas a partir de uma visão clara de benefícios, o que remete à recomendação seguinte;

- Apresentação de propostas de valor: a equipe da intervenção pode utilizar casos de estudos aplicados, pilotos e experimentos adequados à realidade da empresa

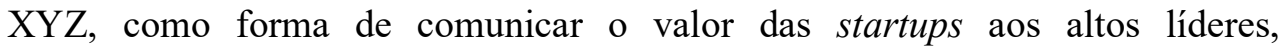
principalmente, aos pares do executivo-patrocinador (Bannerjee, Bielli, \& Haley, 2016; Bonzom \& Netessine, 2016; Prats, Amigó, Ametller, \& Batlle, 2017);

- Gestão dos interesses dos executivos: também se sugere formalizar comunicações frequentes, por meio de uma governança ou, simplesmente, por reuniões recorrentes com executivos envolvidos na intervenção para garantir que suas expectativas estejam alinhadas às ações, além de permitir decisões críticas de forma rápida (Mortara, Napp, Slacik, \& Minshall, 2009; Prats, Amigó, Ametller, \& Batlle, 2017). Neste caso, basta adotar o modus operandi que a empresa XYZ já possui, visando a engajá-los;

- Executivos como 'padrinhos' de iniciativas ou de startups: sugere-se convidar pares do executivo-patrocinador para serem 'padrinhos' de ações internas de aculturamento ou mesmo de startups, sobretudo daquelas que podem trazer exposição positiva, como forma de engajá-los (Simon, Houghton, \& Gurney, 1999; Linna, 2017).

Cultura: desenvolver o aspecto cultural para melhor relacionamento com startups requer que a empresa XYZ fomente a cultura empreendedora e a cultura de inovação, além de aproximar os colaboradores do ambiente das startups, a ponto de conhecerem e/ou experienciarem seus desafios e funcionamento. Nesse sentido, recomenda-se as seguintes ações: 
- Imersão Cultural: introdução de programas de imersão, seja pela atuação temporária de colaboradores da corporação dentro das startups, seja pelo estabelecimento de times compactos e autônomos com o objetivo de entregar iniciativas empreendedoras/inovadoras (Bannerjee, Bielli, \& Haley, 2016; De la Tour et al., 2017);

- Sistemas de Informação para propagação de comunicações e engajamento ('Rede Social'): continuidade da 'rede social' ou de outro sistema de informação para propagar as iniciativas e assuntos voltados ao relacionamento com startups (Martins \& Terblanche, 2003; Dombrowski et al., 2007);

- Eventos de Aculturamento: continuidade dos eventos de aculturamento, aperfeiçoados para envolver outros departamentos além do de Tecnologia, a fim de proporcionar melhor integração dos colaboradores com o ecossistema das startups (Bannerjee, Bielli, \& Haley, 2016), principalmente com aqueles envolvidos em processos que as impactem. Ademais, recomenda-se a diversificação de eventos, adotando-se também hackathons e desafios internos, com o objetivo de diminuir a passividade dos eventos e de aumentar a participação e integração entre colaboradores e startups (Bannerjee, Bielli, \& Haley, 2016; Bonzom \& Netessine, 2016);

- Introdução de Recompensas à Inovação: adotar recompensas associadas à inovação, não só para o grupo de intervenção, mas para todos os colaboradores. É recomendado como forma de estimulá-lo a contribuir com novas ideias. Esses incentivos devem estar associados ao acionamento tanto de motivações intrínsecas - reconhecimentos pessoais -, quanto das extrínsecas - reconhecimentos financeiros (Ahmed, 1998; Amabile, 1998; Martins \& Terblanche, 2003).

Equipe: $\mathrm{O}$ fortalecimento do aspecto equipe, associado à intervenção na empresa XYZ, remete a combater a insuficiência do necessário para ações, a volatilidade de membros e a falta de engajamento de alguns participantes. Portanto, recomenda-se que a empresa $\mathrm{XYZ}$ mantenha um time voltado às startups, mesmo que pequeno, mas estável e com tempo adequado para se dedicar ao desenvolvimento das atividades a elas associadas, com autonomia para decisões e com representatividade perante os executivos, por meio de um 'líder' (champion). Outras medidas prévias recomendadas para serem executadas 
no decorrer das ações, voltadas à capacitação do grupo sobre o ecossistema de startups, são:

- Time dedicado, autônomo e lean: recomenda-se à empresa XYZ o estabelecimento de uma equipe compacta (entre 7 e 10 integrantes), com autonomia para decisão, ao menos as táticas e as operacionais, e que seja dedicada à execução das ações, ou com tempo minimamente adequado para elas (Mortara, Napp, Slacik, \& Minshall, 2009; Weiss \& Hoegl, 2016; Schättgen \& Mur, 2016; De la Tour et al., 2017);

- Metas e incentivos proporcionais e pessoais: conforme lições aprendidas com o próprio grupo da intervenção, corroboradas por insumos teóricos e práticos, o time da intervenção deve ter metas proporcionais aos desafios, bem como incentivos financeiros e pessoais que estimulem transpassar o risco de execução das ações (Dombrowski et al., 2007; Bannerjee et al., 2016; Thieme, 2017);

- Definição de 'líder' (champion): devido à complexidade organizacional da empresa XYZ, faz-se necessário designar um 'líder' (champion) com representatividade perante os executivos, a fim de estabelecer uma comunicação mais frequente sobre as ações (Howell \& Boies, 2004). Ademais, conceder poder de decisão estratégico e orçamentário seria ideal para executar pilotos (Bannerjee, Bielli, \& Haley, 2016), mitigando a dependência dos processos complexos da empresa;

- Aprendizagem na intervenção: recomenda-se a continuidade do uso de elementos que permitam ao grupo consolidar seu conhecimento antes e durante a intervenção (Mortara, Napp, Slacik, \& Minshall, 2009). O uso de workshops, seminários e benchmarks com organizações externas foram exemplos positivos de meios de aprendizagem que surgiram de forma empírica no grupo.

Estrutura organizacional: Tratar em definitivo as barreiras associadas ao aspecto 'Estrutura Organizacional' com rigidez organizacional e com estruturas hierárquicas, na empresa XYZ, assim como em outras instituições. Destaca-se que isso não configura um desafio de intervenção, mas um desafio institucional, inerente às empresas que desejem equilibrar seu cotidiano com iniciativas inovadoras (O'Reilly \& Tushman, 2008). 
No entanto, O'Reilly e Tushman (2008) e Bannerjee, Bielli e Haley (2016) sinalizam que as altas lideranças e a comunicação fluída entre os membros têm papel fundamental na mitigação de barreiras associadas à estrutura organizacional. Portanto, recomenda-se que a empresa XYZ implemente as ações citadas que podem impactar de forma indireta nesse aspecto: definição de um 'líder' e equipe dedicada (Aspecto de Equipe), gestão dos interesses dos altos executivos (Aspecto de Alta Liderança).

Adicionalmente, partindo do ponto de vista de Dombrowski et al. (2007), recomenda-se segregar o ambiente de inovação do cotidiano, ou seja, promover a execução de projetos envolvendo startups em local segregado do cotidiano da empresa, de forma temporária, com a participação de um 'líder' de intervenção e de times multidisciplinares internos (Bannerjee, Bielli, \& Haley, 2016; Dombrowski et al., 2007).

Processos internos: $\mathrm{O}$ desenvolvimento do aspecto referente aos processos internos na empresa XYZ envolve simplificar, segregar e adotar abordagens de experimentação das startups, de modo a minimizar os longos processos internos de decisão na organização, bem como sua rigidez:

- Comunicação simples dos processos (cartilha): com resultados considerados positivos, segundo os membros, recomenda-se a evolução e divulgação dessa ferramenta;

- Ferramental para avaliação de startups e necessidades: recomenda-se o uso e aprimoramento da 'ferramenta de avaliação de startups', que requer testes para verificar sua efetividade;

- Revisão (simplificação ou fast-track) de processos críticos: recomenda-se à empresa XYZ revisar os processos críticos de compras, jurídico e tecnológicos, além dos de segurança da informação, buscando simplificá-los ou criar processos paralelos. No entanto, deve ser feito um alinhamento com essas áreas, a fim de mitigar fracassos nessas ações (Linna, 2017);

- Adoção de Experimentação/Piloto: uso de experimentação/pilotos de startups, o que se encaixa com a maturidade da organização que vem dando seus passos iniciais quanto à maior tolerância a riscos. 
Foi possível perceber o quanto esses aspectos estão inter-relacionados na empresa XYZ e que o fortalecimento de um aspecto pode afetar os demais (Mortara, Napp, Slacik, \& Minshall, 2009). Ressalta-se, principalmente, os eixos 'Alta-Administração' e 'Objetivos e Estratégia', que podem garantir direcionamentos, comprometimentos, recursos humanos e financeiros (Shah, Zegveld, \& Roodhart, 2008). Soma-se a este eixo a equipe e um "líder" para manterem um relacionamento próximo e penetrarem nos silos departamentais, além de ajudarem na desobstrução de processos internos (Howell \& Boies, 2004).

Figura 29 - Framework de Aspectos Internos, Barreiras e Proposições para a empresa XYZ

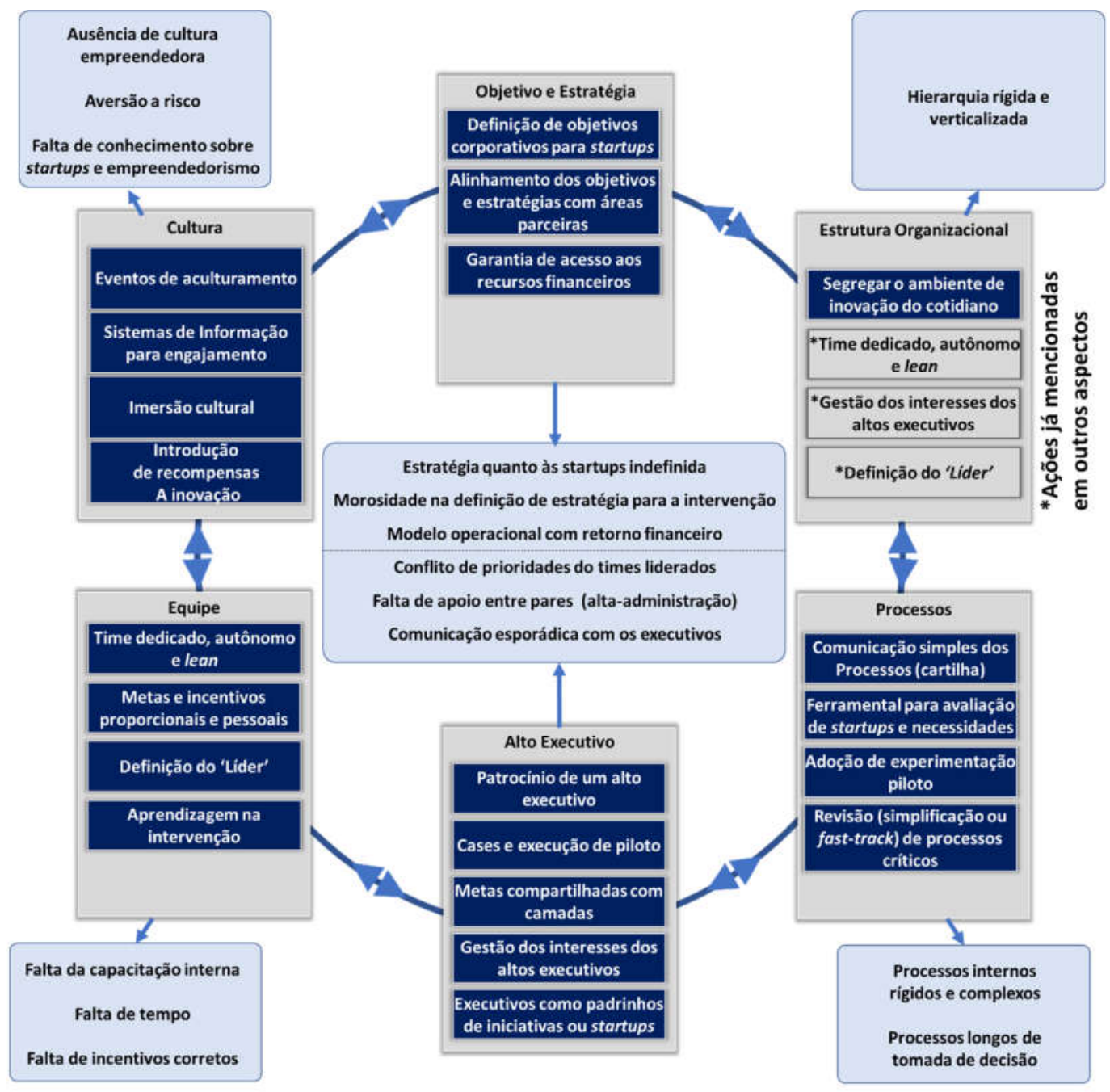

Fonte: Elaborada pelo autor. 


\section{CONSIDERAÇÕES FINAIS, RECOMENDAÇÕES E LIMITAÇÕES DO ESTUDO}

O relacionamento entre grandes empresas e startups tem crescido no Brasil e gerado oportunidades para os envolvidos nesse ecossistema de empreendedorismo (Salles, 2018).

As instituições financeiras veem nas startups possibilidades para ganharem vantagens em um mercado que vem se modificando rapidamente, vide os exemplos das fintechs. No entanto, ao mesmo tempo em que essa relação gera oportunidades para as grandes empresas, também promove certos desafios.

Um relacionamento do tipo parceria com startups, como o que a empresa XYZ em questão busca melhorar com a Pesquisa-Ação, é assimétrico, começando pela velocidade de mudanças (Weilen \& Chesbrough, 2015; Minshall, Mortara, Napp, \& Probert, 2010). Tanto as empresas quanto as startups precisam se adaptar para que haja sucesso. Porém, modificar internamente uma grande empresa é um desafio complexo, que envolve uma variedade de aspectos e elementos (Martins \& Terblanche, 2003), e que foi experienciado neste processo de intervenção, como detalhado nas análises realizadas.

Conforme apresentado no Capítulo 3, a Pesquisa-Ação dentro da empresa XYZ enfrentou esse desafio. Embora os membros não tivessem inicialmente a clareza nem do seu tamanho e nem de seu escopo, foi possível verificar que o escopo da intervenção saiu de uma ideia, baseada em grandes problemas, para gerar ações internas como é o caso de estabelecer parcerias com startups no provisionamento de soluções. Boas práticas internas e adversidades surgiram, incluindo acertos e erros na elaboração e execução das ações. E, por fim, foi possível propor um conjunto de 8 (oito) ações direcionadas ao aculturamento, ao ferramental e à comunicação de processos, ações que foram moldadas de acordo com a maturidade e as limitações da organização.

Paralelamente, de forma acadêmica, realizou-se uma investigação exploratória sobre a intervenção, a 'Pesquisa-Ação Dissertação', buscando responder ao seguinte problema de 
pesquisa inicialmente definido: 'Como as ações internas podem melhorar o relacionamento da empresa XYZ com as startups?'

Tal indagação foi ponto de partida da investigação realizada, que buscou o seguinte objetivo acadêmico-profissional: 'Viabilizar o melhor relacionamento entre uma grande empresa e startups'.

O cumprimento desse objetivo, conforme demonstrado na Figura 2 - Matriz de Amarração -, deu-se por meio de objetivos específicos atrelados aos capítulos, a saber:

(1) Identificar barreiras internas que impeçam a realização das ações de aproximação com startups. O Capítulo 5 apresenta a análise, a partir da experiência dos membros e observações do pesquisador. No decorrer das análises, foi possível destacar barreiras associadas à cultura de aversão aos riscos, limitações de tempo, capacitação da equipe, problemas com lideranças e pares, aproximação com o líder, problemas em tangibilizar objetivos e estratégia, além de falta de compreensão dos processos. Em contrapartida, ações de aculturamento, como eventos e a 'rede social', tiveram percepção de impacto positivo, bem como as ações voltadas às comunicações dos processos e à avaliação. Destaca-se, ainda, o ganho de experiência do time que, ao longo de todo o processo, conseguiu se manter estável. Em relação às ações futuras, houve menções distribuídas, mas as aproximações com os líderes, as metas compartilhadas, a continuidade de aculturamento, o time dedicado e as modificações nos processos foram identificados como principais proposições dos membros;

(2) Compreender boas práticas e oportunidades de melhoria identificadas a partir da experiência do grupo de intervenção. No Capítulo 6, as barreiras, os habilitadores e as melhores práticas foram aproximadas dos referenciais, percebendo-se a aderência entre eles, exceto pela proposição de aplicação do Kaizen para processos de transformação. O pesquisador supõe que essa aderência possa ter se originado na capacitação do grupo, que leu inúmeras publicações e conversou com diversas entidades que atuam diretamente com startups para conseguir entender suas melhores práticas; 
(3) Analisar recomendações extraídas da teoria e da prática à luz da intervenção na organização. No Capítulo 6, diante das barreiras internas de Alta Liderança e Estrutura Organizacional, foi possível encontrar proposições não mapeadas pelo grupo, a saber: apadrinhamento de startups; gerenciamento dos interesses dos executivos; estabelecimento de governança para iniciativas envolvendo startups; e segregação entre ambiente do dia a dia e o da inovação. Além disso, também foi possível identificar na literatura, que ações como ter um patrocinador e um 'líder' podem também ajudar a mitigar outras barreiras como a hierarquia rígida;

(4) Propor um conjunto de ações voltadas aos aspectos internos que possam aproximar a empresa XYZ das startups. No Capítulo 6 - subitem 6.6 sintetizou-se um conjunto de 21 (vinte e uma) recomendações à empresa XYZ para os próximos ciclos da intervenção, no sentido de aproximá-la das startups.

Uma consideração abrangente sobre a intervenção foi que as ações viabilizadas pelo time - cultural, ferramental, e comunicação de processos - foram coerentes com o grau de maturidade da empresa e do grupo em relação às startups, haja vista as iniciativas anteriores não terem ultrapassado a barreira do planejamento. Outras ações envolvendo mudanças estruturais, como a eliminação de silos departamentais, dependeriam de uma coalizão entre as lideranças, algo que não ocorreu. Talvez a inviabilidade para executar esse tipo de iniciativa seja uma das razões pela qual não foram encontradas proposições do grupo quanto ao aspecto de estrutura organizacional.

Os desafios, associados à implementação de ações que aproximassem a empresa de startups, demostraram ser muitos. Entretanto, alguns aspectos destacaram-se para que as ações pudessem acontecer, dentre estes, a equipe, que, com seu amadurecimento, capacitação e motivação, permitiu que atividades como os eventos de aculturamento e as ferramentas de avaliação pudessem ser realizadas. No entanto, se fosse disponibilizado maior tempo de dedicação ao time, poderiam ter sido viabilizadas maiores quantidades de ações ou ações mais complexas durante a intervenção. 
Isso não quer dizer que todas as ações pudessem ter sido realizadas, uma vez que outras áreas departamentais precisariam estar envolvidas quando se trata de mudanças de processos. Em uma grande organização, como é o caso da empresa XYZ, ações ou projetos envolvendo parcerias com startups não poderiam ser realizados por uma área isoladamente. Tal situação leva a concluir que outras medidas seriam necessárias, como o alinhamento estratégico com outras áreas e o estabelecimento de incentivo e metas compartilhadas.

Nota-se, por fim, outros dois aspectos que foram e serão relevantes para viabilizar ações na empresa XYZ: a Alta Liderança e 'Objetivos e Estratégias'. Personificada na figura do diretor-patrocinador, a Alta Liderança mostrou-se essencial para viabilizar as iniciativas. Não se pode pensar que a Pesquisa-Ação aconteceria sem esse apoio, pois ele viabiliza a própria intervenção, a equipe e os incentivos sendo o fio condutor para a atuação.

Quando se observa a empresa XYZ, pode-se concluir que há forte interdependência entre os aspectos internos estudados, o que pode e poderá continuar afetando as ações tanto positiva quanto negativamente.

Não se pode deixar de mencionar o aspecto da Cultura e suas ações. Uma mudança cultural exige muito mais do que a realização de eventos ou a construção de um portal para conscientizar os colaboradores e deixá-los mais próximos do ambiente das startups. Eliminar preconceitos é um passo importante para que haja um relacionamento mais colaborativo e menos assimétrico. Ademais, as medidas recomendadas podem fortalecer esse aspecto, advertindo que sempre haverá interpendências.

Por fim, por mais que haja oportunidades nas ações realizadas e recomendações, visando à melhoria do relacionamento da empresa XYZ com startups, o pesquisador entende que o próprio fato de gerar ações nesse sentido já sinaliza um avanço para a organização, que vem percorrendo um caminho de construção de relacionamento com startups, no contexto da intervenção focada em parcerias. 
Deste modo, recomenda-se para eventuais trabalhos futuros que, para o aprofundamento das relações entre os aspectos internos organizacionais e os modos como esses afetam a aproximação com startups, utilize-se uma base maior de organizações. O presente estudo não se aprofundou nessa relação, por ter sido exploratório e focado em apenas uma unidade de pesquisa - a empresa XYZ.

Outro tema que se recomenda para eventual estudo futuro é a investigação dos efeitos das ações de aculturamento interno, referentes ao relacionamento de grandes corporações com startups, mas com um recorte temporal mais longo, isto é, por um período de tempo mais prolongado. O presente estudo não possibilitou a verificação do quanto essas ações seriam sustentáveis.

Os aspectos identificados, as barreiras e as ações propostas nesta pesquisa foram de natureza exploratória, mas podem ser utilizadas e/ou adaptadas como base para estudos em outras organizações que busquem se relacionar com startups. Todo o processo, entre a intervenção e a dissertação, foi desenvolvido ao longo de 30 meses, tornando-se um ativo, com experiências que podem vir a ser úteis para que empresas acelerem os diagnósticos de problemas e proponham ações, antecipando riscos de eventuais barreiras.

Cabe lembrar que os desafios de uma grande empresa, na busca por colaborar com startups, podem variar de acordo com o setor de atuação e com a maturidade da própria organização. No entanto, uma visão mais abrangente remete à árdua batalha entre manter o cotidiano de suas operações e buscar novas capacidades.

Do ponto de vista das startups, de forma exploratória, este estudo traz subsídios para o entendimento dos desafios internos de seus potenciais parceiros. Ter uma melhor compreensão das limitações das grandes empresas pode ajudar na previsibilidade de problemas ao estabelecer parcerias, bem como ao elaborar planos de ações, por exemplo, melhores acordos comerciais.

Este estudo pretendeu, assim, contribuir com a Academia, dando um passo adiante na exploração do tema 'Parcerias Assimétricas'. Nesse caso, entre uma grande empresa e startups, trazendo à luz os desafios internos de grandes empresas para construírem esse tipo de relacionamento. 
Indiretamente, este estudo também acabou contribuindo com a associação entre os termos Corporate Venturing, Inovação Aberta e Corporate-Startup Engagement. Quanto ao termo Corporate-Startup Engagement, por exemplo, em pesquisa aberta no Google Scholar, realizada em 10 de julho de 2019, momento de finalização desta dissertação, levantou-se apenas 35 (trinta e cinco) registros, e esse termo já vem sendo utilizado no meio profissional (100 Open Startups, 2017).

Destaca-se, por fim, que a presente dissertação além de ter tido como objetivo contribuir acadêmica e profissionalmente, também teve como premissa o respeito para com os indivíduos e as instituições envolvidas na pesquisa, prezando pela veracidade dos fatos e pela fidelidade das informações obtidas, conforme detalhado no capítulo sobre os procedimentos metodológicos, seguindo as orientações de Coghlan e Brannick (2005). Cabe reforçar que, como mencionado anteriormente, o processo foi autorizado pela empresa XYZ, seguindo seu protocolo interno, e pelos entrevistados, que assinaram o 'Termo de Consentimento Livre e Esclarecido'.

Por ter se tratado de uma pesquisa exploratória, não se pôde extrapolar os seus resultados e proposições para todas as situações que envolvessem o relacionamento de grandes empresas com startups. Mesmo no caso da empresa XYZ, há outras unidades que atuam com iniciativas de inovação, além da área pesquisada, portanto, os desafios aqui apresentados não correspondem a todo o seu universo, que, ademais, também vem evoluindo desde o início da pesquisa.

Segundo Coghlan e Brannick (2005), a Pesquisa-Ação é um empreendimento político em qualquer organização. Os resultados, ao final da jornada, não poderiam ter sido anteriormente previstos e, portanto, as reflexões e análises podem trazer consequências aos membros do grupo ou mesmo à organização, dependendo das mudanças e da situação da organização. Nesse intuito, optou-se por apresentar, de forma anônima, os indivíduos e as organizações envolvidas, a fim de se ater à pesquisa e não aos seus atores individualmente. 
Cabe destacar ainda que outra característica da Pesquisa-Ação é contar com o pesquisador no papel de membro participante, o que exige a mitigação de viés. Os planos de ação adotados visaram a clarificar as funções do pesquisador durante os ciclos, a utilizar as entrevistas como dado principal das análises e complementarmente a cotejar as observações do pesquisador, segregando os comentários e as autorreflexões dos relatos apresentados. Os entrevistados também estavam diretamente envolvidos na intervenção, portanto, outros atores externos poderiam ter percepções diferentes das ações realizadas.

Outra limitação refere-se ao fato de que não há como garantir que as sugestões de melhorias sejam implementadas pela organização nos próximos ciclos de intervenção e nem será possível ficar ciente se foram ou não bem-sucedidas. Para tanto, seria necessário um estudo longitudinal, investigando o efeito das ações ao longo do tempo.

As ações propostas nesta dissertação não são, portanto, nem absolutas e nem definitivas. Segundo a própria literatura base para essa pesquisa, há diferentes formas de se desenvolver um mesmo aspecto ou tema, por exemplo, o cultural (Dombrowski et al., 2007). Por fim, o pesquisador não se propôs no presente trabalho nem a teorizar e nem a justificar os artefatos da 'Pesquisa-Ação Central', pois o escopo de estudo da Dissertação estava associado aos desafios e impactos da intervenção em si, conforme descrito nos objetivos, e não na teorização de cada prática em particular utilizada pela intervenção.

É nítida a evolução da empresa XYZ desde dezembro de 2017, quando a pesquisa foi iniciada, até julho de 2019, quando a dissertação estava prestes a ser concluída. Essa organização sofreu alterações em sua estrutura hierárquica, tornando-se mais horizontalizada, abrandando problemas de comunicação e alçadas. Atualmente, há outras pessoas dedicadas a liderar os desafios internos da organização com startups, o que também aumentou exponencialmente o número de experimentos e pilotos com startups. Novos desafios de Inovação Aberta foram lançados no mercado, para que startups pudessem inovar com as empresas.

Por fim, cabe destacar que a Empresa XYZ tem transpassado os desafios internos inerentes a qualquer grande empresa que busque por novas capacidades e tem se mantido na vanguarda da inovação, atuando com startups, ao passo que é constantemente desafiada em um ambiente no qual o número de competidores cresce cada vez mais. 
Mesmo assim, a organização vem mantendo sua posição e tem sido procurada com frequência por outras grandes empresas por ser referência na forma como se relaciona com startups. 


\section{REFERÊNCIAS}

100 Open Startups. (2017). Como grandes empresas e startups se relacionam. 100 Open Startups. Recuperado em 15 de Julho de 2018, de https://www.openstartups.net/brpt/ebooks/

Abstartups. (2019). Estatísticas. Recuperado em 20 de Junho de 2019, de Startupbase: https://startupbase.com.br/stats

Accenture. (2015). Harnessing the Power of Entrepreneurs to Open Innovation. Accenture. Recuperado em 10 de Agosto de 2018, de https://www.accenture.com/t20151005T162506_w__usen/_acnmedia/Accenture/next-gen/B20/Accenture-G20-YEA-2015-Open-InnovationExecutive-Summary.pdf

Ahmed, P. K. (1998). Culture and climate for innovation. European Journal of Innovation Management, 1(1), pp. 30-43.

Ahn, J. M., Minshall, T., \& Mortara, L. (2015). Open Innovation: A New Classification and Its Impact on Firm Performance in Innovative SMEs. Journal of Innovation Management, 3(2), pp. 33-54.

Amabile, T. M. (1998). How to kill creativity. Harvard Business Review, 75(5), pp. 77-87.

Ander-Egg, E. (1990). Repensando la Investigación-Acción Participativa. Ciudad de Mexico: El Ateneo.

Angehrn, A. A., Luccini, A. M., \& Maxwell, K. (2009). InnoTube: A video-based connection tool supporting collaborative innovation. Interactive Learning Environments, 17(3), pp. 205-220.

Anprotec \& Sebrae. (2018). Corporate Venturing no Brasil: um guia para corporações e entidades de apoio co-inovando em rede. Recuperado em 15 de Julho de 2019, de http://anprotec.org.br/site/wp-content/uploads/2019/06/Corporate-VenturingAnprotec-e-Sebrae.pdf

Baldissera, A. (Agosto de 2001). Pesquisa-Ação: Uma Metodologia do "Conhecer" e do "Agir" Coletivo. Sociedade em Debate, 7(2), pp. 5-25.

Bannerjee, S., Bielli, S., \& Haley, C. (2016). Scaling Together: overcoming barriers in corporate-startup collaboration. Londres: NESTA.

Barabel, M., Meier, O., \& Soparnot, R. (2014). Asymmetric alliances between SMEs and large firms in the area of innovation: strategic determinants and cultural effects. Gestion 2000, 31, pp. 87-106.

Battistini, B., Hacklin, F., \& Baschera, P. (2013). The State of Corporate Venturing: Insights from a Global Study. Research-Technology Management, 56(1), pp. 31-39. 
BBStartups. (2019). BB Startups - Conecte sua Startup com o Banco do Brasil. Recuperado em 02 de Junho de 2019, de https://startup.labbs.com.br/

Birkinshaw, J., van Basten-Batenburg, R., \& Murray, G. C. (2002). Venturing to Succeed. Business Strategy Review, 13, pp. 10-17.

Blank, S. (2010). What's A Startup? First Principles. Recuperado em 01 de Novembro de 2016, de https://steveblank.com/2010/01/25/whats-a-startup-first-principles/

Blank, S., \& Dorf, B. (2014). Startup: Manual do Empreendedor (1 ${ }^{\mathrm{a}}$ ed.). Rio de Janeiro: Alta Books.

Block, Z., \& MacMillan, I. C. (1993). Corporate venturing: Creating new businesses within the firm. Boston: Harvard Business School Press.

Bonzom, A., \& Netessine, S. (2016). \#500corporations: How do the world's biggest companies deal with the startup revolution? 500 Startups \& INSEAD.

Bryman, A. (1989). Research methods and organization studies. Londres: Unwin Hyman.

Burgelman, R. A. (1983). A Process Model of Internal Corporate Venturing in the Diversified Major Firm. Administrative Science Quarterly, 28(2), pp. 223-244.

Campbell, A., Birkinshaw, J., Morrison, A., \& Batenburg, V. B. (2003). The future of corporate venturing. MIT Sloan Management Review, 45, pp. 30-37.

Chesbrough, H. (2002). Making Sense of Corporate Venture Capital. Harvard Business Review, pp. 90-100.

Chesbrough, H. W. (2003). Open Innovation: The New Imperative for Creating and Profiting from Technology. Boston: Harvard Business Press.

Chesbrough, H. W. (2011). Bringing open innovation to services. MIT Sloan Management Review, 52(2), pp. 85-90.

Chesbrough, H. W., \& Brunswicker, S. (2013). Managing Open Innovation in Large Firms. Stuttgart: Mediendienstleistungen des Fraunhofer-Informationszentrum.

Chesbrough, H., \& Tucci, C. (2004). Corporate Venture Capital in the Context of Corporate Innovation. Academy of Management Journal, 22(4), pp. 303-321.

Clarke, A. H., Evald, M. R., \& Munksgaard, K. B. (2012). Combining open innovation with corporate venturing: a case of how to balance incremental and radical innovation. Int. J. Entrepreneurship and Innovation Management, 15(4), pp. 253-274.

Coghlan, D., \& Brannick, T. (2005). Doing Action Research in your Own Organization (2a ed.). Wiltshire: SAGE.

Coughlan, P., \& Coghlan, D. (2002). Action research for operations management. International Journal of Operations \& Production Management, 22(2), pp, 220-240. 
Covin, J. G., \& Miles, M. P. (1999). Corporate Entrepreneurship and the Pursuit of Competitive Advantage. Entrepreneurship Theory and Practice, 23(3), pp. 47-63.

Covin, J. G., \& Miles, M. P. (2007). Strategic Use of Corporate Venturing. Entrepreneurship Theory and Practice, 31(2), pp. 183-207.

Creswell, J. W. (2007). Projeto de Pesquisa. Porto Alegre: Bookman.

Cubo. (2019). Sobre o Cubo. Recuperado em 09 de Julho de 2019, de https://cubo.network/

CVM. (07 de Junho de 2016). Portaria CVM/PTE/N 105. Institui o Núcleo de Inovação em Tecnologias. Rio de Janeiro, RJ, São Paulo: Ministério da Fazenda.

Das, P., Verburg, R., Verbraeck, A., \& Bonebakker, L. (2018). Barriers to innovation within large financial services firms. European Journal of Innovation Management, 21(1), pp. 96-112.

Dauderstädt, P. (2013). Success Factors in Strategic Corporate Venturing. Tese de Doutorado. Technischen Universität Berlin.

De la Tour, A., Soussan, P., Harlé, N., Chevalier, R., \& Duportet, X. (2017). From Tech to Deep Tech: Fostering collaboration between corporates and startups. BCG.

Delloite. (2015). Banking Industry Outlook: Banking reimagined. Recuperado em 1 de Novembro de 2016, de https:/www2.deloitte.com/us/en/pages/financialservices/articles/banking-industry-outlook.html

Dewar, R., \& Dutton, J. (1986). The Adoption of Radical and Incremental Innovations: An Empirical Analysis. Management Science, 32(11), pp. 1422-1433.

Dombrowski, C., Kim, J. Y., Desouza, K. C., Braganza, A., Papagari, S., Baloh, P., \& Jha, S. (2007). Elements of Innovative Cultures. Knowledge and Process Management, 15(3), pp. 190-202.

Enkel, E., Gassmann, O., \& Chesbrough, H. (2009). Open R\&D and open innovation: exploring the phenomenon. R\&D Management, 39(4), pp. 311-316.

Fasnacht, D. (2009). Open Innovation in the Financial Services: Growing Through Openness, Flexibility, and Customer Integration. Berlim: Springer-Verlag Berlin Heidelberg.

Febraban. (2018). Pesquisa FEBRABAN de Tecnologia Bancária. Delloite. Recuperado em 20 Julho de 2019, de https://cmsportal.febraban.org.br/Arquivos/documentos/PDF/febraban_2018_Final.pdf

Fintechlab. (2019). Report Fintechlab. Recuperado em 1 de Julho de 2019, de https://fintechlab.com.br/index.php/2019/06/12/8a-edicao-do-radar-fintechlabregistra-mais-de-600-iniciativas/

Freeman, J., \& Engel, J. S. (2007). Models of Innovation: Startups and Mature Corporations. California Management Review, 50(1), pp. 94-119. 
Gassmann, O., \& Enkel, E. (2004). Towards a Theory of Open Innovation: Three Core Process Archetypes. R\&D Management Conference (RADMA), pp. 1-18.

Gatignon, H., Tushman, M., Smith, W., \& Anderson, P. (2002). A Structural Approach to Assessing Innovation: Construct Development of Innovation Locus, Type, and Characteristics. Management Science, 48(9), pp. 1103-1122.

Gil, A. C. (1991). Como elaborar projetos de pesquisa. São Paulo: Atlas.

Gobble, M. (2018). The Varieties of Corporate Venturing. Research-Technology Management, 61(2), pp. 58-63.

Groote, J., \& Backmann, J. (2019). Initiating Open Innovation Collaborations Between Incumbents and Startups: How Can David and Goliath Get Along? International Journal of Innovation Management, pp. 1-33.

Gummesson, E. (2000). Qualitative Methods in Management Research (2 ed.). Thousand Oaks: Sage.

Guth, W. D., \& Ginsberg, A. (1990). Guest editors' introduction: Corporate entrepreneurship. Strategic Management Journal, 11, pp. 5-15.

Gutmann, T. (2019). Harmonizing corporate venturing modes: an integrative review and research agenda. Management Review Quarterly, 69(2), pp. 121-157.

He, Z. L., \& Wong, P. K. (2004). Exploration vs. exploitation: An empirical test of the ambidexterity hypothesis. Organization Science, 15(4), pp. 481-494.

Hill, C. W., \& Rothaermel, F. T. (2003). The Performance of Incumbent Firms in the Face of Radical Technological Innovation. The Academy of Management Review, 28(2), pp. 257-274.

Hill, S. A., \& Birkinshaw, J. (2014). Ambidexterity and Survival in Corporate Venture Units. Journal of Management, 40(7), pp. 1899-1931.

Hill, S. A., \& Birkinshaw, J. (2008). Strategy-structure configurations in corporate venture units: impact on performance and survival. Journal of Business Venturing, 23, pp. 423-444.

Howell, J. M., \& Boies, K. (2004). Champions of technological innovation: The influence of contextual knowledge, role orientation, idea generation, and idea promotion on champion emergence. The Leadership Quarterly, 15, pp. 123-143.

Howell, J. M., \& Higgins, C. A. (1990). Champions of technological innovation. Administrative Science Quarterly, 35, pp. 317-341.

Huizingh, E. K. (2011). Open innovation: State of the art and future perspectives. Technovation, 31(1), pp. 2-9.

Inovabra. (2019). Institucional. Recuperado em 20 de Julho de 2019, de https://www.inovabra.com.br/index.html 
Kanbach, D. K., \& Stubner, S. (2016). Corporate Accelerators As Recent Form Of Startup Engagement: The What, The Why, And The How. The Journal of Applied Business Research, 32(6), pp. 1761-1776.

Keil, T. (2002). External Corporate Venturing: Strategic Renewalin Rapidly Changing Industries. Westport: Quorum.

Kelly, S., Ferenzy, D., \& McGrath, A. (2017). How Financial Institutions and Fintechs Are Partnering for Inclusion: Lessons from the Frontlines. Institute of International Finance e Accion.

Kohler, T. (2016). Corporate accelerators: Building bridges between corporations and startups. Business Horizons, 59, pp. 347-357, Available.

Kolb, D. (1984). Experiential learning: experience as the source of learning and development. Englewood Cliffs: Prentice-Hall.

KPMG. (2015). New Horizons 2015: On the road to corporate startup collaboration. Amstelveen: KPMG Advisory N.V.

Kuratko, D. F. (2007). Entrepreneurial Leadership in the $21^{\text {st }}$ Century. Journal of Leadership and Organizational Studies, 13(4), pp. 1-11.

Kuratko, D. F., \& Goldsby, M. G. (2004). Corporate entrepreneurs or rogue middle managers? A framework for ethical corporate entrepreneurship. Journal of Business Ethic, 55(13), pp. 3-30.

Kuratko, D. F., Hornsby, J. S., \& Covin, J. G. (2014). Diagnosing a firm's internal environment for corporate entrepreneurship. Business Horizons, 57(1), pp. 37-47.

Laukkanen, H. P., Sainio, L.-M., \& Jauhiainen, T. (2008). Appropriability Regime for Radical and Incremental Innovations. R\&D Management, 38(3), pp. 278-289.

Leal-Rodríguez, A. L., Albort-Morant, G., \& Martelo-Landroguez, S. (28 de Novembro de 2016). Links between entrepreneurial culture, innovation, and performance: The moderating role of family firms. International Entrepreneurship and Management Journal, 13(3), pp. 819-835.

Lee, S. M., \& Peterson, S. (2000). Culture, entrepreneurial orientation, and global competitiveness. Journal of World Business, 35(4), pp. 401-416.

Leifer, R., O'Connor, G. C., \& Rice, M. (2001). Implementing radical innovation in mature firms: The role of hubs. Academy of Management Perspectives, 15(3), pp. 102-123.

Lewin, K. (1946). Action research and minority problems. Journal of Social Issues, pp. 34-36.

Lichtenthaler, U. (2008). Open innovation in practice: An analysis of strategic approaches to technology transactions. IEEE Transactions on Engineering Management, 55(1), pp. $148-157$. 
Linna, E. (2017). Corporate Startup Growth Program. Dissertação de Mestrado. Aalto University.

Long, D. W., \& Fahey, L. (2000). Diagnosing Cultural Barriers to Knowledge Management. The Academy of Management Executive, 14(4), pp. 113-127.

MacMillan, I. C., Block, Z., \& Narasimha, P. N. (1986). Corporate venturing: alternatives, obstacles encountered, and experience effects. Journal of Business Venturing, 1(2), pp. 177-191.

Makri, M., Lane, P. J., \& Gomez-Mejia, L. R. (2006). CEO incentives, innovation, and performance in technology-intensive firms: a reconciliation of outcome and behaviorbased incentive schemes. Strategic Management Journal. 27(11), pp. 1057-1080.

Markham, S. K., Gentry, S. T., Hume, D., Ramachandran, R., \& Kingon, A. I. (2005). Strategies and Tactics for External Corporate Venturing. Research-Technology Management, 48(2), pp. 49-59.

Martins, E. C., \& Terblanche, F. (2003). Building organizational culture that stimulates creativity and innovation. European Journal of Innovation Management, 6(1), pp. 6474.

Mayer, K. J., \& Teece, D. (2008). Unpacking strategic alliances: The structure and purpose of alliance versus supplier relationships. Journal of Economic Behavior \& Organization, 66(1), pp. 106-127.

Mazzon, J.A. (2018). Using the methodological association matrix in marketing studies. Brazilian Journal of Marketing - BJMkt, 17(5), Special Issue, pp. 747-770.

Mcniff, J., Lomax, P., \& Whitehead, J. (1996). You and your action research project. London: Routledge.

Meio\&Mensagem. (2018). A nova linguagem dos bancos. Recuperado em 15 de Junho de 2019, de https://www.meioemensagem.com.br/home/marketing/2018/02/08/coworkingsaceleradoras-e-hubs-a-nova-linguagem-dos-bancos.html

Mello, C., Turrioni, J. B., Xavier, A. F., \& Campos, D. F. (2012). Pesquisa-ação na engenharia de produção: proposta de estruturação para sua condução. Produção, 22(1), pp. 1-13. DOI: $10.1590 / \mathrm{S} 0103-65132011005000056$

Miles, M. P., \& Covin, J. G. (2002). Exploring the Practice of Corporate Venturing: Some Common Forms and Their Organizational Implications. Entrepreneurship Theory and Practice, 26(3), pp. 21-40.

Mind the Bridge \& Nesta. (2017). Open Innovation in Europe - A Snapshot of the SEP Europe's Corporate Startup Stars 2017. Londres: Mind the Bridge \& Nesta. Recuperado em 20 de Fevereiro de 2019, de https://startupeuropepartnership.eu/reports/

Minshall, T., Mortara, L., Napp, J., \& Probert, D. (2010). Improving the management of 'asymmetric' partnerships. Research-Technology Management, 53(3), pp. 53-63. 
Minshall, T., Mortara, L., Valli, R., \& Probert, D. (2010). Making “Asymmetric” Partnerships Work. 53(3), pp. 53-63.

Mocker, V., Bielli, S., \& Haley, C. (2015). Winning together: A guide to successful corporatestartup collaboration. Londres: Nesta. Recuperado em 10 de Abril de 2019, de https://media.nesta.org.uk/documents/winning__together-june-2015.pdf

Morris, M. H., Kuratko, D. F., \& Covin, J. G. (2010). Corporate Entrepreneurship \& Innovation. Mason: Cengage Learning.

Morris, M., \& Kuratko, D. (2002). Corporate entrepreneurship. Mason: South-Western College Publishers.

Mortara, L., \& Minshall, T. (2011). How do large multinational companies implement open innovation. Technovation, 31(10-11), pp. 586-597.

Mortara, L., Napp, J., Slacik, I., \& Minshall, T. (2009). How to Implement Open Innovation: lessons from studying large multinational companies. Cambridge: Cambridge Editorial Partnership Ltd.

Mortara, L., Slacik, I., Napp, J. J., \& Minshall, T. (Março de 2010). Implementing open innovation: Cultural issues. International Journal of Entrepreneurship and Innovation Management, 11, pp. 369-397.

Moschner, S.-L., A. Fink, A., Kurpjuweit, S., Wagner, S., \& Herstatt, C. (2019). Toward a better understanding of corporate accelerator models. Business Horizons, pp. 1-11.

Nagano, M. S., Stefanovitz, J. P., \& Guimaraes, T. (2015). Assessing some important factors to reduce obstacles in product innovation. International Journal of Innovation Management, 20(3).

Narayanan, V., Yang, Y., \& Zahra, S. (2009). Corporate venturing and value creation: A review and proposed framework. Research Policy, 38(1), pp. 58-76.

Neumann, M., Hintzen, D., Riel, A., Waldhausen, G., \& Dismon, H. (2019). Startup Engagement as Part of the Technology Strategy Planning - How Rheinmetall Automotive Increases Innovation by Using Corporate Venturing. EuroAsiaSPI. Edinburgh.

Niven, P., \& Lamorte, B. (2016). Objectives and Key Results: Driving Focus, Alignment. New Jersey: Wiley.

OCDE. (2005). Manual de Oslo - Diretrizes para a coleta e interpretação de dados sobre inovação. FINEP.

O'Reilly, C. A., \& Tushman, M. L. (2008). Organizational Ambidexterity in Action: How Managers Explore and Exploit. California Management Review, 53(4), pp. 5-22.

Osterloh, M., \& Frey, B. S. (2000). Motivation, Knowledge Transfer, and Organizational Forms. Organization Science, 11(5), pp. 538-550. 
Parhankangas, A., \& Arenius, P. (2003). From a corporate venture to an independent company: a base for a taxonomy for corporate spin-off firms. Research Policy, 32(3), pp. 463 481.

Pedroso, M. C. (2010). Um modelo de gestão estratégica para serviços de saúde. São Paulo: USP.

Pekar, P., \& Margulis, M. (2003). Equity Alliances Take Centre Stage. Business Strategy Review, 14, pp. 50-62.

Perry, C., \& Zuber-Skerritt, O. (1992). Action research in graduate management research programs. Higher Education, p. 208.

Phan, P. H., Wright, M., Ucbasaran, D., \& Tan, W.-L. (2009). Corporate entrepreneurship: Current research and future directions. Journal of Business Venturing, 24(3), pp. 197205.

Prats, M. J., Amigó, P., Ametller, X., \& Batlle, A. (2017). Corporate Venturing: Achieving Profitable Growth Through Startups. IESE Business School.

Prats, M. J., Siota, J., Canonici, T., \& Contijoch, X. (2018). Open Innovation: Building, Scaling and Consolidating Your Firm's Corporate Venturing Unit. IESE Business School. Recuperado em 13 de Janeiro de 2019, de https://media.iese.edu/research/pdfs/ST0478-E.pdf.

Puschmann, T. (2017). Fintech. Business \& Information Systems Engineering, 59, pp. 69-76.

Rehder, P., \& Levi, D. (2011). Innovation Excellence: What Banks Can Learn from Top Innovators in Other Industries. Estados Unidos: Accenture. Recuperado em 13 de Março de 2019, de https://www.accenture.com/t20150527T210356_w__auen/_acnmedia/Accenture/Conversion-Assets/DotCom/Documents/Local/en$\mathrm{gb} / \overline{\mathrm{PDF}} /$ Accenture-APAC-BNK-BrightIdeas.pdf

Reimsbach, D., \& Hauschild, B. (2012). Corporate venturing: An extended typology. Journal of Management Control, 23, pp. 71-80.

Reuer, J., Olk, P., \& Arino, A. (2011). Entrepreneurial Alliances. Boston: Pearson.

Ries, E. (2012). A Startup Enxuta. São Paulo: Leya.

Rumelt, R. P. (1995). Inertia and transformation. Em C. A. Montgomery, Resource-Based and Evolutionary Theories of the Firm: Towards a Synthesis (pp. 101-132). Boston: Springer.

Rundquist, E., \& Österling, A. (2018). Critical Success Factors in the Offering of a CorporateStartup Program. Dissertação de Mestrado. Lund University.

Saalasti, S. (2016). Startup Activities of Established Finnish Companies. Dissertação de Mestrado. University of Tampere. 
Salles, D. G. (2018). Grandes corporações e startups: relações de inovação aberta no mercado brasileiro. São Paulo: USP.

Santander. (2019). Radar Santander. Recuperado em 10 de Junho de 2019, de https://www.santander.com.br/hotsite/radar/

Schättgen, N., \& Mur, S. (2013). The age of collaboration. Arthur D. Little.

Schildt, H. A., Maula, M. V., \& Keil, T. (2005). Explorative and Exploitative Learning from External Corporate Ventures. Entrepreneurship Theory and Practice, 29(4), pp. 493515.

Schueffel, P., \& Vadana, I. (2015). Open Innovation in the Financial Services Sector - A global literature review. Journal of Innovation Management, 3(1), pp. 25-48.

Schumpeter, J. A. (1982). Teoria do desenvolvimento econômico. São Paulo: Abril Cultural.

Schwab, K., \& Sala-I-Martin, X. (2016). The Global Competitiveness Report 2016-2017. Genova: World Economic Forum.

Sebrae. (2015). Pesquisa Lado/A, Lado/B Startups. São Paulo: SEBRAE.

Shah, C. M., Zegveld, M. A., \& Roodhart, L. (2008). Designing Ventures That Work. ResearchTechnology Management, 51(2), pp. 17-25.

Sharma, P., \& Chrisman, J. (1999). Toward a Reconciliation of the Definitional Issues in the Field of Corporate Entrepreneurship. Entrepreneurship Theory and Practice, 23(3), pp. 11-28.

Simon, M., Houghton, S. M., \& Gurney, J. (1999). Succeeding at internal corporate venturing: roles needed to balance autonomy and control. Journal of Applied Management Studies, 8(2), pp. 145-159.

Spender, J.-C., Corvello, V., Grimaldi, M., \& Rippa, P. (2017). Startups and open innovation: a review of the literature. European Journal of Innovation Management, 20(1), pp. 430 .

Stringer, R. (2000). How to manage radical innovation. California Management Review, 42(4), pp. $70-88$.

Thieme, K. (2017). The strategic use of Corporate-Startup Engagement. Dissertação de Mestrado. Delft University of Technology.

Thiollent, M. (1997). Pesquisa-Ação nas Organizaçães. São Paulo: Atlas.

Thiollent, M. (2005). Metodologia da Pesquisa-ação (14ª ed.). São Paulo: Cortez.

Thompson, F., \& Perry, C. (2004). Generalising results of an action research project in one work place to other situations: principles and practice. European Journal of Marketing, 38(3/4), pp. 401-417.

Tidd, J., \& Bessant, J. (2015). Gestão da Inovação (5ª ed.). Porto Alegre: Bookman. 
Tidd, J., \& Taurins, S. (1999). Learn or Leverage? Strategic Diversification and Organizational Learning Through Corporate Ventures. Creativity and Innovation Management, 8 , pp. 122-129.

Tietz, R., \& Kugler, P. (2018). Matching Score for Co-operations between Mature Firms and Start-ups. ISPIM Innovation Symposium, pp. 1-6. Manchester.

Traitler, H., Watzke, H. J., \& Saguy, I. S. (2011). Reinventing R\&D in an Open Innovation Ecosystem. Journal of Food Science, 76(2), R62-R68.

Tushman, M. L., \& O'Reilly, C. A. (1996). Ambidextrous Organizations: Managing Evolutionary and Revolutionary Change. California Management Review, 38(4), pp. 8-29.

Usman, M., \& Vanhaverbeke, W. (2017). How start-ups successfully organize and manage open innovation with large companies. European Journal of Innovation Management, 20(1), pp. 171-186.

Van De Vandre, V., Jong, J., Vanhaverbeke, W., \& Rochemont, M. (Junho-Julho de 2009). Open innovation in SMEs: Trends, motives and management challenges. Technovation, 29(6-7), pp. 423-437.

Vanhaverbeke, W., Van de Vrande, V., \& Chesbrough, H. (2008). Understanding Advantages of Open Innovation in Terms of Real Options. Creativity and Innovation Management, 17(4), pp. 251-258.

Von Hippel, E. (1977). The sources of innovation. New York: Oxford University Press.

WEF. (2018). Collaboration between Start-ups and Corporates A Practical Guide for Mutual Understanding. Genebra: World Economic Forum 2018.

Weiblen, T., \& Chesbrough, H. (2015). Engaging with startups to enhance corporate innovation. California Management Review, 57(2), pp. 66-99.

Weiss, M., \& Hoeg, M. (2016). Effects of relative team size on teams with innovative tasks: An understaffing theory perspective. Organizational Psychology Review, 6(4), pp. 324 351.

West, J., \& Bogers, M. (2014). Leveraging External Sources of Innovation: A Review of Research on Open Innovation. Journal of Product Innovation Management, 31(4), pp. 814-831.

Williams, C., \& Lee, S. (2009). Exploring the internal and external venturing of large R\&Dintensive firm. R\&D Management, 39(3), pp. 231-246.

Zahra, S. A. (1995). Corporate entrepreneurship and financial performance: The case of management leveraged buyouts. Journal of Business Venturing, 10(3), pp. 225-247.

Zaremba, B. W., Bode, C., \& Wagner, S. M. (2017). New Venture Partnering Capability: An Empirical Investigation into How Buying Firms Effectively Leverage the Potential of Innovative New Ventures. Journal of Supply Chain Management, 53(1), pp. 41-64. 


\section{APÊNDICES}

\section{APÊNDICE 1 - ROTEIRO DE PERGUNTAS}

\begin{tabular}{|c|c|c|}
\hline Código & Roteiro de Entrevista & $\begin{array}{l}\text { Categoria da } \\
\text { Pergunta }\end{array}$ \\
\hline 1 & Perfil dos Respondentes & \\
\hline 1.1 & Em qual área você atua na [empresa XYZ]? & Perfil \\
\hline 1.2 & Qual o cargo que ocupa na organização? & Perfil \\
\hline 1.3 & Há quantos anos você trabalha na [empresa XYZ]? & Perfil \\
\hline 1.4 & Qual a sua formação de ensino superior? & Perfil \\
\hline 1.5 & Fez mais algum curso após a graduação? Qual(is)? & Perfil \\
\hline 2 & Contexto, Propósito e Percepções iniciais & \\
\hline 2.1 & $\begin{array}{l}\text { Você já havia atuado em algum projeto envolvendo startups dentro da } \\
\text { [empresa XYZ]? E fora da [empresa XYZ]? }\end{array}$ & Perfil \\
\hline 2.2 & $\begin{array}{l}\text { Você tinha algum conhecimento sobre a relação de startups com grandes } \\
\text { empresas antes desta intervenção? }\end{array}$ & Cultura \\
\hline 2.4 & $\begin{array}{l}\text { Como você descreveria o nível de empreendedorismo do time envolvido na } \\
\text { intervenção? }\end{array}$ & Cultura \\
\hline 2.5 & $\begin{array}{l}\text { Qual a sua percepção sobre o nível da cultura empreendedora do público-alvo } \\
\text { (colaboradores de TI) das ações? }\end{array}$ & Cultura \\
\hline 2.6 & $\begin{array}{l}\text { Como você descreveria a capacidade e entendimento do time que conduziu a } \\
\text { iniciativa sobre o relacionamento da [empresa XYZ] com startups? }\end{array}$ & Equipe \\
\hline 2.7 & As suas metas profissionais estão associadas às ações da iniciativa? & Equipe \\
\hline 2.8 & Como chegou ao projeto? O que levou você a escolher atuar na iniciativa? & Equipe \\
\hline 2.9 & Quais as expectativas que seu executivo superior tinha quanto à iniciativa? & $\begin{array}{l}\text { Objetivo e } \\
\text { Estratégia }\end{array}$ \\
\hline 2.10 & $\begin{array}{l}\text { Como você definiria a estratégia adotada pela [empresa XYZ] para atuar com } \\
\text { startups? }\end{array}$ & $\begin{array}{l}\text { Objetivo e } \\
\text { Estratégia }\end{array}$ \\
\hline 3 & Fases de Diagnósticos & \\
\hline 3.1 & $\begin{array}{l}\text { Como você avalia o nível de assertividade sobre as principais barreiras } \\
\text { identificadas nos workshops? (somente Grupo 1) }\end{array}$ & Geral \\
\hline 3.2 & $\begin{array}{l}\text { Como você avalia as atividades subsequentes aos workshops? Como elas } \\
\text { fluíram? Intervenção (somente Grupo 1) }\end{array}$ & Geral \\
\hline 3.3 & $\begin{array}{l}\text { Quais fatores você elencaria como críticos para mitigar/eliminar as barreiras } \\
\text { identificadas na intervenção? }\end{array}$ & Geral \\
\hline 3.4 & $\begin{array}{l}\text { Qual a sua percepção em relação à contribuição dos artigos sobre } \\
\text { relacionamento de startups com grandes empresas para a iniciativa? (somente } \\
\text { Grupo 2) }\end{array}$ & Geral \\
\hline 3.5 & $\begin{array}{l}\text { Qual o seu entendimento sobre a contribuição dos benchmarks com grandes } \\
\text { empresas e startups para as atividades da iniciativa? }\end{array}$ & Geral \\
\hline 3.6 & $\begin{array}{l}\text { Quais eram as suas expectativas relacionadas com as ações para mitigar } \\
\text { pontos identificados? }\end{array}$ & Geral \\
\hline 3.7 & O que você melhoraria quanto às ações de diagnóstico? & Geral \\
\hline
\end{tabular}




\begin{tabular}{|c|c|c|}
\hline 3.8 & $\begin{array}{l}\text { Que informações você recebeu das ações subsequentes para mitigar as } \\
\text { barreiras identificadas? (somente Grupo 1) }\end{array}$ & Geral \\
\hline 4 & Fases de Planejamento & \\
\hline 4.1 & $\begin{array}{l}\text { Como você descreveria os processos de decisão dos executivos para priorizar } \\
\text { as ações da intervenção? E para executar essas ações? }\end{array}$ & Alta Liderança \\
\hline 4.2 & $\begin{array}{l}\text { Como você descreveria os processos de decisão do time para priorizar as } \\
\text { ações da intervenção? E para executar essas ações? }\end{array}$ & Equipe \\
\hline 5 & Fases de Ações & \\
\hline 5.1 & $\begin{array}{l}\text { Como foi a influência dos processos internos da [empresa XYZ] sobre as } \\
\text { atividades da iniciativa? Quais aspectos positivos você destacaria? E quais } \\
\text { aspectos negativos? }\end{array}$ & $\begin{array}{c}\text { Estrutura } \\
\text { Organizacional e } \\
\text { Processos Internos }\end{array}$ \\
\hline 5.2 & $\begin{array}{l}\text { Como você percebeu o apoio e influência dos executivos de TI (Diretor, } \\
\text { Superintendentes) sobre as ações realizadas na iniciativa? }\end{array}$ & $\begin{array}{c}\text { Objetivo e } \\
\text { Estratégia / Cultura }\end{array}$ \\
\hline 5.3 & $\begin{array}{l}\text { Como você diria que foi a qualidade de comunicação entre os membros do } \\
\text { grupo? (Caso seja negativa: O que poderia ser feito para melhoria da } \\
\text { comunicação?) }\end{array}$ & Equipe \\
\hline 5.4 & $\begin{array}{l}\text { Como você percebeu a comunicação e divulgação das atividades da } \\
\text { intervenção para o público-alvo (colaboradores da área de TI)? }\end{array}$ & $\begin{array}{c}\text { Estrutura } \\
\text { Organizacional e } \\
\text { Processos Internos/ } \\
\text { Cultura } \\
\end{array}$ \\
\hline 5.5 & $\begin{array}{l}\text { Como você acredita que as ações da intervenção afetem } \\
\begin{array}{l}\text { (positiva/negativamente) } \\
\text { organização? }\end{array}\end{array}$ & Cultura \\
\hline 5.6 & $\begin{array}{l}\text { Você poderia descrever a sua percepção sobre os resultados das ações } \\
\text { realizadas? }\end{array}$ & Geral \\
\hline 5.7 & Quais os principais obstáculos identificados para realizar as ações propostas? & Geral \\
\hline 5.8 & $\begin{array}{l}\text { Quais os principais fatores que permitiram que as ações fossem realizadas? } \\
\text { Na sua opinião, há algo que poderia ser feito de forma diferente? }\end{array}$ & Geral \\
\hline 5.9 & $\begin{array}{l}\text { Como você entende que foi o nível de motivação dos envolvidos [direta e } \\
\text { indiretamente] no decorrer das ações executadas? }\end{array}$ & $\begin{array}{l}\text { Equipe / Objetivo } \\
\text { e Estratégia }\end{array}$ \\
\hline 5.10 & $\begin{array}{l}\text { Quais ações realizadas você acredita que impactaram o clima para inovação } \\
\text { na organização? (EXPLORAR: mudança de mindset de colaboradores, visão } \\
\text { das lideranças, incentivos dos colaboradores) }\end{array}$ & Cultura \\
\hline 5.11 & $\begin{array}{l}\text { Qual sua percepção sobre a aceitação de iniciativas envolvendo startups por } \\
\text { parte do público-alvo (colaboradores de TI)? }\end{array}$ & Cultura \\
\hline 5.12 & $\begin{array}{l}\text { Como alguém que atuou diretamente nas ações, como você, definiria o } \\
\text { engajamento do público-alvo (colaboradores da área de TI)? }\end{array}$ & Cultura \\
\hline 6 & Avaliação de oportunidade de melhorias & \\
\hline 6.1 & $\begin{array}{l}\text { Como você avalia o seu entendimento sobre startups antes e após as ações da } \\
\text { iniciativa? }\end{array}$ & Equipe / Cultura \\
\hline 6.2 & $\begin{array}{l}\text { Você crê que as ações realizadas esclarecem ou ajudam na definição da } \\
\text { estratégia da [empresa XYZ] quanto a startups? }\end{array}$ & $\begin{array}{l}\text { Objetivo e } \\
\text { Estratégia }\end{array}$ \\
\hline 6.3 & $\begin{array}{l}\text { Na sua visão, que ações poderiam ser feitas nos processos envolvendo as } \\
\text { startups? }\end{array}$ & $\begin{array}{c}\text { Estrutura } \\
\text { Organizacional e } \\
\text { Processos Internos }\end{array}$ \\
\hline 6.4 & $\begin{array}{l}\text { Quais ações você proporia para desenvolver o aculturamento dentro da } \\
\text { organização? }\end{array}$ & Cultura \\
\hline 6.5 & $\begin{array}{l}\text { Que ações poderiam ser propostas para tornar os colaboradores mais } \\
\text { preparados para atuar em iniciativas envolvendo startups? }\end{array}$ & Equipe \\
\hline 6.6 & $\begin{array}{l}\text { Além dessas, quais ações você proporia ou priorizaria nas próximas } \\
\text { interações? }\end{array}$ & Geral \\
\hline
\end{tabular}




\begin{tabular}{|l|l|c|}
\hline 6.7 & $\begin{array}{l}\text { Que tipo de modificações você crê que precisem ser efetuadas para melhorar } \\
\text { a eficiência das ações executadas? }\end{array}$ & Geral \\
\hline 6.8 & $\begin{array}{l}\text { Que recomendaços sobre preparo das atividades você proporia para o time } \\
\text { nas futuras interações? E tem alguma recomendação para condução dessas } \\
\text { atividades? }\end{array}$ & Equipe \\
\hline 6.9 & $\begin{array}{l}\text { Quais melhorias você crê que poderiam ser implementadas para melhorar o } \\
\text { engajamento na atuação da [empresa XYZ] com startups? }\end{array}$ & Cultura \\
\hline 6.10 & $\begin{array}{l}\text { Para encerrar, estando você numa posição de efetuar qualquer mudança no } \\
\text { programa, que sugestões ou recomendações você daria para dar continuidade } \\
\text { a ele? }\end{array}$ & Geral \\
\hline
\end{tabular}




\section{APÊNDICE 2 - MODELO DO TERMO DE CONSENTIMENTO LIVRE E ESCLARECIDO}

\section{TERMO DE CONSENTIMENTO LIVRE E ESCLARECIDO}

\section{DADOS DE IDENTIFICAÇÃO DO SUJEITO DA PESQUISA}

1.NOME:

DOCUMENTO DE IDENTIDADE No.:

SEXO: M F

DATA DE NASCIMENTO:

ENDEREÇO:

BAIRRO:

CIDADE

CEP:

TELEFONE: DDD (

...)...

\section{DADOS SOBRE A PESQUISA}

1. TÍTULO DO PROTOCOLO DE PESQUISA: Relacionamentos entre uma Grande Empresa e Startups: Barreiras Internas e Proposição de Ações a partir de uma Pesquisa-Ação

PESQUISADOR: Tiago Lemos de Oliveira CARGO/FUNÇÃO: Mestrando da Faculdade de Economia, Administração e Contabilidade da Universidade de São Paulo UNIDADE DA FEAUSP: Departamento de Administração - Programa de Mestrado Profissional em Empreendedorismo

\section{AVALIAÇÃO DO RISCO DA PESQUISA:}

\begin{tabular}{|c|c|l|l|}
\hline & RISCO MÍNIMO & & RISCO MÉDIO \\
\hline $\mathrm{X}$ & RISCO BAIXO & & RISCO MAIOR \\
\hline
\end{tabular}

3. DURAÇÃO DA PESQUISA: 12 meses 
1 - Essas informações estão sendo fornecidas para sua participação voluntária neste estudo, que visa a identificar barreiras internas associadas ao relacionamento da [empresa XYZ] com startups, bem como a proposição de recomendações de ações;

2 - O procedimento a ser realizado consiste em uma entrevista presencial com roteiro baseado em um questionário estruturado;

3 - A entrevista adota um roteiro estruturado de perguntas a serem efetuadas. Estas se referem às etapas de intervenção realizadas, bem como à associação com aspectos internos organizacionais. A entrevista será gravada com o objetivo de coletar os dados de forma fiel e permitir análises mais detalhadas posteriormente;

4 - Não há risco ou desconforto associado aos procedimentos descritos nos itens 2 e 3;

5 - Não há benefício direto para o participante. Trata-se de estudo de natureza exploratória que analisa as experiências que o entrevistado teve ao executar uma intervenção numa grande empresa que está buscando a melhoria do relacionamento com startups. Somente no final do estudo poderemos concluir a presença de algum benefício;

6 - Garantia de acesso: em qualquer etapa do estudo, você terá acesso aos profissionais responsáveis pela pesquisa para esclarecimento de eventuais dúvidas. O principal investigador é Tiago Lemos de Oliveira, que pode ser contatado através do [Endereço] - tel.: [telefone] - E-mail: tiagolemos@usp.br. Se você tiver alguma consideração ou dúvida sobre a ética desta pesquisa, entre em contato com o Comitê de Ética em Pesquisa (CEP) - Endereço: Av. Professor Lineu Prestes, 580 - Bloco 13-A - Superior - São Paulo SP - CEP 05508-000 - Telefone: (11) 2648-0959;

8 - É garantida a liberdade da retirada de consentimento a qualquer momento e a não participação no estudo, sem qualquer prejuízo à continuidade de seu tratamento na Instituição;

9 - Há o direito de confidencialidade. No trabalho a ser publicado, não constarão os nomes das pessoas entrevistadas ou citadas, nem a identificação das organizações envolvidas na pesquisa;

10 - Há o direito de ser mantido atualizado sobre os resultados parciais das pesquisas ou sobre os resultados que de conhecimento do pesquisador;

11 - Despesas e compensações: não há despesas pessoais para o participante em qualquer fase do estudo. Também não há compensação financeira relacionada à sua participação. Se existir qualquer despesa adicional, ela será absorvida pelo orçamento da pesquisa;

12 - Em caso de dano pessoal, diretamente causado pelos procedimentos ou tratamentos propostos neste estudo (nexo causal comprovado), o participante tem direito às indenizações legalmente estabelecidas;

13 - Há o compromisso do pesquisador em utilizar os dados e o material coletado somente para esta pesquisa.

Acredito ter sido suficientemente informado a respeito das informações que li ou que foram lidas para mim, descrevendo o estudo "Relacionamentos entre uma Grande Empresa e Startups: Barreiras Internas e Proposição de Ações a partir de uma Pesquisa-Ação".

Eu discuti com o pesquisador Tiago Lemos de Oliveira sobre a minha decisão em participar nesse estudo. Ficaram claros para mim quais são os propósitos do mesmo, os procedimentos a serem realizados, seus desconfortos e riscos, as garantias de confidencialidade e de esclarecimentos permanentes. Ficou claro também que minha participação é isenta de despesas. Concordo voluntariamente em participar deste estudo e poderei retirar o meu consentimento a qualquer momento, antes ou durante a execução do mesmo, sem penalidades ou prejuízo ou perda de qualquer benefício que eu possa ter adquirido.

Assinatura do Participante

Data: / /

Declaro que obtive de forma apropriada e voluntária o

Consentimento Livre e Esclarecido deste participante para a participação neste

Assinatura do responsável pelo estudo

Data: / /


APÊNDICE 3 - AMOSTRA DO DIÁRIO DE BORDO

\begin{tabular}{|c|c|c|c|c|c|c|c|}
\hline Data & Assunto & Conteúdo & $\begin{array}{l}\text { Pessoa } \\
\text { Origem }\end{array}$ & $\begin{array}{l}\text { Tipo de } \\
\text { Coleta }\end{array}$ & Ciclo & Percepções & $\begin{array}{l}\text { Documento de } \\
\text { Referência }\end{array}$ \\
\hline 03/02/2017 & Cartilha & $\begin{array}{l}\text { Foi contextualizado a todos os participantes } \\
\text { a necessidade de estabelecimento de uma } \\
\text { frente de atuação quanto ao a } \\
\text { desenvolvimento de uma "Cartilha" com } \\
\text { orientações sobre o macroprocesso a ser } \\
\text { percorrido numa eventual necessidade de } \\
\text { contratação de alguma startup. Atualmente, } \\
\text { o processo de contratação de startups é } \\
\text { desconhecido pela maioria das pessoas, além } \\
\text { de moroso e burocrático. } \\
\text { Foi pontuada a necessidade de envolver } \\
\text { todas as áreas afetadas com o objetivo de } \\
\text { garantir que, ao definirmos o Macroprocesso } \\
\text { de contratação, os processos em menor nível } \\
\text { estejam preparados para atender às } \\
\text { necessidades desse tipo de contratação. Caso } \\
\text { contrário, a cartilha não funcionará. } \\
\text { Para darmos início ao trabalho de } \\
\text { levantamento do processo AS IS, } \\
\text { precisamos preliminarmente do } \\
\text { envolvimento das seguintes pessoas: } \\
\text { [Pessoas] }\end{array}$ & Tiago & Observação & Ciclo 1 & $\begin{array}{l}\text { Uma das ideias abordadas era mapear todo o } \\
\text { processo atual de atuação com startups. } \\
\text { As reuniões ocorridas não foram boas. Cada } \\
\text { pessoa tinha uma visão de processo. As discussões } \\
\text { eram longas e não fechavam uma atuação. } \\
\text { Chegou-se a tal ponto que o grupo resolveu que } \\
\text { aquele mapeamento não geraria valor suficiente } \\
\text { para justificar o esforço. O time 'perdeu-se' no AS } \\
\text { IS e não conseguia descer num nível detalhado } \\
\text { para fazer as entregas comprometidas com todos. }\end{array}$ & cartilha_v2.pdf \\
\hline$\ldots$ & $\ldots$ & $\ldots$ & $\ldots$ & $\ldots$ & $\ldots$ & & $\cdots$ \\
\hline
\end{tabular}




\begin{tabular}{|c|c|c|c|c|c|c|c|}
\hline Data & Assunto & Conteúdo & $\begin{array}{l}\text { Pessoa } \\
\text { Origem }\end{array}$ & $\begin{array}{l}\text { Tipo de } \\
\text { Coleta }\end{array}$ & Ciclo & Percepções & $\begin{array}{l}\text { Documento de } \\
\text { Referência }\end{array}$ \\
\hline $07 / 03 / 2017$ & $\begin{array}{l}\text { Modelo } \\
\text { evolutivo para } \\
\text { avaliação de } \\
\text { startups }\end{array}$ & $\begin{array}{l}\text { Segue material que mostrei rapidamente. } \\
\text { O que pudemos propor a fazer foi criar um } \\
\text { processo claro dos caminhos por onde uma } \\
\text { necessidade de negócio pode passar. Essa } \\
\text { proposta segue numa linha de que } \\
\text { deveríamos ter orçamento inicial aprovado } \\
\text { para fazer testes com startups. }\end{array}$ & Tiago & Conversa & Ciclo 1 & $\begin{array}{l}\text { A ideia de vender um fluxo totalmente modificado } \\
\text { foi interessante, porém as mudanças nos processos } \\
\text { eram grandes. 'Vocês vão mover todos os } \\
\text { processos para executar iniciativas com uma } \\
\text { startup?' Perguntou um executivo, quando } \\
\text { apresentamos o plano. }\end{array}$ & $\begin{array}{l}\text { 20170223_apresen } \\
\text { tação_fluxo.pptx }\end{array}$ \\
\hline$\ldots$ & $\ldots$. & & $\ldots$ & $\ldots$ & $\ldots$ & $\ldots$ & $\cdots$ \\
\hline $27 / 04 / 2017$ & Benchmarks & $\begin{array}{l}\text {... A partir da próxima quinta, começaremos } \\
\text { nossas visitas, com o intuito de compreender } \\
\text { melhor o ambiente de relacionamento entre } \\
\text { startups e grandes empresas. Para tornar } \\
\text { nosso trabalho produtivo, acredito que } \\
\text { tenhamos que nos dividir em } 2 \text { ou } 3 \text { grupos. }\end{array}$ & [CA2] & E-mail & Ciclo 2 & $\begin{array}{l}\text { Nosso grupo tinha um planejamento bem } \\
\text { estabelecido de visitas às organizações externas, o } \\
\text { que ajudou muito na execução das atividades. Na } \\
\text { quinta, visitamos a [empresa X]. O modelo de } \\
\text { negócios que ela utiliza é muito interessante. } \\
\text { Pudemos aproveitar parte dele na proposta das } \\
\text { ações. }\end{array}$ & \\
\hline$\ldots$ & $\ldots$ & $\ldots$ & $\ldots$ & $\ldots$ & $\ldots$ & $\ldots$ & $\ldots$ \\
\hline $14 / 07 / 2017$ & $\begin{array}{l}\text { Apresentação } \\
\text { ao Executivo }\end{array}$ & $\begin{array}{l}\text {... Vamos revisar nossas prioridades dando } \\
\text { foco [na intervenção] no pilar de cultura, } \\
\text { conforme direcionamento do [diretor] ... }\end{array}$ & Tiago & Reunião & Ciclo 2 & $\begin{array}{l}\text { A reunião foi a balizadora para começar o Ciclo } 3 \text {. } \\
\text { Dentre os feedbacks, os principais foram para } \\
\text { focarmos em coisas mais simples para se resolver, } \\
\text { além de procurarmos por uma abordagem de se } \\
\text { relacionar com startups naquela intervenção, } \\
\text { considerando-as como provedoras de solução. } \\
\text { Nesse ponto, nos foi pedido para priorizar fatores } \\
\text { culturais. } \\
\text { Alguns acharam que foi um banho de água fria; } \\
\text { outros entenderam que foi um acerto de rota } \\
\text { importante. O direcionamento mudou a tal ponto o } \\
\text { que estávamos pensando, que tivemos que } \\
\text { postergar nossa reunião de trabalho para refletir } \\
\text { sobre o plano. }\end{array}$ & \\
\hline$\ldots$ & $\ldots$ & $\ldots$ & $\ldots$ & & $\ldots$ & & \\
\hline
\end{tabular}

